\title{
Teaching and assessment of professional behaviour : rhetoric and reality
}

Citation for published version (APA):

van Mook, W. N. K. A. (2011). Teaching and assessment of professional behaviour : rhetoric and reality. [Doctoral Thesis, Maastricht University]. Datawyse / Universitaire Pers Maastricht.

https://doi.org/10.26481/dis.20110513wm

Document status and date:

Published: 01/01/2011

DOI:

10.26481/dis.20110513wm

Document Version:

Publisher's PDF, also known as Version of record

\section{Please check the document version of this publication:}

- A submitted manuscript is the version of the article upon submission and before peer-review. There can be important differences between the submitted version and the official published version of record.

People interested in the research are advised to contact the author for the final version of the publication, or visit the DOI to the publisher's website.

- The final author version and the galley proof are versions of the publication after peer review.

- The final published version features the final layout of the paper including the volume, issue and page numbers.

Link to publication

\footnotetext{
General rights rights.

- You may freely distribute the URL identifying the publication in the public portal. please follow below link for the End User Agreement:

www.umlib.nl/taverne-license

Take down policy

If you believe that this document breaches copyright please contact us at:

repository@maastrichtuniversity.nl

providing details and we will investigate your claim.
}

Copyright and moral rights for the publications made accessible in the public portal are retained by the authors and/or other copyright owners and it is a condition of accessing publications that users recognise and abide by the legal requirements associated with these

- Users may download and print one copy of any publication from the public portal for the purpose of private study or research.

- You may not further distribute the material or use it for any profit-making activity or commercial gain

If the publication is distributed under the terms of Article $25 \mathrm{fa}$ of the Dutch Copyright Act, indicated by the "Taverne" license above, 
Teaching and assessment of professional behaviour:

rhetoric and reality 
The research reported in this dissertation was carried out at Maastricht University

in the School of Health Professions Education

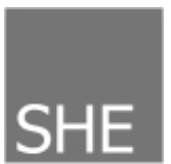

(c) Walther N.K.A. van Mook, Maastricht

ISBN 978-94-6159-053-4

Cover design: Datawyse Maastricht

Cover illustrations: Con Tonnaer, kunstschilder, Valkenburg aan de Geul

Layout:

Tiny Wouters

Production: $\quad$ Datawyse | Universitaire Pers Maastricht

The publication of this dissertation was financially supported by Vifor Pharma Nederland BV, Gilead Sciences, Pfizer BV, Astrazeneca BV, Merck Sharp en Dohme BV, Lamepro BV, Philips Healthcare, Novo Nordisk BV, Rabobank Maastricht e.o., Department of Intensive Care Medicine MUMC+, and the Maastricht University Medical Centre+. 


\title{
Teaching and assessment of
}

\author{
professional behaviour:
}

\author{
rhetoric and reality
}

\section{PROEFSCHRIFT}

Ter verkrijging van de graad van doctor

aan de Universiteit Maastricht, op gezag van de Rector Magnificus,

Prof. mr. G.P.M.F. Mols,

volgens het besluit van het College van Decanen,

in het openbaar te verdedigen

op vrijdag 13 mei 2011 om 12.00 uur

door

Walther Nicolaas Karel Anton van Mook

geboren op 16 november 1967 te Helmond

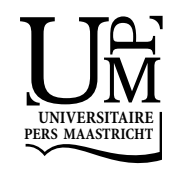


Promotores:

Prof. dr. L.W.T. Schuwirth

Prof. dr. C.P.M. van der Vleuten

Prof. dr. J.H. Zwaveling

Beoordelingscommissie:

Prof. dr. R.P. Koopmans (voorzitter):

Dr. E. Driessen

Prof. dr. F. Scheele (VUMC, Amsterdam)

Prof. dr. C.D.A. Stehouwer

Prof. dr. J.E. Tulleken (UMCG, Groningen) 
Good judgement comes from experience Experience comes from bad judgement 



\section{Contents}

Chapter 1 General introduction and scope of the dissertation 9

Chapter 2 Bad apples spoil the barrel: addressing unprofessional $\quad 35$ behaviour

Medical Teacher 2010;32:891-898

Chapter 3 Promoting professional behaviour in undergraduate medical, dental and veterinary curricula in the Netherlands:

evaluation of a joint effort

Medical Teacher 2010;32:733-739

Chapter 4 Combined formative and summative professional behaviour assessment approach in the bachelor phase of medical

school: a Dutch perspective

Medical Teacher 2010;32:e517-531

Chapter 5 Factors impeding assessment of students' professional

behaviour in the tutorial group in problem based learning

Medical Education 2007;41:849-856

Chapter 6 Web-assisted assessment of professional behaviour: more feedback, yet no improvement?

Advances in Health Sciences Education, accepted for publication

Chapter 7 Fellows' in intensive care medicine views on professionalism and how they learn it

Intensive Care Medicine 2010;36:296-303

Chapter 8 Intensive care medicine trainees' perception of

professionalism: a qualitative study

Anaesthesia and Intensive Care 2011;39:107-115

Chapter 9 The minority reports: Elements of professionalism in unsolicited health care complaints

Under peer review

Chapter 10 Discussion, conclusions and recommendations

Summary

Samenvatting

List of abbreviations

List of publications

Dankwoord

Curriculum Vitae 



\section{Chapter 1}

General introduction and scope of the dissertation

Parts published in:

Eur J Int Med 2009;20:e81-84

Eur J Int Med 2009;20:e85-89

Eur J Int Med 2009;20:e90-95

Eur J Int Med 2009;20:e96-100

Eur J Int Med 2009;20:e105-111

Eur J Int Med 2009;20:e148-152

Eur J Int Med 2009;20:e153-158 
$10 \mid$ Chapter 1 


\section{General introduction}

Professionalism and professional behaviour are receiving increasing attention in undergraduate and postgraduate medical education today ${ }^{1,2}$. This is reflected in an annual research output in recent years of over 300 professionalismrelated scientific publications. It is therefore not surprising that this dissertation deals with issues of professionalism and professional behaviour in general, both in undergraduate medical education and in postgraduate education, the latter in intensive care medicine in particular. But first it may be helpful to provide some background to the complicated topic of professionalism and professional behaviour, for, despite the wealth of publications, consensus about its definition remains elusive. The purpose of this introductory chapter is to provide the reader with some historical background of professionalism in medicine as well as some insights into the contemporary framework of teaching and assessing professionalism in medical education. We will start with a description of the concepts of professionalism and professional behaviour and their development, touching upon general aspects of teaching and learning in relation to professionalism and more specifically on how these are currently translated into daily practice. After a discussion of general considerations around assessment and current assessment formats and tools, the focus shifts to linkages and differences between professionalism in undergraduate, postgraduate and continuing medical education and training. Finally, professionalism is discussed from the perspective of patient safety and quality of care, an approach that only recently sprouted from the professionalism tree. At the end of this Chapter the research questions are presented and the resulting research projects outlined.

\section{The evolution of the concept of professionalism}

A profession can be defined as a vocation with its own body of knowledge and skills, which is put into service for the good of others and the welfare of society. If we accept this definition, then medicine is an archetypal profession ${ }^{3,4}$. Society has traditionally granted autonomy to the medical profession based on the understanding that doctors will put the welfare of their patients before their own and the profession is self-regulated by a code of ethics as well as laws and statutory frameworks governing licensing, regulation and guidelines ${ }^{5-9}$. The medical code of ethics dates back to the Hippocratic oath ${ }^{10}$. The word 'profess', in the sense of making a public commitment to adhere to a set of values ${ }^{11}$, was first used by Scribonius, a physician and pharmacist in the court of the Roman emperor Claudius ${ }^{12,13}$. He linked humanism to virtues such as 'compassion', 'mercy' and 'competence', specifically with reference to prescribing practice. 
Thereafter the lion's share of the concept of professionalism became grounded in the non-cognitive domain, with the word 'profession' being intrinsically linked to the above-mentioned virtues. The term was first formally recorded in the Oxford English Dictionary in $1541^{4}$. Subsequent references to medical professionalism are found during the middle ages and in more recent histories of other cultures, Japanese culture for example $e^{3,10,13,14}$. So, the doctor was originally placed in the role of a healer, around which later the ideals of the professional and professionalism developed. The doctor's services were traditionally seen as beneficial to and in the interest of the welfare of society ${ }^{4}$. As society has changed, so have the public's perceptions of medical professionalism and the role of the doctor therein ${ }^{15}$. After two millennia of stability and invariability in this respect, the rise of for-profit organisations in the 1960s and 1970s was the first development to threaten the primacy of the goal of quality health care and arouse misgivings that issues important to society might no longer always be adequately addressed ${ }^{4,7}$. Although William Osler had argued that "the practice of medicine is not a business, and never can be one. Our fellow creatures cannot be dealt with as man deals in corn and coal"16, a perceived "breaking of the social contract" by doctors was nevertheless seen to emerge ${ }^{4}$. It became apparent that the concept of professionalism was context related, depending on "the structure of society and its general conception of the world"17. The contrasting mottos of commercialism ('caveat emptor' or 'buyer beware') and medicine ('primum no nocere' or 'first do no harm') are salient reminders of the fundamental tensions that surfaced at that time. Today, important contemporary societal factors continue to shape the perceptions of professionalism ${ }^{5,18}$ (Table 1.1). In response to a changing world, professionalism must somehow be capable of incorporating change. A new balance ('new professionalism') must be found between changing medical practice and changing societal priorities, not by avoiding conflict, but by negotiation $^{8,18,19}$. Only relatively recently, leaders in medicine and medical education rediscovered and newly recognised the importance of addressing professionalism and professional behaviour during medical education, and the traditional standards of professionalism were reviewed in the light of societal change. In the 1980s, the American Board of Internal Medicine (ABIM) started to reflect on the humanitarian aspects of the work of a doctor. This resulted in Project Professionalism a decade later, in which the ABIM identified the elements of altruism, accountability, duty, excellence, honour, integrity and respect for others ${ }^{20,21}$. This project dominated the debate about professionalism for several years and resulted in a succession of important contributions attempting to define the meaning of professionalism in present-day society. 
Table 1.1 Examples of societal factors influencing current changes in professionalism and professional behaviour ${ }^{5,18}$

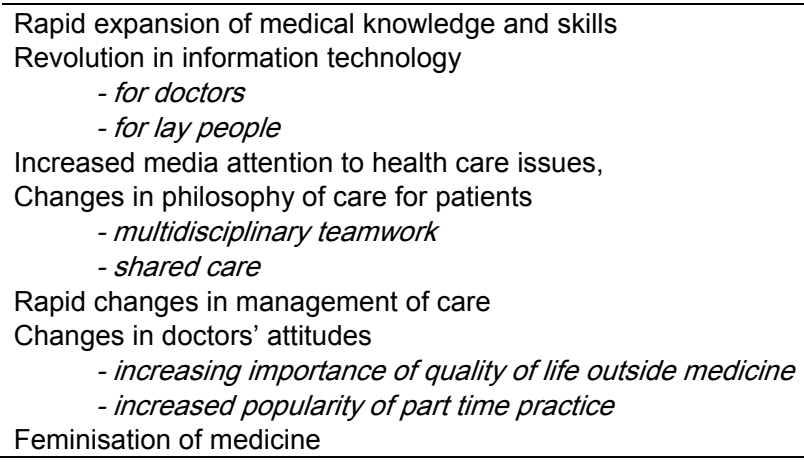

\section{Professionalism and professional behaviour}

In contemporary medical education, two mainstreams of thinking about professionalism can be discerned. One defines professionalism in terms of character traits, the other in terms of observable behaviour. This section discusses the differences between these concepts and their implications for education.

In North America, the concept of professionalism is the prevailing one. It is a theoretical construct, framed in abstract, idealistic terms, such as honesty, integrity and accountability, terms that refer to character traits rather than behaviour. Although difficult to challenge, the fact that the construct is not very concrete or specific makes it difficult to observe and consequently to assess ${ }^{22}$.

A more practical definition couched in terms of professional behaviour stems from the European continent, where the Consilium Abeundi (advice to leave) working group of the Association of Universities in the Netherlands framed professionalism as observable behaviours from which the norms and values of the medical professional can be inferred ${ }^{22,23}$. Evidently, observable behaviour as the basis for assessment and teaching facilitates the practical implementation of professionalism in medical education, although it is as yet unknown to which extent the changes suggested by the guidelines have actually been implemented. The contrast between abstract ideals and concrete behaviours is a crucial but under-researched aspect of the understanding of professionalism and its integration into professional practice. The complexity of the relationship between external professional behaviour and internal values/attitudes is likewise poorly researched and understood. The question "Do we want physicians who are professional, or will we settle for physicians 
who can act in a professional manner?" is frequently asked ${ }^{24}$. To what extent can inner virtues and outer conduct be expected to differ and to what extent can they be allowed to do so? We should realise, however, that construct validation always starts with inferring from prior observations (including observed behaviour). In other words, the assumptions (e.g. driven by preexisting knowledge) underlying a construct influence its validation. It might be helpful if we were to begin to look upon professionalism and professional behaviour as two sides of the same coin. Otherwise we are stuck with the virtual impossibility of designating observation of professionalism as either isolated behaviour in a certain context (a state) or as behaviour reflecting a stable underlying trait.

The following examples serve to illustrate this dilemma. Every physician knows that the haemoglobin level (inferred from past studies) is not subject to circadian variation. Thus, any variation found in repeated tests of adequately homogenised blood samples taken from the same (non-treated) patient, conducted at 10-minute intervals using the same analyser can only be attributed to the analytic process and not to real variations in haemoglobin level over time. By analogy, when we conceptualise professionalism as a stable entity, a fixed trait, we would have no choice but to interpret all behavioural variations as errors or irrelevant variations in the measurement. By implication, all interventions would be useless a priori. It may therefore be more appropriate to compare professionalism to for example human blood pressure, which is known to be a continuum of variation. Unlike haemoglobin level, blood pressure is sensitive to external factors, such as stress, and so changes in blood pressure cannot automatically be attributed to an error of measurement.

Looking at the literature on professionalism and professional behaviour in the light of the previous metaphors, we notice that the context of the behaviour is indeed important and that in the presence of significant external constraints the relationship between attitudes and behaviour is not a very firm and stable one ${ }^{25}$. Professionalism, like blood pressure, appears to be non-static and variable over time and contexts. In this perspective, it becomes plausible that students who are known to hold adequate professional standards may, at moments of strong external pressure, display episodes of unprofessional behaviour, so-called professional lapses. This inevitably brings us to the conclusion that professional behaviour can be stage-managed (or is subject to 'impression' or 'perception' management) and students can theoretically learn to fake desirable professional behaviour. However, the problem posed by this conclusion is far more serious when we have to answer survey questions exploring students' professional behaviour than when we observe actual behaviour in the workplace on a day-to-day basis. 
Despite evidence of (too much) discomfort caused by the seeming incompatibility of the concepts underlying the terms professionalism and professional behaviour, the issue currently remains unresolved, although one might see a future role for subjective, holistic judgements, a subject that has not yet been adequately addressed ${ }^{26}$. In the future the difference between professionalism and professional behaviour may come to be framed in terms of complementarity rather than contradiction. For now, in this dissertation, the terms will be used interchangeably.

\section{Growing agreement on the definition, but full consensus remains elusive}

Despite the described discrepancies, some consensus seems to be emerging. The European Federation of Internal Medicine (EFIM), the American College of Physicians and American Society of Internal Medicine (ACP-ASIM) Foundation and the American Board of Internal Medicine (ABIM) simultaneously published their comparable views on professionalism in a 'Physician's charter on professionalism' in different journals in $2002^{21}$. The charter was aimed at providing an ethical, educational and practical framework for professionalism to guide physicians in the practice of medicine and their relationships with patients, colleagues and society, applicable to different cultures and political systems ${ }^{21}$. The charter puts forward three fundamental principles: primacy of patients' welfare, patients' autonomy and social justice ${ }^{21}$. In order to attain these high standards, the physician has to meet a set of professional responsibilities (Table 1.2). Despite the consensus suggested by the joint publication, the concept of professionalism has continued to evolve ever since. This is reflected in an ever expanding variety of empirical definitions of professionalism proposed by numerous authors and organisations offering varying interpretations mostly relating to differences in overlap of and emphasis on basically identical elements ${ }^{3,27}$. For example, the American Board of Internal Medicine $^{20}$, the Society of Academic Emergency Medicine ${ }^{28}$, the Accreditation Council on Graduate Medical Education (ACGME) ${ }^{29}$, the UK General Medical Council $^{30,31}$, the Royal College of Physicians in the UK ${ }^{32,33}$ and the Royal College of Physicians and Surgeons in Canada ${ }^{34,35}$ have each defined professionalism in their own way. More recently, in 2005, the Royal College of Physicians' publication Doctors in Society presented its own definition and description of medical professionalism ${ }^{30,36}$. 
Table 1.2 Set of professional responsibilities as defined in the Physicians' charter on Professionalism by the American Board of Internal Medicine, the European Federation of Internal Medicine, and the American College of Physicians and American Society of Internal Medicine ${ }^{21}$

\begin{tabular}{|c|c|c|}
\hline No. & Commitment & Actions including, amongst others \\
\hline 1 & professional competence & lifelong learning to maintain medical knowledge and skills \\
\hline 2 & honesty with patients & $\begin{array}{l}\text { complete and honest information, including reporting of } \\
\text { medical error }\end{array}$ \\
\hline 3 & patients' confidentiality & disclosure of patient's information \\
\hline 4 & $\begin{array}{l}\text { maintaining appropriate } \\
\text { relationships with patients }\end{array}$ & avoid sexual advances, financial gain \\
\hline 5 & improving quality of care & $\begin{array}{l}\text { reducing medical error and increase patient safety, optimize } \\
\text { outcome }\end{array}$ \\
\hline 6 & $\begin{array}{l}\text { just distribution of finite } \\
\text { resources }\end{array}$ & $\begin{array}{l}\text { wise and cost-effective management of limited clinical } \\
\text { resources }\end{array}$ \\
\hline 7 & scientific knowledge & promote research, create new knowledge \\
\hline 8 & $\begin{array}{l}\text { maintain trust by managing } \\
\text { conflicts of interest }\end{array}$ & recognize, disclose and deal with conflicts of interest \\
\hline 9 & professional responsibilities & $\begin{array}{l}\text { collaborate respectfully, participate in process of self- } \\
\text { regulation, and standard setting }\end{array}$ \\
\hline
\end{tabular}

\section{Benefits and beneficiaries of teaching and assessing professionalism}

The assumption underlying the inclusion of professionalism in the undergraduate medical curriculum is that problems arising with professional behaviour during students' and residents' medical training can project into their professional careers if insufficient attention is paid to the development of professionalism during education and training ${ }^{37-39}$. Lapses of professionalism displayed in medical school or during residency training are thus considered predictive of unprofessional behaviour after graduation. In fact, the supposed relationship between unprofessional behaviour in medical school and subsequent problems as a practising physician was confirmed by recent research $^{38,39}$. There is evidence from retrospective studies that practising physicians who have faced disciplinary action from medical licensing boards had a higher incidence of prior unprofessional behaviour in medical school ${ }^{38}$ and internal medicine residency training ${ }^{39}$. It seems therefore reasonable to 
assume that early identification of patterns of professional lapses followed by remediation attempts can offer opportunities to prevent persisting future unprofessionalism.

Several beneficiaries of education in professionalism can be identified. The individual student can build on individual strengths and remediate weaknesses, improve self-reflection and remediation skills and gain access to advanced training. Similarly, the institution may be able to promote faculty development, identify areas for curricular change, create curricular cohesion, and identify candidates for promotion. For the public, professionalism education might serve to reassure them that all certified and qualified medical graduates have been educated to meet well defined standards of professionalism. It should be pointed out, however, that today we have no research-based evidence to support the assumption that the inclusion of professionalism education in the medical school curriculum (or thereafter for that matter) will impact positively on attitudes towards professionalism and professional behaviour whether in medical school or subsequent practice settings ${ }^{26}$.

\section{Teaching and learning in practice}

Despite the general lack of evidence regarding an effect of training and teaching professionalism on outcome measures, progress in professionalism education in medical schools is such that almost all 23 UK medical schools in 2006 reported the existence of attitudinal objectives ${ }^{1}$, whereas similar work in the US in 2002 reported that only about $50 \%$ of medical schools had identified relevant elements of professionalism and developed written criteria for their assessment ${ }^{3}$. Since, compared to teaching and learning, assessment of professionalism receives far more attention in the literature, we know little about students' and residents' views regarding (the teaching and learning of) professionalism. The students' and residents' 'view from the trenches', however, is paramount when developing professionalism training programmes. For now, the existing data points to a general lack of awareness of and knowledge about professionalism ${ }^{40}$. Overall, more than half of the students are dissatisfied with current training practices relating to professionalism ${ }^{41}$, although a significant association was found between hours of formal coursework in professionalism and overall satisfaction with professionalism training ${ }^{41}$. Clinically-oriented, multidisciplinary (e.g. ethics) approaches continue to be the favoured approach, especially during the clinical training phases (despite frequent negative experiences 'on the job', see below) ${ }^{41,42}$.

In the perspective described in the previous section, David Stern's recent proposal to divide the learning of professionalism into three building blocks, the 
'setting of expectations', 'providing experiences' and 'evaluation of outcomes', appears to make excellent educational sense ${ }^{43}$. Setting expectations involves explicitly defining professionalism and its goals and objectives at an institution, which promotes awareness and creates an adequate mindset regarding its importance. Providing experiences should start early in the curriculum, and experiences should be projected into clerkship and residency programmes. Also, there are more opportunities for teaching professionalism in the formal curriculum that one might initially be inclined to think. Teaching knowledge aspects of professionalism and learning adequate communication, reflection and feedback skills are some, often ignored or forgotten but nevertheless important, aspects of classroom education formats for professionalism. In addition to the formal curriculum, the informal or 'hidden' curriculum gives rise to 'on the job' learning during unscheduled, informal encounters with patients and health care staff ${ }^{44}$. The fact that we can all still name those who were memorable examples during our own medical training highlights the invaluable significance of positive role models. On the other hand students' negative practical experiences with others' professional lapses (e.g. mistreatment and abuse, unprofessional clinical environment and poor role modelling) are known to act as a potent inhibitor of the adoption of adequate professional behaviour $^{40}$. Obviously, the hidden curriculum impacts more on residents and students during clinical training than during the preclinical phase $e^{45-47}$. The ongoing dilemma, however, is that the explicitly and formally taught professional values often fail to be mirrored by the implicit values of the hidden curriculum ${ }^{48}$. Our rhetoric is thus not always congruent with our practice. Renewed attention to role modelling seems crucial if we are to redress this discongruence ${ }^{45-47,49}$, but it should not stand alone. Reflection in and on action and subsequent discussion are indispensable ${ }^{50}$. The building blocks suggested by Stern are modified and amplified in Table $1.3^{48}$. 
Table 1.3 Teaching and learning professionalism issues (modified from Stern, with permission ${ }^{43}$ )

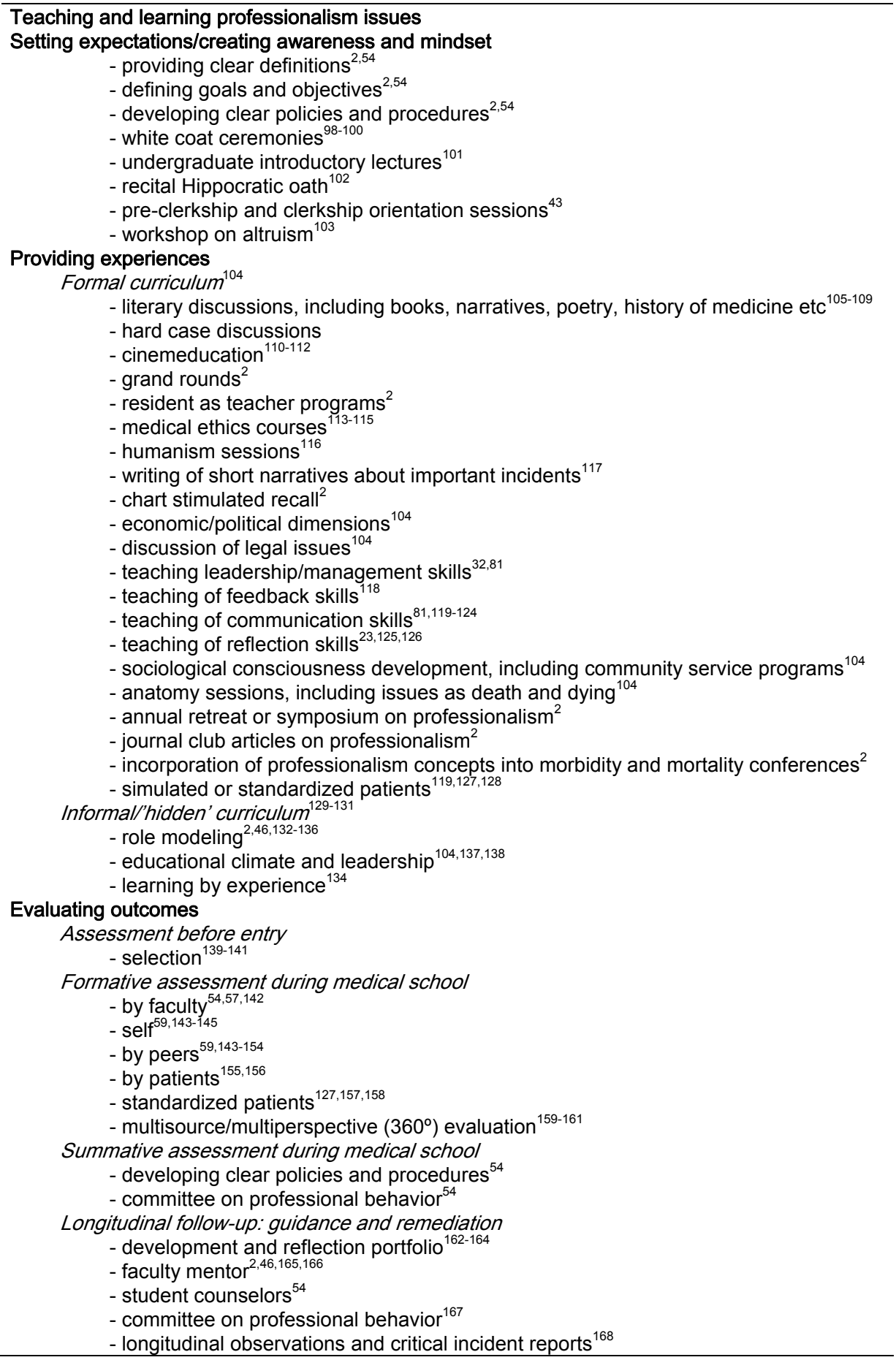




\section{Evaluation of outcomes (assessment)}

It has become apparent that merely setting expectations and providing experiences is not a sufficient guarantee for effective teaching and learning of professionalism. For teaching and learning to lead to desired outcomes, they must be complemented by assessment. The challenge of assessment of professionalism can be summarised in two statements: "If it can't be measured, it can't be improved", and "They don't respect what you expect, whereas they respect what you inspect" ${ }^{\prime 1}$. Assessment is increasingly being recognised as a powerful stimulus for learning (formative assessment, or assessment for learning), but it can also be used for assessment of learning (summative assessment). Inevitably, assessment will occasionally reveal episodes of unprofessional behaviour, and addressing this behaviour can offer an alternative, complementary approach to the informal and formal teaching and learning of professionalism.

Assessment instruments should preferably measure professionalism in the most authentic context. In other words, it should not be directed at competence 'in vitro' but at professional performance 'in vivo', that is, performance in daily practice (the does level at the top of Miller's pyramid ${ }^{52}$ ). Assessment of professional behaviour should be targeted at observable behaviour on the one hand, and the ability to reflect on feedback on that behaviour on the other. Feedback on performance should preferably be given during or directly after observation. Furthermore, transparency (disclosure of process and outcome of the assessment) and symmetry (all levels of the institutional hierarchy are preferably evaluated using the same methods) influence assessment. Unfortunately, the latter is far from routine practice ${ }^{40}$. Whether norm-referenced or criterion-referenced standards are to be used depends on the assessors' experience. Assessors that are initially relatively unfamiliar with the professionalism topics under assessment tend to prefer criterion-referenced standards. These usually take the form of a checklist requiring assessors to indicate whether the student's performance is adequate in relation to the questions/statements on the list. The test scores are then translated into a statement about the behaviour that is expected based on that score (satisfactory or not). When these standards have been shaped by the assessors' experience, norm-referenced standards can be utilised: the assessors have become experts in the field. With norm-referenced standards, the performance of individual students is compared with the performance of other students in the same group. Assessment (in general) should preferably meet criteria of reliability, validity, feasibility (especially cost) and acceptability (to all stakeholders). Evidently, in daily practice trade-offs and compromises between these criteria are inevitable ${ }^{53-56}$. The usefulness of an instrument is a 
function of the relationship between the different criteria, which is likely to vary depending on the context. For a high stakes examination, validity and reliability are of crucial importance ${ }^{53}$. An infrequently considered, but nevertheless very relevant, aspect is the prevalence of a problem in the population in a specific context. Low prevalence of unprofessional behaviour, as found in most medical schools, leads to a low positive predictive value and high negative predictive value, resulting in more false positive than false negative outcomes. Studies on assessment methods for professionalism rarely report on the utility criteria and, to our knowledge, few well-validated tools for professionalism assessment exist. The Professionalism Mini-evaluation Exercise (or P-MEX) is a notable exception $^{57}$. In the absence of a 'magic bullet', the current 'state-of-the-art' in professionalism assessment advocates combining multiple methods (triangulation) in varied contexts with multiple observers preferably over a longitudinal trajectory (all factors that increase the reliability of the assessment), with adequate follow-up and opportunities for remediation (or dismissal from medical school).

The most commonly used methods for professionalism assessment are selfand peer assessment, objective structured clinical examinations (OSCE), direct observation by faculty during regular educational sessions, critical incident reports and learner maintained portfolios. Often mildly structured, standardised checklists are used, so that the quality of the information gathered is at least partly dependent on the user (teacher, coach, tutor) ${ }^{51,58,59}$. In the Maastricht curriculum a form containing a semi-standardised checklist based on the Consilium Abeundi guidelines is used to document feedback based on selfand peer (formative) assessment, with responsibility for the final (summative) assessment residing with the tutor. Until recently, the students' point of view with regard to the feasibility, acceptability and perceived usefulness of assessment of professional behaviour in the tutorial groups remained to be elucidated. This aspect is therefore addressed in a Chapter in this dissertation. A more novel development is the inclusion of assessment in admission procedures, a subject that recently gave rise to heated debate in the Dutch media between supporters and opponents of this idea ${ }^{60}$. Since the interest in direct assessment of professionalism is a fairly recent development, a separate Chapter of this dissertation is devoted to an in-depth discussion of the different professionalism assessment methods that are currently under investigation. 


\section{Professionalism in and beyond medical school: an educational continuum?}

All major organisational bodies have developed competency frameworks for both undergraduate and postgraduate training, all of which emphasise professionalism $^{29,36,61}$. The vast majority of studies deal with professionalism in undergraduate medical education (medical school). At the transitions from undergraduate to postgraduate and from postgraduate to continuing medical education, the assessment context changes. Obviously, the emphasis shifts to different aspects of professionalism over the course of a medical career as a doctor takes on new responsibilities and roles. The context thus changes from training phase to training phase in all specialties. Due to differences between specialties, these changes occur at different moments and/or at a different pace in the various specialties. Rapid changes in health care, such as duty hour regulations and the recent increase in the popularity of part-time work, also shape and modify the context in which trainees work. As a consequence, professionalism is specialty, training phase and era dependent. Most organisational bodies, including the Accreditation Council for Graduate Medical Education in the US, the Royal College of Physicians and Surgeons in Canada, and the General Medical Council in the UK, also require that residents' professional behaviour be addressed and assessed ${ }^{62}$. So far, studies on professionalism in postgraduate training (residency) have been conducted in family medicine and paediatrics ${ }^{63}$, surgery and paediatrics ${ }^{64}$, internal medicine, neurology and family practice ${ }^{65}$ and among heterogeneous groups of residents $^{66}$. Under the aegis of the European Society of Intensive Care Medicine (ESICM), the Competency-Based Training programme in Intensive Care in Europe (CoBaTrICE) has defined twelve competency domains for intensive care medicine $(\mathrm{ICM})^{67}$, with a strong emphasis on professionalism, which is given equal prominence to technical ability ${ }^{67}$. So far, few studies have examined intensive care fellows' views on professionalism: the way it is currently taught and the way it should preferably be taught. Although everyone agrees that professionalism training is important, there is a paucity of information about curricular content, teaching strategies and evaluation methods (again most information stems from undergraduate training) ${ }^{62,68}$. Likewise continuing medical education (CME), which is increasingly recognised as the hallmark of professionalism ${ }^{69}$, shows a tendency to focus on knowledge to the exclusion of skills and professionalism issues ${ }^{70}$. Efforts pertaining to the latter have so far been minimal or absent ${ }^{71}$.

As previously stated, recent landmark studies provide evidence that (un)professional behaviour interlinks across the different training phases. Persistent irresponsibility (e.g. poor compliance with immunisation and course 
evaluation) during medical school has been shown to be associated with a higher risk of disciplinary action as a physician ${ }^{37,38,72}$. Likewise, poor performance on behavioural and cognitive measures during internal medicine residency has been linked to a greater risk of state licensing board actions after graduation $^{39}$. Frequently, problems with professional behaviour are associated with problems relating to medical knowledge (and skills) ${ }^{73,74}$. Despite the identified statistical relationships between undergraduate, postgraduate and continuing medical education, a formal training continuum for the development of professionalism across these phases is currently lacking. Transfer of formative and summative assessment outcomes relating to professionalism from medical school to specialty training programmes and thereafter into CME does not occur regularly. Feedback from past experiences and associated performance are thereby lost. Previous go/no go, pass/fail decisions or, in a worst case scenario, suspension or dismissal decisions may also be lost to follow up. Ensuring transfer of information within and between training phases (e.g. between institutions) and even between states or countries seems paramount to facilitate optimal guidance or, in rare instances, prevent unprofessional students or doctors from being admitted to training programmes or licensed to practice elsewhere. Such measures are essential, for example for the implementation of the new Dutch higher education act which introduced a ludicium Abeundifor students showing unprofessional behaviour ${ }^{75,76}$.

\section{Professionalism, quality of care and patient safety}

A fairly new angle in the literature on professionalism is to approach the issue from the perspective of quality of care and patient safety ${ }^{77}$. It is estimated that somewhere in their career, approximately $15 \%$ of physicians will be 'impaired' in the sense of being unable to fulfil their professional responsibilities ${ }^{78}$. Apart from diagnostic and treatment errors, impairment may also result in inappropriate professional behaviour, such as ineffective communication, failure to attend to patients' psychological needs, an uncaring or disrespectful manner, not relating appropriately to patients and boundary violations ${ }^{79,80}$. These violations of standards of professionalism are not only associated with poor adherence to guidelines, impeded collaboration, information transfer, workplace relationships, low staff morale and turnover, but also to medical errors, adverse outcomes and malpractice suits ${ }^{81-91}$. Patients' perceptions regarding the professionalism of health care staff is a factor that merits serious consideration. Data on patient satisfaction and complaints has only recently been recognised as a valuable source of information about professionalism ${ }^{1,2,15,29,92-97}$. In the light of findings that patients evaluate the patient-doctor relationship in greater depth than other assessors ${ }^{63,96}$, 
incongruence between physicians' rhetoric and professionalism as perceived by patients may be anticipated. So far, studies addressing these potential differences have not been performed.

\section{Aims and outline of the dissertation}

The aim of the studies presented in this dissertation is to advance our insight into practical aspects of teaching and assessing professionalism. The dissertation adds to the extensive theoretical literature on professionalism education and additionally investigates its contemporary implementation in practice and the practical barriers and potential improvements during all phases of medical education and training.

\section{Research questions}

The following research questions are addressed in this dissertation:

\section{Research question 1}

How can the approach to unprofessional behaviour in practice fit within the contemporary framework of professionalism education (Chapters 2 and 4)?

\section{Research question 2}

To what extent have national and local implementation of previously published guidelines on teaching and assessing professional behaviour been implemented nationally and locally, and which enabling and limiting conditions can be identified in undergraduate education (Chapters 3, 4 and 5)?

\section{Research question 3}

Which enabling and limiting conditions in relation to teaching and assessing professional behaviour can be identified in postgraduate education (Chapters 7 and 8)?

\section{Research question 4}

To what extent can innovations in professionalism assessment in undergraduate education be considered improvements (Chapter 6)?

\section{Research question 5}

How can the concept of professional behaviour be further refined: the perspectives of the medical educationist (Chapter 2), the physician (Chapters 7 and 8) and the patient (Chapter 9)? 


\section{Studies addressing the research questions}

The Chapters of this dissertation present different contributions to the search for answers to the research questions.

Ch. 2 Chapter 2 presents an in-depth theoretical elaboration of the added value of addressing unprofessional behaviour (as well as teaching, learning and further improvement of professional behaviour) before (selection) and after admission to medical school, a topic that was recently spotlighted in the media ${ }^{60}$.

The following four Chapters focus on the operationalisation of professionalism in relation to teaching and assessment in undergraduate medical education.

Ch. 3 Evaluation of the extent to which the guidelines designed to promote teaching and learning of professional behaviour in the undergraduate medical, dental and veterinary curricula in the Netherlands have been followed by the different faculties (Chapter 3): has the joint effort led to curriculum changes regarding teaching and assessing professsionalism?

Ch. 4 Description and evaluation of the combined formative and summative approach to the assessment of professional behaviour in the bachelor phase of the medical faculty of Maastricht University (Chapter 4): can formative and summative assessment of professional behaviour represent two sides of the same coin? An evaluation of four years experience in the bachelor phase.

Ch. 5 Factors inhibiting assessment of students' professional behaviour in problem-based tutorial groups (Chapter 5): which factors lead to a suboptimal assessment process in the first two years of medical school and are they related to either students or teachers or both?

Ch. 6 Web-assisted assessment of professional behaviour (Chapter 6): can web-assisted assessment of professional behaviour improve the current method of professionalism assessment in the tutorial group? Do students and tutors give more feedback when an electronic assessment form is used? Does the quality of feedback improve when an electronic form is used compared to the paper form?

The subsequent two studies focus on defining the relevance of professionalism elements and aspects of teaching and assessing professionalism in postgraduate medical training. Being the author's specialty, intensive care medicine was chosen as the research arena. Two studies were designed to elucidate the relevance of aspects of professionalism in the ICU as a learning environment and how they are learned in that environment. The first study used a previously 
published survey, the second focus group interviews. Both studies were conducted on a national scale. The resulting Chapters are:

Ch. 7 The views of fellows in intensive care medicine on professionalism and how they learn it (Chapter 7), and

Ch. 8 Intensive care medicine trainees' perceptions of professionalism: a qualitative study (Chapter 8).

The final study reported in this dissertation focuses on professionalism from the newly emerged perspective of quality of care and patient safety, using five-year data from unsolicited complaints filed with the Complaints Committee of Maastricht University Medical Centre. The study focuses on professionalism issues in postgraduate and continuing education from the patient's (and their relatives') point of view. Categories of professionalism elements were identified and compared with elements previously identified as important from a physician's point of view in order to determine areas of incongruence.

Ch. 9 The minority reports: elements of professionalism in unsolicited health care complaints (Chapter 9).

In Chapter 10 the findings of the previous Chapters and their implications for teaching and assessing professionalism are discussed from the perspective of the research questions. For each research questions a succinct conclusion is formulated and future challenges are (at least partly) outlined. 
General introduction and scope of the dissertation

\section{References}

1. Stephenson AE, Adshead LE, Higgs RH. The teaching of professional attitudes within UK medical schools: reported difficulties and good practice. Med Educ 2006;40:1072-80.

2. Lee AG, Beaver HA, Boldt HC, Olson R, Oetting TA, Abramoff M, Carter K. Teaching and assessing professionalism in ophthalmology residency training programs. Surv Ophthalmol 2007;52:300-14.

3. Arnold L. Assessing professional behaviour: yesterday, today, and tomorrow. Acad Med 2002;77:502-15.

4. Bloom SW. Professionalism in the practice of medicine. Mt Sinai J Med 2002;69:398-403.

5. Irvine D. The performance of doctors. I: Professionalism and self regulation in a changing world. BMJ Clinical research ed 1997;314:1540-2.

6. Arnold EL, Stern DT. What is medical professionalism? In: Measuring medical professionalism. Stern, DT (ed) Oxford University Press, New York, 2006 ISBN-13: 978-0-19517226-3 2006.

7. Cruess SR, Cruess RL. Professionalism must be taught. BMJ Clinical research ed 1997;315:1674-7.

8. Wynia MK, Latham SR, Kao AC, Berg JW, Emanuel LL. Medical professionalism in society. N Engl J Med 1999;341:1612-6.

9. Pellegrino ED, Relman AS. Professional medical associations: ethical and practical guidelines. JAMA 1999;282:984-6.

10. Sohl P, Bassford HA. Codes of medical ethics: traditional foundations and contemporary practice. Social Science \& Medicine (1982) 1986;22:1175-9.

11. Cruess RL, Cruess SR, Johnston SE. Professionalism: an ideal to be sustained. Lancet 2000;356:156-9.

12. Hamilton JS. Scribonius Largus on the medical profession. Bull Hist Med 1986;60:209-16.

13. Pellegrino ED, Pellegrino AA. Humanism and ethics in Roman medicine: translation and commentary on a text of Scribonius Largus. Lit Med 1988;7:22-38.

14. Nitobe I. Bushido: The Soul of Japan. ISBN 1599869136 2007; Filiquarian Publishing, LLC.

15. van Mook W, de Grave W, Wass V, O'Sullivan $\mathrm{H}$, Zwaveling JH, Schuwirth LW, van der Vleuten CP. Professionalism: Evolution of the concept. Eur J Int Med 2009;20:e81-e4.

16. Osler W. On the educational value of the medical society. In: Aequanimitas 1932;ISBN 0070479151(329-45).

17. Marti-lbanez F. Henry E. Sigerist on the History of Medicine. New York:, MD Publications 1960:14-5.

18. Castellani B, Wear D. Physician views on practicing professionalism in the corporate age. Qual Health Res 2000;10:490-506.

19. Irvine D. The performance of doctors: the new professionalism. Lancet 1999;353:1174-7.

20. American Board of Internal Medicine Committee on Evaluation of Clinical Competence. Project Professionalism. ABIM, Philadelphia. 1995:5-6.

21. Project Medical Professionalism. Medical professionalism in the new millennium: a physicians' charter. Lancet 2002;359:520-2.

22. van Mook W, van Luijk S, O'Sullivan H, Wass V, Harm Zwaveling J, Schuwirth LW, van der Vleuten CP. The concepts of professionalism and professional behaviour: Conflicts in both definition and learning outcomes. Eur J Int Med 2009;20:e85-e9.

23. Project Team Consilium Abeundi van Luijk SJe. Professional behaviour: Teaching, assessing and coaching students. Final report and appendices. Mosae Libris 2005.

24. Hafferty F. Measuring medical professonalism: a commentary. In: Measuring medical professionalism Stern, DT (ed) Oxford University Press, New York, 2006 ISBN-13: 978-0-19517226-3 2006.

25. Wallace D, Paulson R, Lord C, Bond CJ. Which Behaviors Do Attitudes Predict? MetaAnalyzing the Effects of Social Pressure and Perceived Difficulty. Review of General Psychology 2005;9:214-27. 
$28 \mid$ Chapter 1

26. Jha V, Bekker HL, Duffy SR, Roberts TE. A systematic review of studies assessing and facilitating attitudes towards professionalism in medicine. Med Educ 2007;41:822-9.

27. Jha V, Bekker HL, Duffy SR, Roberts TE. Perceptions of professionalism in medicine: a qualitative study. Med Educ 2006;40:1027-36.

28. Adams J, Schmidt T, Sanders A, Larkin GL, Knopp R. Professionalism in emergency medicine. SAEM Ethics Committee. Society for Academic Emergency Medicine. Acad Emerg Med 1998;5:1193-9.

29. Accreditation Council for Graduate Medical Education. ACGME Outcome Project enhancing residency education throught outcomes assessment: General competencies. 1999;Accessed Febr 13th 2006: http://www.acgme.org/outcome/comp/compFull.asp.

30. General Medical Council. Tomorrow's doctors. Recommendations on undergraduate medical education. 2003.

31. General Medical Council. Good medical practice. 2001.

32. Royal College of Physicians. Doctors in Society: medical professionalism in a changing word. Report of a Working Party of the Royal College of Physicians of London. ISBN 1-86016-255X Lavenham Press Ltd Suffolk, Great Brittain; http://www.rcplondon.ac.uk/pubs/books/ docinsoc 2005.

33. Working Party of the Royal College of Physicians. Doctors in society. Medical professionalism in a changing world. Clinical medicine (London, England) 2005;5(6 Suppl 1):S5-40.

34. The Royal College of Physicians and Surgeon's of Canada. The royal college of physicians and surgeon's of Canada's Canadian Medical Education directions for Specialists 2000 project. Skills for the new millenium: report of the societal needs working group. CanMeds 2000 Project 1996;Ottawa, Ontario, Canada.

35. Frank JRe. The CanMEDS 2005 Physician Competency Framework. Better standards. Better physicians. Better care. 2005;Ottawa: The Royal College of Physicians and Surgeons of Canada.

36. General Medical Council. Tomorrow's Doctors: Education Outcomes and standards for undergraduate medical education. ISBN: 978-0-901458-36-0 2009.

37. Stern DT, Frohna AZ, Gruppen LD. The prediction of professional behaviour. Med Educ 2005;39:75-82.

38. Papadakis MA, Teherani A, Banach MA, Knettler TR, Rattner SL, Stern DT, Veloski JJ, Hodgson CS. Disciplinary action by medical boards and prior behaviour in medical school. N Engl J Med 2005;353:2673-82.

39. Papadakis MA, Arnold GK, Blank LL, Holmboe ES, Lipner RS. Performance during internal medicine residency training and subsequent disciplinary action by state licensing boards. Ann Intern Med 2008;148:869-76.

40. Brainard $\mathrm{AH}$, Brislen $\mathrm{HC}$. Viewpoint: learning professionalism: a view from the trenches. Acad Med 2007;82:1010-4.

41. Roberts LW, Green Hammond KA, Geppert CM, Warner TD. The positive role of professionalism and ethics training in medical education: a comparison of medical student and resident perspectives. Acad Psychiatry 2004;28:170-82.

42. Fryer-Edwards K, Wilkins MD, Baernstein A, Braddock $\mathrm{CH}$, 3rd. Bringing Ethics Education to the Clinical Years: Ward Ethics Sessions at the University of Washington. Acad Med 2006;81:626-31.

43. Stern DT, Papadakis M. The developing physician--becoming a professional. N Engl J Med 2006;355:1794-9.

44. Hafferty FW, Franks R. The hidden curriculum, ethics teaching, and the structure of medical education. Acad Med 1994;69:861-71.

45. Wright SM, Kern DE, Kolodner K, Howard DM, Brancati FL. Attributes of excellent attendingphysician role models. N Engl J Med 1998;339:1986-93.

46. Wright S, Wong A, Newill C. The impact of role models on medical students. J Gen Intern Med 1997;12:53-6.

47. Wright SM, Carrese JA. Excellence in role modelling: insight and perspectives from the pros. CMAJ 2002;167:638-43. 
48. van Mook W, van Luijk S, de Grave W, O'Sullivan H, Wass V, Schuwirth LW, van der Vleuten CP. Teaching and learning professional behaviour in practice. Eur J Int Med 2009;20: e105-11.

49. Jones WS, Hanson JL, Longacre JL. An intentional modeling process to teach professional behaviour: students' clinical observations of preceptors. Teaching and Learning in Medicine 2004;16:264-9.

50. Brailovsky C, Charlin B, Beausoleil S, Cote S, Van der Vleuten C. Measurement of clinical reflective capacity early in training as a predictor of clinical reasoning performance at the end of residency: an experimental study on the script concordance test. Med Educ 2001;35:430-6.

51. Cohen JJ. Professionalism in medical education, an American perspective: from evidence to accountability. Med Educ 2006;40:607-17.

52. Miller G. The assessment of clinical skills/competence/performance. Acad Med65(suppl) 1990;65 (suppl):S63-7.

53. van der Vleuten CPM. The assessment of professional competence: developments, research and practical implications. Adv Health Sc Ed 1996;1:41-7.

54. van Luijk SJ, Smeets SGE, Smits J, Wolfhagen IH, Perquin MLF. Assessing professional behaviour and the role of academic advice at the Maastricht Medical School. Medical Teacher 2000;22:168- 72.

55. Veloski JJ, Fields SK, Boex JR, Blank LL. Measuring professionalism: a review of studies with instruments reported in the literature between 1982 and 2002. Acad Med 2005;80:366-70.

56. Thistlethwaite JE, Spencer Je. Professionalism in medicine. Radcliffe Publishing Ltd, Abingdon, UK; ISBN 13: 978-185775 76372008.

57. Cruess R, Mcllroy JH, Cruess S, Ginsburg S, Steinert Y. The professionalism mini-evaluation exercise: a preliminary investigation. Acad Med 2006;81(10 Suppl):S74-8.

58. Fowell SL, Bligh JG. Recent developments in assessing medical students. Postgrad Med J 1998;74:18-24.

59. Asch E, Saltzberg D, Kaiser S. Reinforcement of self-directed learning and the development of professional attitudes through peer- and self-assessment. Acad Med 1998;73:575.

60. Crommentuyn R. Decentrale selectie ter discussie. Medisch Contact 2010;9:380-2.

61. The Royal College of Physicians and Surgeons in Canada http://rcpscmedical.org/canmeds/ indexphp, accessed October 10th 2006.

62. Snell L. Teaching professionalism and fostering professional values during residency: the McGill experience. In: Teaching medical Professionalism (Cruess RL, Cruess, SR, Steiner Y, eds) 2009.

63. Wagner P, Hendrich J, Moseley G, Hudson V. Defining medical professionalism: a qualitative study. Med Educ 2007;41:288-94.

64. Ephgrave K, Stansfield RB, Woodhead J, Sharp WJ, George T, Lawrence J. The resident view of professionalism behaviour frequency in outstanding and "not outstanding" faculty. Am J Surg 2006;191:701-5.

65. Ratanawongsa N, Bolen S, Howell EE, Kern DE, Sisson SD, Larriviere D. Residents' perceptions of professionalism in training and practice: barriers, promoters, and duty hour requirements. J Gen Intern Med 2006;21:758-63.

66. Brownell AK, Cote L. Senior residents' views on the meaning of professionalism and how they learn about it. Acad Med 2001;76:734-7.

67. Bion JF, Barrett $H$. Development of core competencies for an international training programme in intensive care medicine. Intensive Care Med 2006;32:1371-83.

68. Larkin GL. Mapping, modeling, and mentoring: charting a course for professionalism in graduate medical education. Camb Q Healthc Ethics 2003;12:167-77.

69. D'Auria D. Reality checks, CME and the pursuit of professionalism. Occup Med (Lond) 1997;47:449.

70. Tang GW. Continuing professional development--a surrogate for recertification? Ann Acad Med Singapore 2004;33:711-4.

71. Davis D. Continuing professional development: A focus on professionalism. In: Teaching medical Professionalism (Cruess RL, Cruess, SR, Steiner Y, eds) 2009;ISBN 978-0-52188104-3:263-78. 
$30 \mid$ Chapter 1

72. Papadakis MA, Hodgson CS, Teherani A, Kohatsu ND. Unprofessional behaviour in medical school is associated with subsequent disciplinary action by a state medical board. Acad Med 2004;79:244-9.

73. Haurani MJ, Rubinfeld I, Rao S, Beaubien J, Musial JL, Parker A, Reickert C, Raafat A, Shepard A. Are the communication and professionalism competencies the new critical values in a resident's global evaluation process? J Surg Educ 2007;64:351-6.

74. Rhoton MF. Professionalism and clinical excellence among anesthesiology residents. Acad Med 1994;69:313-5.

75. Wet op hoger onderwijs en wetenschappelijk onderzoek. http://wettenoverheid.nl/ BWBR0005682/Opschrift/geldigheidsdatum_01-05-2009 Accessed 1 mei 2009.

76. van der Hoeven MJA, Rutte M. Memorie van toelichting op WHOO. In te zien op: http://www.minocw.nl/documenten/Mvtwetophethogeronderwijsenonderzoek.pdf 2006.

77. Russell TR. Quality and safety initiatives in the future practice of surgery: meeting patient demands for enhanced professionalism. Surgery Today 2009;39:739-45.

78. Boisaubin EV, Levine RE. Identifying and assisting the impaired physician. Am J Med Sci 2001;322:31-6.

79. Irvine D. Patients, professionalism, and revalidation. BMJ Clinical research ed 2005;330: 1265-8.

80. Galletly CA. Psychiatrist-patient sexual relationships: the ethical dilemmas. Aust $\mathrm{N} Z \mathrm{~J}$ Psychiatry 1993;27:133-9.

81. Hickson GB, Pichert JW, Webb LE, Gabbe SG. A complementary approach to promoting professionalism: identifying, measuring, and addressing unprofessional behaviors. Acad Med 2007;82:1040-8.

82. Leape LL, Fromson JA. Problem doctors: is there a system-level solution? Ann Intern Med 2006;144:107-15.

83. McLemore MR. Workplace aggression: beginning a dialogue. Clinical Journal of Oncology Nursing 2006;10:455-6.

84. Rosenstein $\mathrm{AH}$. Original research: nurse-physician relationships: impact on nurse satisfaction and retention. The American Journal of Nursing 2002;102:26-34.

85. Rosenstein $\mathrm{AH}$, O'Daniel M. Study links disruptive behaviour to negative patient outcomes. OR manager 2005;21:1, 20, 2.

86. Rosenstein AH, O'Daniel M. Disruptive behaviour and clinical outcomes: perceptions of nurses and physicians. The American Journal of Nursing 2005;105:54-64.

87. Rosenstein $\mathrm{AH}$, O'Daniel $\mathrm{M}$. Impact and implications of disruptive behaviour in the perioperative arena. Journal of the American College of Surgeons 2006;203:96-105.

88. Rosenstein $\mathrm{AH}$, O'Daniel M. A survey of the impact of disruptive behaviors and communication defects on patient safety. Joint Commission journal on quality and patient safety / Joint Commission Resources 2008;34:464-71.

89. Rosenstein AH, O'Daniel M. Invited article: Managing disruptive physician behaviour: impact on staff relationships and patient care. Neurology 2008;70:1564-70.

90. Rosenstein $\mathrm{AH}$, Russell H, Lauve R. Disruptive physician behaviour contributes to nursing shortage. Study links bad behaviour by doctors to nurses leaving the profession. Physician Executive 2002;28:8-11.

91. Felps WA, Mitchell TR, Byington EK. How, when and why bad apples spoil the barrel: negative group members and dysfunctional groups. Research in Organizational Behaviour 2006;27:181-230.

92. Edelstein SB, Stevenson JM, Broad K. Teaching professionalism during anesthesiology training. J Clin Anesth 2005;17:392-8.

93. Rowley BD, Baldwin DC, Jr., Bay RC, Cannula M. Can professional values be taught? A look at residency training. Clin Orthop Relat Res 2000(378):110-4.

94. Medische Vervolgopleidingen.nl. http://www.medischevervolgopleidingen.nl/pages/content aspx?content=10010000000029_2_10000000001651\&contentcode=competentiesspecialist, accessed October 10th 2006.

95. Royal College of Physicians and Surgeons in Canada. The CanMeds Framework. http://www.rcpscmedical.org/canmeds/indexphp Accessed November 27th 20082005. 
General introduction and scope of the dissertation

96. Wofford MM, Wofford JL, Bothra J, Kendrick SB, Smith A, Lichstein PR. Patient complaints about physician behaviors: a qualitative study. Acad Med 2004;79:134-8.

97. Montini T, Noble AA, Stelfox HT. Content analysis of patient complaints. Int J Qual Health Care 2008;20:412-20.

98. Branch WT, Jr. Deconstructing the white coat. Ann Intern Med 1998;129:740-2.

99. Cohn F, Lie D. Mediating the gap between the white coat ceremony and the ethics and professionalism curriculum. Acad Med 2002;77:1168.

100. Huber SJ. The white coat ceremony: a contemporary medical ritual. Journal of Medical Ethics 2003;29:364-6.

101. Sulmasy DP, Geller G, Levine DM, Faden RR. A randomized trial of ethics education for medical house officers. Journal of Medical Ethics 1993;19:157-63.

102. Wear D. On white coats and professional development: the formal and the hidden curricula. Ann Intern Med 1998;129:734-7.

103. Gedeit R, Murkowski K, Miller S. A workshop to teach and evaluate medical students' altruism. Acad Med 2001;76:506.

104. Wear D, Castellani B. The development of professionalism: curriculum matters. Acad Med 2000;75:602-11.

105. Shem S. The House of God. ISBN 0-385-33738-8 1978.

106. Leiderman DB, Grisso JA. The gomer phenomenon. J Health Soc Behav 1985;26:222-32.

107. Wear D. The House of God: another look. Acad Med 2002;77:496-501.

108. Wear D, Nixon LL. Literary inquiry and professional development in medicine: against abstractions. Perspect Biol Med 2002;45:104-24.

109. Weisberg M, Duffin J. Evoking the moral imagination: using stories to teach ethics and professionalism to nursing, medical, and law students. J Med Humanit 1995;16:247-63.

110. Alexander M. The doctor: a seminal video for cinemeducation. Fam Med 2002;34:92-4.

111. Alexander M, Hall MN, Pettice YJ. Cinemeducation: an innovative approach to teaching psychosocial medical care. Fam Med 1994;26:430-3.

112. Alexander M, Lenahan $P$, Pavlov $A$. Cinemeducation: $A$ Comprehensive Guide to Using Film in Medical Education ISBN-10 : 1857756924, Radcliffe Publishing Ltd, UK 2004.

113. Eckles RE, Meslin EM, Gaffney M, Helft PR. Medical ethics education: where are we? Where should we be going? A review. Acad Med 2005;80:1143-52.

114. Fox E, Arnold RM, Brody B. Medical ethics education: past, present, and future. Acad Med 1995;70:761-9.

115. Goldie J. Review of ethics curricula in undergraduate medical education. Med Educ 2000;34:108-19.

116. Beckman H, Frankel R, Kihm J, Kulesza G, Geheb M. Measurement and improvement of humanistic skills in first-year trainees. J Gen Intern Med 1990;5:42-5.

117. Epstein RM, Cole DR, Gawinski BA, Piotrowski-Lee S, Ruddy NB. How students learn from community-based preceptors. Arch Fam Med 1998;7:149-54.

118. Fidler H, Lockyer JM, Toews J, Violato C. Changing physicians' practices: the effect of individual feedback. Acad Med 1999;74:702-14.

119. Hodges B, Turnbull J, Cohen R, Bienenstock A, Norman G. Evaluating communication skills in the OSCE format: reliability and generalizability. Med Educ 1996;30:38-43.

120. Rees C, Sheard C, McPherson A. Medical students' views and experiences of methods of teaching and learning communication skills. Patient Educ Couns 2004;54:119-21.

121. Schnabl GK, Hassard TH, Kopelow ML. The assessment of interpersonal skills using standardized patients. Acad Med 1991;66(9 Suppl):S34-6.

122. Peskin E, O'Dell K. Communication skills in women's health care: helping students clarify values related to challenging topics in ob-gyn. Acad Med 2001;76:509-10.

123. Lewin LO, Cole-Kelly K, Greenfield M. A year-long course for third-year students on ethics, professionalism, and communication. Acad Med 2001;76:511.

124. Torke AM, Quest TE, Kinlaw K, Eley JW, Branch WT, Jr. A workshop to teach medical students communication skills and clinical knowledge about end-of-life care. J Gen Intern Med 2004;19:540-4. 
125. Boenink AD. Teaching and learning reflection on medical professionalism (thesis). Gildeprint Drukkerijen BV, Enschede 2006;ISBN 90-8659-031-4.

126. Robertson K. Reflection in professional practice and education. Aust Fam Physician 2005;34:781-3.

127. van Zanten M, Boulet JR, Norcini JJ, McKinley D. Using a standardised patient assessment to measure professional attributes. Med Educ 2005;39:20-9.

128. Mazor KM, Zanetti ML, Alper EJ, Hatem D, Barrett SV, Meterko V, Gammon W, Pugnaire MP. Assessing professionalism in the context of an objective structured clinical examination: an in-depth study of the rating process. Med Educ 2007;41:331-40.

129. Hundert EM, Douglas-Steele D, Bickel J. Context in medical education: the informal ethics curriculum. Med Educ 1996;30:353-64.

130. Hundert EM, Hafferty F, Christakis D. Characteristics of the informal curriculum and trainees' ethical choices. Acad Med 1996;71:624-42.

131. Stern DT. In search of the informal curriculum: when and where professional values are taught. Acad Med 1998;73(10 Suppl):S28-30.

132. Ambrozy DM, Irby DM, Bowen JL, Burack JH, Carline JD, Stritter FT. Role models' perceptions of themselves and their influence on students' specialty choices. Acad Med 1997;72:1119-21.

133. Cote $\mathrm{L}$, Leclere $\mathrm{H}$. How clinical teachers perceive the doctor-patient relationship and themselves as role models. Acad Med 2000;75:1117-24.

134. Fishbein RH. Professionalism and 'the master clinician'--an early learning experience. J Eval Clin Pract 2000;6:241-3.

135. Kenny NP, Mann KV, MacLeod H. Role modeling in physicians' professional formation: reconsidering an essential but untapped educational strategy. Acad Med 2003;78:1203-10.

136. Lublin JR. Role modelling: a case study in general practice. Med Educ 1992;26:116-22.

137. Firth-Cozens J, Mowbray D. Leadership and the quality of care. Qual Health Care 2001;10 Suppl 2:ii3-7.

138. Smith KL, Saavedra R, Raeke JL, O'Donell AA. The journey to creating a campus-wide culture of professionalism. Acad Med 2007;82:1015-21.

139. Benor DE, Notzer N, Sheehan TJ, Norman GR. Moral reasoning as a criterion for admission to medical school. Med Educ 1984;18:423-8.

140. Eva KW, Rosenfeld J, Reiter HI, Norman GR. An admissions OSCE: the multiple miniinterview. Med Educ 2004;38:314-26.

141. Knights JA, Kennedy BJ. Medical school selection: screening for dysfunctional tendencies. Med Educ 2006;40:1058-64.

142. Norcini JJ, Blank LL, Duffy FD, Fortna GS. The mini-CEX: a method for assessing clinical skills. Ann Intern Med 2003;138:476-81.

143. Bryan RE, Krych AJ, Carmichael SW, Viggiano TR, Pawlina W. Assessing professionalism in early medical education: experience with peer evaluation and self-evaluation in the gross anatomy course. Ann Acad Med Singapore 2005;34:486-91.

144. Davis JD. Comparison of faculty, peer, self, and nurse assessment of obstetrics and gynecology residents. Obstet Gynecol 2002;99:647-51.

145. Reiter HI, Eva KW, Hatala RM, Norman GR. Self and peer assessment in tutorials: application of a relative-ranking model. Acad Med 2002;77:1134-9.

146. Arnold L, Stern D. Content and context of peer assessment. In: Measuring medical professionalism Stern, DT (ed) Oxford University Press, New York, 2006 ISBN-13: 978-0-19517226-3 2006.

147. Arnold L, Shue CK, Kritt B, Ginsburg S, Stern DT. Medical students' views on peer assessment of professionalism. J Gen Intern Med 2005;20:819-24.

148. Arnold L, Willoughby L, Calkins V, Gammon L, Eberhart G. Use of peer evaluation in the assessment of medical students. Journal of medical education 1981;56:35-42.

149. Dannefer EF, Henson LC, Bierer SB, Haag M, Barclay C, Epstein RM. Peer assessment of professional competence. Med Educ 2005;39:713-22.

150. Davis JK, Inamdar S. Use of peer ratings in a pediatric residency. Journal of Medical Education 1988;63:647-9. 
151. English R, Brookes ST, Avery K, Blazeby JM, Ben-Shlomo Y. The effectiveness and reliability of peer-marking in first-year medical students. Med Educ 2006;40:965-72.

152. Freedman JA, Lehmann HP, Ogborn CJ. Web-based peer evaluation by medical students. Acad Med 2000;75:539-40.

153. Norcini JJ. Peer assessment of competence. Med Educ 2003;37:539-43.

154. Ramsey PG, Wenrich MD, Carline JD, Inui TS, Larson EB, LoGerfo JP. Use of peer ratings to evaluate physician performance. JAMA 1993;269:1655-60.

155. Carney SL, Mitchell KR. Satisfaction of patients with medical student's clinical skills. Journal of Medical Education 1986;61:374-9.

156. Woolliscroft JO, Howell JD, Patel BP, Swanson DB. Resident-patient interactions: the humanistic qualities of internal medicine residents assessed by patients, attending physicians, program supervisors, and nurses. Acad Med 1994;69:216-24.

157. Prislin MD, Lie D, Shapiro J, Boker J, Radecki S. Using standardized patients to assess medical students' professionalism. Acad Med 2001;76(10 Suppl):S90-2.

158. Rethans JJ, van Boven CP. Simulated patients in general practice: a different look at the consultation. Br Med J (Clin Res Ed) 1987;294:809-12.

159. Koestler JL. 360 degrees: planning a new pediatric clerkship. Acad Med 2002;77:1163.

160. Lockyer J. Multisource feedback in the assessment of physician competencies. The Journal of continuing education in the health professions 2003;23:4-12.

161. Rees $C$, Shepherd M. The acceptability of 360-degree judgements as a method of assessing undergraduate medical students' personal and professional behaviours. Med Educ 2005;39:49-57.

162. Driessen EW, van Tartwijk J, Overeem K, Vermunt JD, van der Vleuten CP. Conditions for successful reflective use of portfolios in undergraduate medical education. Med Educ 2005;39:1230-5.

163. Fryer-Edwars K, Pinsky L, Robbins L. The use of portfolios to assess professionalism. In: Measuring medical professionalism Stern, DT (ed) Oxford University Press, New York, 2006 ISBN-13: 978-0-19-517226-3 2006.

164. Jarvis RM, O'Sullivan PS, McClain T, Clardy JA. Can one portfolio measure the six ACGME general competencies? Acad Psychiatry 2004;28:190-6.

165. Epstein RM. Mindful practice. JAMA 1999;282:833-9.

166. Ludmerer KM. Instilling professionalism in medical education. JAMA 1999;282:881-2.

167. van Mook WNKA, van Luijk SJ, Fey-Schoenmakers MJG, Gulikers MTH, Schuwirth LW, Van der Vleuten CPM. Bespreking en beoordeling van professioneel gedrag aan de Faculteit Geneeskunde te Maastricht. Tijdschrift voor Medisch Onderwijs 2007;26:237-46.

168. Papadakis MA, Loeser $H$. Using critical incident reports and longitudinal observations to assess professionalism. In: Measuring medical professionalism Stern, DT (ed) Oxford University Press, New York, 2006 ISBN-13: 978-0-19-517226-3 2006:159-74. 



\section{Chapter 2}

Bad apples spoil the barrel: addressing unprofessional behaviour

Walther NKA van Mook, Simone L Gorter, Willem S de Grave, Scheltus J van Luijk, Valerie Wass, Jan Harm Zwaveling, Lambert W Schuwirth, Cees PM van der Vleuten 


\section{Abstract}

Given the changes in society we are experiencing, the increasing focus on patient centred care and acknowledgment that medical education including professionalism issues needs to continue not only in the residency programs but throughout the doctors career, is not surprising. Although most of the literature on professionalism pertains to learning and teaching professionalism issues, addressing unprofessional behaviour and related patient safety issues forms an alternative or perhaps complementary approach. This article describes the possibility of selecting applicants for medical school based on personality characteristics, the attention to professional lapses in contemporary undergraduate training, as well as the magnitude, aetiology, surveillance and methods of dealing with reports of unprofessional behaviour in postgraduate education and CME. 


\section{Introduction}

Professionalism is increasingly receiving attention in undergraduate as well as postgraduate training ${ }^{1,2}$. Definitions and approaches to teaching and assessment of professionalism are variable ${ }^{3-10}$. Although most of the published literature on professionalism pertains to promoting professionalism through learning, teaching, and assessment ${ }^{11-14}$, reports on unprofessional behaviour of students and physicians frequently draw disproportionate attention ${ }^{15-18}$. Recent landmark studies revealed that unprofessional behaviour during undergraduate and postgraduate education is associated with unprofessional behaviour and subsequent disciplinary actions by medical boards after graduation ${ }^{19-21}$. It should be emphasized however that an important minority of practising doctors are clinically inadequate, ineffectively communicating and/or inappropriately relating to patients ${ }^{22}$. Although episodes of disruptive, unprofessional behaviour are thus not common, neither are they rare ${ }^{3}$. Unprofessional behaviours are associated with poor adherence to guidelines, impediment of communication, collaboration, information transfer, and workplace relationships, low staff morale and turnover, medical errors and adverse outcomes and malpractice suits $^{3,23-32}$. It can be easily envisaged that educational programmes underpinning professionalism "can be effectively torpedoed by unprofessional physician models",32. Consequently, there is little debate that attention to professionalism and associated patient safety issues is important. Medical schools are nowadays increasingly recognising the importance of professionalism ${ }^{33,34}$. At the same time a developmental shift towards competency-based specialty training programmes is taking place ${ }^{35-39}$. Progress is such that all major organisational bodies now include professionalism in their competence frameworks ${ }^{2,38,40}$. Clinicians are thereafter expected to continue to learn how to be "better professionals" as 'continuous medical education' (CME), which builds on foundations laid before and during medical school, and during post-graduate training, becomes the norm ${ }^{2,41-43}$.

Nevertheless continuous medical education is still in its infancy regarding professionalism issues ${ }^{2}$. Mandating it is however certainly ineffective ${ }^{44}$, and may prove counterproductive as it may "be seen as personally irrelevant, or even insulting" ${ }^{3}$. Notwithstanding further developments in this area, identifying, measuring and addressing unprofessional behaviours may form an alternative, complementary approach, alongside teaching and stimulating professionalism ${ }^{3,10,45}$. As Hickson et al. stated: "The challenges for leaders in academic medicine are to think not only about how best to promote professionalism, but simultaneously to renew our commitment to addressing unprofessional or disruptive behaviours whenever they occur"3. Considering the 'numerus fixus' (limited admission policy with an abundance of applicants), allocating the limited resources to those who have the best a priori chance of 
ultimately delivering adequate patient care using such selection instruments may be cost-effective ${ }^{46}$, contribute to the principles of social justice, and increase public trust in the profession. The current article provides an in depth discussion of possible approaches to addressing unprofessional behaviour in medical students and physicians. Consecutively selection of candidates for medical school, the current attention for professional lapses in undergraduate training, in postgraduate training and in $\mathrm{CME}$, as well as costs and potential benefits of the approach will be addressed.

\section{Selection for medical school}

Since many medical schools have very low rates of attrition, the admissions procedure is argued to be the most important evaluation exercise conducted by North American schools ${ }^{47,48}$, and is increasingly used on the European continent as well. Selection is frequently based on academic merit, written application and/or interview. The pre-admission cumulative or science gradepoint average (GPA), and Medical College Admissions Test (MCAT) scores are the of most frequently used measures of academic performance in North America $^{48}$. However, previous academic performance proves only a limited predictor of achievement in medical training. It accounts for $23 \%$ of the variance in performance in undergraduate medical training and only $6 \%$ of that in postgraduate competency ${ }^{49}$. Consequently, many students (70\%!) who excelled in the clinical courses did not so in the basic sciences ${ }^{50}$. The differences can perhaps at least partly be explained by the fact that cognitive scores do not assess creativity, cultural and gender biases and do not reflect motivation $^{48}$. This has resulted in more attention to the non-cognitive criteria in the admissions process. In a United Kingdom study, assessment of students' attitudinal behaviour during selection is reported to be already performed in 11 out of 23 medical schools ${ }^{33}$. A distinction in two different approaches can be made: the first is to attempt to select applicants on attributes that predispose them to become competent, caring, professional physicians are thus promising $^{48}$, the other to identify those most likely to develop unprofessional behaviour ${ }^{46,51-53}$. With both approaches, it is difficult to obtain consensus as to exactly which pre-medical behaviours are associated with what specific aspects of professionalism ${ }^{48}$. Despite this limitation, letters of recommendation, personal statements on the application forms, supplemental application forms, interviews are used ${ }^{54}$ and self assessment measures of personality characteristics $^{51}$, and measures of moral orientation ${ }^{55}$ have been developed ${ }^{48}$. The predictive validity of MCAT scores with respect to professionalism has only very limitedly been studied ${ }^{48,56}$. The MCAT Verbal Reasoning score and the personal interview were both found to be useful in predicting communication 
skills on the licensing examination at the Medical Council of Canada ${ }^{56} .99 \%$ of the US medical schools now use the interview as part of the admissions process $^{57}$. In spite of its popularity, the admission interview is plagued by at least two remediable problems. First, it fails to take into account non-cognitive attributes formed for example by personality traits ${ }^{58}$, secondly it is plagued by the problem of context specificity. These issues will consecutively be discussed in the section below.

\section{Screening for personality traits and influence of context}

First, the sensitivity to detect dysfunctional tendencies due to personality characteristics is considered too low in an interview ${ }^{59}$. These personality traits could however indicate a student's fit with the formal curriculum. It is known that dysfunctional personality characteristics have a negative impact on the learning process, academic motivation, academic grades, and course attendance. They are associated with higher levels of anxiety and negative mood before examinations, lack of self-confidence, fear of failure, social skills deficits, and personal and social relationship problems ${ }^{46}$. Dysfunctional tendencies have indeed been related to substance abuse, suicide, mental illness, verbal and/or physical abuse, sexual harassment and unethical behaviour $^{51,60}$. This varying response to abuse is related to psychopathological personality characteristics present at entry into medical school ${ }^{61-63}$. Dysfunctional tendencies can be activated by stress, for example caused by the inability to deal with factual knowledge and concepts, examinations about which the student feel insecure, or medical student abuse in the hidden curriculum (the latter is the most widely reported contributor to stress) ) $^{62,64,65}$. Fear is that the presence of dysfunctional personality characteristics increases the risk that mistreatment may be adopted and directed to patients ${ }^{51}$. Personality assessment could thus be an effective tool in identifying dysfunctional interpersonal deficiencies ${ }^{51,66}$.

Knights et al. have extensively studied this subject ${ }^{46,51}$. They report that dysfunctional tendencies are not uncommon in a survey among first year medical students. Strikingly high scores $(0.8,10.7,33.1$, and $26.4 \%)$ on 1 of four defined dysfunctional syndromes ${ }^{51}$. Only when these dysfunctional personality characteristics appear and operate in an intense neurotic framework, they become rigid, compulsive, and indiscriminate, and a dominant behaviour pattern will emerge at extreme levels (personal communication WvM/JK). Far fewer students had high scores on more than one syndrome: no subjects scored high on all four or any of the three syndromes, but 18 out of 159 applicants scored in the high range of two out of four dysfunctional 
syndromes (personal communication WvM/JK). What specific combinations of (extreme scores on) personality traits is associated with the highest risk of specific unprofessional behaviour in practice is not addressed ${ }^{51}$. Nevertheless, in a more recent study the same author negatively correlated academic grades to such dysfunctional personality characteristics ${ }^{46}$. Another example of another self-reporting method to specifically assess interpersonal problems is the Hogan Development Survey. It was a shown to be able to identify negative personality characteristics in medical students, that were not detected in the selection interview ${ }^{51}$. So far however, the number of papers on this topic is however limited $^{52,53,55,67-69}$, and sufficient data on validity and reliability as well as positive and negative predictive power of the tests are lacking.

Furthermore, the interview is plagued by the problem of context specificity, the fact that many of our cognitive 'skills' are highly dependent on context ${ }^{70}$. A person's performance is commonly less determined by 'trait', the personality characteristics, than by the 'state', e.g. the context within which the performance is elicited ${ }^{47}$. To overcome this problem a multiple mini-interview protocol consisting of a series of short OSCE-style stations was developed. It covers the domains of critical thinking, ethical decision-making, communication skills, and knowledge of the health care system. During this multiple sample approach to the interview, candidates discuss a health-related issue (e.g. the use of placebos) with an interviewer, interact with a standardised confederate while an examiner observes the interpersonal skills displayed, or answer traditional interview questions ${ }^{47}$. Indeed the variance component attributable to candidate-station interaction was greater than that attributable to candidate, supporting the hypothesis that the context specificity reduces the validity of traditional interviews ${ }^{47}$.

In summary, it appears that selection for medical school is an interesting and promising approach to addressing professionalism. However, whether the adoption of any single selection process can result in sufficient improvement in positive or negative predictive value remains to be unravelled. Once the contemporary process of medical school entry is completed using combined, triangulated approaches, addressing (un)professional behaviour in the medical curriculum is the next step.

\section{Attention to professional lapses in undergraduate training}

Different approaches to signalling unprofessional behaviour can be adopted ${ }^{71}$. The first is a system in which faculty members reflect on students' professional performance over a longer period of close observations and guidance. The 
second approach seems especially appropriate for the hectic clinical environment where faculty have brief interactions with students. The evaluation in that context more resembles 'one-time snapshots'. These so called 'critical incidents' document a specific sentinel event in detail and are "particularly useful for the students at the extremes of performance". They are particularly "directed to the extreme outliers of behaviours, students with whom educational leaders spend an inordinate amount of time" ${ }^{\prime 2}$. The approach effectively "lowers the radar" for professional behaviours ${ }^{72}$, although in general a failure to both detect and respond to even minor lapses is still experienced in undergraduate as well as postgraduate training ${ }^{73}$. Although several, mainly US' examples of critical incidents reporting systems can be found in the literature ${ }^{45,71,74}$, examples from the European continent are so far lacking.

When attempting to establish whether a certain behaviour is acceptable or not, the behaviour should look at it within its appropriate context, the environment in which it occurred ${ }^{75,76}$. The context can shape behaviour on the one, and influence the quality of the assessment on the other ${ }^{75}$. Since every professional has a range of behaviours, incidental occurrences of inappropriate behaviour (so-called lapses) are not per se synonymous with unprofessional behaviour. However, some extreme behaviour in rare cases can and should definitely be judged unacceptable. The person or organ that addresses the professional lapses depends on the training phase and institutional organization. For undergraduate medical students it can for example be the clerkship director, dean for student affairs, or Committee on Professional Behaviour ${ }^{75}$. Early lapse identification is critical to facilitate institution of such strategies before such behaviour becomes refractory to change ${ }^{75}$. Normally, the extent to which the behaviour can be remedied, the willingness and possibility of the person involved to change the unprofessional behaviour, and its eventual persistence over time all determine whether the behaviour will ultimately be categorized as unprofessional or not. Longitudinal tracking of critical incidents can thus be used to monitor the effectiveness of remediation strategies ${ }^{72}$.

Practical aspects such as having clear objectives before scheduled, witnesses, and scribing, setting transparent goals and expectations as well as the timeframe in which these should be fulfilled, and assuring adequate guidance and frequent performance feedback sessions are of paramount importance ${ }^{75}$. More in depth discussion of these issues can be found elsewhere ${ }^{75}$.

It is needless to say that candid documentation of every incident, the remediation strategy and the response is required. All reports should be confidentially handled, and complainant should receive follow-up of review and resulting actions ${ }^{75}$. For example, lapses can result in leave of absence, more 
intensive guidance for example by the bureau of student advisors or a mentor, psychological or psychiatric guidance or other attempts for remediation. Persisting multiple incidents over time, despite adequate remediation strategies, triggers a more formal response, and can ultimately lead to dismissal from medical school $^{72}$. Insight and awareness of the problem, willingness to change, consistency in adhering to the plan can contribute to success. Comparable to reports by Papadakis et al, we have the strong impression that students who receive multiple critical incident reports have significant deficits in professional development, and frequently encounter that do not accept responsibility for the problems identified, and accuse the evaluators of unfairness and inaccuracy ${ }^{72}$. Denial and a weak follow up plan are contributors to remediation failure ${ }^{75}$.

\section{Unprofessional behaviour in postgraduate education and CME}

\section{Magnitude of the problem}

Estimates of the magnitude of the problem of impaired physicians at some point in their careers vary from $3-5 \%$ to approximately $15 \%{ }^{23,77}$. Impairment means more than making incorrect diagnosis. It may also include avoidance of patients and their psychological needs, dehumanised care, inappropriate treatment, or over involvement in care with sexual exploitation as the most serious form of boundary violation. Doctors from all areas of medicine have been implicated in such boundary violations ${ }^{78}$. When unsolicited complaints are used as a proxy indicator of unprofessional behaviour, about 20 to $25 \%$ apparently dissatisfy their patients (and thus more than two thirds of physicians never or very rarely generate unsolicited patient complaints) $)^{3,79,80} .6 \%$ of doctors however received 25 or more complaints over a 6 -year period ${ }^{79}$. Nurse surveys suggest that $4-5 \%$ of physicians display behavior ${ }^{27,81}$, physician executive surveys report a percentage between 1 and $5 \%{ }^{82}$.

\section{Aetiologies of unprofessional behaviour}

The aetiologies of unprofessional behaviour include at least the following drivers: substance abuse, psychological issues, inappropriate handling of narcissism, perfectionism and/or selfishness, spill over of chronic or acute family/home problems, poorly controlled anger due to different causes (e.g. poor clinical/administrative support), rewarding of unprofessional behaviour since it yields desired results, and clinical and administrative inertia (no early feedback provided), and similar behaviours are observed in the environ- 
ment $^{3,23}$. Categories also frequently overlap ${ }^{23}$. To provide some idea about the magnitude of the problem: about $1-2 \%$ of US doctors abuse drugs, and up to $15 \%$ of doctors may have significant alcohol problems, with clear implications for clinical practice ${ }^{23,83}$. The medical board of California estimated that $18 \%$ of physicians in its state abuse alcohol or other drugs at some point during their career $^{23}$. The life time incidence of major depressive disorders in the general population is $16 \%$ in the general population ${ }^{84}$, but may be higher in physicians considering the elevated incidence in suicide $(40 \%$ in males, two-fold in females) compared to the general population ${ }^{23,85,86}$. Some conclude that "when all conditions are considered, at least one third of all physicians will experience, at some time in their career, a period during which they have a condition that impairs their ability to practice medicine safely"23. The professional realm is usually the last area for the described disorders to manifest, whereas the relationship of the involved physician's with significant others has usually been impaired for a long time ${ }^{23}$.

\section{Surveillance and reporting}

The eyes and ears of patients, visitors and health care team members are considered to be the most effective surveillance tools for detecting unprofessional behaviour. Physician and resident based complaints are often centrally reported. Also patient advocates record patient observations, ensure service recovery is attempted, and relay information to the parties involved. In many hospitals patient and family complaints are routinely coded according to the individuals named in the complaint, type of complaints and locations. Many of the reports concern isolated, single, unprofessional incidents. Nevertheless, the complaints are then aggregated to identify attendings, physicians or units that demonstrate disproportionate shares of complaints ${ }^{3,79,80,87}$. Such unsolicited complaints to reliably indicate malpractice risk, and identify patterns of alleged disruptive behaviour among patients and relatives.

Medical team members may likewise report unprofessional behaviours, for example using a web-based electronic risk event reporting system. These reports are likewise reviewed to promote identification of the 'whys' of the event, as well as to assistant in pattern recognition. These reported complaints however may represent the top of the iceberg since it is well-known that not all observed and experienced frustration is reported ${ }^{3,87-89}$. Surveillance by patients and health care team members alone will not suffice. Intervention is always necessary, even in the case of single incidents. So far, no literature specifically addressing the analysis of professionalism aspects of unsolicited patient and/or family complaints can be found in the literature. 


\section{Dealing with the reports}

When unprofessional behaviour by a resident is observed, the program director is responsible for addressing the problem. For practicing physicians the department's chair, a hospital's review committee, state or national licensing board, or judicial tribunal is responsible ${ }^{75}$. So far however, few organisations have formal programs to identify problem doctors ${ }^{3,23}$, and management of problems, once identified, has frequently been haphazard, ad hoc, informal and reactive $^{23}$. Guidelines for postgraduate training in the Netherlands is likewise lacking, and are currently being developed by the professionalism working group of the Dutch Society for Medical Education (NVMO). Furthermore, professionals often lack training in the how-to's of managing professional behaviour, and therefore this training (e.g. regarding provision of bad news) should be provided. Often providing feedback informally, during 'a cup of tea conversation', on the observed behaviour is sufficient ${ }^{3}$. The nature of some events and/or rules dictated by law however sometimes mandates prompt reporting, documentation and action, for example in the case of substance abuse or allegations of sexual boundary violations ${ }^{90,91}$.

\section{Formalising the response}

To optimise dealing with professional lapses and unprofessional behaviour, implementing a routine, formal, pro-active system of monitoring and remediation has been proposed ${ }^{23}$. Some examples have been published. Hickson et al described the Vanderbilt University School of Medicine's (VUSM) strategies for identification, measuring, and addressing unprofessional behaviour $^{3}$. Again clear policies, models and leadership commitment were stressed as determinants of success. Their structure of dealing with unprofessional behaviour starts with surveillance and registration of all unprofessional incidents. During further longitudinal monitoring patterns can arise leading to a so-called 'awareness intervention'23. The awareness intervention may be conducted by an authority figure, or sometimes a peer, and most often results in substantial positive adjustments in behaviour ${ }^{3}$. A smaller proportion of professionals is either unable or unwilling to respond to an awareness intervention, and requires an 'authority intervention', with leaders' institution of further improvement and evaluation plans. Failure to respond to the 'authority intervention' subsequently leads to disciplinary action ${ }^{3}$ (see Figure 2.1). 


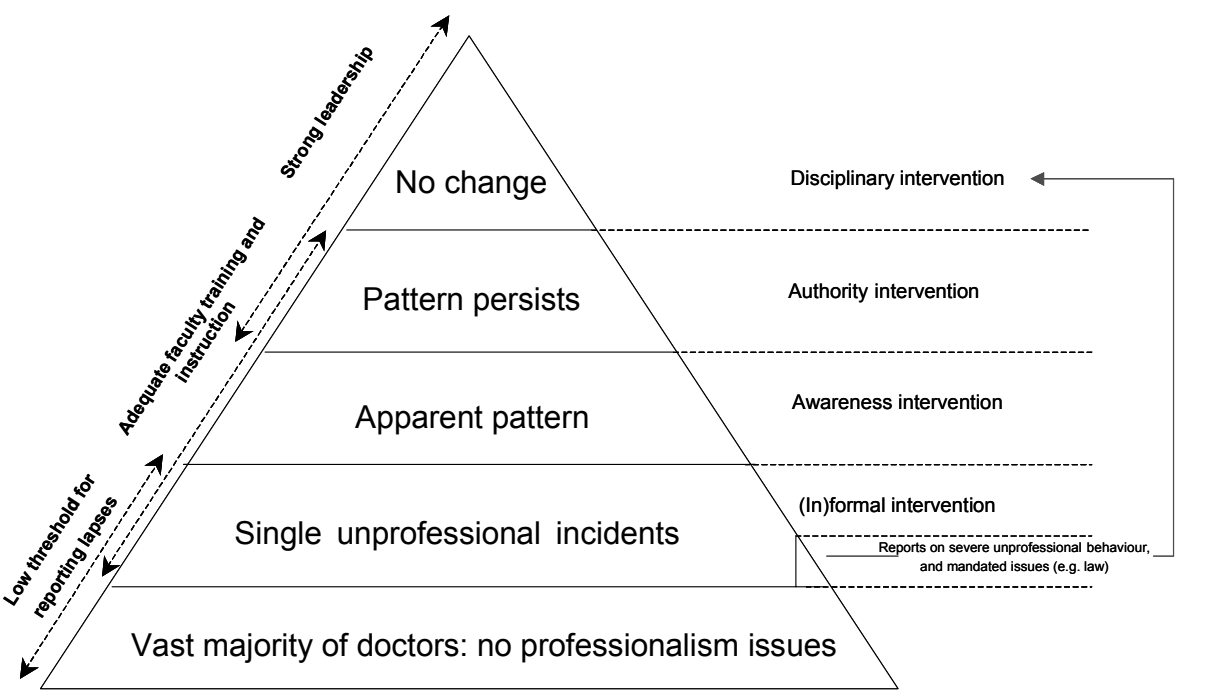

Figure 2.1 The disruptive behaviour pyramid describing a possible approach to unprofessional behaviour (adapted with permission from Hickson et al. ${ }^{3}$ )

\section{Costs and potential benefits}

When implementing an assessment system for professional behaviour for all students in all years of medical school, the accompanying administrative burden (and related cost) is enormous, but unavoidable ${ }^{10,76}$. Although the number of postgraduate trainees in a certain area is more limited, the relative cost per trainee is comparably high ${ }^{3}$. Leadership and faculty time that is spent on a programme addressing unprofessional behaviour cannot be spend on for example providing service, or teaching. Setting up and maintaining surveillance systems are costly, and the same is true for training programmes, adequate guidance, counselling, and remediation. A concrete estimate is difficult to give, and costs may vary per institution. Dealing with those displaying unprofessional behaviour potentially contributes to ultimately cost-saving benefits including improved staff satisfaction and retention, improved reputation of the university centre and their leaders, institutional culture building and role modelling, improved patient safety, and reduced liability exposure ${ }^{3}$. It will most certainly contribute to re-establishing the feeling of trust of the public in the medical profession, realizing that institutions do everything in its power to have only competent doctors graduate and enter health care. 


\section{Conclusions}

Addressing unprofessional behaviour is an alternative, complementary approach to the informal and formal teaching and learning of professionalism. Although the ultimate incidence of persisting, severe unprofessional behaviour is low, this approach may contribute to restoring society's trust in the medical profession, as well as be cost-effective. Selection on the basis of personal attributes predisposing students to become excellent doctors on the one, or identifying those most likely to develop unprofessional behaviour is increasingly studied, and appears to have merit. Once in medical school the threshold for reporting professional lapses should be kept low, staff and student awareness and training regarding professionalism optimized, formative and summative assessment methods implemented, and a formal structure for dealing with lapses and/or unprofessional behaviour developed. The institutional culture change associated with such changes requires strong institutional leadership. Whereas most contemporary medical schools have implemented, or even already revisited their policies, guidelines or frameworks pertaining to dealing with unprofessional behaviour in postgraduate training and CME are far more difficult to find. Nevertheless, the importance of developing such monitoring and intervention frameworks for restoring our reciprocal accountability and our obligations to society cannot be overemphasized. 
Bad apples spoil the barrel: addressing unprofessional behaviour

\section{References}

1. van Mook WN, de Grave WS, van Luijk SJ, O'Sullivan H, Wass V, Schuwirth LW, van der Vleuten $\mathrm{CP}$. Training and learning professionalism in the medical school curriculum: Current considerations. Eur J Int Med 2009;20:e96-e100.

2. van Mook WN, Gorter SL, de Grave WS, van Luijk SJ, O'Sullivan H, Wass V, Zwaveling JH, Schuwirth LW, van der Vleuten CP. The educational continuum: professionalism in and beyond medical school. Eur J Int Med 2009;20:e148-52.

3. Hickson GB, Pichert JW, Webb LE, Gabbe SG. A complementary approach to promoting professionalism: identifying, measuring, and addressing unprofessional behaviors. Acad Med 2007;82:1040-8.

4. van Mook WN, van Luijk SJ, O'Sullivan H, Wass V, Harm Zwaveling J, Schuwirth LW, van der Vleuten CP. The concepts of professionalism and professional behaviour: Conflicts in both definition and learning outcomes. Eur J Int Med 2009;20:e85-e9.

5. van Mook WN, van Luijk SJ, de Grave W, O'Sullivan H, Wass V, Schuwirth LW, van der Vleuten $\mathrm{CP}$. Teaching and learning professional behavior in practice. Eur $\mathrm{J}$ Int Med 2009;20:e105-11.

6. van Mook WN, van Luijk SJ, O'Sullivan H, Wass V, Schuwirth LW, van der Vleuten CP. General considerations regarding assessment of professional behaviour. Eur J Int Med 2009;20:e90-e5.

7. Wasserstein AG, Brennan PJ, Rubenstein AH. Institutional leadership and faculty response: fostering professionalism at the University of Pennsylvania School of Medicine. Acad Med 2007;82:1049-56.

8. Viggiano TR, Pawlina W, Lindor KD, Olsen KD, Cortese DA. Putting the needs of the patient first: Mayo Clinic's core value, institutional culture, and professionalism covenant. Acad Med 2007;82:1089-93.

9. Smith KL, Saavedra R, Raeke JL, O'Donell AA. The journey to creating a campus-wide culture of professionalism. Acad Med 2007;82:1015-21.

10. van Luijk SJ, Smeets SGE, Smits J, Wolfhagen IH, Perquin MLF. Assessing professional behaviour and the role of academic advice at the Maastricht Medical School. Medical Teacher 2000;22:168- 72.

11. Thistlethwaite JE, Spencer Je. Professionalism in medicine. Radcliffe Publishing Ltd, Abingdon, UK 2008.

12. Stern DT (ed.). Measuring medical professionalism. Oxford University Press, New York, ISBN 978-0-19-517226-3 2006.

13. Cruess R, Cruess S, Steinert $Y$. Teaching medical professionalism. ISBN 978-0-521-88104-3 2009.

14. Wear D, Aultman J. Professionalism in medicine. ISBN 0-387-32726-6 2006.

15. Postma CT, Thoben A, Timmermans L, van Spaendonck K. Horken en huilebalken. Medisch Contact 2006;61:883-5.

16. Rynja S, Cents R, Morsink M. Tabee lomperikken en horken. Medisch Contact 2006;62:73-5.

17. O'Neill B. Doctor as murderer. Death certification needs tightening up, but it still might not have stopped Shipman. BMJ Clinical research ed 2000;320:329-30.

18. Esmail A. Physician as serial killer--the Shipman case. N Engl J Med 2005;352:1843-4.

19. Papadakis MA, Arnold GK, Blank LL, Holmboe ES, Lipner RS. Performance during internal medicine residency training and subsequent disciplinary action by state licensing boards. Ann Intern Med 2008;148:869-76.

20. Papadakis MA, Hodgson CS, Teherani A, Kohatsu ND. Unprofessional behavior in medical school is associated with subsequent disciplinary action by a state medical board. Acad Med 2004;79:244-9.

21. Papadakis MA, Teherani A, Banach MA, Knettler TR, Rattner SL, Stern DT, Veloski JJ, Hodgson CS. Disciplinary action by medical boards and prior behavior in medical school. $\mathrm{N}$ Engl J Med 2005;353:2673-82. 
48 $\mid$ Chapter 2

22. Irvine D. Patients, professionalism, and revalidation. BMJ Clinical research ed 2005;330: 1265-8.

23. Leape LL, Fromson JA. Problem doctors: is there a system-level solution? Ann Intern Med 2006;144:107-15.

24. McLemore MR. Workplace aggression: beginning a dialogue. Clinical Journal of Oncology Nursing 2006;10:455-6.

25. Rosenstein $\mathrm{AH}$. Original research: nurse-physician relationships: impact on nurse satisfaction and retention. The American Journal of Nursing 2002;102:26-34.

26. Rosenstein $\mathrm{AH}, \mathrm{O}$ 'Daniel $\mathrm{M}$. Study links disruptive behavior to negative patient outcomes. OR Manager 2005;21:1, 20, 2.

27. Rosenstein $\mathrm{AH}, \mathrm{O}$ 'Daniel $\mathrm{M}$. Disruptive behavior and clinical outcomes: perceptions of nurses and physicians. The American Journal of Nursing 2005;105:54-64; quiz -5.

28. Rosenstein $\mathrm{AH}$, O'Daniel $\mathrm{M}$. Impact and implications of disruptive behavior in the perioperative arena. Journal of the American College of Surgeons 2006;203:96-105.

29. Rosenstein $\mathrm{AH}$, O'Daniel M. A survey of the impact of disruptive behaviors and communication defects on patient safety. Joint Commission journal on quality and patient safety / Joint Commission Resources 2008;34:464-71.

30. Rosenstein $\mathrm{AH}, \mathrm{O}^{\prime}$ Daniel M. Invited article: Managing disruptive physician behavior: impact on staff relationships and patient care. Neurology 2008;70:1564-70.

31. Rosenstein $A H$, Russell H, Lauve R. Disruptive physician behavior contributes to nursing shortage. Study links bad behavior by doctors to nurses leaving the profession. Physician Executive 2002;28:8-11.

32. Felps WA, Mitchell TR, Byington EK. How, when and why bad apples spoil the barrel: negative group members and dysfunctional groups. Research in Organizational Behavior 2006;27:181-230.

33. Stephenson AE, Adshead LE, Higgs RH. The teaching of professional attitudes within UK medical schools: reported difficulties and good practice. Med Educ 2006;40:1072-80.

34. van Mook WN, de Grave WS, Wass V, O'Sullivan H, Zwaveling JH, Schuwirth LW, van der Vleuten CP. Professionalism: Evolution of the concept. Eur J Int Med 2009;20:e81-e4.

35. Lee AG, Beaver HA, Boldt HC, Olson R, Oetting TA, Abramoff M, Carter K. Teaching and assessing professionalism in ophthalmology residency training programs. Surv Ophthalmol 2007;52:300-14.

36. Edelstein SB, Stevenson JM, Broad K. Teaching professionalism during anesthesiology training. J Clin Anesth 2005; 17:392-8.

37. Rowley BD, Baldwin DC, Jr., Bay RC, Cannula M. Can professional values be taught? A look at residency training. Clin Orthop Relat Res 2000:110-4.

38. The Royal College of Physicians and Surgeons in Canada. http://rcpscmedicalorg/canmeds/ indexphp, accessed October 10th 2006.

39. Medische Vervolgopleidingen.nl. http://www.medischevervolgopleidingen.nl/pages/ contentaspx? content $=10010000000029 \_2 \_10000000001651 \&$ contentcode=competentiesspe cialist, accessed October 10th 2006.

40. Accreditation Council for Graduate Medical Education. ACGME Outcome Project enhancing residency education throught outcomes assessment: General competencies. 1999;Accessed Febr 13th 2006: http://www.acgme.org/outcome/comp/compFull.asp.

41. Gruen RL, Arya J, Cosgrove EM, Cruess RL, Cruess SR, Eastman AB, Fabri PJ, Friedman P, Kirksey TD, Kodner IJ, Lewis FR, Liscum KR, Organ CH, Rosenfeld JC, Russell TR, Sachdeva AK, Zook EG, Harken AH; American College of Surgeons Task Froce on Professionalism. Professionalism in surgery. Journal of the American College of Surgeons 2003;197:605-8.

42. Larkin GL. Evaluating professionalism in emergency medicine: clinical ethical competence. Acad Emerg Med 1999;6:302-11.

43. Stern DT, Papadakis M. The developing physician--becoming a professional. N Engl J Med 2006;355:1794-9.

44. Stross JK, Harlan WR. Mandatory continuing medical education revisited. Mobius 1987;7: 22-7. 
45. Papadakis MA, Osborn EH, Cooke M, Healy K. A strategy for the detection and evaluation of unprofessional behavior in medical students. University of California, San Francisco School of Medicine Clinical Clerkships Operation Committee. Acad Med 1999;74:980-90.

46. Knights JA, Kennedy BJ. Medical school selection: impact of dysfunctional tendencies on academic performance. Med Educ 2007;41:362-8.

47. Eva KW, Rosenfeld J, Reiter HI, Norman GR. An admissions OSCE: the multiple miniinterview. Med Educ 2004;38:314-26.

48. Wagoner N. Admission to medical school: selecting applicants with the potential for professionalism (Chapter 13). In: Measuring medical professionalism (Stern, D, Ed) Oxford University Press, New York, ISBN 978-0-19-517226-3 2006.

49. Ferguson E, James D, Madeley L. Factors associated with success in medical school: systematic review of the literature. BMJ Clinical research ed 2002;324:952-7.

50. Rhoads JM, Gallemore JL, Jr., Gianturco DT, Osterhout S. Motivation, medical school admissions, and student performance. Journal of medical Medical Education 1974;49:1119-27.

51. Knights JA, Kennedy BJ. Medical school selection: screening for dysfunctional tendencies. Med Educ 2006;40:1058-64.

52. Morrison J. How to choose tomorrow's doctors. Med Educ 2005;39:240-2.

53. Morrison J. Professional behaviour in medical students and fitness to practise. Med Educ 2008;42:118-20.

54. Brownell K, Lockyer J, Collin T, Lemay JF. Introduction of the multiple mini interview into the admissions process at the University of Calgary: acceptability and feasibility. Medical Teacher 2007;29:394-6.

55. Bore M, Munro D, Kerridge I, Powis D. Selection of medical students according to their moral orientation. Med Educ 2005;39:266-75.

56. Kulatunga-Moruzi C, Norman GR. Validity of admissions measures in predicting performance outcomes: a comparison of those who were and were not accepted at McMaster. Teaching and Learning in Medicine 2002;14:43-8.

57. Puryear JB, Lewis LA. Description of the interview process in selecting students for admission to U.S. medical schools. Journal of Medical Education 1981;56:881-5.

58. Benor DE, Notzer N, Sheehan TJ, Norman GR. Moral reasoning as a criterion for admission to medical school. Med Educ 1984;18:423-8.

59. Stern DT, Frohna AZ, Gruppen LD. The prediction of professional behaviour. Med Educ 2005;39:75-82.

60. Ashton $\mathrm{CH}$, Kamali F. Personality, lifestyles, alcohol and drug consumption in a sample of British medical students. Med Educ 1995;29:187-92.

61. Hohaus LC, Berah EF. Impairment of doctors: are beginning medical students psychologically vulnerable? Med Educ 1985;19:431-6.

62. Rosenberg DA, Silver HK. Medical student abuse. An unnecessary and preventable cause of stress. JAMA 1984;251:739-42.

63. Baldwin DC, Jr., Daugherty SR, Eckenfels EJ. Student perceptions of mistreatment and harassment during medical school. A survey of ten United States schools. West $\mathrm{J}$ Med 1991;155:140-5.

64. Uhari M, Kokkonen J, Nuutinen M, Vainionpaa L, Rantala H, Lautala P, Väyrynen M. Medical student abuse: an international phenomenon. JAMA 1994;271:1049-51.

65. Silver HK, Glicken AD. Medical student abuse. Incidence, severity, and significance. JAMA 1990;263:527-32.

66. McManus IC. Factors affecting likelihood of applicants being offered a place in medical schools in the United Kingdom in 1996 and 1997: retrospective study. BMJ Clinical research ed 1998;317:1111-6.

67. Albanese MA, Snow MH, Skochelak SE, Huggett KN, Farrell PM. Assessing personal qualities in medical school admissions. Acad Med 2003;78:313-21.

68. Lumsden MA, Bore M, Millar K, Jack R, Powis D. Assessment of personal qualities in relation to admission to medical school. Med Educ 2005;39:258-65. 
50 $\mid$ Chapter 2

69. Lowe M, Kerridge I, Bore M, Munro D, Powis D. Is it possible to assess the "ethics" of medical school applicants? Journal of Medical Ethics 2001;27:404-8.

70. Eva KW, Neville AJ, Norman GR. Exploring the etiology of content specificity: factors influencing analogic transfer and problem solving. Acad Med 1998;73(10 Suppl):S1-5.

71. van Mook WN, Gorter SL, O'Sullivan H, Wass V, Schuwirth LW, van der Vleuten CP. Approaches to professional behaviour assessment: tools in the professionalism toolbox. Eur $\mathrm{J}$ Int Med 2009;20:e153-7.

72. Papadakis MA, Loeser $\mathrm{H}$. Using critical incident reports and longitudinal observations to assess professionalism. In: Measuring medical professionalism Stern, DT (ed) Oxford University Press, New York, 2006 ISBN-13: 978-0-19-517226-3 2006.

73. Thisthethwaite J, Spencer J. Assessing professionalism. In: Professionalism in Medicine 2008;ISBN-13: 9781857757637

74. Papadakis MA, Loeser H, Healy K. Early detection and evaluation of professionalism deficiencies in medical students: one school's approach. Acad Med 2001;76:1100-6.

75. Sullivan C, Arnold L. Assessment and remediation in programs of teaching professionalism. In: Teaching medical Professionalism (Cruess RL, Cruess, SR, Steiner Y, eds) 2009;ISBN 978-0-521-88104-3:124-49.

76. Fochtmann L. Professionalism and the Heisenberg uncertainty principle. In: Professionalism in Medicine Critical perspectives Wear D, Aultman JM (Eds) 2006

77. Boisaubin EV, Levine RE. Identifying and assisting the impaired physician. Am J Med Sci 2001;322:31-6.

78. Galletly CA. Psychiatrist-patient sexual relationships: the ethical dilemmas. Aust $\mathrm{N} Z \mathrm{~J}$ Psychiatry 1993;27:133-9.

79. Hickson GB, Federspiel CF, Pichert JW, Miller CS, Gauld-Jaeger J, Bost P. Patient complaints and malpractice risk. JAMA 2002;287:2951-7.

80. Hickson GB, Federspiel CF, Blackford J, Pichert JW, Gaska W, Merrigan MW, Miller CS. Patient complaints and malpractice risk in a regional healthcare center. Southern Medical Journal 2007;100:791-6.

81. Diaz AL, McMillin JD. A definition and description of nurse abuse. West $J$ Nurs Res 1991;13:97-109.

82. Linney BJ. Confronting the disruptive physician. Physician Executive 1997;23:55-8.

83. Lawrence JM. The impaired doctor. The Medical Journal of Australia 1992;157:4-6.

84. Kessler RC, Berglund P, Demler O, Jin R, Koretz D, Merikangas KR, Rush AJ, Walters EE, Wang PS; National Comorbidity Survey Replication. The epidemiology of major depressive disorder: results from the National Comorbidity Survey Replication (NCS-R). JAMA 2003;289:3095-105.

85. Schernhammer E. Taking their own lives -- the high rate of physician suicide. N Engl J Med 2005;352:2473-6.

86. Schernhammer ES, Colditz GA. Suicide rates among physicians: a quantitative and gender assessment (meta-analysis). Am J Psychiatry 2004;161:2295-302.

87. Pichert JW, Miller CS, Hollo AH, Gauld-Jaeger J, Federspiel CF, Hickson GB. What health professionals can do to identify and resolve patient dissatisfaction. Jt Comm J Qual Improv 1998;24:303-12.

88. Shue CK, Arnold L, Stern DT. Maximizing participation in peer assessment of professionalism: the students speak. Acad Med 2005;80(10 Suppl):S1-5.

89. Campbell EG, Regan S, Gruen RL, Ferris TG, Rao SR, Cleary PD, Blumenthal D. Professionalism in medicine: results of a national survey of physicians. Ann Intern Med 2007;147:795-802.

90. Sexual misconduct in the practice of medicine. Council on Ethical and Judicial Affairs, American Medical Association. JAMA 1991;266:2741-5.

91. O'Connor PG, Spickard A, Jr. Physician impairment by substance abuse. Med Clin North Am 1997;81:1037-52. 


\section{Chapter 3}

Promoting professional behaviour in undergraduate medical, dental and veterinary curricula in the Netherlands: evaluation of a joint effort 


\section{Abstract}

\section{Background}

From 2002 onwards, a nationwide working group of representatives from all medical (8), dental (3) and veterinary medicine (1) schools collaborated in order to develop and implement recommendations for teaching and assessing professional behaviour.

\section{Aim}

The aim of the present paper is to describe the outcomes of this process, including hurdles encountered and challenges to be met.

\section{Method}

Using a qualitative survey, information was gathered regarding teaching of professional behaviour, assessment, instruments used, consequences of unprofessional behaviour, and faculty training.

\section{Results}

All schools have adopted at least parts of the 2002 recommendations. Differences exist mainly in the organisational structure of teaching and assessment as well as in the assessment instruments used. In all schools a longitudinal assessment of professional behaviour was accomplished.

\section{Conclusions}

All schools involved have made progress since 2002 with regard to teaching and assessment of professional behaviour, resulting in a shift from an instrumental to a cultural change for some schools. An enabling factor was society's call to focus on patient safety and therefore on assessment of unprofessional behaviour. Hurdles yet to be taken are the involvement of students in the assessment process, teacher confidence in personal assessment capacities, remediation programs and logistic and administrative support. 


\section{Introduction}

Professional behaviour in the medical educational context is currently a major issue $^{1}$. An ever increasing number of scientific publications pertaining to professionalism and professional behaviour has been written elaborating for example on professional behaviour from the perspective of societal expectations ${ }^{2,3}$, patient safety ${ }^{4}$, the definition of terms involved ${ }^{5-8}$, teaching and learning ${ }^{3,5,9}$, the development and use of different assessment methods ${ }^{10-13}$, dealing with unprofessional behaviour ${ }^{14-16}$, and legal implications ${ }^{17}$.

In line with this internationally shared urgency to describe and develop educational tools for teaching professional behaviour, all medical (8), dental (3) and veterinary (1) schools in the Netherlands have jointly invested in the development of a practical structure to optimise students' learning and assessment of professional behaviour. The paper presented herein describes the background and outcome of this combined effort ${ }^{18,19}$. Limitations and hurdles in implementation will be discussed and future challenges will be touched upon.

\section{Professional behaviour in Dutch undergraduate curricula}

In the Netherlands, medical and veterinary studies last for six years; dental studies lasted for five years until 2009, and have now become six years too. Most students enter medical (dental, veterinary) school after finishing high school at the age of 18. Freshmen numbers are limited, by government order, ranging from about 80 (dental schools) to about 350 students per year (medical schools). A weighted lottery by the government in which grade point average scores of high school exams are decisive in who is admitted to the studies and who is not. From 2001 onwards, schools are permitted to select freshmen by themselves to a maximum of $50 \%$ of enrolment. Most Dutch medical schools now have a mainly preclinical (years 1-3) and a clinical (years 4-6) programme. The preclinical period is more theoretical; in the clinical programme, students focus more on clinical experience. Elements of teaching and assessing professional behaviour have been introduced in the early nineties in some medical schools, expanding to all schools around 2000.

During medical school, a student is expected to perform according to appropriate medical norms and values. The student has to be prepared for internalising these values and norms during the curriculum. To achieve this goal, teachers and assessors scaffold by giving appropriate formative or summative feedback on students' performance. This feedback is helpful for all 
$54 \mid$ Chapter 3

students but, from the perspective of patient safety, is especially important for those students deviating from expected norms and values.

Before 2002, all medical, dental and veterinarian schools in the Netherlands had their own style and structure dealing with (un)professional behaviour by their students. This situation resulted in a wide variety of approaches, with schools ranging from hardly any explicit focus on professional behaviour, to other schools where evaluation forms were systematically used to examine students' performance. At that time most schools had no administrative system to record incidents of serious unprofessional behaviour.

To facilitate a more uniform way to teach and assess professional behaviour, the Association of Universities in The Netherlands (VSNU) instituted a Special Interest Group on Professional Behaviour. Representatives of all Dutch medical, dental and veterinary faculties collaborated to this end. This group finalised a report on professional behaviour in medical undergraduate education in $2002^{18,19}$. This report included recommendations for teaching, assessment, coaching, and temporarily excluding students with unprofessional behaviour.

\section{Defining professional behaviour}

Professional behaviour is a term mainly used in a European setting, and seems to contrast with the term professionalism mainly used in the United States and Canada $^{20}$. While professional behaviour refers to observable behaviour, and includes a public centred view of professionals (outer shell) ${ }^{21,22}$, professionalism refers to values and norms of the profession (inner core). The latter comprises altruism, compassion, et cetera, and the relation of the profession with society ${ }^{23-25}$.

It is obvious that both approaches are two sides of the same coin. The Consilium Abeundi report provided a workable, practical description of professional behaviour. Basically, the description points to the fact that one should focus upon observable behaviour in which the standards and values of professional practice are demonstrated. For example, communication, behaviour, and appearance, all aimed at establishing the trust between the professional and the patient. The following dimensions of professional behaviour were distinguished: dealing with tasks or work, dealing with others and dealing with oneself ${ }^{26}$.

\section{The recommendations}

All the schools involved have agreed to adhere to the guidelines and 
recommendations formulated by the report. These recommendations focus on four categories: (1) general core elements with respect to professional behaviour, (2) recommendations about education and assessment, (3) recommendations about coaching students, (4) recommendations concerning legal status. More specific information concerning these recommendations is listed in Table 3.1.

Table 3.1 Project Team Consilium Abeundi recommendations $2002^{18,19}$

\section{A The recommendations contained the following general core elements}

- each faculty should make professional behaviour in its own curriculum as clear as possible (based on the nationwide blueprint curriculum recommendations ${ }^{33}$

- in order to do so, both teachers and students should be involved;

- the assessment of professional behaviour should be calibrated nationwide among the faculties;

- a national working group should be installed in which coordinators of the faculties participate, in order to exchange information about developments in education and assessment of professional behaviour.

$B$ With regard to education and assessment the following recommendations were made

- each faculty should determine which parts of the curriculum are suitable for measuring and discussing professional behaviour;

- in case not enough suitable courses or stages that match this goal can be traced, new ones should be implemented that do match;

- reflection upon one's behaviour is considered the core skill that needs to be developed by the student;

- assessment should focus upon observable behaviour in the educational environment and on the student's reflection upon that behaviour;

- the assessment cannot be compensated for other aspects of clinical competencies;

- assessments should be organised in a longitudinal way, spread across the curriculum, with a growing complexity;

- assessment results should be kept in a central dossier;

- the final examination of professional behaviour should be based upon the assessments of at least four to six independent judges;

- it should be clear to the students in which situations, at which moments, and according to which criteria they are assessed;

- education in and examination of professional behaviour should be explicitly part of the rules and regulations from the Examination Board;

- teachers should be trained in providing feedback on students' behaviour.

C With regard to the coaching of students with unprofessional behaviour the following recommendations were made

- the coaching of students with unprofessional behaviour should be recorded in a written report, making clear which employees were involved and who coordinated the coaching of the student;

- the coaching is aimed at providing possibilities for the student to continue academic studies in another field, or by obtaining a degree in the present study without a clinical license;

- case studies and examples of remedial teaching should be exchanged by the participants of the national working group.

\section{Recommendations concerning legislation}

- since currently unprofessional behaviour cannot lead to dismissal from medical school, university boards should emphasise the need for changes in the current law on higher education (WHW) that would make it possible to exclude students from further education once proven to be unsuitable for the profession. 
The aim of the present paper is to describe the outcomes of the process to implement the guidelines, including hurdles encountered and challenges still to be met.

\section{Methods}

Seven years after finishing the report the authors explored to what extent the recommendations had been implemented. In Spring 2009, a questionnaire was distributed by mail among the 12 participating schools to survey this. All schools' representatives responsible for teaching and assessing professional behaviour in the curriculum were requested to address 10 questions using an open answer format. This leaves the following questions to be discussed: (1) How is professional behaviour taught in the curriculum? (2) In which years and in which situations does behavioural assessment take place? (3) Who assesses professional behaviour? (4) Which instruments for assessment are used? (5) What happens in cases of a negative assessment? (6) How is faculty trained in teaching and assessing professional behaviour?

Additional questions explored stimulating or inhibiting factors experienced in the implementation process of the recommendations. Participants were asked to formulate three stimulating and three inhibiting factors related to the implementation of the recommendations.

All twelve schools participated. After the first round of information gathering, each school's representative was given the opportunity, by direct mail contact, to adjust the categorisation results. All respondents approved the final results.

\section{Results}

The results show that the goals of teaching and assessing professional behaviour as stated by medical (dental, veterinary) faculties are still fully endorsed by all schools. Although discussions about assessment of professional behaviour are mostly focused on the poorly performing 'unprofessional' students, it must be stressed that all schools try to emphasise that assessing students' performance is very beneficial for all students.

In general, all schools use similar teaching and assessment formats. These results are summarised in Table 3.2. 
Table 3.2 Summary of the questionnaire results across all Dutch medical schools

\begin{tabular}{ll}
\hline How is & Teaching professional behaviour \\
professional & - publishing rules of adequate professional behaviour of medical students \\
behaviour taught in & - plenary sessions about themes related to professional behaviour (e.g. \\
the curricula? & ethics, medical law) \\
& - small group sessions (tutorial groups, coaching groups) by discussing \\
& professional behaviour around case histories of patients in health care \\
- & small group sessions (tutorial groups, coaching groups) by discussing group \\
& responsibilities or responsibilities of individual group members \\
- & white coat ceremony \\
& role modelling (informal)
\end{tabular}

In which years and All schools assess professional behaviour during all years of the curriculum in which situations although not always specified (or named) as professional behaviour is professional behaviour assessed?

\section{Context for assessing (parts of) professional behaviour}

In general: all teaching activities in which a teacher is able to see students frequently in a given period

- scheduled courses, clinical rotations, electives and/or small group sessions.

- skills training sessions, simulated patient contacts

\section{Frequency of assessment / feedback}

- from one or two times a year up to six times a year, either formative or summative

- during an educational activity assessment halfway (formative) and at the end (summative or formative)

Apart from the regular assessment for all students, some schools also have the possibility to report (critical) incidents about unprofessional behaviour of individual students to the examination board or dean.

\begin{tabular}{lll}
$\begin{array}{l}\text { By whom is } \\
\text { professional }\end{array}$ & - & teachers who guide students in longitudinal training sessions (teachers, \\
behaviour & tutors, coaches, supervisors, residents). \\
assessed? & peers in student groups (formative assessment) \\
\hline
\end{tabular}

\begin{tabular}{|c|c|}
\hline $\begin{array}{l}\text { Which instruments } \\
\text { are used for } \\
\text { assessment? }\end{array}$ & $\begin{array}{l}\text { A variety of instruments is used for assessment } \\
\text { - } \text { assessment/feedback instruments directly related to professional } \\
\text { behaviour containing three domains dealing with tasks/work, dealing with } \\
\text { others, dealing with oneself } \\
\text { - } \text { assessment/feedback instruments contain aspects of professional } \\
\text { behaviour (e.g. portfolio for reflection; communication rating scales by } \\
\text { OSCE s) } \\
\text { - most frequently qualitative judgements, not quantitative }\end{array}$ \\
\hline
\end{tabular}


Table 3.2 (continued)

\begin{tabular}{lll}
\hline What happens in & Different phases of action according & Different measures \\
case of a negative & to the degree of unprofessional & - feedback discussions \\
judgement of & behaviour & - warning \\
students' & - direct feedback from teachers in & - suspension for some time (max 1 \\
professional & -educational setting & year) from training and assessment \\
behaviour? & - formal feedback from examiner & Every measure is accompanied by \\
& board or dean & \\
& Phases are related to the severity of & \\
& unprofessional behaviour & \\
\hline How is faculty & - faculty follows basic and advanced teaching courses, partly directly relevant \\
trained in teaching & for teaching and assessing professional behaviour (for example feedback \\
and assessing & training) \\
professional & - courses for faculty directly focussed on professional behaviour are sparse; \\
behaviour? & emphasis is put on using the rating scales or checklists \\
& - peer review groups of teachers are successful, but only the most committed \\
& teachers show up \\
\hline
\end{tabular}

Data show that some aspects of teaching and assessment at the different schools can be improved. First, the role of the student in the assessment process is often marginal. Students are assessed by teachers but can, especially in small groups, also be invited to assess each other using peer assessment. This is hardly the case in most schools. Subsequently, training students to assess professional behaviour is not common in all schools. This holds for teachers as well. Despite the fact that most teachers have had a general teacher training, only a few schools have teacher training courses specifically directed toward discussing and assessing professional behaviour.

Another aspect that arises from the data is that most schools have no overview of the number of students with unprofessional behaviour. This hinders defining the magnitude and content of the problem. In addition to training, communication about teaching and assessing professional behaviour can also be improved in most faculties. Focussed information through booklets or internet about mission, vision, teaching activities, and assessment of professional behaviour is sometimes not sufficiently available.

Although most schools focus on the same teaching methods and assessment procedures for professional behaviour, there is still a great variety in how and to what extent schools implement it. Some schools have already implemented a system that is integrated into many educational activities and discussions about professional behaviour have become more and more part of the 'culture', while others still try to get professional behaviour prominently on the agenda. Several factors contribute to the implementation of professional behaviour in a curriculum. The results of our investigation into supporting and inhibiting factors for implementation are summarised in Table 3.3. 
Table 3.3 Stimulating and inhibiting factors regarding implementation of the recommendations for professional behaviour in medical, dental and veterinary schools in the Netherlands ${ }^{18,19}$

\begin{tabular}{|c|c|}
\hline Stimulating factors & Inhibiting factors \\
\hline \multicolumn{2}{|l|}{ Law and regulations } \\
\hline $\begin{array}{l}\text { - nationwide report about implementing teaching } \\
\text { and assessing PB } \\
\text { - Blueprint end objectives medical studies } \\
\text { - accreditation of institutions }\end{array}$ & $\begin{array}{l}\text { - till now no possibilities in Dutch law to } \\
\text { expel students from the studies despite } \\
\text { serious misconduct }\end{array}$ \\
\hline
\end{tabular}

\section{Organisation}

- positive culture in the organisation towards professional behaviour

- listalling a special committee responsible for the implementation of $\mathrm{PB}$ in the curriculum

- assigning credit points (ECTS) to PB teaching and assessment

- antegration of PB assessment with the examination rules

- PB assessment not compensatory

- mandatory teacher training sessions about PB teaching and assessment

- new curriculum which allows PB to be integrated into other educational and assessment activities

- commitment of leaders in education with clinical background

- clear mission statement

- financing PB activities adequately

- allocation of educational hours for coordinator PB

- nationwide group acting as expert group
- PB bureaucracy (over-organising, overstructuring)

- large educational groups of students; PB needs small scale education

- patchy contacts with students

- little understanding that implementation of PB teaching and assessment means a lot of measures on organisational level with subsequent financial support

- PB teaching and assessment means a heavy burden for the organisation

\section{User}

- clear tasks and backing for teachers and assessors $\mathrm{PB}$

- the urgent need to cope with unprofessional behaviour of students

- patient safety

- role models as teachers (enthusiastic, clinical background)
- too much focus on technical skills

- competition with other disciplines in relation to educational time

- extra work, extra time

- motivation of teachers

- teachers feel insecure about judging PB of students

- too many reflection assignments for students

- giving negative assessments leads to stress for teachers and creates a lot of work

- persistent lack of (competent) tutors

- too much emphasis on reflection

\section{Instrument}

- 'lean and mean' instruments

- growing attention for PB also in resident training

- no clear link with professional practice (patient care)

- no link with portfolio to follow student progress longitudinally

- discussions about the distinction from other concepts and skills 


\section{Discussion}

The aim of the present survey was to evaluate the progress made in promoting teaching and assessment of professional behaviour in Dutch medical, dental, and veterinary education since the joined presentation of a report with recommendations in 2002. When looking at the results of the questionnaire (Table 3.2) and comparing them with the original recommendations from 2002 (Table 3.1) the following conclusions can be drawn.

\section{General core elements}

With respect to the general core elements it can be said that every school focuses much more on matters concerning professional behaviour than was the case in 2002.

\section{Teaching and assessment}

With respect to teaching, there is a tendency to make professional behaviour more explicit and visible in the curriculum, rather than teaching new content. The introduction of professional behaviour as a defined concept has made students and faculty more aware of its importance and has given participants a 'language' in which to discuss behaviour with each other.

With respect to assessment, much more has been changed. Several committees of professional behaviour were installed to support the local examination boards in their task to organise assessment procedures and to give advice on how to handle unprofessional behaviour of students.

The rules and regulations in almost all schools consist of chapters about assessing professional behaviour and the consequences when students do not meet the criteria.

With regard to training faculty, much has been done but probably not enough. Teachers follow general teacher training sessions. However, sessions especially focused on professional behaviour are rare and should be offered more frequently. In doing so, teachers can be made more aware of the specific skills needed and can be trained in critical incidents when discussing elements of professional behaviour with a single student or a group of students. This will also enforce the implementation and contribute to changing the 'culture' when discussing each other's performance in line with the research of Steinert ${ }^{27,28}$. 
Students too should be involved in training, when we consider them as serious partners in discussing performance. For them it is as difficult as for teachers to give feedback to peers. Moreover, training them is part of their professional training because after graduation they are also expected to give feedback to unprofessional colleagues. Therefore training students to give feedback to their peers about professional behaviour is still a goal to be met. It stimulates reflective skills ${ }^{29}$.

\section{Coaching of students with unprofessional behaviour}

The recommendations stated that reflection upon one's behaviour is a core skill that needs to be developed by students. There is definitely more attention paid to reflection skills in the Dutch curricula now ${ }^{30}$. However, the impression still exists that there are too few opportunities for students to train and to develop reflection skills. Most schools use assignments to stimulate reflection, but students tend to dislike such assignments. Schools are still looking for other practical and evidence based teaching formats supporting reflective skills. Examination boards or committees of professional behaviour have almost no possibilities to help unprofessional students who lack self-reflection within a curriculum. This is a serious unsolved problem in training professional behaviour.

The recommendations favoured an exchange of case studies or examples of remedial teaching activities. This has been done during the past few years in several groups of student counsellors and also in the Netherlands Association for Medical Education - Special Interest Group on Professional Behaviour (NVMO). Despite these developments, it was not yet possible to construct a sound model for guiding students with unprofessional behaviour. Herein lays a clear challenge for the years to come. It is an extremely important issue and is also highly relevant for postgraduate education.

\section{Legislation}

Fortunately, Dutch law has changed per 1 September 2010, now making it possible to suspend students permanently from medical school in case of undisputed unprofessional behaviour ${ }^{31,32}$.

\section{General considerations}

Implementation of professional behaviour in the curricula requires a process development in order to be successful. Awareness of the importance of the topic among faculty is crucial. Furthermore, leadership, organisational support and efficient assessment tools are crucial. If one of these elements lacks, the 
implementation stands on hold or is likely to fade out. An important question is whether all efforts during the last years have led to better professional performance of students and therefore to a fewer number of reports of unprofessional behaviour. Unfortunately, this question cannot be answered yet. This is partly because most of the schools have little overview on the number of students with unprofessional behaviour and partly due to more awareness among teachers and assessors and to clearer procedures on how to handle this problem. Therefore, it can be expected that more reports on unprofessional behaviour will appear in the years to come, instead of fewer, but probably not reflecting a higher incidence of unprofessional behaviour.

This study has its limitations. It was based on a questionnaire sent to all medical, dental, veterinary schools in the Netherlands. The authors collected and categorised the open ended questions, thus leaving room for some subjective interpretation developments reported. However, each participating school representative was given the opportunity, by direct mail contact, to correct misinterpretations. The results may therefore be considered representative for the Dutch situation.

\section{Conclusions}

It can be concluded that, following the recommendations in 2002, much has been done on teaching and assessing professional behaviour in the medical, dental and veterinary schools in the Netherlands. Most important for these developments are societal developments in which patient safety has become a major public issue. The recommendations have contributed to giving medical (dental, veterinary) schools a structure to respond to these societal developments.

\section{Epilogue}

After presentation of the 2002 report, the members of the task group continued to meet on a regular basis, between two to four times a year, with other professionals involved in teaching and assessing professional behaviour. This provided a - possibly unique - expert team to engage professionals representing all medical, dental and veterinarian schools in one country to further develop the implementation of professional behaviour in each school's curriculum. This team is organised as the Netherlands Association for Medical Education - Special Interest Group on Professional Behaviour (NVMO). 


\section{References}

1. van Mook WN, de Grave WS, van Luijk SJ, O'Sullivan H, Wass V, Schuwirth LW, van der Vleuten CP. Training and learning professionalism in the medical school curriculum: Current considerations. Eur J Int Med 2009;20:e96-e100.

2. van Mook WN, Gorter SL, de Grave WS, van Luijk SJ, O'Sullivan H, Wass V, Zwaveling JH, Schuwirth LW, van der Vleuten CP. The educational continuum: professionalism in and beyond medical school. Eur J Int Med 2009;20:e148-52.

3. Hickson GB, Pichert JW, Webb LE, Gabbe SG. A complementary approach to promoting professionalism: identifying, measuring, and addressing unprofessional behaviors. Acad Med 2007;82:1040-8.

4. van Mook WN, van Luijk SJ, O'Sullivan H, Wass V, Harm Zwaveling J, Schuwirth LW, van der Vleuten CP. The concepts of professionalism and professional behaviour: Conflicts in both definition and learning outcomes. Eur J Int Med 2009;20:e85-e9.

5. van Mook WN, van Luijk SJ, de Grave W, O'Sullivan H, Wass V, Schuwirth LW, van der Vleuten CP. Teaching and learning professional behavior in practice. Eur $\mathrm{J}$ Int Med 2009;20:e105-11.

6. van Mook WN, van Luijk SJ, O'Sullivan H, Wass V, Schuwirth LW, van der Vleuten CP. General considerations regarding assessment of professional behaviour. Eur J Int Med 2009;20:e90-e5.

7. Wasserstein AG, Brennan PJ, Rubenstein AH. Institutional leadership and faculty response: fostering professionalism at the University of Pennsylvania School of Medicine. Acad Med 2007;82:1049-56.

8. Viggiano TR, Pawlina W, Lindor KD, Olsen KD, Cortese DA. Putting the needs of the patient first: Mayo Clinic's core value, institutional culture, and professionalism covenant. Acad Med 2007;82:1089-93.

9. Smith KL, Saavedra R, Raeke JL, O'Donell AA. The journey to creating a campus-wide culture of professionalism. Acad Med 2007;82:1015-21.

10. van Luijk SJ, Smeets SGE, Smits J, Wolfhagen IH, Perquin MLF. Assessing professional behaviour and the role of academic advice at the Maastricht Medical School. Medical Teacher 2000;22:168- 72.

11. Thistlethwaite JE, Spencer Je. Professionalism in medicine. Radcliffe Publishing Ltd, Abingdon, UK 2008.

12. Stern DT (ed.). Measuring medical professionalism. Oxford University Press, New York, ISBN 978-0-19-517226-3 2006.

13. Cruess R, Cruess S, Steinert $Y$. Teaching medical professionalism. ISBN 978-0-521-88104-3 2009.

14. Wear D, Aultman J. Professionalism in medicine. ISBN 0-387-32726-6 2006.

15. Postma CT, Thoben A, Timmermans L, van Spaendonck K. Horken en huilebalken. Medisch Contact 2006;61:883-5.

16. Rynja S, Cents R, Morsink M. Tabee lomperikken en horken. Medisch Contact 2006;62:73-5.

17. O'Neill B. Doctor as murderer. Death certification needs tightening up, but it still might not have stopped Shipman. BMJ Clinical research ed 2000;320:329-30.

18. Esmail A. Physician as serial killer--the Shipman case. N Engl J Med 2005;352:1843-4.

19. Papadakis MA, Arnold GK, Blank LL, Holmboe ES, Lipner RS. Performance during internal medicine residency training and subsequent disciplinary action by state licensing boards. Ann Intern Med 2008;148:869-76.

20. Papadakis MA, Hodgson CS, Teherani A, Kohatsu ND. Unprofessional behavior in medical school is associated with subsequent disciplinary action by a state medical board. Acad Med 2004;79:244-9.

21. Papadakis MA, Teherani A, Banach MA, Knettler TR, Rattner SL, Stern DT, Veloski JJ, Hodgson CS. Disciplinary action by medical boards and prior behavior in medical school. $\mathrm{N}$ Engl J Med 2005;353:2673-82. 
64 $\mid$ Chapter 3

22. Irvine D. Patients, professionalism, and revalidation. BMJ Clinical research ed 2005;330: 1265-8.

23. Leape LL, Fromson JA. Problem doctors: is there a system-level solution? Ann Intern Med 2006;144:107-15.

24. McLemore MR. Workplace aggression: beginning a dialogue. Clinical Journal of Oncology Nursing 2006;10:455-6.

25. Rosenstein $\mathrm{AH}$. Original research: nurse-physician relationships: impact on nurse satisfaction and retention. The American Journal of Nursing 2002;102:26-34.

26. Rosenstein $\mathrm{AH}, \mathrm{O}$ 'Daniel $\mathrm{M}$. Study links disruptive behavior to negative patient outcomes. OR manager 2005;21:1, 20, 2.

27. Rosenstein $\mathrm{AH}, \mathrm{O}$ 'Daniel $\mathrm{M}$. Disruptive behavior and clinical outcomes: perceptions of nurses and physicians. The American Journal of Nursing 2005;105:54-64.

28. Rosenstein $\mathrm{AH}$, O'Daniel $\mathrm{M}$. Impact and implications of disruptive behavior in the perioperative arena. Journal of the American College of Surgeons 2006;203:96-105.

29. Rosenstein $\mathrm{AH}$, O'Daniel M. A survey of the impact of disruptive behaviors and communication defects on patient safety. Joint Commission journal on quality and patient safety / Joint Commission Resources 2008;34:464-71.

30. Rosenstein $\mathrm{AH}, \mathrm{O}^{\prime}$ Daniel $\mathrm{M}$. Invited article: Managing disruptive physician behavior: impact on staff relationships and patient care. Neurology 2008;70:1564-70.

31. Rosenstein $\mathrm{AH}$, Russell $\mathrm{H}$, Lauve R. Disruptive physician behavior contributes to nursing shortage. Study links bad behavior by doctors to nurses leaving the profession. Physician Executive 2002;28:8-11.

32. Felps WA, Mitchell TR, Byington EK. How, when and why bad apples spoil the barrel: negative group members and dysfunctional groups. Research in Organizational Behavior 2006;27:181-230.

33. Stephenson AE, Adshead LE, Higgs RH. The teaching of professional attitudes within UK medical schools: reported difficulties and good practice. Med Educ 2006;40:1072-80.

34. van Mook WN, de Grave WS, Wass V, O'Sullivan H, Zwaveling JH, Schuwirth LW, van der Vleuten CP. Professionalism: Evolution of the concept. Eur J Int Med 2009;20:e81-e4.

35. Lee AG, Beaver HA, Boldt HC, Olson R, Oetting TA, Abramoff M, Carter K. Teaching and assessing professionalism in ophthalmology residency training programs. Surv Ophthalmol 2007;52:300-14.

36. Edelstein SB, Stevenson JM, Broad K. Teaching professionalism during anesthesiology training. J Clin Anesth 2005; 17:392-8.

37. Rowley BD, Baldwin DC, Jr., Bay RC, Cannula M. Can professional values be taught? A look at residency training. Clin Orthop Relat Res 2000:110-4.

38. The Royal College of Physicians and Surgeons in Canada. http://rcpscmedicalorg/canmeds/ indexphp, accessed October 10th 2006.

39. Medische Vervolgopleidingen.nl. http://www.medischevervolgopleidingen.nl/pages/ contentaspx? content $=10010000000029 \_2 \_10000000001651 \&$ contentcode=competentiesspe cialist, accessed October 10th 2006.

40. Accreditation Council for Graduate Medical Education. ACGME Outcome Project enhancing residency education throught outcomes assessment: General competencies. 1999;Accessed Febr 13th 2006: http://www.acgme.org/outcome/comp/compFull.asp.

41. Gruen RL, Arya J, Cosgrove EM, Cruess RL, Cruess SR, Eastman AB, Fabri PJ, Friedman P, Kirksey TD, Kodner IJ, Lewis FR, Liscum KR, Organ CH, Rosenfeld JC, Russell TR, Sachdeva AK, Zook EG, Harken AH; American College of Surgeons Task Froce on Professionalism. Professionalism in surgery. Journal of the American College of Surgeons 2003;197:605-8.

42. Larkin GL. Evaluating professionalism in emergency medicine: clinical ethical competence. Acad Emerg Med 1999;6:302-11.

43. Stern DT, Papadakis M. The developing physician--becoming a professional. N Engl J Med 2006;355:1794-9.

44. Stross JK, Harlan WR. Mandatory continuing medical education revisited. Mobius 1987;7: 22-7. 
45. Papadakis MA, Osborn EH, Cooke M, Healy K. A strategy for the detection and evaluation of unprofessional behavior in medical students. University of California, San Francisco School of Medicine Clinical Clerkships Operation Committee. Acad Med 1999;74:980-90.

46. Knights JA, Kennedy BJ. Medical school selection: impact of dysfunctional tendencies on academic performance. Med Educ 2007;41:362-8.

47. Eva KW, Rosenfeld J, Reiter HI, Norman GR. An admissions OSCE: the multiple miniinterview. Med Educ 2004;38:314-26.

48. Wagoner N. Admission to medical school: selecting applicants with the potential for professionalism (Chapter 13). In: Measuring medical professionalism (Stern, D, Ed) Oxford University Press, New York, ISBN 978-0-19-517226-3 2006.

49. Ferguson E, James D, Madeley L. Factors associated with success in medical school: systematic review of the literature. BMJ Clinical research ed 2002;324:952-7.

50. Rhoads JM, Gallemore JL, Jr., Gianturco DT, Osterhout S. Motivation, medical school admissions, and student performance. Journal of Medical Education 1974;49:1119-27.

51. Knights JA, Kennedy BJ. Medical school selection: screening for dysfunctional tendencies. Med Educ 2006;40:1058-64.

52. Morrison J. How to choose tomorrow's doctors. Med Educ 2005;39:240-2.

53. Morrison J. Professional behaviour in medical students and fitness to practise. Med Educ 2008;42:118-20.

54. Brownell K, Lockyer J, Collin T, Lemay JF. Introduction of the multiple mini interview into the admissions process at the University of Calgary: acceptability and feasibility. Medical Teacher 2007;29:394-6.

55. Bore M, Munro D, Kerridge I, Powis D. Selection of medical students according to their moral orientation. Med Educ 2005;39:266-75.

56. Kulatunga-Moruzi C, Norman GR. Validity of admissions measures in predicting performance outcomes: a comparison of those who were and were not accepted at McMaster. Teaching and Learning in Medicine 2002;14:43-8.

57. Puryear JB, Lewis LA. Description of the interview process in selecting students for admission to U.S. medical schools. Journal of Medical Education 1981;56:881-5.

58. Benor DE, Notzer N, Sheehan TJ, Norman GR. Moral reasoning as a criterion for admission to medical school. Med Educ 1984;18:423-8.

59. Stern DT, Frohna AZ, Gruppen LD. The prediction of professional behaviour. Med Educ 2005;39:75-82.

60. Ashton $\mathrm{CH}$, Kamali F. Personality, lifestyles, alcohol and drug consumption in a sample of British medical students. Med Educ 1995;29:187-92.

61. Hohaus LC, Berah EF. Impairment of doctors: are beginning medical students psychologically vulnerable? Med Educ 1985;19:431-6.

62. Rosenberg DA, Silver HK. Medical student abuse. An unnecessary and preventable cause of stress. JAMA 1984;251:739-42.

63. Baldwin DC, Jr., Daugherty SR, Eckenfels EJ. Student perceptions of mistreatment and harassment during medical school. A survey of ten United States schools. West $\mathrm{J}$ Med 1991;155:140-5.

64. Uhari M, Kokkonen J, Nuutinen M, Vainionpaa L, Rantala H, Lautala $\mathrm{P}$, Väyrynen M. Medical student abuse: an international phenomenon. JAMA 1994;271:1049-51.

65. Silver HK, Glicken AD. Medical student abuse. Incidence, severity, and significance. JAMA 1990;263:527-32.

66. McManus IC. Factors affecting likelihood of applicants being offered a place in medical schools in the United Kingdom in 1996 and 1997: retrospective study. BMJ Clinical research ed 1998;317:1111-6.

67. Albanese MA, Snow MH, Skochelak SE, Huggett KN, Farrell PM. Assessing personal qualities in medical school admissions. Acad Med 2003;78:313-21.

68. Lumsden MA, Bore M, Millar K, Jack R, Powis D. Assessment of personal qualities in relation to admission to medical school. Med Educ 2005;39:258-65.

69. Lowe M, Kerridge I, Bore M, Munro D, Powis D. Is it possible to assess the "ethics" of medical school applicants? Journal of Medical Ethics 2001;27:404-8. 
$66 \mid$ Chapter 3

70. Eva KW, Neville AJ, Norman GR. Exploring the etiology of content specificity: factors influencing analogic transfer and problem solving. Acad Med 1998;73(10 Suppl):S1-5.

71. van Mook WN, Gorter SL, O'Sullivan H, Wass V, Schuwirth LW, van der Vleuten CP. Approaches to professional behaviour assessment: tools in the professionalism toolbox. Eur $\mathrm{J}$ Int Med 2009;20:e153-7.

72. Papadakis MA, Loeser $\mathrm{H}$. Using critical incident reports and longitudinal observations to assess professionalism. In: Measuring medical professionalism Stern, DT (ed) Oxford University Press, New York, 2006 ISBN-13: 978-0-19-517226-3 2006.

73. Thisthethwaite J, Spencer J. Assessing professionalism. In: Professionalism in Medicine 2008;ISBN-13: 9781857757637

74. Papadakis MA, Loeser H, Healy K. Early detection and evaluation of professionalism deficiencies in medical students: one school's approach. Acad Med 2001;76:1100-6.

75. Sullivan C, Arnold L. Assessment and remediation in programs of teaching professionalism. In: Teaching medical Professionalism (Cruess RL, Cruess, SR, Steiner Y, eds) 2009;ISBN 978-0-521-88104-3:124-49.

76. Fochtmann L. Professionalism and the Heisenberg uncertainty principle. In: Professionalism in Medicine Critical perspectives Wear D, Aultman JM (Eds) 2006

77. Boisaubin EV, Levine RE. Identifying and assisting the impaired physician. Am J Med Sci 2001;322:31-6.

78. Galletly CA. Psychiatrist-patient sexual relationships: the ethical dilemmas. Aust $\mathrm{N} Z \mathrm{~J}$ Psychiatry 1993;27:133-9.

79. Hickson GB, Federspiel CF, Pichert JW, Miller CS, Gauld-Jaeger J, Bost P. Patient complaints and malpractice risk. JAMA 2002;287:2951-7.

80. Hickson GB, Federspiel CF, Blackford J, Pichert JW, Gaska W, Merrigan MW, Miller CS. Patient complaints and malpractice risk in a regional healthcare center. Southern Medical Journal 2007;100:791-6.

81. Diaz AL, McMillin JD. A definition and description of nurse abuse. West $J$ Nurs Res 1991;13:97-109.

82. Linney BJ. Confronting the disruptive physician. Physician Executive 1997;23:55-8.

83. Lawrence JM. The impaired doctor. The Medical Journal of Australia 1992;157:4-6.

84. Kessler RC, Berglund P, Demler O, Jin R, Koretz D, Merikangas KR, Rush AJ, Walters EE, Wang PS; National Comorbidity Survey Replication. The epidemiology of major depressive disorder: results from the National Comorbidity Survey Replication (NCS-R). JAMA 2003;289:3095-105.

85. Schernhammer E. Taking their own lives -- the high rate of physician suicide. N Engl J Med 2005;352:2473-6.

86. Schernhammer ES, Colditz GA. Suicide rates among physicians: a quantitative and gender assessment (meta-analysis). Am J Psychiatry 2004;161:2295-302.

87. Pichert JW, Miller CS, Hollo AH, Gauld-Jaeger J, Federspiel CF, Hickson GB. What health professionals can do to identify and resolve patient dissatisfaction. Jt Comm J Qual Improv 1998;24:303-12.

88. Shue CK, Arnold L, Stern DT. Maximizing participation in peer assessment of professionalism: the students speak. Acad Med 2005;80(10 Suppl):S1-5.

89. Campbell EG, Regan S, Gruen RL, Ferris TG, Rao SR, Cleary PD, Blumenthal D. Professionalism in medicine: results of a national survey of physicians. Ann Intern Med 2007;147:795-802.

90. Sexual misconduct in the practice of medicine. Council on Ethical and Judicial Affairs, American Medical Association. JAMA 1991;266:2741-5.

91. O'Connor PG, Spickard A, Jr. Physician impairment by substance abuse. Med Clin North Am 1997;81:1037-52. 


\section{Chapter 4}

Combined formative and summative professional behaviour assessment approach in the bachelor phase of medical school: a Dutch perspective

Walther NKA van Mook, Scheltus J van Luijk, Marij JG Fey-Schoenmakers, Guido Tans, Jan-Joost E Rethans, Lambert W Schuwirth, Cees PM van der Vleuten

Medical Teacher 2010;32:e517-31. 


\section{Abstract}

\section{Background}

Teaching and assessment of professional behaviour (PB) has been receiving increasing attention in the educational literature and educational practice. Although the focus tends to be summative aspects, it seems perfectly feasible to combine formative and summative approaches in one procedural approach.

\section{Aims and method}

Although many examples of frameworks of professionalism and professional behaviour can be found in the literature, most originate from North America, and only few are designed in other continents. This paper presents the framework for professional behaviour that is used at Maastricht medical school, the Netherlands.

\section{Results}

The approach to professional behaviour used in the Dutch medical schools is described with special attention to four years (2005-2009) of experience with professional behaviour education in the first three years of the six-year undergraduate curriculum of Maastricht medical school. Future challenges are identified.

\section{Conclusions}

The adages "Assessment drives learning" and "They do not respect what you do not inspect"1 suggest that formative and summative aspects of professional behaviour assessment can be combined within an assessment framework. Formative and summative assessment do not represent contrasting but rather complementary approaches. The Maastricht medical school framework combines the two approaches, as two sides of the same coin. 


\section{Introduction}

Medical schools today are increasingly recognising the importance of professionalism and professional behaviour ${ }^{2-4}$. Concurrently, postgraduate training programmes are undergoing a developmental shift towards competency-based programmes, most of which include professionalism ${ }^{5,6-10}$. After completion of postgraduate training, clinicians are expected to attend continuous medical education (CME) programmes to continue to strive to be "better professionals"11-13. Teaching around professionalism involves "setting expectations", "providing experiences in the curriculum" and "evaluating outcomes by assessment"13,14. Assessment of professional behaviour (PB) serves a formative ('assessment (derived feedback) drives learning') as well as a summative purpose ('no learning, no pass' or 'go/no-go decisions'). The formative aspect is obviously essential and should benefit students and doctors alike ${ }^{15-18}$. The summative aspects, identifying the few 'bad apples', however, often receive more emphasis ${ }^{19-22}$. Unprofessional behaviour should indeed be taken seriously since it has been shown to be associated with later poor adherence to guidelines, impediments to communication, collaboration, information transfer and workplace relationships, low staff morale and high staff turnover, medical errors, adverse outcomes and malpractice suits, while it can seriously undermine public trust in the profession ${ }^{23-33}$. Identifying, measuring, addressing and assessing unprofessional behaviour may thus be a complementary approach alongside teaching and promoting professsionalism ${ }^{23,34,35}$. Although formative and summative aspects of professional behaviour may appear to be incompatible and mutually exclusive at first glance, it has been proven possible to join both aspects in a structured framework of professional behaviour. However, definitions of and approaches to concepts of professionalism and professional behaviour as well as legal possibilities for dismissal of dysfunctioning students differ not only between countries but also between continents. Whereas many North American examples of such frameworks can be found in the literature, published examples from other continents are scarce ${ }^{36}$. In this paper we present the prevailing educational approach to professional behaviour in the Netherlands with special attention for the experiences with assessment of professional behaviour in the bachelor programme of Maastricht medical school. We also describe some future challenges. 


\section{Legal boundaries and current guidelines regarding assessment of professional behaviour in the Netherlands}

\section{The current and future Higher Education and Research Act}

The current Higher Education and Research Act (WHW) does not include provisions regarding expulsion from medical school on the grounds of unprofessional behaviour. The only legal provision for mandatory cessation of studies within the act is the possibility for the Board of Directors of a university to issue a 'negative, obligatory study advice' in the first year of medical school. Thereafter, mandatory cessation of studies is no longer an option. But the new Higher Education and Research Act (WHOO), which is currently in preparation, does contain a provision for mandatory cessation of medical studies and permanent dismissal in cases of persisting and non-remediable unprofessional behaviour. The specification of cases where dismissal is warranted prevents dismissal on the basis of relatively minor, isolated events, such as an incidental breach of the peace.

\section{National guidelines for professional behaviour}

There are striking international differences between approaches to professionalism ${ }^{2}$. In the Netherlands the so-called Blueprint for undergraduate medical education (which has been revised recently, Blueprint 2001) formulates final competency levels for graduating doctors regarding knowledge, skills and professional behaviour ${ }^{37}$. The working-group 'Consilium Abeundi' of the Association of Universities in the Netherlands, comprising members from the Dutch faculties of medicine, dentistry, and veterinary medicine, added requirements concerning professional behaviour. 'Consilium Abeundi' refers to non-binding advice given to a student to leave the study programme he or she is attending. The working group proposed a practical definition of professional behaviour $^{38}$ : observable behaviours that reflect the norms and values of the medical profession. The group also formulated nationwide guidelines with regard to the learning, teaching, and assessment of professional behaviour and recommendations for guidance of students showing unprofessional behaviour $^{39}$. Three professional behaviour related categories are distinguished: 'Dealing with daily work and tasks', 'Dealing with others', and 'Dealing with selffunctioning ${ }^{34,39}$. An overview of the different categories and attributes is provided in Table 4.1. The use of observable behaviours as the basis for assessment and guidance was intended to facilitate the practical implementation of education related to aspects of professional behaviour. Maastricht medical school has implemented a teaching and assessment 
framework that is in line with the recommendations of the Consilium Abeundi working group and complies with the current legal requirements.

Table 4.1 Dimensions of professional behaviour as defined by the Project Team Consilium Abeundi of the Association of Universities in the Netherlands ${ }^{38}$ (reproduced with permission from ${ }^{2}$ )

\begin{tabular}{|c|c|c|c|}
\hline Dimension & Aspects & Subcategory & Details \\
\hline $\begin{array}{l}\text { Dealing with } \\
\text { tasks/work }\end{array}$ & 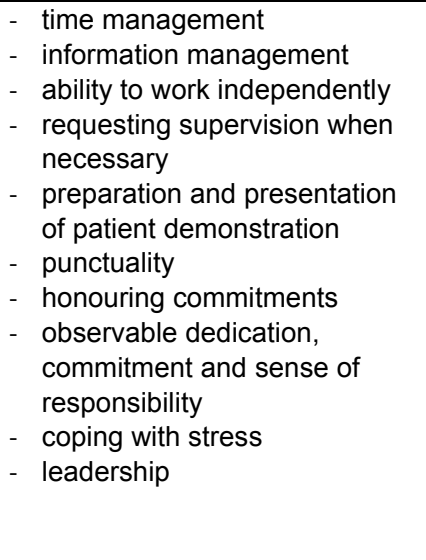 & $\begin{array}{l}\text { monitoring } \\
\text { level of } \\
\text { competence } \\
\text { monitoring } \\
\text { limitations of } \\
\text { competence }\end{array}$ & $\begin{array}{l}\text { keeping up to date in the } \\
\text { professional field, loyally to the } \\
\text { profession, responsibility and } \\
\text { independence } \\
\text { indicating where competence } \\
\text { ends, abstaining from } \\
\text { behaviour/statements that are not } \\
\text { within one's competence, even } \\
\text { when colleagues put pressure on } \\
\text { one to exceed these limitations } \\
\text { forms of teamwork to achieve } \\
\text { team competence, delegating } \\
\text { and division of tasks, chairing } \\
\text { meetings, substituting for others, } \\
\text { honouring commitments, loyalty } \\
\text { to decisions made }\end{array}$ \\
\hline $\begin{array}{l}\text { Dealing with } \\
\text { others }\end{array}$ & 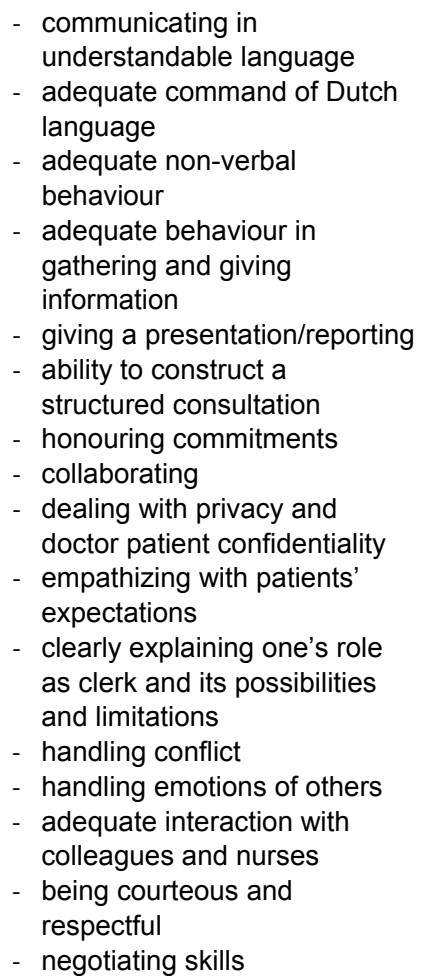 & $\begin{array}{l}\text { gathering } \\
\text { information } \\
\text { from another } \\
\text { person's } \\
\text { perspective } \\
\text { providing } \\
\text { information } \\
\text { from another } \\
\text { person's } \\
\text { perspective }\end{array}$ & $\begin{array}{l}\text { includes empathy, being } \\
\text { unprejudiced, finding contextual } \\
\text { information, active awareness of } \\
\text { the emotional implications of } \\
\text { information } \\
\text { all behaviours directed at } \\
\text { information and advice tailored to } \\
\text { the recipient: e.g. adapting } \\
\text { information to the other person's } \\
\text { emotions and capabilities for } \\
\text { understanding, presenting } \\
\text { concrete information, checking } \\
\text { whether the information has } \\
\text { actually been received, inviting } \\
\text { response } \\
\text { all behaviours directed at } \\
\text { facilitating decision making, } \\
\text { taking into account both the other } \\
\text { person's perspective and the } \\
\text { doctor's competence. E.g. } \\
\text { encouraging someone to } \\
\text { respond, meta communication, } \\
\text { implementation of informed } \\
\text { consent procedures }\end{array}$ \\
\hline
\end{tabular}


Table 4.1 (continued)

\begin{tabular}{|c|c|c|c|}
\hline $\begin{array}{l}\text { Dealing with } \\
\text { oneself }\end{array}$ & $\begin{array}{l}\text { - } \text { ability to self-reflect } \\
\text { - dealing with feedback and } \\
\text { criticism } \\
\text { - good personal appearance } \\
\text { - } \text { self management/setting } \\
\text { boundaries } \\
\text { - } \text { dealing with uncertainty }\end{array}$ & $\begin{array}{l}\text { reflection on } \\
\text { own } \\
\text { behaviour and } \\
\text { the underlying } \\
\text { dynamics }\end{array}$ & $\begin{array}{l}\text { self observation, gaining insight } \\
\text { into and dealing with one's } \\
\text { emotions, motivation, cognitions } \\
\text { including values, standards, } \\
\text { prejudices, as well as how these } \\
\text { have evolved, and their effect on } \\
\text { one's own behaviour }\end{array}$ \\
\hline
\end{tabular}

\section{The Maastricht framework}

\section{Brief introduction to the Maastricht curriculum}

In order to understand how professional behaviour is evaluated and assessed in the Maastricht curriculum, some knowledge of this curriculum is essential. The school offers a three-year bachelor followed by a three year master curriculum in medicine and uses a predominantly problem-based learning (PBL) approach. Annually, 340 to 370 students are admitted to the first bachelor year. The first two years emphasise knowledge and skills acquisition and simulated patients are used as 'problems', serving as the starting points for learning by problem solving. The curriculum is structured in six to ten week thematic blocks during which the main educational format is small groups of around ten students facilitated by a tutor, which meet twice weekly. The first session of the week is devoted to understanding and brainstorming around a (patient) problem, culminating in concrete learning goals. After the session students collect information regarding these issues, which they report and discuss in the second session of the week. In year 3, paper patient problems are replaced by real patient encounters in the student outpatient clinic in the academic hospital, and the master phase is dominated by clinical clerkships ${ }^{40}$.

\section{Organisation of education in professional behaviour}

The Examination Committee $(\mathrm{EC})$ of Maastricht medical school (the regulatory body responsible for all examinations) underscored the importance of students' development with regard to professional behaviour and instituted a Committee on Professional Behaviour (CPB), which is formally responsible for teaching and assessment of professional behaviour in the bachelor programme. In brief, the CPB longitudinally discusses all judgements of all students' professional behaviour by different assessors during the educational sessions in one academic year (see the section on Assessment below), determines the end-ofyear judgements, and intensively communicates with the EC. The EC also 
meets regularly with student advisors to discuss all students that have received negative judgements ('fail') or missed too many sessions to allow reliable judgement of professional behaviour ('no judgement possible'). The CPB consists of five members, in varying combinations of doctors, educationalists and students, and is supported by a secretary appointed by the medical school. Student members are not present when personal issues regarding their peers are discussed. The following sections are concerned with the current framework for teaching and assessing professional behaviour during the bachelor programme.

\section{Creating awareness of and staff development regarding professional behaviour}

Failure to detect and respond to even minor lapses in professional behaviour is frequently reported in both undergraduate and postgraduate training ${ }^{39,41}$. In the past staff were often uninformed or indulgent with regard to students' nonprofessional behaviour. Possible reasons were fear of unpleasant or time consuming encounters with students or staff or fear of lawsuits ${ }^{42}$. To overcome these problems, new and experienced Maastricht tutors are provided with practical guidelines for assessing professional behaviour. At least two important messages are conveyed. First, in cases of doubt ('pass' or 'fail') staff are explicitly advised to opt for a 'fail' instead of a 'borderline-pass'. This policy is supported by evidence that equivocal feedback on assessment forms for professional behaviour correlates negatively with quantitative judgements (marks) in the same assessment ${ }^{43}$. Second, it is the tutor that determines the usefulness of the assessment, e.g. by writing extensive feedback on the form. Without formal, written feedback the assessment is far less useful, if not useless $^{44}$.

(Mandatory) tutor instruction (teach-the-teacher sessions) takes place in sixweek cycles at the beginning of each new block and is complemented by an annual meeting in which teachers share their experiences and discuss questions and problems regarding evaluation and assessment of professional behaviour. Web-based information about the background and practice in relation to professional behaviour is available to students and staff. Course coordinators are requested to schedule time for assessment of professional behaviour, in recognition of the status of professional behaviour as an integral and important part of the curriculum. This policy has reduced the practice of superficial and brief evaluations of professional behaviour. 
Teaching and learning professional behaviour during the Consultation and Reflection Programme

In addition to teaching (awareness) and assessment of professional behaviour in all curricular blocks with changing groups of students and tutors, professional behaviour has a central role in a longitudinal programme in each bachelor year, the CORE (Consultation and Reflection) programme. This programme uses problem based and experimental teaching methods, such as individual videorecorded consultations with simulated patients, to help students acquire theoretical knowledge and skills in communicating with patients and reflecting on their future role as a doctor. Students remain in the same group with the same teacher for the duration of the academic year. Ten days after taking part in individual consultations with simulated patients, the CORE group meets to discuss these contacts based on students' individual requests for feedback, which result in individual strength-weakness analyses. During discussions moderated by experienced, trained teachers, students' awareness and mindfulness of professional behaviour are stimulated. Due to its content and longitudinal nature, the CORE programme is eminently suitable for learning and assessment of professional behaviour. Over twenty additional optional modules, for example dealing with non-verbal and intercultural communication and dealing with emotions and commercialisation in medicine, are offered to facilitate further development of professional behaviour.

\section{Other ways of teaching and learning around professional behaviour}

All first year students have to create a portfolio aimed at promoting self reflection skills and containing reflections on educational activities, including the CORE programme. As part of the portfolio process, mentors guide individual students during their longitudinal development of strengths and weaknesses in communication and reflection, and help students to set intermediate learning goals (formative assessment). Formal, summative portfolio assessment, however, is performed by an assessor with no involvement in the student's guidance. Furthermore, background information about professional behaviour is provided during a plenary lecture early in the first year, and aspects of medical history, ethics, sociology, humanism, law and other areas involving professionalism issues are dispersed over the curriculum. Notwithstanding the strong importance of the above-mentioned educational formats, (behavioural) skills relevant for adequate functioning in a group are primarily learned during tutorials, with feedback on students' functioning being provided by the tutors. 


\section{Assessment of professional behaviour}

We hope that the preceding has shown that in the first two years education (and consequently assessment) in professional behaviour is mainly focused on the student-teacher and student-peers relationship. In later years the emphasis shifts to the student-patient and student-physician relationships, and assessment comprises two different approaches ${ }^{45}$, which we will discuss in the following sections: 1) reflection of staff members on students' professional performance over a longer period of close observations and guidance and 2) reports of 'critical incidents'.

\section{Assessment by staff during scheduled educational activities}

For assessment of students' performance during formal educational activities a professional behaviour assessment form is used ${ }^{34,39}$ (Figure 4.1). The form provides ample space for narrative feedback, which staff are strongly encouraged to provide. During each block professional behaviour is discussed at the start, halfway through and at the end of the block. In the first group session assessment forms are distributed, the background of evaluation and assessment of professional behaviour is discussed briefly and the timing of evaluations is clarified. The session halfway the course is the most time consuming of the three evaluations, lasting an hour on average (for 9 to 11 students in one tutorial group). Careful home preparation and reflection on their behaviour during group sessions precede individual students' plenary reflections as to which aspects of their professional behaviour need work and which are already acceptable or even excellent. Peers and tutor give their views, with feedback and suggestions for improvement. Based on these discussions the tutor formulates an intermediate formative judgement of each student. Negative judgements are to be followed by confrontation, feedback and proposals for remediation from the tutor ${ }^{34,39}$. The mid-course judgement combined with new qualitative comments derived from the second part of the course are the basis for the final summative judgement in the form of a 'pass', 'fail' or 'no judgement possible' when a student has missed too many (or all) sessions to enable reliable and valid judgement. The end-of-course assessment is substantiated verbally and in writing, and the student is requested to sign the assessment form, although this does not imply agreement with the judgement. In addition to these regular assessments of professional behaviour, the CPB has instituted the possibility of filing reports on critical incidents concerning professional behaviour. 
76 $\mid$ Chapter 4

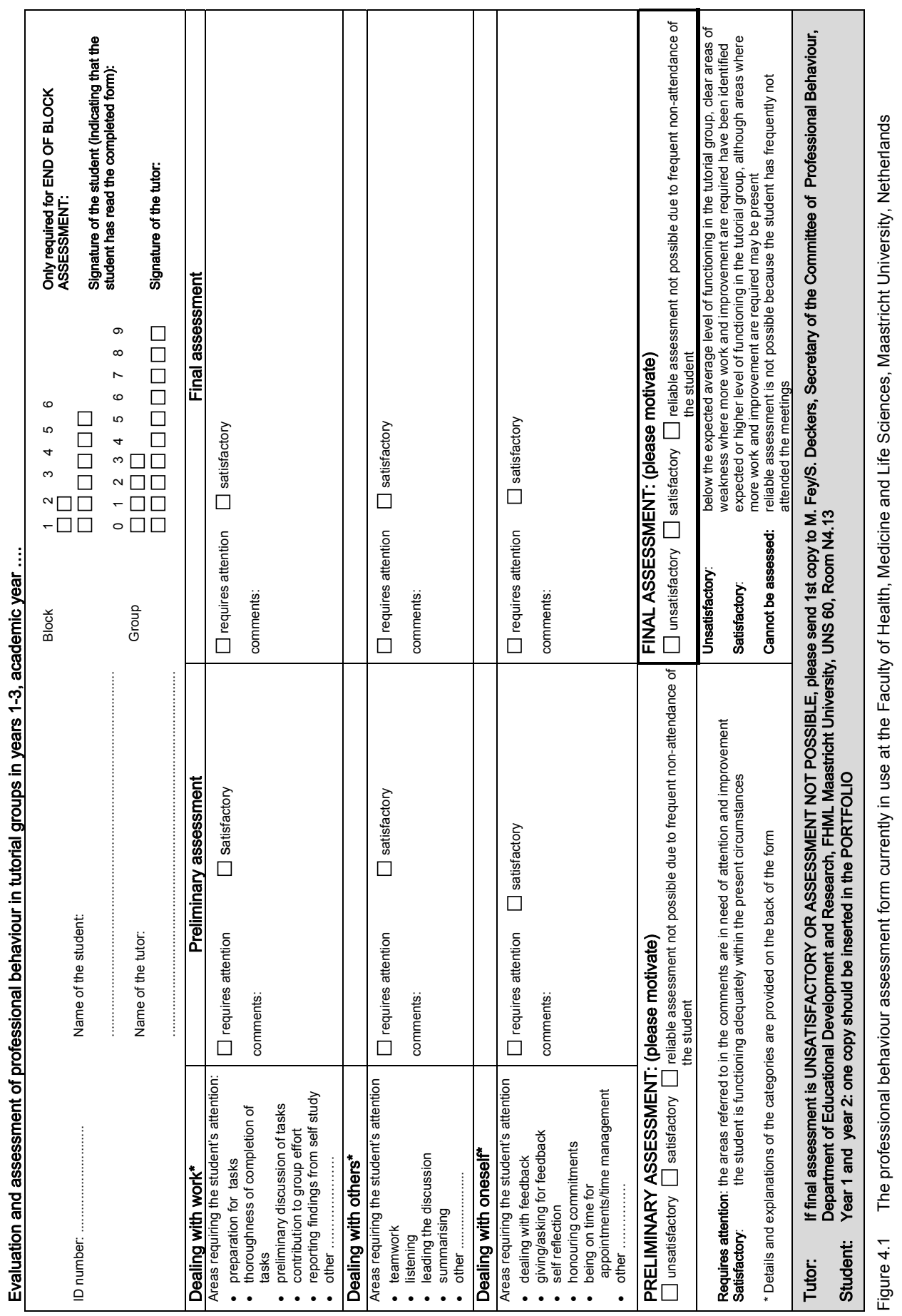




\section{Negative critical incident reports}

Reports of 'critical incidents' by staff document in detail a specific event in which a student showed negative professional behaviour. These reports are directed in particular to "the extreme outliers of behaviours, students on whom staff spend an inordinate amount of time" ${ }^{\prime 4}$. The nature of these so-called incident reports is often more serious than negative judgements during formal educational activities and may result in a student being denied access to an educational activity. Examples are reports of sexual harassment or intimidation, verbal aggression or threatening behaviour. Dealing with these reports is often urgent, which makes this task an educational emergency. Starting in the 2005-2006 academic year the procedure for dealing with cases of 'fail', 'no judgement possible' and critical incidents has been refined. The current procedure and the associated time frame will be discussed in detail.

\section{Structure for dealing with regular fail judgements and critical incident reports}

Early identification of lapses in behaviour is critical to enable remediation before behaviour has become refractory to change ${ }^{47}$. The threshold for reporting umprofessional behaviour should therefore be kept low. The CPB gathers and files all judgements of professional behaviour and requests all students to elaborate on the reasons for negative judgements by e-mail, even if only one single lapse is concerned. In accordance with the adversarial principle, all students who receive a negative judgement are also invited to clarify their behaviour in a meeting with the CPB. If necessary, the tutor is asked to explain his/her judgement as documented in the professional behaviour form. Persistent failure to respond to these requests is considered unprofessional behaviour and results in a negative end-of-year judgement. Prior to the CPB meeting all judgements are discussed with the student advisors in order to optimise advice, guidance and possible subsequent counselling. During the CPB meeting the background and principles of assessment of professional behaviour are explained to the student in question, and the reasons for the negative judgement are discussed extensively. Since every professional has a range of behaviour, incidental occurrences of inappropriate behaviour (so-called lapses) are not necessarily considered synonymous with unprofessional behaviour. In decisions whether a certain behaviour is acceptable or not, the behaviour should be considered within its appropriate context, including the environment in which it occurred as well as the student's phase of training ${ }^{47,48}$. This may shape both the behaviour and influence assessment quality ${ }^{47}$. 
It should be stressed that a negative judgement of professional behaviour can never be compensated for by favourable judgements of other aspects of clinical competence $^{39}$. The CPB decides whether a judgement provides sufficient grounds for an immediate negative end-of-year assessment and/or an immediate leave of absence. This decision is sent to the EC, the student, the tutor and, if appropriate, the mentor, since students are obliged to incorporate all judgements of professional behaviour in their portfolios and a 'fail' must always be discussed with the mentor. Whenever required, students are advised of remediation strategies. If the CPB advice alone is considered insufficient, the student is referred to a student advisor, student psychologist or mentor. In extreme cases the student's GP, spiritual advisor or psychiatrist can be consulted, with the student's consent. A clear remediation plan should be tailored to the student's needs, and may involve meetings with for example the student advisors, the CPB and a psychologist. Ideally, there should be a regular exchange of information between all parties involved, provided the student consents to this. Practical requirements for productive meetings with the student include setting clear objectives before the scheduled meeting, the presence of witnesses, note taking and setting transparent goals and expectations. A timeframe for the process and adequate guidance with frequent feedback sessions are also of paramount importance ${ }^{47}$. Any progress and agreements that are reported should be tested against the original plan of action $^{39}$. Candid documentation of every incident, the remediation strategy and the student's response is required. All reports should be handled confidentially and complainants should receive follow-up of review and resulting actions ${ }^{47}$. Normally, the extent to which behaviour can be remedied, the willingness and ability of the person involved to change his or her unprofessional behaviour as well as possible persistence of the behaviour over time all determine whether the behaviour will ultimately be categorised as unprofessional or not. Insight into and awareness of the problem, willingness and ability to change, consistency in adhering to the remediation plan can contribute to success. Likewise, denial and a weak follow-up plan are contributors to remediation failure ${ }^{47}$. Longitudinal tracking of negative judgements of professional behaviour and reports of critical incidents can thus be used to monitor the effectiveness of remediation strategies ${ }^{46}$.

A similar procedure to that for critical incidents is used in cases of repeated instances of 'no judgement possible', generally due to frequent nonattendance. This can be an early clue and warning sign of structural problems, especially if they occur in succession. In the authors' experience repeated absence is indeed predictive of other signs of unprofessional behaviour, and is frequently also associated with unsatisfactory results on skills and knowledge 
tests. When deemed necessary by the CPB and/or student advisors, a student is asked to provide written clarification and/or invited to meet with the CPB.

The algorithm in Figure 4.2 provides an overview of the assessment procedure for professional behaviour during regular courses and critical incident reports in the first two year. A comparable framework is available for the end-of-year assessment procedure.

\section{The end-of-year assessment procedure}

For the end-of-year judgement, all available information (regular judgements of professional behaviour and critical incident reports) is weighed qualitatively with account being taken of the number, nature and order of receipt of negative judgements over the year as well as the educational activities involved. An algorithmic advice (summation and subtraction of the numbers of negative and positive judgements) has been abandoned for several reasons. First of all, the sequence of judgements is meaningful. A series of negative judgements followed by several 'passes' has other implications than a series of negative judgements after a successful start. After all, professional behaviour develops longitudinally. Second, the contexts of judgements may differ and the weight attributed to a judgement will vary accordingly. The CPB gives more weight to judgements resulting from educational activities with longitudinal follow-up, such as the CORE programme. Third, algorithmic advice ignores the qualitative aspects of each negative judgement. For example, a negative judgement of a student who structurally shows up late for tutorials but whose participation and communication are deemed good carries a different weight and requires a different approach regarding advice and guidance than combined negative judgements concerning timeliness, knowledge, participation and communication. Finally, incidental reports of critical incidents are not considered in an algorithmic advice. The diagram in Figure 4.3 provides an overview of the end-of-year procedure in the first two years.

No judgement due to non-attendance or a negative end-of-year judgement means that the student is not awarded the associated educational credit points, which may preclude admission to the next year of the medical school programme. When a pass on professional behaviour would result in the required credits, a conditional pass can be granted and the student is allowed to enter the next year. In the following years the students must gain 'passes' on all assessments of professional behaviour to compensate for the earlier 'fail'. Repeated negative judgements, despite adequate remediation efforts, are followed by a more formal response and ultimately lead to penalties ${ }^{46}$. Thus, depending on the nature and extent of their unsatisfactory professional 
behaviour, students may either not progress to the next year or provisionally pass and move on to the next year, in both cases with mandatory, individualised remediation programmes. Practical tips based on the preceding discussion of the implementation of assessment of professional behaviour are summarised in Table 4.2.

Table 4.2 Lessons learned regarding teaching and assessment of professional behaviour

No. Tip

1. Create awareness regarding the importance of professional behaviour in students early in the curriculum, for example by giving a lecture or implementing a white coat ceremony.

2. Aspects of medical history, ethics, sociology, humanism, law and other areas where professionalism issues are represented, should be dispersed throughout the curriculum.

3. The formative aspect of professional behaviour assessment is obviously essential, and should compliment summative professional behaviour assessment

4. Use professional behaviour forms which provide ample space for narrative evaluative feedback, which faculty are highly encouraged to complete.

5. Create awareness regarding the importance of professional behaviour assessment by instituting mandatory staff development programs, and making it a mandatory and scheduled part of each course.

6. In case of doubt between 'pass' or 'fail' the committee urges staff to preferably give the judgement 'fail' over 'pass-by-mercy'.

7. The tutor fulfils a pivotal role regarding professional behaviour assessment, and largely determines the quality of professional behaviour assessment. The instrument itself (the form) itself has limited intrinsic value.

8. Development of additional training programmes (such as the described CORE program), underscoring the importance of aspects of professionalism and emphasis on professional behaviour development can compliment professional development during regular educational activities.

9. Since every professional has a range of behaviours, incidental occurrences of inappropriate behaviour (so-called lapses) are not per se synonymous with unprofessional behaviour.

10. Early lapse identification is critical to facilitate remediation attempts before behaviour becomes refractory to change

11. Furthermore, a negative judgement regarding PB should never be compensated for by other aspects of clinical competence.

12. A clear remediation plan should be individually tailored to the student's needs, and may involve alternating meetings with for example the student advisors, the CPB and a psychologist, with regular information exchange between all those involved.

13. Practical aspects are having clear objectives before scheduled meetings, having witnesses present, scribing, and setting transparent goals and expectations.

14. Any progress reported and agreements made, should be tested against the original plan of action.

15. A timeframe in which these should be fulfilled, and assuring adequate guidance and frequent performance feedback sessions are also of paramount importance.

16. Nevertheless, all reports should be confidentially handled, and complainants should receive follow-up of review and resulting actions.

17. An algorithmic advice (summation and subtraction of number of negative and positive judgements) should be abandoned for several reasons.

18. Changes will certainly not occur in the absence of strong institutional leadership! 
Formative and summative professional behaviour assessment $\quad 81$

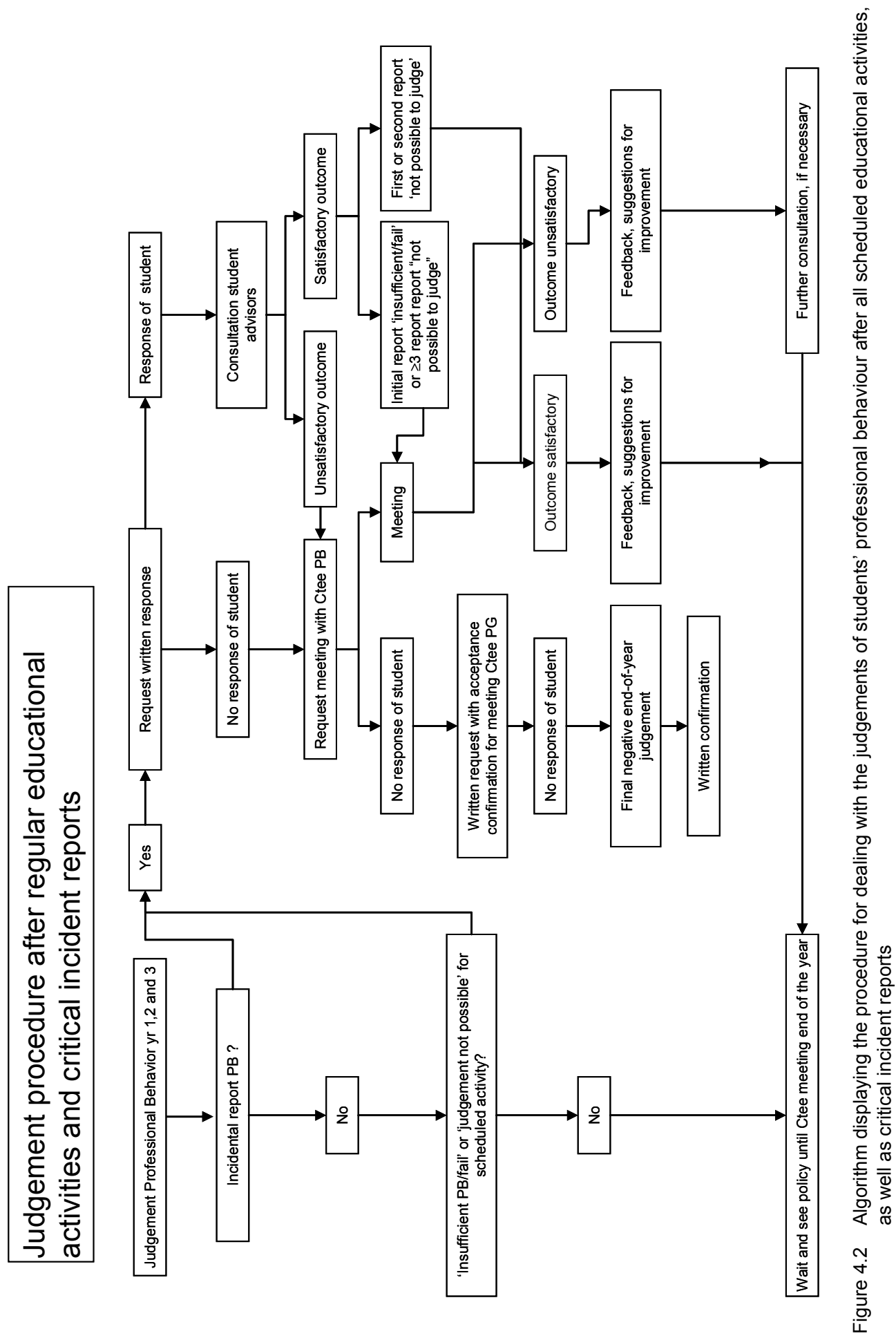


82 $\mid$ Chapter 4

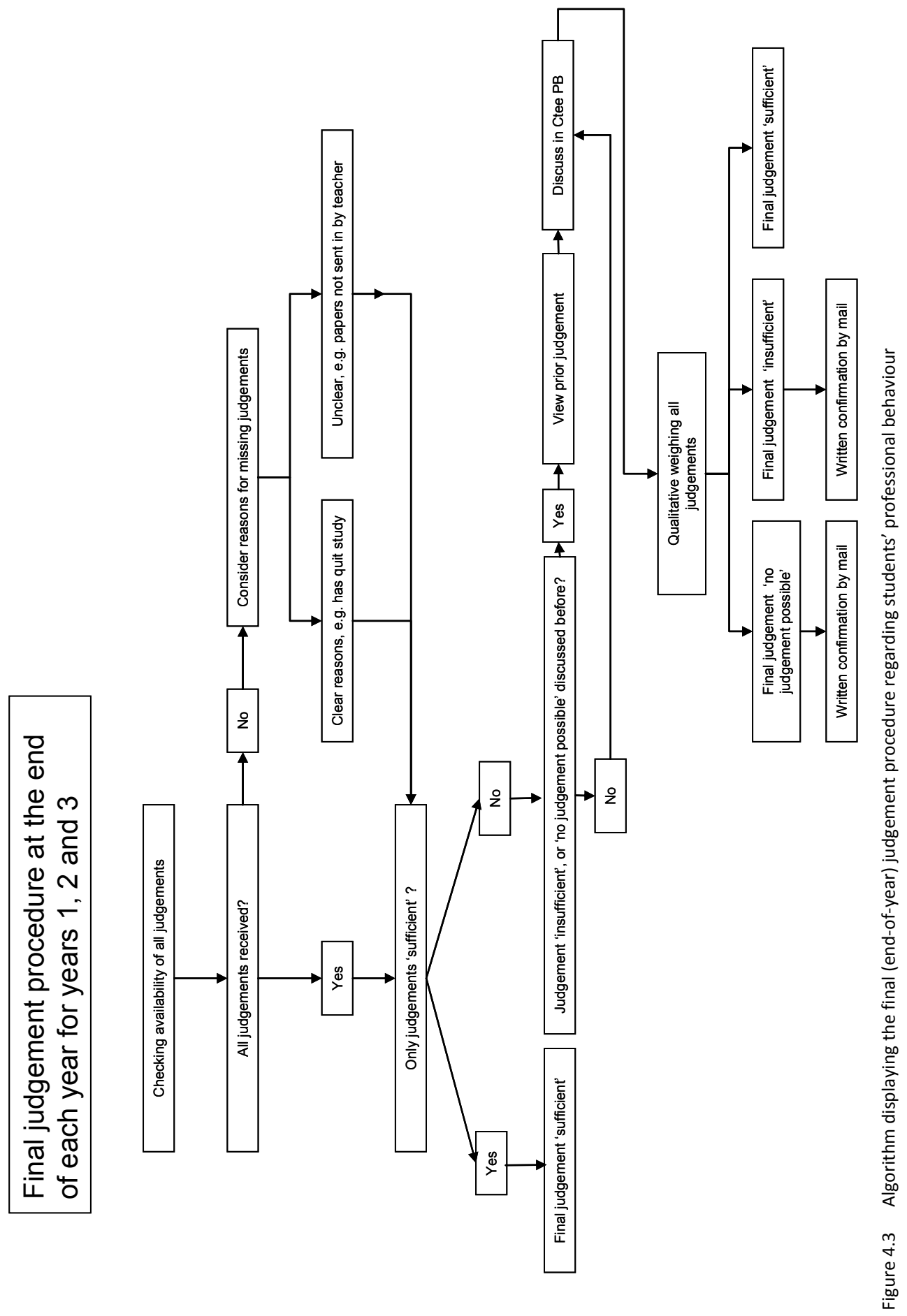




\section{Voluntary ending of studies versus dismissal}

Although most students improve their professional behaviour after feedback, some continue to show unprofessional behaviour. As was also reported by Papadakis et al., we think that multiple critical incident reports are a sign of significant shortcomings in a student's professional development. These students often refuse to accept responsibility for their problems and accuse their evaluators of unfairness and inaccuracy ${ }^{46}$. However, we should point out that these students are rarely encountered in our institution. In the same group knowledge and skills test results as well as clinical performance are also frequently below average ${ }^{39,49,50}$. This combination seems indicative of a structural problem often caused by a personality disorder and/or persisting conditions in a student's social environment ${ }^{39}$. The EC determines the consequences for the student's study progress and decides on appropriate penalties after consultation with the CPB. Students whose behaviour fails to improve can ultimately be advised to end their studies. When a student complies with this advice, the medical school is under an obligation to help him or her find an alternative career, albeit that this obligation is not required by law and of limited duration. Possible solutions include pursuing an alternative degree in medicine, which does not involve contact with patients, or enrolment in a related master's degree programme, such as medical biology) ${ }^{39}$. For such measures to be feasible, it is of paramount importance that assessment of professional behaviour is firmly embedded in the medical school's examination regulations. In the Netherlands, however, changes in the law are also required to enable medical schools to deny persistently dysfunctioning students access to education if they refuse to accept one of the above-mentioned alternatives. As matters stand today, the law only recognises a negative study advice issued in the first year by the $\mathrm{EC}^{39}$ as a valid reason to expel a student from medical school. Thereafter, dismissal is only possible after a legal verdict. Such problems do not arise in the USA, for example, where persistent unprofessional behaviour is considered a violation of the contract signed on admission to medical school, which automatically results in dismissal.

\section{From theory to practice: the results of the Maastricht framework 2005-2010}

Quantitative and qualitative data were gathered prospectively. The most apparent findings will be presented briefly. 


\section{Numerical facts regarding regular educational activities and critical incident reports}

Table 4.3 summarises quantitative data obtained in Maastricht between 2005 and 2010. Since year 3 was only recently added to the CPB's responsibilities, limited data for that year is available. Several phenomena can be noticed. First, the number of negative assessments of professional behaviour ('fails') during regular educational courses has remained stable over the years in the first and second years. In contrast, there is a recent increase in the number of "no judgement possible' in first year, whereas this number has remained stable in second year. The increase in the number of meetings of students with the CPB is a reflection of the repetitive nature of these judgements, students' (unsatisfactory) explanatory responses and/or the perceived necessity of a meeting with the CPB suggested by the student advisors. The number of critical incident reports also shows a recent increase among first-year students. Third, with the exception of one year, male students received more negative judgements and 'no judgement possible' compared to their female counterparts, a finding for which we could find no clear explanation. Whether gender differences, for example in interpersonal communication skills, make male students more prone to unprofessional behaviour is not clear. In the study by Papadakis et al. gender was not statistically associated with disciplinary action by medical boards (odds ratio 2.24, $p=0.09)^{51}$, but the same authors reported a greater proportion of male students displaying problematic behaviour in for example obstetrics-gynaecology (46 vs. 29 male vs. female students) $)^{46}$.

\section{Reasons for negative judgements of professional behaviour}

The reasons for negative judgements of professional behaviour during regular courses in the first two years are comparable, comprising frequent nonattendance and unsatisfactory performance in preparing for, reporting back and participation in tutorials and, to a lesser extent, insufficient cooperation with peers, lack of improvement of participation and poor planning and timekeeping. Combinations of the above occur frequently. It is noticeable that students repeatedly fail to respond to tutors' communication requests. Poor selfreflection is reported rarely. Thus, negative judgements almost always relate to the categories 'Dealing with work' and 'Dealing with others'. The relative absence of issues relating to 'Dealing with self-functioning' may be attributable to first year tutorials being less suitable for judgements of students' selfreflection and responses to feedback. Nevertheless, many negative judgements and reports of critical incidents occur after repeated feedback has failed to result in behaviour change. This suggests that students lack selfreflective abilities (and/or abilities to change). The past few years have shown a 
significant decrease in unauthorised absence as a reason for negative judgements. Although this may have contributed to the increase in 'no judgement possible', the magnitude of the increase in 'no judgement' far exceeds the decrease in negative judgements. An example of a negative judgement of professional behaviour during regular courses is displayed in Table 4.4, box 1 .

\section{Reasons for critical incident reports}

Critical incident reports in the first year are frequently related to absence without notice from simulated patient encounters or resits, not meeting obligations related to the portfolio, or repeatedly failing to respond to hepatitis $B$ immunisation appeals. The recent increase in critical incident reports from CORE programme coaches as well as unauthorised absence from resits may be due to increased awareness of the possibility of and procedure for filing critical incident reports. The immunisation non-compliance reports are especially interesting in view of recent reports by Stern et al. that only immunisation non-compliance and failure to complete required evaluation forms in the first two years of medical school were predictive of subsequent discussion in the academic review board in third year of medical school. These two predictors accounted for almost $14 \%$ of the variance in academic review board appearances. Immunisation non-compliance predicted low overall internal medicine clerkship professional evaluation scores accounting for just over $10 \%$ of the variance of this outcome ${ }^{52}$. Absence without notice and noncompliance with remediation assignments during electives, absence without notice during resits, and absence and failure to meet other obligations related to simulated patient contacts (e.g. providing peer feedback) were reasons for critical incident reports in second year. The literature is non-informative regarding no-shows at standardised patient encounters. However, students who underestimated their actual performance on a standardised patient exercise early in medical school received higher (more positive) ratings and students who overestimated their performance received lower ratings on the same exercise ${ }^{52}$. An example of a critical incident report is displayed in Table 4.4 , box 2 . 
86 $\mid$ Chapter 4
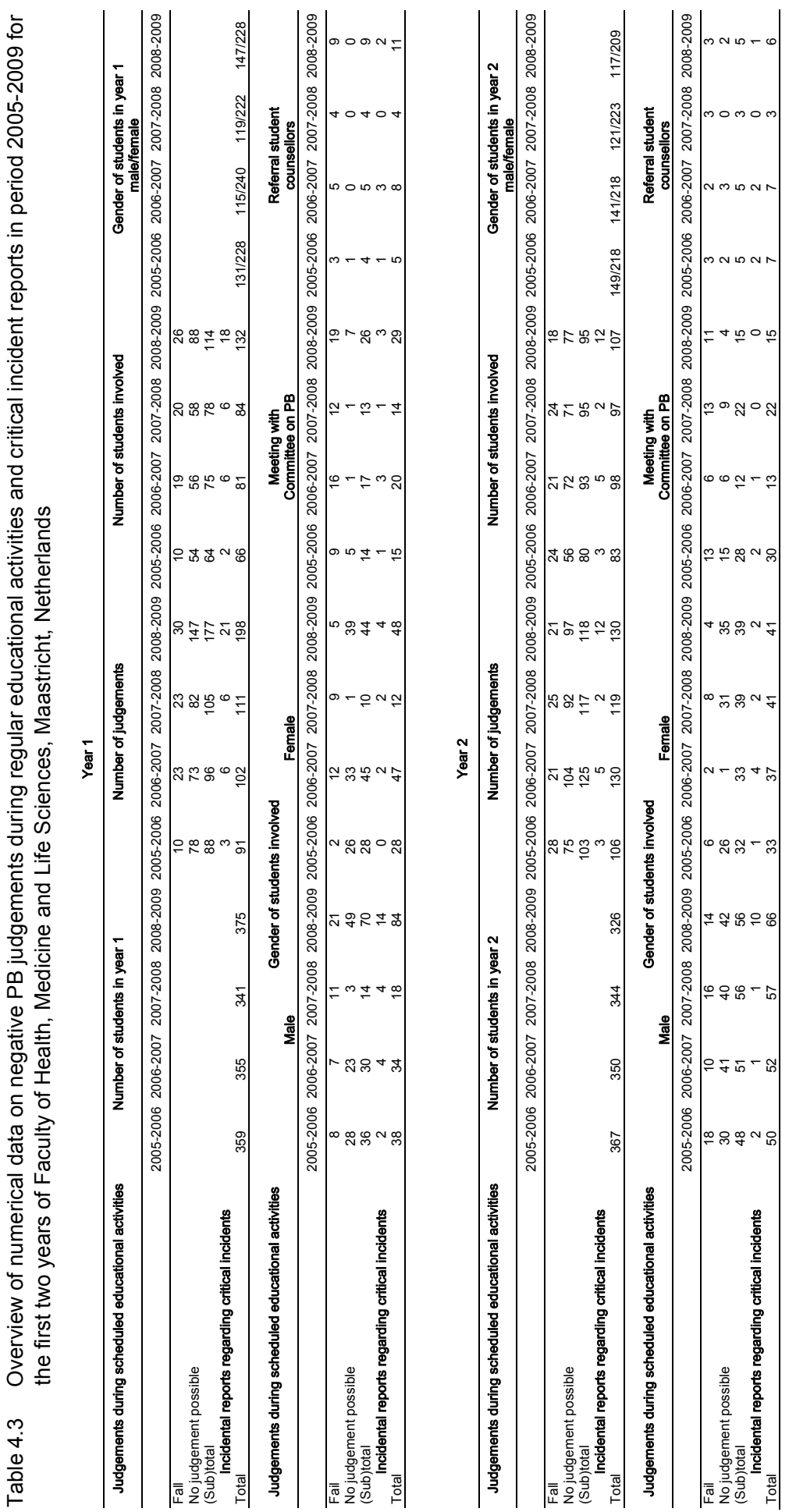
Table 4.4 Illustrative examples of negative professional behaviour judgement during a regular educational course, an isolated critical incident report, as well as multiple and persisting negative professional behaviour judgements despite remediation attempts

\begin{tabular}{ll}
\hline Box & Example \\
\hline $1 . \quad$ Isolated negative professional behaviour judgement during a regular educational course \\
Student A was given a negative professional behaviour judgement by the tutor during a 6- \\
week course in the second year for reasons of unexplained absence during a tutorial group \\
meeting. The student was previously known with neither PB, nor knowledge and skills \\
deficits. During the CPB meeting the student explained that absence during 2 tutorial group \\
meetings was unavoidable due to participation in the management of an international \\
student association. This absence had been cleared with the tutor prior to the meeting. \\
Returning from the meeting student was confronted with the severe illness of a relative, \\
which he subsequently visited. Student failed to inform the tutor of this absence, \\
considering it merely a private matter. Soon thereafter the relative passed away. The \\
funeral was not attended since it would have resulted in additional absence. In retrospect \\
the student regrets non-informing the tutor, designates it as unprofessional and not \\
acceptable. Honesty would have been more appropriate. The CPB empathizes with the \\
reasons for the absence, but prior explaining would have contributed to the tutor's \\
understanding. The advice was given to communicate more clearly with staff regarding \\
such matters. No further negative PB judgements have been received thereafter.
\end{tabular}

2. Isolated critical incident report

The CPB received a critical incident report on student B written by the mentor and COREcoach. For reasons of absence during simulated patient contacts and their subsequent discussion during the CORE meetings, and related insufficient communication with the coach and peers. After several remediation attempts the student was refused further participation in the CORE programme. The student responded in writing, and later before the CPB, that the student struggled with chronic health problems. Complaints, medical testing, treatment, and doctors' visits limited the ability to participate in the training programmes. Student was not aware of special arrangements for students with a chronic illness. Referral to the student advisors and dean for student affairs resulted in less strict attendance requirements, pre-registration possibilities for skills training and tutorial groups, and individual examination possibilities of extended duration. The CPB advised to rediscuss the persisting health problems with the mentor and CORE-coordinator, and be frank to peers regarding possible future limitations to peers. Ultimately re-entering of the CORE programme was not feasible, and student repeated the programme a year later.

3. Multiple persisting negative professional behaviour judgements despite remediation attempts

Student $\mathrm{C}$ was repeatedly given negative professional behaviour judgements as well as received multiple critical incident reports during the first, second and third year. This pattern was paralleled by frequent and repeated failure on knowledge and skills testing. Passing the first two year of medical school took more than a lustrum. Major problems identified were communications problems and not being able to adequately cooperate regarding assignments with peers, lack of self-reflection, repeatedly ignoring feedback, perception of intentional humiliation and insulting by tutors, aggressive writing style when responding to questions by tutors and peers, criticising tutors and coaches when provided with constructive feedback, not showing up for resits, and too frequent unauthorised absence. Despite intensive guidance by the student advisors no improvement was observed. A comparable pattern was observed during correspondence and meetings with the $\mathrm{EC}$ and CPB. Reponses were primary, with an unpleasant, pejorative undertone which seemed to confirm instead of refuting the assessors' views. Although communication during meetings was less hostile, e-mails send to the EC and CPB, often without delay, accused them of e.g. 'wilful bullying, intimidation, abuse of power and rights, and willingly obstructing study progress'. Repeatedly, an advice to end the study was not appreciated. Since mandatory cessation of study is so far impossible in the Netherlands, expiring study results ultimately formed the basis for preventing graduation from medical school. 


\section{Results of end-of-year assessment}

An overview is provided in Table 4.5. Although the number of student advisorreferrals has remained relatively stable for first year medical students, an increase can be observed in the final curriculum year, probably due to the increased number of both negative judgements and 'no judgement possible'. The number of negative end-of-year judgements in the first year shows a parallel steep increase, even after correction for changes in the total number of judgements. By contrast, the emerging pattern for the second-year is stable again. The overall relatively stable numbers of fail judgements and critical incident reports may be suggestive of failure to change behaviour during the educational experience. It should be noted, however, that overall numbers of students are compared between years, and individualised data are not presented. Although the overall number of negative judgements is relatively stable, these judgements are infrequently generated by the same students during the (first three) years. One-time professional lapses are far more common than persisting unprofessional behaviour. In other words, a small minority of students (one to three per cohort) displays severe and persisting dysfunctional behaviour despite intensive long-term counselling and guidance (and is ultimately advised to end their studies). Since this selected group has been proven to be lacking in reflective abilities, it is hardly surprising that this advice is hardly ever heeded. Cessation of studies can then only result from expiring examination results, lack of funds or a legal process. An example of a student with persisting unprofessional behaviour is presented in Table 4.4, Box 3.

\section{Future challenges}

Several aspects of necessary innovation and change should be mentioned here. First, the current framework is labour intensive and thus relatively costly. A planned reduction of the number of courses incorporating assessment of professional behaviour could reduce costs without compromising reliability and validity, provided the option of critical incident reports is maintained. This management decision, however, opposes the face validity argument of integration of professional behaviour in the entire curriculum. Furthermore, the longitudinal aspect of assessment of professional behaviour currently receives insufficient attention. Over the course of several courses, teachers should be able to follow up on end-of-course judgements and learning goals from previous courses. Transfer of results and goals between activities, phases (bachelor-master, undergraduate-graduate) and teaching facilities (e.g. teaching hospitals offering clerkship rotations) is currently being explored. 
Other methods to strengthen longitudinal development which are being considered are: non-block and non-course related sessions in which professional behaviour is evaluated and assessed (e.g. sessions in which small groups of students reflect on paper cases, video vignettes or cases experienced in practice) $)^{53-55}$. Regular CPB meetings to optimise formal communication with the EC facilitate longitudinal tracking of student performance. Expansion of the CPB's responsibilities to include all six years of medical school is considered pivotal. The contexts in which professional behaviour is assessed in the first three years are limited to tutorials, but extend to the broader context of hospital wards in the clinical years. Continued assessment of professional behaviour during the clinical years coordinated by the same CPB would be essential to investigate to which extent behaviour in the first three years predicts later behaviour (in medical school). But this expansion is hampered by obvious financial constraints, and its implementation will therefore most likely be gradual. Third, emphasis is placed on teach-theteacher sessions to create awareness of professional behaviour, teach the necessary feedback, communication and assessment skills, stimulate provision of in-depth qualitative feedback and improve the educational climate in all curriculum years. Attention to role modelling during clinical training is of particular significance if we are to make our practice congruent with our rhetoric.

Table 4.5 Overview of end-of-year judgements in period 2005-2009 for the first two years of Faculty of Health, Medicine and Life Sciences, Maastricht, Netherlands

\begin{tabular}{lcccc}
\hline & Year 1 & No. of judgements (\%) \\
\hline Final end-of-year judgement & \multicolumn{5}{c}{$2007-2008$} & $2008-2009$ \\
\hline Pass & $2005-2006$ & $2006-2007$ & $2007(90)$ \\
No judgement possible & $326(96)$ & $319(93)$ & $302(92)$ & $297(90)$ \\
Fail & $9(3)$ & $20(6)$ & $21(6)$ & $16(5)$ \\
Total & $3(1)$ & $3(1)$ & $5(2)$ & $17(5)$ \\
\hline
\end{tabular}

\begin{tabular}{lcccc} 
Final end-of-year judgement & Year 2 & No. of judgements (\%) \\
\hline & $2005-2006$ & $2006-2007$ & $2007-2008$ & $2008-2009$ \\
\hline Pass & $331(94)$ & $314(93)$ & $310(93)$ & $278(94)$ \\
No judgement possible & $14(4)$ & $19(6)$ & $19(6)$ & $16(5)$ \\
Fail & $6(2)$ & $5(1)$ & $2(1)$ & $4(1)$ \\
Total & $351(100)$ & $338(100)$ & $321(100)$ & $298(100)$ \\
\hline
\end{tabular}




\section{Conclusions}

The adages 'Assessment drives learning' and 'They do not respect what you do not inspect' ${ }^{\text {' }}$ suggest that formative and summative aspects of assessment of professional behaviour can be combined within an assessment framework. Formative and summative assessment are not so much contrasting as complementary approaches. The Maastricht medical school framework combines these approaches: they are two sides of the same coin. 
Formative and summative professional behaviour assessment

\section{References}

1. Cohen JJ. Professionalism in medical education, an American perspective: from evidence to accountability. Med Educ 2006;40:607-17.

2. van Mook WN, van Luijk SJ, O'Sullivan H, Wass V, Harm Zwaveling J, Schuwirth LW, van der Vleuten CP. The concepts of professionalism and professional behaviour: Conflicts in both definition and learning outcomes. Eur J Int Med 2009;20:e85-e9.

3. Stephenson AE, Adshead LE, Higgs RH. The teaching of professional attitudes within UK medical schools: reported difficulties and good practice. Med Educ 2006;40:1072-80.

4. van Mook WN, de Grave WS, Wass V, O'Sullivan $\mathrm{H}$, Zwaveling JH, Schuwirth LW, van der Vleuten CP. Professionalism: Evolution of the concept. Eur J Int Med 2009;20:e81-e4.

5. Accreditation Council for Graduate Medical Education. ACGME Outcome Project enhancing residency education through outcomes assessment: General competencies. 1999;Accessed Febr 13th 2006: http://www.acgme.org/outcome/comp/compFull.asp.

6. Royal College of Physicians and Surgeons in Canada. The CanMeds Framework. http://rcpscmedicalorg/canmeds/indexphp Accessed November 27th 2008

7. Lee AG, Beaver HA, Boldt HC, Olson R, Oetting TA, Abramoff M, Carter K. Teaching and assessing professionalism in ophthalmology residency training programs. Surv Ophthalmol 2007;52:300-14.

8. Edelstein SB, Stevenson JM, Broad K. Teaching professionalism during anesthesiology training. J Clin Anesth 2005;17:392-8.

9. Rowley BD, Baldwin DC, Jr., Bay RC, Cannula M. Can professional values be taught? A look at residency training. Clin Orthop Relat Res 2000:110-4.

10. Stuurgroep Modernisering Opleiding en Beroepsuitoefening in de Gezondheidszorg. Medische vervolgopleidingen. $\mathrm{nl}$. Accessed Januari1 $9^{\text {th }} 2007 \mathrm{http}: / /$ wwwmedischevervolgopleidingennl// content/documenten/documentatie/projectplan\%20mmvpdf.

11. Gruen RL, Arya J, Cosgrove EM, Cruess RL, Cruess SR, Eastman AB, Fabri PJ, Friedman P, Kirksey TD, Kodner IJ, Lewis FR, Liscum KR, Organ CH, Rosenfeld JC, Russell TR, Sachdeva AK, Zook EG, Harken AH; American College of Surgeons Task Froce on Professionalism. Professionalism in surgery. Journal of the American College of Surgeons 2003;197:605-8.

12. Larkin GL. Evaluating professionalism in emergency medicine: clinical ethical competence. Acad Emerg Med 1999;6:302-11.

13. Stern DT, Papadakis M. The developing physician--becoming a professional. N Engl J Med 2006;355:1794-9.

14. van Mook WN, van Luijk SJ, de Grave W, O'Sullivan H, Wass V, Schuwirth LW, van der Vleuten CP. Teaching and learning professional behavior in practice. Eur $\mathrm{J}$ Int Med 2009;20:e105-11.

15. Thistlethwaite JE, Spencer Je. Professionalism in medicine. Radcliffe Publishing Ltd, Abingdon, UK 2008.

16. Stern DTe. Measuring medical professionalism. Oxford University Press, New York, ISBN 978-0-19-517226-3 2006.

17. Cruess R, Cruess S, Steinert Y. Teaching medical professionalism. ISBN 978-0-521-88104-3 2009.

18. Wear D, Aultman J. Professionalism in medicine. ISBN 0-387-32726-6 2006.

19. Postma CT, Thoben A, Timmermans L, van Spaendonck K. Horken en huilebalken. Medisch Contact 2006;61:883-5.

20. Rynja S, Cents R, Morsink M. Tabee lomperikken en horken. Medisch Contact 2006;62:73-5.

21. O'Neill B. Doctor as murderer. Death certification needs tightening up, but it still might not have stopped Shipman. BMJ Clinical research ed 2000;320:329-30.

22. Esmail A. Physician as serial killer--the Shipman case. N Engl J Med 2005;352:1843-4.

23. Hickson GB, Pichert JW, Webb LE, Gabbe SG. A complementary approach to promoting professionalism: identifying, measuring, and addressing unprofessional behaviors. Acad Med 2007;82:1040-8. 
92 $\mid$ Chapter 4

24. Leape LL, Fromson JA. Problem doctors: is there a system-level solution? Ann Intern Med 2006;144:107-15.

25. McLemore MR. Workplace aggression: beginning a dialogue. Clinical Journal of Oncology Nursing 2006;10:455-6.

26. Rosenstein $\mathrm{AH}$. Original research: nurse-physician relationships: impact on nurse satisfaction and retention. The American Journal of Nursing 2002;102:26-34.

27. Rosenstein $\mathrm{AH}, \mathrm{O}$ 'Daniel $\mathrm{M}$. Study links disruptive behavior to negative patient outcomes. OR manager 2005;21:1, 20, 2.

28. Rosenstein $\mathrm{AH}, \mathrm{O}$ 'Daniel $\mathrm{M}$. Disruptive behavior and clinical outcomes: perceptions of nurses and physicians. The American Journal of Nursing 2005;105:54-64.

29. Rosenstein $\mathrm{AH}$, O'Daniel $\mathrm{M}$. Impact and implications of disruptive behavior in the perioperative arena. Journal of the American College of Surgeons 2006;203:96-105.

30. Rosenstein AH, O'Daniel M. A survey of the impact of disruptive behaviors and communication defects on patient safety. Joint Commission journal on quality and patient safety / Joint Commission Resources 2008;34:464-71.

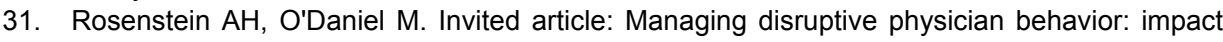
on staff relationships and patient care. Neurology 2008;70:1564-70.

32. Rosenstein $\mathrm{AH}$, Russell $\mathrm{H}$, Lauve R. Disruptive physician behavior contributes to nursing shortage. Study links bad behavior by doctors to nurses leaving the profession. Physician Executive 2002;28:8-11.

33. Felps WA, Mitchell TR, Byington EK. How, when and why bad apples spoil the barrel: negative group members and dysfunctional groups. Research in Organizational Behavior 2006;27:181-230.

34. van Luijk SJ, Smeets SGE, Smits J, Wolfhagen IH, Perquin MLF. Assessing professional behaviour and the role of academic advice at the Maastricht Medical School. Medical Teacher 2000;22:168-72.

35. Papadakis MA, Osborn EH, Cooke M, Healy K. A strategy for the detection and evaluation of unprofessional behavior in medical students. University of California, San Francisco School of Medicine Clinical Clerkships Operation Committee. Acad Med 1999;74:980-90.

36. Schonrock-Adema J, Heijne-Penninga M, van Duijn MA, Geertsma J, Cohen-Schotanus J. Assessment of professional behaviour in undergraduate medical education: peer assessment enhances performance. Med Educ 2007;41:836-42.

37. Metz JCM, A.M.M V-W, Huisjes HJ. Raamplan 2001 Artsopleiding. Bijgestelde eindtermen van de artsopleiding. Nijmegen Mediagroep 2001.

38. Project Team Consilium Abeundi van Luijk SJe. Professional behaviour: Teaching, assessing and coaching students. Final report and appendices. Mosae Libris 2005.

39. Projectteam Consilium Abeundi. Professioneel gedrag: Onderwijs, toetsing, begeleiding en regelgeving; 2002.

40. Diemers AD, Dolmans DH, Verwijnen MG, Heineman E, Scherpbier AJ. Students' opinions about the effects of preclinical patient contacts on their learning. Adv Health Sci Educ Theory Pract 2008;13:633-47.

41. Thistlethwaite J, Spencer J. Assessing professionalism. In: Professionalism in Medicine 2008;ISBN-13: 9781857757637

42. Pellegrino ED. Professionalism, profession and the virtues of the good physician. Mt Sinai $\mathrm{J}$ Med 2002;69:378-84.

43. Frohna A, Stern D, LaSala KB, Nelson J. The nature of qualitative comments in evaluating professionalism. Med Educ 2005;39:763-8.

44. van Mook WN, de Grave WS, Huijssen-Huisman E, de Witt-Luth M, Dolmans DH, Muijtjens AM, Schuwirth LW, van der Vleuten CP. Factors inhibiting assessment of students' professional behaviour in the tutorial group during problem-based learning. Med Educ 2007;41:849-56.

45. van Mook WN, de Grave WS, Huijssen-Huisman E, de Witt-Luth M, Dolmans DH, Muijtjens AM, Schuwirth LW, van der Vleuten CP. Approaches to professional behaviour assessment: tools in the professionalism toolbox. Eur J Intern Med. 2009;20:e153-7. 
46. Papadakis MA, Loeser H. Using critical incident reports and longitudinal observations to assess professionalism. In: Measuring medical professionalism Stern, DT (ed) Oxford University Press, New York, 2006 ISBN-13: 978-0-19-517226-3 2006.

47. Sullivan $\mathrm{C}$, Arnold L. Assessment and remediation in programs of teaching professionalism. In: Teaching medical Professionalism (Cruess RL, Cruess, SR, Steiner Y, eds) 2009;ISBN 978-0-521-88104-3:124-49.

48. Fochtmann L. Professionalism and the Heisenberg uncertainty principle. In: Professionalism in Medicine Critical perspectives Wear D, Aultman JM (Eds) 2006

49. Haurani MJ, Rubinfeld I, Rao S, Beaubien J, Musial JL, Parker A, Reickert C, Raafat A, Shepard A. Are the communication and professionalism competencies the new critical values in a resident's global evaluation process? J Surg Educ 2007;64:351-6.

50. Rhoton MF. Professionalism and clinical excellence among anesthesiology residents. Acad Med 1994;69:313-5.

51. Papadakis MA, Teherani A, Banach MA, Knettler TR, Rattner SL, Stern DT, Veloski JJ, Hodgson CS. Disciplinary action by medical boards and prior behavior in medical school. N Engl J Med 2005;353:2673-82.

52. Stern DT, Frohna AZ, Gruppen LD. The prediction of professional behaviour. Med Educ 2005;39:75-82.

53. Alexander M, Lenahan P, Pavlov A. Cinemeducation: A Comprehensive Guide to Using Film in Medical Education ISBN-10 : 1857756924, Radcliffe Publishing Ltd, UK 2004.

54. Boenink AD. Teaching and learning reflection on medical professionalism (thesis). Gildeprint Drukkerijen BV, Enschede 2006;ISBN 90-8659-031-4.

55. van Mook WN, Gorter SL, de Grave WS, van Luijk SJ, O'Sullivan H, Wass V, Zwaveling JH, Schuwirth LW, van der Vleuten CP. The educational continuum: professionalism in and beyond medical school. Eur J Int Med 2009;20:e148-52. 



\section{Chapter 5}

Factors inhibiting assessment of students' professional behaviour in the tutorial group in problem based learning

Walther NKA van Mook, Willem S de Grave, Elise J Huijssen-Huisman, Marianne E de Witt-Luth, Diana HJM Dolmans, Arno MM Muijtjens, Lambert W Schuwirth, Cees PM van der Vleuten 


\section{Abstract}

\section{Introduction}

We addressed assessment of professional behaviour in tutorial groups by investigating students' perceptions of the frequency and impact of critical incidents that impede this assessment and five factors underlying these critical incidents.

\section{Methods}

A questionnaire asking students to rate on a five-point Likert scale the frequency and impact of 40 critical incidents relating to effective assessment of professional behaviour was developed and sent to all undergraduate medical students in years 2-4 of a six-year undergraduate curriculum.

\section{Results}

The response rate was $70 \%, \mathrm{n}=393$. Important factors underlying the critical incidents are: Lack of effective interaction, lack of thoroughness, tutors' failure to confront students with unprofessional behaviour, lack of effort to find solutions, and lack of student motivation. Confirmatory factor analysis showed a good model fit. Because the relationship between frequency of occurrence and degree of impediment varies, the best information about the true impact of critical incidents and the underlying factors is provided by the product of frequency and degree of impediment. Frequency of occurrence remains stable and degree of impediment increases in years 2-4.

\section{Conclusions}

The results of this study can be used to design and improve faculty development programmes aimed at improving assessment of professional behaviour. Training programmes should motivate tutors by providing background information as to why and how sound assessment of professional behaviour is to be performed and encourage tutors to confront students with and discuss all aspects of professional behaviour as well as provide appropriate feedback. 


\section{Introduction}

Professionalism encompasses elements like altruism, accountability, duty, excellence, honour, integrity, and respect for others ${ }^{1}$. It is a complex theoretical construct and although the elements are conceptually recognisable and widely accepted as relevant, their presence is not directly observable, and thus difficult to measure. A more practical, behavioural approach to professionalism involves moving from the general concept of professionalism to the more concrete concept of professional behaviour, which is observable and therefore easier to assess. Teaching and assessing professional behaviour in undergraduate medical education serves an important societal, public purpose. This is supported by the finding that disciplinary action by medical boards against practising physicians is strongly associated with a history of unprofessional behaviour during undergraduate medical training ${ }^{2}$. Incorporating professional behaviour in the undergraduate curriculum may offer opportunities for timely remediation for students who exhibit dysfunctional behaviour ${ }^{3,4}$. Professional behaviour can be taught and assessed in a variety of ways ${ }^{5}$. A learning environment like problem based learning, with its characteristic features of small tutorial groups, focus on learners, and self-directed and experiential learning, seems to be eminently suited to foster appropriate professional behaviour. Although it is well known that what tutors do is important for the effective functioning of tutorial groups $s^{6,7}$, relatively little is known about factors in tutorial groups that may impede teaching and assessment of professional behaviour in particular. This is unfortunate, as awareness of such impediments can be used to design and improve faculty development programmes ${ }^{8}$. Because we were interested to learn about the development of students' professional behaviour in the undergraduate curriculum, we investigated which factors are perceived by students as impediments to effective assessment of professional behaviour in tutorial groups. We asked students to recount critical incidents relating to assessment of professional behaviour and examined these to find answers to the following research questions:

1. which factors underlie the critical incidents that students perceive as impediments to effective assessment of professional behaviour in tutorial groups?

2. how do students rate the negative impact of these different critical incidents on the assessment of professional behaviour in tutorial groups?

3. how do students rate the frequency of occurrence of these different critical incidents in tutorial groups?

4. what is the actual impact of the factors underlying these critical incidents on the assessment of professional behaviour in tutorial groups? 
5. do students in different years of the curriculum differ in their perceptions with regard to the frequency and impact of factors that are perceived as impediments to effective assessment of professional behaviour?

\section{Methods}

\section{Context and subjects}

The study was performed among the students in preclinical years 2-4 of the six-year undergraduate medical curriculum of the Faculty of Medicine, Maastricht University, the Netherlands. In each of the years studied, individual students' professional behaviour is assessed twice: a formative assessment halfway the year and a summative assessment at the end of the year. Assessment is based on peer assessment and assessment by tutors, whose judgement is decisive.

\section{Instrument}

We used an inductive approach to develop a questionnaire consisting of critical incidents relating to assessment of students' professional behaviour by tutors. Two groups consisting of ten self-selected students, distributed evenly over years 2-4 of the undergraduate curriculum, participated in one focus group interview each. These interviews yielded a preliminary list of critical incidents that were perceived as having a detrimental effect on assessment of professional behaviour in tutorial groups. After research assistants had elaborated on the list and three local and national key experts had made some additions, the list consisted of forty critical incidents. In order to validate the questionnaire and investigate the critical incidents, we asked all the students in years 2-4 to complete the questionnaire. The questionnaire consisted of descriptions of the critical incidents and students were asked to indicate for each critical incident on a five-point Likert scale (1=strongly disagree; $5=$ strongly agree) how they perceived the frequency of its occurrence and its negative impact on effective assessment of professional behaviour. Tables 5.1 and 5.2 show critical incidents relating to the different factors. Guided by theories of performance assessment and feedback on work performance ${ }^{9}$ and based on the literature about assessment of professional behaviour and small group functioning ${ }^{10-13}$, we identified five factors underlying the critical incidents that might play a major role in impeding assessment of professional behaviour in tutorial groups: (1) Lack of effective interaction between students and tutors, (2) Students and tutors lacking thoroughness in addressing professional behaviour, (3) Tutors failing to confront students with their unprofessional 
behaviour, (4) Lack of effort to resolve problems, and (5) Lack of motivation among students. We assumed that these were the factors underlying the forty critical incidents.

Table 5.1 The critical incidents with the highest ratings on a five-point Likert scale (1=strongly disagree; $5=$ strongly agree) in response to the statement "I experience this situation as impeding effective assessment of professional behaviour" for each of the five factors.

\begin{tabular}{|c|c|}
\hline Factor & Critical incident \\
\hline \multirow[t]{3}{*}{ Lack of effective interaction } & 'Good feedback?’ \\
\hline & $\begin{array}{l}\text { During the assessment one of the students is completely } \\
\text { 'destroyed', because he "really never ever does anything!" }\end{array}$ \\
\hline & Feedback is not given appropriately. \\
\hline \multirow[t]{2}{*}{ Lack of thoroughness } & 'The tutor does not feel like doing the assessment' \\
\hline & $\begin{array}{l}\text { The tutor is reluctant to do the assessment: "Shall we do the } \\
\text { assessment or move on?" It is decided that a 'quick' } \\
\text { assessment will be done. }\end{array}$ \\
\hline \multirow[t]{3}{*}{ Failure to confront students } & 'Quiet person' \\
\hline & One of the students says very little during group sessions. \\
\hline & $\begin{array}{l}\text { The tutor does not say anything about it when assessing that } \\
\text { student's professional behaviour. }\end{array}$ \\
\hline \multirow[t]{3}{*}{ Lack of effort to find solutions } & 'Wrong time' \\
\hline & $\begin{array}{l}\text { One of the students was not present at the assessment of } \\
\text { professional behaviour half way through the course. At the } \\
\text { end of the course he complains about something that the } \\
\text { other members of the group have already discussed. }\end{array}$ \\
\hline & $\begin{array}{l}\text { However, no attempts are made to discuss and solve the } \\
\text { problem. }\end{array}$ \\
\hline \multirow[t]{2}{*}{ Lack of motivation } & $\begin{array}{l}\text { 'The more experienced the student, the more useless the } \\
\text { assessment seems' }\end{array}$ \\
\hline & $\begin{array}{l}\text { During the assessment one of the students says that over the } \\
\text { course of the curriculum he has participated in so many } \\
\text { assessments that "the whole exercise has become useless" }\end{array}$ \\
\hline
\end{tabular}

\section{Statistical analysis}

We performed confirmatory factor analysis using AMOS $5.0^{14}$ and examined the adequacy of the theoretical five factor model for the assessment of professional behaviour (construct validity) to determine how well the model fitted with the data. Chi square and degrees of freedom, sample size, p-value, and the root mean square error of approximation (RMSEA) were used as absolute goodness-of-fit indices. Two additional fit indices were included: the comparative fit index (CFI) and the Tucker-Lewis index (TLI).

We estimated the internal consistency of critical incidents clusters associated with the different factors by calculating Cronbach's $\alpha$ using SPSS $12.0 .1^{15}$. The $\alpha$ coefficient ranges from 0 to $1^{16}$. The higher the score, the more consistent the 
scale is. Nunnaly has indicated that 0.7 is an acceptable reliability coefficient but lower thresholds are sometimes used ${ }^{17}$.

For each student two measures were determined for each factor: the perceived frequency of occurrence of the critical incidents associated with the factor, and the impediment of effective assessment of professional behaviour of the critical incidents associated with the factor. The frequency score was obtained by calculating the mean frequency of the associated critical incidents, and the degree of impediment score was similarly obtained by averaging the impediment scores of the associated critical incidents. Standard deviations across critical incidents as well as the critical incident with the highest rating were determined for each factor. In addition, a third measure was obtained for each student and factor to represent the actual impact of a factor on the impediment of the assessment of professional behaviour. Therefore, the product of frequency and impediment score per critical incident was calculated, and subsequently, the mean of this product was obtained for the critical incidents associated with a factor ${ }^{15}$.

The question whether the impact of the different factors on the assessment of professional behaviour varied between years 2-4 was analysed by investigating between-year differences in the average frequency, impediment and product score for each factor in a one-way ANOVA ${ }^{15}$.

\section{Results}

\section{Response rate}

The response rate was $70 \%$. The questionnaire was completed and returned by 393 students in years 2-4, i.e. 145, 142, and 106 students for years 2, 3, and 4 , respectively.

\section{Fit of the model with the data}

The results of the confirmatory factor analysis show that $\chi^{2}$ divided by degrees of freedom is 2.228 , RMSEA is $0.056, \mathrm{CFI}$ is 0.917 , and TLI is 0.890 . All test results indicate a fairly good to good fit of the model with the data (Table 5.3).

Cronbach's $\alpha$ varies between 0.66 and 0.77 (Table 5.4) for the clusters of critical incidents associated with the different factors. Table 5.4 shows that the $\alpha$ for factor 5 is relatively low, with the $\alpha$ for the other factors ranging from satisfactory to good. 
Table 5.2 Critical incidents concerning assessment of professional behaviour with the highest frequency ratings per factor

\begin{tabular}{|c|c|c|c|c|}
\hline Rank & Critical incident & Mean & SD & Factor \\
\hline 1 & $\begin{array}{l}\text { \# } 34 \text { 'Filling out the form during the group } \\
\text { session' } \\
\text { The tutor has not prepared for the assessment } \\
\text { and starts to fill out the forms during the group } \\
\text { session. }\end{array}$ & 3.97 & 1.09 & $\begin{array}{l}\text { Lack of effective } \\
\text { communication }\end{array}$ \\
\hline 2 & $\begin{array}{l}\text { \# } 22 \text { 'Present, yet absent' } \\
\text { A student is physically present but does not } \\
\text { contribute to the group process. Nevertheless he } \\
\text { meets the criteria of the assessment form and is } \\
\text { given a satisfactory grade. }\end{array}$ & 3.75 & 1.08 & $\begin{array}{l}\text { Failure to confront } \\
\text { students }\end{array}$ \\
\hline 3 & $\begin{array}{l}\text { \# } 15 \text { 'Time is up' } \\
\text { While the assessment of professional behaviour } \\
\text { is in progress, the students start to get ready to } \\
\text { leave. The assessment is finished in no time at } \\
\text { all so that everybody can catch their bus or train. }\end{array}$ & 3.50 & 1.12 & Lack of thoroughness \\
\hline 4 & $\begin{array}{l}\text { \# } 25 \text { 'All is well' } \\
\text { Because it is mandatory, an attempt is made to } \\
\text { assess professional behaviour. However, it is } \\
\text { considered futile since things are going well, so } \\
\text { what's the point?" }\end{array}$ & 3.46 & 1.18 & Lack of thoroughness \\
\hline 5 & $\begin{array}{l}\text { \# } 30 \text { 'Quiet person' } \\
\text { A student says very little during group sessions } \\
\text { but the tutor fails to mention it. }\end{array}$ & 3.40 & 1.19 & $\begin{array}{l}\text { Failure to confront } \\
\text { students }\end{array}$ \\
\hline
\end{tabular}

$\mathrm{SD}=$ standard deviation

How do students rate the negative impact of the different critical incidents on the assessment of professional behaviour in tutorial groups?

The mean scores (4-th column of Table 5.4) show that 'Lack of effective interaction', 'Lack of effort to find solutions' and 'Lack of motivation' are perceived as the main impediments. Table 5.4 shows the mean scores (scale 1-5) per factor and Table 5.1 presents the critical incidents with the highest loadings for each of the five factors.

\section{How do students rate the frequency of occurrence of the different critical incidents in tutorial groups?}

Table 5.2 shows the critical incidents with the highest frequency ratings in descending order of frequency. The critical incidents 22 and 30 are examples of critical incidents with high ratings for both frequency and impeding effect on assessment of professional behaviour. Several other critical incidents with high frequency ratings are not perceived as important impediments. The most striking example is critical incident 34 , which has the highest mean frequency rating and the lowest perceived impeding effect. On the other hand, critical incident 17 which refers to the tutor not knowing the students and getting them 
mixed up is perceived as a substantial impediment but of infrequent occurrence.

Table 5.3 Summary of goodness-of-fit statistics for the hypothesised model

\begin{tabular}{lcccc}
\hline Index & Value & $\begin{array}{c}\text { Value indicating a } \\
\text { good fit }\end{array}$ & Ref \\
Impediment & $\begin{array}{c}\text { Product of frequency and } \\
\text { degree of impediment }\end{array}$ & \\
\hline$\chi^{2} /$ degrees of freedom & 2.23 & 2.39 & $<3$ & 22 \\
RMSEA & 0.056 & 0.06 & $<0.05$ & 23 \\
CFI & 0.92 & 0.90 & $\geq 0.90$ & $22-24$ \\
TLI & 0.89 & 0.87 & $\geq 0.95$ & 23,24 \\
\hline
\end{tabular}

RMSEA = root mean square error of approximation; CFI = comparative fit index; TLI = TuckerLewis index

Table 5.4 Mean scores (five-point Likert scale) and reliability coefficients of the factors underlying the impeding effects of critical incidents on effective assessment of professional behaviour in tutorial groups for students in years 2-4 and for each year separately.

\begin{tabular}{lccccccccccc}
\hline Factor & $\begin{array}{c}\text { Total no. } \\
\text { of } \\
\text { students }\end{array}$ & $\begin{array}{c}\text { No. of } \\
\text { critical }\end{array}$ & $\begin{array}{c}\text { Mean } \\
\text { scidents }\end{array}$ & Srs 2-4 & & $\begin{array}{c}\text { Coefficient } \\
\boldsymbol{a}\end{array}$ & $\begin{array}{c}\text { Mean } \\
\text { yr 2 }\end{array}$ & $\begin{array}{c}\text { Mean } \\
\text { yr 3 }\end{array}$ & $\begin{array}{c}\text { Mean } \\
\text { yr 4 }\end{array}$ & $\begin{array}{c}\text { F- } \\
\text { test }\end{array}$ & $\begin{array}{c}\text { p- } \\
\text { value }\end{array}$ \\
\hline $\begin{array}{l}\text { Lack of effective } \\
\text { interaction }\end{array}$ & 372 & 4 & 4.00 & 1.03 & 0.70 & 3.96 & 3.96 & 4.12 & 1.72 & 0.180 \\
$\begin{array}{l}\text { Lack of } \\
\text { thoroughness }\end{array}$ & 374 & 4 & 3.42 & 1.17 & 0.77 & 3.27 & 3.51 & 3.50 & 3.19 & 0.042 \\
$\begin{array}{l}\text { Failure to confront } \\
\text { students }\end{array}$ & 382 & 4 & 3.49 & 1.19 & 0.74 & 3.30 & 3.65 & 3.55 & 6.08 & 0.003 \\
$\begin{array}{l}\text { Lack of effort to } \\
\text { find solutions }\end{array}$ & 373 & 4 & 3.55 & 1.08 & 0.71 & 3.43 & 3.52 & 3.70 & 3.55 & 0.030 \\
Lack of motivation & 379 & 3 & 3.75 & 1.06 & 0.66 & 3.51 & 3.68 & 3.85 & 5.13 & 0.006 \\
\hline
\end{tabular}

$\mathrm{SD}=$ standard deviation

What is the actual impact of the factors underlying the critical incidents on the assessment of professional behaviour in tutorial groups?

Table 5.5 shows that for the product of the frequency of occurrence and the degree of impediment, the score for the factor 'Failure to confront students with unprofessional behaviour' is higher compared to the score for impediment only.

However, although this factor ranks only fourth in severity of impediment, it is the highest-ranking factor when both frequency of occurrence and severity of impediment are taken into account (Table 5.5). Other important factors are 'Lack of effective interaction' and 'Lack of effort to find solutions'. These factors 
are also rated highly on degree of impediment alone (Table 5.4). Internal consistency analysis for the mean product scores reveals values between 0.573 and 0.820 . The values are 'acceptable' to 'high' for the first three factors, but 'relatively low' for the other two factors (Table 5.5).

Table 5.5 Mean score and reliability of the products of the degree of impediment and the frequency of occurrence for the different factors (divided by 5 to arrive at a scale from 1-5) for all the years studied and for each year separately

\begin{tabular}{|c|c|c|c|c|c|c|c|c|c|c|}
\hline Factor & $\begin{array}{c}\text { Total no. } \\
\text { of } \\
\text { students }\end{array}$ & $\begin{array}{c}\text { No. of } \\
\text { critical } \\
\text { incidents }\end{array}$ & $\begin{array}{l}\text { Mean } \\
\text { score } \\
\text { yrs 2-4 }\end{array}$ & SD & $\begin{array}{c}\text { Coefficient } \\
a\end{array}$ & $\begin{array}{c}\text { Mean } \\
\text { score } \\
\text { yr } 2\end{array}$ & $\begin{array}{c}\text { Mean } \\
\text { score } \\
\text { yr } 3\end{array}$ & $\begin{array}{c}\text { Mean } \\
\text { score } \\
\text { yr } 4\end{array}$ & $\begin{array}{l}\mathrm{F}- \\
\text { test }\end{array}$ & $\begin{array}{c}\mathrm{p}- \\
\text { value }\end{array}$ \\
\hline $\begin{array}{l}\text { Lack of effective } \\
\text { interaction }\end{array}$ & 370 & 4 & 1.77 & 0.71 & 0.64 & 1.68 & 1.82 & 1.83 & 1.89 & 0.153 \\
\hline $\begin{array}{l}\text { Lack of } \\
\text { thoroughness }\end{array}$ & 374 & 4 & 1.66 & 0.72 & 0.68 & 1.62 & 1.69 & 1.67 & 0.34 & 0.713 \\
\hline $\begin{array}{l}\text { Failure to confront } \\
\text { students }\end{array}$ & 380 & 4 & 2.40 & 1.06 & 0.82 & 2.15 & 2.53 & 2.58 & 6.86 & 0.001 \\
\hline $\begin{array}{l}\text { Lack of effort to } \\
\text { find solutions }\end{array}$ & 372 & 4 & 1.75 & 0.69 & 0.59 & 1.61 & 1.77 & 1.91 & 5.85 & 0.003 \\
\hline Lack of motivation & 378 & 3 & 1.62 & 0.75 & 0.57 & 1.53 & 1.66 & 1.69 & 1.54 & 0.216 \\
\hline
\end{tabular}

$\mathrm{SD}=$ standard deviation

Do students in different years of the curriculum (2-4) differ in their perceptions with regard to frequency and impact of factors that impede effective assessment of professional behaviour?

There are no significant differences between years 2-4 in frequency of occurrence, except for the factor 'Failure to confront students with unprofessional behaviour', of which the mean rating increased from 3.22 in year 2 to 3.51 in year 4 ( $p=0.031$, data not shown). For four factors, the mean ratings for degree of impediment differ significantly between the years (crosssectional) $(p<0.05)$, but for 'Lack of effective interaction' this is not so. The ratings for 'Lack of thoroughness', 'Lack of effort to find solutions', and 'Lack of motivation' show increases in each year; and the ratings for 'Failure to confront students' increase after year 2 and then start to level off (Table 5.4). That the impact of the factors differs between the years is shown by the increasing products of the ratings on impediment and frequency of occurrence for all factors, except for 'Lack of thoroughness', which shows a levelling off after year 3 (Table 5.5). Statistical significance is reached for 'Failure to confront students', and 'Lack of effort to find solutions' ( $p=0.001$ and 0.003 , respectively) (Table 5.4). 


\section{Discussion}

\section{Factors impeding assessment of professional behaviour}

Although published studies have addressed the general occurrence of critical incidents in tutorial groups ${ }^{9,11,13,18,19}$, to our knowledge, the present study is the first to address critical incidents in relation to the assessment of professional behaviour in tutorial groups. Five factors underlying the critical incidents are identified. These factors and the critical incidents can be translated into training needs of tutors and students. The first four factors (Tables 5.4 and 5.2) are indicative of a need to improve tutors' role performance, and factors 1,2 , and 5 suggest that students should be better informed on assessment of professional behaviour. Based on the critical incidents and the underlying factors, we have designed video fragments, which we have used to train Maastricht tutors in assessing professional behaviour. Although the results of this study appear to suggest that the main emphasis should be on tutor training, it would be misguided to ignore the students' role. Training aimed at improving group productivity seems important ${ }^{7}$, since the effectiveness of tutorial group functioning has been shown to depend on group productivity amongst other things ${ }^{20,21}$. As from 2006, the videotaped critical incidents will be used early in the curriculum to enhance students' knowledge and skills regarding professional behaviour.

\section{Discrepancies between severity of impediment and frequency of occurrence of the factors}

Some students said that on the whole they considered professional behaviour a rather time-consuming and futile exercise. The high ratings on both the frequency and effects of the adverse critical incidents seem to reflect this view. However, caution is imperative when drawing such a conclusion exclusively on the basis of either the frequency of occurrence or the severity of the impediment. The product of frequency of occurrence and degree of impediment seems to offer the best approximation of the true impact of factors. The results show that a relatively low frequency score can occur alongside a high impediment score and vice versa. This means that frequency and impediment alone would misrepresent the real impact of some factors.

The results do indeed reveal differences between frequency and impact of critical incidents. The critical incidents that students perceive as most frequent are not always also perceived as the strongest impediments and vice versa. Lack of preparation for the assessment of professional behaviour by tutors, for example, seems almost universal (judging from the frequency of its occurrence), but it is not considered of vital importance, because the severity of 
its impact is not rated very highly. On the other hand, a tutor not knowing the students and getting them mixed up is perceived as a very serious impediment, but it is perceived to be of rare occurrence. The discrepancies between frequency of occurrence and extent of impediment underline the need to take account of both aspects in prioritising factors as subjects for training of tutors and students. Training should focus especially on those factors that are perceived as strong impediments and on those that occur somewhat frequently and are moderately impeding, i.e. factors with high product scores of frequency of occurrence and magnitude of impediment.

\section{Do differences between the years reflect changes over time?}

The severity of impediment associated with the factors increases over the years, except for 'Lack of effective interaction', which remains consistently high in all years. Frequency shows no changes between the years, except for 'Failure to confront students'. It should be noted that a high impact in each year reflects a very strong impact. The results suggest that students have a keen awareness of problems relating to the assessment of professional behaviour, but may be lacking in effective coping strategies. Another consideration is that the assessment of professional behaviour is a relatively new feature in the Maastricht undergraduate medical curriculum. Thus it cannot be ruled out that the implementation phase of this type of assessment has induced spurious variation between the years. Our data, which reflect cross-sectional differences between three cohorts of students, are not a sound basis for conclusions on changes over time, since no longitudinal follow-up was performed. However, several explanations have been postulated for the fact that students' perceptions of characteristics of dysfunctional tutorial groups differ between years of medical training ${ }^{13}$. In the first years of a problem-based curriculum, students may be more dependent on the tutorial group. As they gain more knowledge about group dynamics through 'learning by doing' over the years, they may become more adept at spotting problems with assessment of professional behaviour and at identification of impediments to effective assessment. Nevertheless, increased awareness of problems does not preclude the possibility of a real increase in frequency of occurrence and/or severity of impediment over the years.

\section{Limitations of the study}

One of the limitations of this study is its exclusive focus on students' perceptions. As a consequence no comparisons can be made between tutors and students' points of view. Furthermore, the study being cross-sectional, no firm conclusions can be drawn regarding real changes over time, which would require a proper longitudinal design. 


\section{Conclusions}

The results of this study can be of practical use in guiding instruction and training of tutors and students. Training should be aimed at motivating tutors, for example by providing background information as to why and how sound assessment of professional behaviour is to be achieved and at encouraging tutors not to avoid confronting students but to discuss students' professional behaviour and give appropriate and constructive feedback. The results of this study have already been used to design video fragments to facilitate training of tutors and students in assessment of professional behaviour. Although tutors can make an important contribution to improving assessment of professional behaviour, the contribution of the students is by no means to be ignored. 
Factors inhibiting assessment of students' professional behaviour

\section{References}

1. American Board of Internal Medicine, Committee on Evaluation of Clinical Competence. Project Professionalism. ABIM, Philadelphia. 1995:5-6.

2. Papadakis MA, Teherani A, Banach MA, Knettler TR, Rattner SL, Stern DT, Veloski JJ, Hodgson CS. Disciplinary action by medical boards and prior behavior in medical school. $\mathrm{N}$ Engl J Med 2005;353:2673-82.

3. Papadakis MA, Loeser H, Healy K. Early detection and evaluation of professionalism deficiencies in medical students: one school's approach. Acad Med 2001;76:1100-6.

4. Phelan S, Obenshain SS, Galey WR. Evaluation of the noncognitive professional traits of medical students. Acad Med 1993;68:799-803.

5. Stern DT, Papadakis M. The developing physician--becoming a professional. N Engl J Med 2006;355:1794-9.

6. Gijselaers W, Schmidt HG. Development and evaluation of a causal model of problem-based learning. In: Innovation in Medical Education: An evaluation of its present status Eds: AM Nooman, HG Schmidt, ES Ezzat 1990;Springer, New York, ISBN 0-8261-5850-1:95-113.

7. Steinert Y. Student perceptions of effective small group teaching. Med Educ 2004;38:286-93.

8. Steinert Y, Cruess S, Cruess R, Snell L. Faculty development for teaching and evaluating professionalism: from programme design to curriculum change. Med Educ 2005;39:127-36.

9. Dolmans $\mathrm{DH}$, Wolfhagen $\mathrm{IH}$, van der Vleuten $\mathrm{CP}$. Motivational and cognitive processes influencing tutorial groups. Acad Med 1998;73(10 Suppl):S22-4.

10. Lynch DC, Surdyk PM, Eiser AR. Assessing professionalism: a review of the literature. Medical Teacher 2004;26:366-73.

11. Tipping J, Freeman RF, Rachlis AR. Using faculty and student perceptions of group dynamics to develop recommendations for PBL training. Acad Med 1995;70:1050-2.

12. Hitchcock MA, Anderson AS. Dealing with dysfunctional tutorial groups. Teaching and Learning in Medicine 1997;9:19-24.

13. de Grave WS, Dolmans DH, van Der Vleuten CP. Student perceptions about the occurrence of critical incidents in tutorial groups. Medical Teacher 2001;23:49-54.

14. Arbuckle J. Amos 5.0. Chicago: SmallWaters Corporation 2003.

15. Inc. S. SPSS 12.0.1. 2003; Chicago, U.S.A.

16. Cronbach LJ. Coefficient alpha and the internal structure of tests. Psychometrika 1951;16: 297-334.

17. Nunnaly J. Psychometric theory. New York: McGraw-Hill ISBN: 0070474656 1978;2nd edition

18. Visschers-Pleijers AJ, Dolmans $\mathrm{DH}$, Wolfhagen $\mathrm{IH}$, Van der Vleuten CP. Student perspectives on learning-oriented interactions in the tutorial group. Adv Health Sci Educ Theory Pract 2005; 10:23-35.

19. Mpofu DJS, Das M, Stewart TS, Dunn E, Schmidt HG. Perceptions of group dynamics in problem-based learning sessions: a time to reflect on group issues. Medical Teacher 1998;20:421-7.

20. Dolmans $\mathrm{DH}$, Wolfhagen $\mathrm{IH}$. Complex interactions between tutor performance, tutorial group productivity and the effectiveness of PBL units as perceived by students. Adv Health Sci Educ Theory Pract 2005;10:253-61.

21. Nieminen J, Sauri P, Lonka K. On the relationship between group functioning and study success in problem-based learning. Med Educ 2006;40:64-71.

22. Bentler PM. On the fit of models to co variances and methodology to the Bulletin. Psychol Bull 1992;112:400-4.

23. Byrne BM. Chapter 3: Application 1: Testing for the factorial validity of a theoretical construct. in: Structural equation modelling with AMOS: Basic concepts, applications, and programming 2001;Lawrence Erlbaum Associates, Publishers, Mahwah, New Jersey. ISBN 0-8058-3322-6.

24. Hu L-T, Bentler PM. Cut-off criteria for fit indexes in covariance structure analysis: Conventional criteria versus new alternatives. Structural Equation Modelling: A Multidisciplinary Journal 1999;6:1-55. 



\section{Chapter $\mathbf{6}$}

Web-assisted assessment of professional behaviour: more feedback, yet no improvement?

Walther NKA van Mook, Arno MM Muijtjens, Simone L Gorter, Jan Harm Zwaveling, Lambert W Schuwirth, Cees PM van der Vleuten Advances in Health Sciences Education, accepted for publication 


\section{Abstract}

\section{Introduction}

Although other web-based approaches to assessment of professional behaviour have been studied, no publications studying the potential advantages of a web-based instrument versus a 'classic', paper-based method have been published to date.

\section{Objectives and methods}

This study has two research goals: it focuses on the quantity and quality of comments provided by students and their peers (two researchers independently scoring comments as correct and incorrect in relation to five commonly used feedback rules (and resulting in an aggregated score of the five scores) on the one, and on the feasibility, acceptability and perceived usefulness of the two approaches on the other hand (using a survey).

\section{Results}

The amount of feedback was significantly higher in the web-based group than in the paper-based group for all three categories (dealing with work, others and oneself). Regarding the quality of feedback, the aggregated score for each of the three categories was not significantly different between the two groups, neither for the interim, nor for the final assessment. Some, not statistically significant, but nevertheless noteworthy trends were nevertheless noted. Feedback in the webbased group was more often unrelated to observed behaviour for several categories for both the interim and final assessment. Furthermore, most comments relating to the category 'Dealing with oneself' consisted of descriptions of a student's attendance, thereby neglecting other aspects of personal functioning. The survey identified significant differences between the groups for all questionnaire items regarding feasibility, acceptability and perceived usefulness in favour of the paper-based form.

\section{Conclusions}

The use of a web-based instrument for professional behaviour assessment yielded a significantly higher number of comments compared to the traditional paper-based assessment. Unfortunately, the quality of the feedback obtained by the web-based instrument as measured by several generally accepted feedback criteria did not parallel this increase. 


\section{Introduction}

Professionalism is becoming increasingly central in undergraduate and postgraduate training, and the herewith associated research results in a vast increase in the number of papers on the topic ${ }^{1}$. Tools for assessing professionalism and professional behaviour have been developed to identify, counsel, and remediate the performance of students and trainees demonstrating unacceptable professional behaviour ${ }^{2,3}$. Since validated tools are scarce ${ }^{4}$, combining currently available instruments has become the current norm $^{5,6}$. Self- and peer assessment and direct observation by faculty during regular educational sessions ${ }^{7-11}$ are some of these tools. Self-assessment is defined as personal evaluation of one's professional attributes and abilities against perceived norms ${ }^{12-14}$. So far, there is a scarcity of published studies on self-assessment of professionalism ${ }^{15}$. Given the poor validity of selfassessment in general ${ }^{14}$, it seems ill advised to use self-assessment in isolation without triangulation from other sources. Peer assessment involves assessors with the same level of expertise and training and similar hierarchical institutional status. Medical students usually know which of their classmates they would trust to treat their family members, which illustrates the intrinsic potential of peer assessment ${ }^{16}$. However, a recent analysis of instruments for peer assessment of physicians revealed that none met the required standards for instrument development ${ }^{17}$. Studies addressing peer assessment of professional behaviour of medical students are beginning to appear ${ }^{16,18-22}$. Observation and assessment by faculty using rating scales is another commonly used method of professional behaviour assessment ${ }^{6,23,24}$. Prior studies have revealed that such teacher-led sessions are highly dependent on the teacher's attitudes, motivation and instructional skills ${ }^{25}$. When teachers' commitment declines, assessment of professional behaviour may become more trivialised. This may misplace emphasis on attendance rather than participation and on completion of tick boxes rather than informative feedback and students' contribution and motivation ${ }^{25}$. In an attempt to further improve professional behaviour assessment, the triangulated teacher-led discussion of self- and peer-assessment of professional behaviour using a paper form is the contemporary practice at Maastricht medical school ${ }^{23}$.

However, digital technologies have come to influence our ways of working and communicating, and created technology driven ways of teaching, learning and assessing $^{26}$. Adaptation to some of these changes can be useful ${ }^{26}$, for example to reduce the time and expense involved in collecting self and peer ratings and facilitate anonymous information gathering and information analysis. In the National Board of Medical Examiners (NBME)' Assessment of Professional Behaviours (APB) program such web-based technology is contemporarily 
used $^{27-29}$. The study presented in this paper investigated the potential advantages of a web-based instrument versus a 'classic', paper-based method to assess professional behaviour. In a comparison of these two approaches we focused on:

1. the quantity and quality of comments provided by students and the feedback provided by their tutor and peers, and on

2. the feasibility, acceptability and perceived usefulness of the two approaches.

\section{Methods and research tools}

The study involved all medical students enrolled in the second, ten-week course in year 2 at the Faculty of Health, Medicine and Life Sciences, Maastricht University, the Netherlands. During the bachelor programme of the six-year medical curriculum, professional behaviour is assessed on various occasions in all regular courses ${ }^{23}$. The information from these assessments is supplemented by critical incident reports ${ }^{23}$. For the purpose of this study, the students were divided into two groups: those in tutorial groups with even numbers and those in groups with odd numbers. The first group used a webbased instrument to assess professional behaviour and the other group used the usual method with a paper assessment form. We will first describe the two assessment methods in some detail.

\section{The 'classic' paper-based professional behaviour assessment form}

The working group Consilium Abeundi of the Association of Universities in the Netherlands, proposed a practical definition of professional behaviour ${ }^{23,30,31}$. They framed professionalism as observable behaviours, reflecting the norms and values of the medical professional. Three categories of professional behaviour were distinguished: 'Dealing with work and tasks', 'Dealing with others', and 'Dealing with self-functioning ${ }^{24,30}$. These categories, together with the related clarifying descriptions, are the basis of the professional behaviour assessment form that is currently in use at Maastricht medical school (Figure $6.1)^{23,32}$. Professional behaviour is assessed at the start, halfway through and at the end of each regular course. For the halfway assessment each student prepares a self-reflective assessment and enters it in the form. In the subsequent plenary session of the tutorial group, chaired by the tutor, the professional behaviour of each student is assessed by the group. All group members (students and tutor) are required to contribute to the discussion. All the feedback is documented on the form by the tutor. At the end of the course this process is repeated, followed by a final summative assessment, resulting in a pass or fail ${ }^{23}$. 


\section{The web-based instrument}

The web-based instrument is based on an application that consists of a 360 degree feedback system specifically designed for higher education ${ }^{33}$. Its development involved more than thirty pilot studies and evaluations by over 6000 students. Prior to the current study, the tool was piloted at Maastricht in a group of first year students, which did not participate in the current study. Providing adequate practical information to students and tutors prior to using the application and rephrasing of items to achieve a more detailed focus on aspects of professional behaviour were considered prerequisite for the successful implementation of web-based assessment (unpublished data). Questions about 'professional behaviour' for the web-based instrument were similar and pertained to the same three categories (and clarifying descriptions) also used on the paper form ${ }^{30}$. Ample information about background, confidentiality, timing and some practical matters was made available to students and staff electronically and in writing prior to, and during the opening session of the course, as well as verbally to the tutors during the tutor instruction session. Halfway and at the end of the course each student in the web-based assessment group received an internet link in an e-mail. Clicking the link gave access to the web-based assessment instrument. The students were asked to complete the questions themselves and then invite five peers and the tutor of their group to evaluate their professional behaviour and provide feedback. Selection of the peer students was standardised to the five students listed immediately below the student's name on the centrally randomly generated list of the tutorial group members, resulting in a semi-anonymised feedback procedure. Ample space for narrative feedback relating to the three categories of professional behaviour was provided for each questionnaire item (Figure 6.1). All items were also answered using a Likert scale (1=almost never to $5=a$ almost always). The students received the results of the feedback process in the form of a printable report presenting the results of their self-assessment relative to the assessment by their peers as well as an overview of all the narrative comments. The web-based group used the printed reports and the paper-based group used the completed paper-based forms to discuss each student's professional behaviour during the end-of-course assessment in the final tutorial group of the course.

\section{End-of-course questionnaire}

At the end of the last tutorial group of the course, all students of the two groups were asked to complete a questionnaire addressing fourteen aspects of feasibility, acceptability and perceived usefulness of the two instruments. The tutors were invited to report their findings by e-mail. All data were recorded and analysed anonymously. 
114 Chapter 6

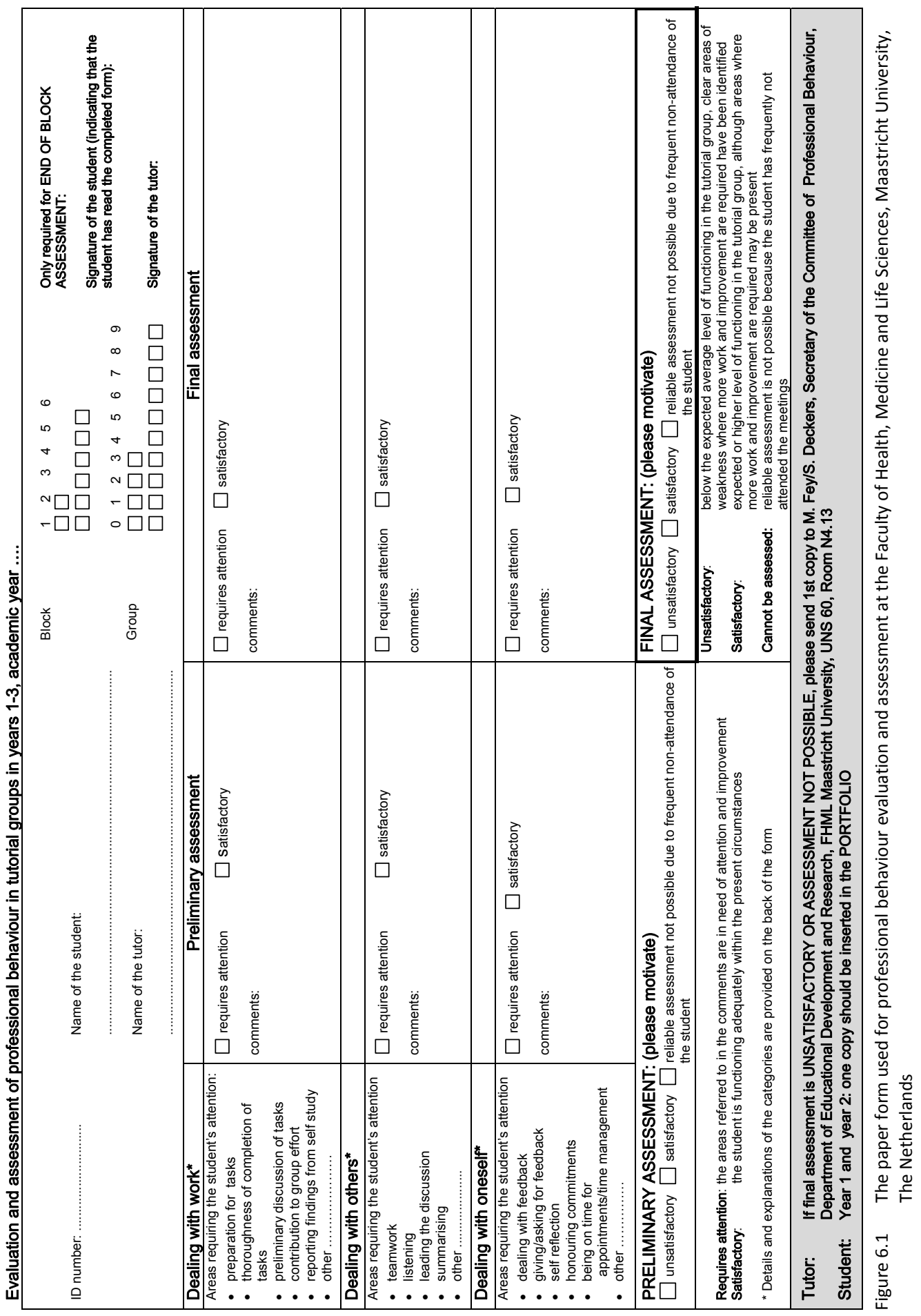




\section{Analysis}

All narrative comments were independently coded and analysed by two blinded researchers (WvM and SG). Units of comments consisting of one grammatical clause but covering different topics were considered to be different units of comments. They used five generally accepted feedback rules to label the units of comments as incorrect or correct feedback (Table 6.1) ${ }^{34,35}$. Since feedback should preferably meet as many criteria as possible, an aggregated score across all five feedback categories was constructed (total scores of 0-3 were considered unsatisfactory and requiring improvement; total scores of 4 and 5 were considered satisfactory). The researchers (WvM and SG) discussed any discrepancies in their coding until agreement was reached. The number and nature of the comments from the interim and final evaluations were compared between the web-based (intervention) group, and the paper-based (control) group using Pearson's Chi Square test. Independent samples T-testing was used to perform quantitative survey analysis of the questionnaire scores. SPSS 16.0.1 was used for the statistical analyse ${ }^{36}$. Effect sizes were computed where applicable as an indicator of the results' practical (clinical) relevance (independent of sample size). For between-group comparison of proportions $P_{p a p e r}$ and $P_{\text {web }}$, effect sizes (ES) were calculated according to

$$
E S=2\left|\arcsin \sqrt{p_{\text {web }}}-\arcsin \sqrt{p_{\text {paper }}}\right|
$$

For between-group comparisons of mean scores $m_{\text {paper }}$, and $m_{\text {web }}$, effect sizes $E S$ were calculated according to

$$
E S=\left|m_{\text {web }}-m_{\text {paper }}\right| / \sigma_{\text {paper }}
$$

Where $\delta_{\text {paper }}$ is the standard deviation in the paper-based group. $E S \cong 0.30$ was considered a small effect of negligible practical importance; ES $\cong 0.50$ was considered a medium effect of moderate practical importance, and $E S \cong 0.8$ was considered a large effect of considerable practical importance ${ }^{37}$.

Table 6.1 Commonly used feedback rules ${ }^{34,35}$

\begin{tabular}{cll}
\hline No. & Adequate feedback & Inadequate feedback \\
\hline 1. & is clear and concrete & is vague and general \\
2. & is constructive and positive & is destructive and negative \\
3. & is specific & is non-specific \\
4. & comments on behaviour & comments on personality \\
5. & is descriptive (formative) & is evaluative (summative) \\
\hline
\end{tabular}




\section{Results}

Of the 307 (198 females, 109 males) medical students enrolled in the second course of the second year, 150 were assigned to tutorial groups with even numbers (web-based group) and 157 to the tutorial groups with odd numbers (paper-based group). Since assessment of professional behaviour is mandatory, the participation rate was $100 \%$. We will first present the results of the quantitative and qualitative analyses of the narrative feedback provided at the interim and final assessment of professional behaviour in the two groups. After that we present the results for the feasibility, acceptability and perceived usefulness of the two assessment instruments.

\section{Analysis of the amount of feedback}

The total numbers of comments per category of professional behaviour for the interim and the final assessments are presented for the web-based and the paper-based group (Table 6.2). In the web-based group a mean of 4.5 invitations to provide feedback were sent by each student (standard deviation 3). The number of comments was significantly higher in this group than in the paper-based group for all three categories (dealing with work, others and oneself). However, at the final assessment the total number of comments relating to the category 'Dealing with oneself' had halved compared to the interim assessment and this decrease was mainly attributable to a marked decrease in the comments provided by the web-based group.

Table 6.2 The total number of comments per category of professional behaviour in the webbased and the paper-based group at the interim and final assessment

\begin{tabular}{|c|c|c|c|c|c|}
\hline & \multicolumn{5}{|c|}{ No. of comments ( $(\%)$ ) } \\
\hline & Total & $\begin{array}{l}\text { Paper- } \\
\text { based }\end{array}$ & $\begin{array}{l}\text { Web- } \\
\text { based }\end{array}$ & $\begin{array}{c}p \text {-value } \\
\chi^{2}\end{array}$ & $\begin{array}{c}\text { Effect } \\
\text { size }\end{array}$ \\
\hline \multicolumn{6}{|l|}{ Interim assessment } \\
\hline Dealing with work & $983(100)$ & $161(16.4)$ & $822(83.6)$ & $p<0.001$ & 0.76 \\
\hline Dealing with others & $692(100)$ & $105(15.2)$ & $587(84.4)$ & $p<0.001$ & 0.80 \\
\hline Dealing with oneself & $539(100)$ & $95(17.6)$ & $444(82.4)$ & $p<0.001$ & 0.73 \\
\hline \multicolumn{6}{|l|}{ Final assessment } \\
\hline Dealing with work & $455(100)$ & $132(29.0)$ & $323(71.0)$ & $p<0.001$ & 0.49 \\
\hline Dealing with others & $337(100)$ & $92(27.5)$ & $245(72.5)$ & $p<0.001$ & 0.49 \\
\hline Dealing with oneself & $227(100)$ & 77 (33.9) & $150(66.1)$ & $p<0.001$ & 0.35 \\
\hline
\end{tabular}

$\chi^{2}=$ Chi-Square

\section{Analysis of the quality of the feedback}

The results for the quality of feedback at the interim and the final assessments are presented for the categories of professional behaviour (dealing with work, others and oneself) as correct and incorrect in relation to the aggregated score 
on the five feedback rules (Table 6.3). The inter-rater agreement during primary coding was $89.9 \%$ (2902 out of 3233 comments).

Table 6.3 Number of correct and incorrect scores in the web-based and paper-based groups regarding the aggregated scores on the five feedback criteria for the categories of professional behaviour at the interim and final assessment

\begin{tabular}{|c|c|c|c|c|c|c|}
\hline \multicolumn{7}{|c|}{ Aggregated score } \\
\hline & \multicolumn{2}{|c|}{ Sufficient (n) } & \multicolumn{2}{|c|}{ Insufficient (n) } & \multirow[b]{2}{*}{$\begin{array}{c}\mathrm{p} \text {-value } \\
\chi^{2}\end{array}$} & \multirow[b]{2}{*}{$\begin{array}{l}\text { Effect } \\
\text { size }\end{array}$} \\
\hline & $\begin{array}{l}\text { Paper- } \\
\text { based }\end{array}$ & $\begin{array}{l}\text { Web- } \\
\text { based }\end{array}$ & $\begin{array}{l}\text { Paper- } \\
\text { based }\end{array}$ & $\begin{array}{l}\text { Web- } \\
\text { based }\end{array}$ & & \\
\hline \multicolumn{7}{|l|}{ Interim assessment } \\
\hline Dealing with work & 146 & 783 & 15 & 39 & 0.020 & 0.18 \\
\hline Dealing with others & 86 & 458 & 19 & 129 & 0.372 & na \\
\hline Dealing with oneself & 85 & 367 & 10 & 77 & 0.101 & na \\
\hline \multicolumn{7}{|l|}{ Final assessment } \\
\hline Dealing with work & 121 & 308 & 11 & 15 & 0.124 & na \\
\hline Dealing with others & 84 & 210 & 9 & 35 & 0.261 & na \\
\hline Dealing with oneself & 65 & 139 & 12 & 11 & 0.051 & na \\
\hline
\end{tabular}

na $=$ not applicable; $\chi^{2}=$ Chi-Square

When statistical significance was corrected for sample size no difference in the aggregated scores on all five feedback categories was found. Several differences of potential practical significance pertaining to the five generally accepted feedback rules were however found, all favouring paper-based assessment. The feedback in the web-based group pertaining to the categories 'Dealing with others' and 'Dealing with oneself' was for example more often unrelated to observed behaviour. However, in the view of the statistical 'multiple comparisons' problem, the statistical significance regarding the between-groups differences revealed by the individual analysis is questionable. Finally, the majority of comments relating to the category 'Dealing with oneself' consisted of descriptions of a student's attendance to the neglect of other aspects of personal functioning.

\section{Feasibility, acceptability and perceived usefulness}

The response to the questionnaire was $96 \%(143 / 157)$ in the paper-based group and $81 \%(121 / 150)$ in the 'web-based' group. Table 6.4 shows the mean scores per questionnaire item for the two groups. The differences between the groups were significant for all items and in favour of the paper-based form. The paper-based group yielded fourteen student comments on the use of the paper form. Nine comments emphasised the usefulness of the form, four offered suggestions for minor adaptations and one stated that the form was time consuming. The tutors did not comment on this form. The students in the webbased groups provided 179 comments (Table 6.5) and the tutors provided fifteen comments. The tutors emphasised the absence of interpersonal contact 
and the necessity of face-to-face contact during assessment of professional behaviour. They also thought that the web-based instrument was time consuming and they reported some technical problems (e.g. printing).

Table 6.4 Scores on the items of the questionnaire on the acceptability, feasibility and usefulness of web-based versus paper-based assessment of professional behaviour

\begin{tabular}{|c|c|c|c|c|c|c|c|}
\hline \multirow[t]{2}{*}{ No. } & \multirow[t]{2}{*}{ Questionnaire item } & \multicolumn{2}{|c|}{$\begin{array}{c}\text { Web-based PB } \\
\text { assessment }(n=121)\end{array}$} & \multicolumn{2}{|c|}{$\begin{array}{c}\text { Paper-based PB } \\
\text { assessment }(n=143)\end{array}$} & \multirow{2}{*}{$\begin{array}{l}\text { Web-based vs } \\
\text { paper-based } \\
\text { Significance* }^{*} \text { (p-value) } \\
\end{array}$} & \multirow[b]{2}{*}{$\begin{array}{l}\text { Effect } \\
\text { size }\end{array}$} \\
\hline & & Mean & $\begin{array}{l}\text { Standard } \\
\text { deviation }\end{array}$ & Mean & $\begin{array}{l}\text { Standard } \\
\text { deviation }\end{array}$ & & \\
\hline 1 & $\begin{array}{l}\text { The program was easy accessible } \\
\text { using the link }\end{array}$ & 4.19 & 1.16 & na & na & na & na \\
\hline 2 & The program/form was easy to use & 3.84 & 1.30 & 4.18 & 0.93 & 0.02 & 0.37 \\
\hline 3 & The program/form was clear & 3.53 & 1.32 & 4.15 & 0.92 & $<0.05$ & 0.67 \\
\hline 4 & $\begin{array}{l}\text { Completing/the program/form } \\
\text { contributed to self-reflection on my } \\
\text { personal function }\end{array}$ & 2.65 & 1.32 & 3.69 & 1.12 & $<0.05$ & 0.93 \\
\hline 5 & $\begin{array}{l}\text { The output (results, report) from } \\
\text { the program was/were clear }\end{array}$ & 2.61 & 1.2 & na & na & na & na \\
\hline 6 & $\begin{array}{l}\text { The tutor has used the program's } \\
\text { results (report)/ form as basis for } \\
\text { discussing professional behaviour } \\
\text { in the tutorial group }\end{array}$ & 2.27 & 1.56 & 4.20 & 0.96 & $<0.05$ & 2.01 \\
\hline 7 & $\begin{array}{l}\text { Discussing the program's results } \\
\text { (report)/completed form in the } \\
\text { tutorial group contributed to self } \\
\text { reflection }\end{array}$ & 2.18 & 1.28 & 3.89 & 0.98 & $<0.05$ & 1.74 \\
\hline 8 & $\begin{array}{l}\text { The program's results (report) } \\
\text { increased the usefulness of the } \\
\text { professional behaviour evaluation } \\
\text { in the tutorial group }\end{array}$ & 1.94 & 1.2 & na & na & na & na \\
\hline 9 & $\begin{array}{l}\text { I recognize the strengths and } \\
\text { weaknesses identified by my peers } \\
\text { and/or tutor }\end{array}$ & 2.93 & 1.08 & 3.96 & 0.93 & $<0.05$ & 1.11 \\
\hline 10 & $\begin{array}{l}\text { The time and effort needed to } \\
\text { complete the program/form were } \\
\text { worthwhile (agree }=1 / \text { disagree }=2 \text { ) }\end{array}$ & 1.85 & 0.70 & 1.26 & 0.70 & $<0.05$ & 0.84 \\
\hline 11 & $\begin{array}{l}\text { Time needed to complete the } \\
\text { program/form (in minutes) }\end{array}$ & 24.09 & 18.89 & 6.29 & 8.63 & $<0.05$ & 2.06 \\
\hline 12 & $\begin{array}{l}\text { Give a mark out of ten for ease of } \\
\text { use (whole mark, 1-10) }\end{array}$ & 6.57 & 1.69 & 7.60 & 1.21 & $<0.05$ & 0.85 \\
\hline \multirow[t]{2}{*}{13} & $\begin{array}{l}\text { Give a mark out of ten for the } \\
\text { usefulness of the evaluation of } \\
\text { professional behaviour (whole } \\
\text { mark, 1-10) }\end{array}$ & 4.55 & 1.98 & 7.00 & 1.46 & $<0.05$ & 1.68 \\
\hline & & No. & $\begin{array}{l}\text { Standard } \\
\text { deviation }\end{array}$ & No. & $\begin{array}{l}\text { Standard } \\
\text { deviation }\end{array}$ & $\begin{array}{c}\text { Significance* } \\
\text { (p-value) }\end{array}$ & $\begin{array}{l}\text { Effect } \\
\text { size }\end{array}$ \\
\hline 14 & Additional comments & 179 & na & 14 & na & na & na \\
\hline
\end{tabular}

Items 1 to 7 were answered using a 1 to 5 Likert scale; $1=$ completely disagree, $5=$ completely agree;

* = Independent samples T-test; na = not applicable 
Table 6.5 Remarks by students regarding web-based professional behaviour assessment

\begin{tabular}{|c|c|c|}
\hline Category & Description & No. of comments \\
\hline 1 & no added value & 28 \\
\hline 2 & difficult to use & 25 \\
\hline 3 & $\begin{array}{l}\text { difficulty with internet access, including late receipt of link } \\
\text { or report }\end{array}$ & 29 \\
\hline 4 & some questions need rephrasing & 26 \\
\hline 5 & $\begin{array}{l}\text { electronic process of professional behaviour assessment } \\
\text { too standardised }\end{array}$ & 14 \\
\hline 6 & time consuming & 13 \\
\hline 7 & hampers provision of feedback & 11 \\
\hline 8 & $\begin{array}{l}\text { rest (including privacy issues, requests for assessment of } \\
\text { professional behaviour of tutor, plea for paper-based } \\
\text { professional behaviour assessment }\end{array}$ & 16 \\
\hline 9 & $\begin{array}{l}\text { problems with report, such as print problems and the } \\
\text { presentation results }\end{array}$ & 10 \\
\hline 10 & $\begin{array}{l}\text { process of professional behaviour evaluation becomes } \\
\text { less personal, more distant }\end{array}$ & 7 \\
\hline
\end{tabular}

\section{Discussion}

Although other web-based approaches to assessment of professional behaviours have been studied ${ }^{28,29,38}$ as well as are contemporarily used ${ }^{27}$, this study is, to our knowledge, the first study to specifically address the amount and quality of feedback resulting from using such approach. The assessment method that is currently used at Maastricht medical school requires each student to reflect on their professional behaviour and requires all members of a tutorial group (tutor and students) to provide feedback on the professional behaviour of each student, which is then recorded by the tutor on the assessment form. This process was deliberately mimicked in the web-based instrument, which elicited feedback from students and tutor on the same three categories and items relating to professional behaviour that are included in the paper form.

The study reveals that the number of comments was significantly higher in the web-based group compared with the paper-based group. The quality of the feedback, however, did not parallel the quantitative increase. When considering the aggregated scores on the five feedback criteria no differences in quality of feedback was found between the groups. Nevertheless, the feedback provided by the web-based group showed poorer quality in relation to several feedback criteria (e.g. was unrelated to the observed behaviour) (Table 6.1). However, as previously mentioned, the real, statistical significance of these findings is questionable. 
Moreover, the survey results on acceptability, feasibility and usefulness of the instruments were strongly in favour of the paper form. It should be noted that this result might be partly due to technical difficulties that were experienced with the web-based instrument despite adequate technical preparation and extensive tutor and student instruction. However, even when these limitations are taken into account, the web-based instrument did not show an improvement in educational impact compared with the existing method of assessing professional behaviour.

Another striking finding, which is unrelated to the nature of the assessment instrument, was the emphasis on attendance in the feedback relating to the category 'Dealing with oneself' and the relative absence of feedback on other aspects of self-functioning. An earlier analysis of four years of experience at Maastricht with paper-based assessment of professional behaviour had yielded similar findings ${ }^{23}$. This suggests that the context (small group sessions) in the earlier years of medical school may be less suited to stimulate self-reflection ${ }^{23}$. Perhaps attendance and time management as measures of responsible behaviour should be evaluated separately from feedback on other aspects of professional behaviour, a suggestion that was also put forward during the plenary discussion at a recent symposium on professionalism ${ }^{23,39}$.

The results of this study cannot be compared to results reported in the literature, because no other published studies have addressed research questions regarding web-based instruments to assess professional behaviour comparable to the one studied herein. However, there are some published reports on the development and use of web-based assessment in general ${ }^{40,41}$. In one study, implementation of a web-based instrument resulted in a substantial reduction in administration and bureaucracy for course organisers and proved to be a valuable research tool, while students and teachers were overwhelmingly in favour of the new course structure ${ }^{40}$. Another study described a successful multi-institutional validation of a web-based core competency assessment system in surgery ${ }^{41}$. However, the transferability of these more general studies to web-based self- and peer- assessment of professional behaviour seems limited. Studies addressing the NBME's APB program however report comparable promising results, with improved faculty comfort and self-assessed skill in giving feedback about professionalism as an example $^{38}$. It seems therefore advisable to conduct further studies to examine the effectiveness and optimal use of web-based assessment of professional behaviour.

Although the literature pertaining to web-based assessment is sparse, the peer assessment literature provides evidence of the importance of anonymity, or at 
least confidentiality, for the acceptance of peer assessment ${ }^{18,19}$. That is why we used a semi-anonymous feedback procedure in the web-based assessment in this study. Although reliability can be enhanced by increasing the number of raters ${ }^{16,42}$, the desired number of raters may not be feasible or acceptable, for example due to time constraints. Consequently, in the current study we limited the number of peer raters to five randomly selected students ${ }^{16,42}$. It seems reasonable for medical schools to base the selection of peer raters on practical and logistical considerations ${ }^{20,43,44}$, since bias due to rater selection has been shown not to affect peer assessment results ${ }^{20}$. Although some anticipated problems could thus be adequately addressed, mention must be made of some remaining limitations of the current study.

\section{Study limitations}

In the preparation phase we were confronted with limited availability of tools for web-based multisource feedback. Because re-designing an existing tool proved costly, some (for the purpose of this study superfluous) features were left unchanged, and this may have influenced the results, for instance those relating to time investment. Furthermore, it cannot be excluded that the results were negatively affected by the participants' unfamiliarity with web-based assessment instruments, even though the implementation process was carefully prepared based on feedback from a pilot study. Ample time was spent on technical preparation and the participants received information and instruction on multiple occasions. Furthermore, the possibility of omitting redundant comments and concretizing comments before noting them by the tutor may have contributed to the lower number and/or the higher quality of the comments in the paper based group. Finally, automated data extraction only enabled feedback analysis at the level of the whole year group, although analysis of data at individual or tutorial group level would have been preferable.

\section{Conclusions}

The results revealed that a confidential web-based assessment instrument for professional behaviour yielded a significantly higher number of comments compared to the traditional paper-based assessment. The quality of the feedback obtained by the web-based instrument was comparable as measured by several generally accepted feedback criteria. However, judging by the questionnaire results students strongly favoured the use of the traditional paper-based method. The interpersonal nature of professional behaviour prompted comments that professional behaviour was eminently suitable for 'en-groupe', face-to-face discussion and assessment. Although teachers and 
students are nowadays preferably 'wired for learning' it seems that, so far, the development of modern, new professionalism does not necessarily require the use of advanced assessment technologies, although such new 'innovative' electronic and/or web-based assessment methods thus do result in more feedback of comparable quality. Their exact position among the currently used assessment armamentarium therefore needs to be subject of further study. 
Web-assisted assessment of professional behaviour

\section{References}

1. van Mook WN, de Grave WS, Wass V, O'Sullivan H, Zwaveling JH, Schuwirth LW, van der Vleuten CP. Professionalism: Evolution of the concept. Eur J Int Med 2009;20:e81-e4.

2. Papadakis MA, Teherani A, Banach MA, Knettler TR, Rattner SL, Stern DT, Veloski JJ, Hodgson CS. Disciplinary action by medical boards and prior behavior in medical school. $\mathrm{N}$ Engl J Med 2005;353:2673-82.

3. Papadakis MA, Arnold GK, Blank LL, Holmboe ES, Lipner RS. Performance during internal medicine residency training and subsequent disciplinary action by state licensing boards. Ann Intern Med 2008;148:869-76.

4. Cruess R, Mcllroy JH, Cruess S, Ginsburg S, Steinert Y. The professionalism mini-evaluation exercise: a preliminary investigation. Acad Med 2006;81(10 Suppl):S74-8.

5. Schuwirth LW, van der Vleuten CP. Changing education, changing assessment, changing research? Med Educ 2004;38:805-12.

6. van Mook WN, Gorter SL, O'Sullivan H, Wass V, Schuwirth LW, van der Vleuten CP. Approaches to professional behaviour assessment: tools in the professionalism toolbox. Eur $\mathrm{J}$ Int Med 2009;20:e153-7.

7. van der Vleuten CP, Schuwirth LW. Assessing professional competence: from methods to programmes. Med Educ 2005;39:309-17.

8. Cohen JJ. Professionalism in medical education, an American perspective: from evidence to accountability. Med Educ 2006;40:607-17.

9. Fowell SL, Bligh JG. Recent developments in assessing medical students. Postgrad Med J 1998; 74:18-24.

10. Singer PA, Robb A, Cohen R, Norman G, Turnbull J. Performance-based assessment of clinical ethics using an objective structured clinical examination. Acad Med 1996;71:495-8.

11. Asch E, Saltzberg D, Kaiser S. Reinforcement of self-directed learning and the development of professional attitudes through peer- and self-assessment. Acad Med 1998;73:575.

12. McKinstry B. BEME Guide No 10: A systematic review of the literature on the effectiveness of self-assessment in clinical education. http://www,bemecollaboration,org/beme/files/ BEME\%20Guide\%20No\%2010/BEMEFinalReportSA240108pdf (accessed October 10th 2008) 2007.

13. Eva KW, Cunnington JP, Reiter HI, Keane DR, Norman GR. How can I know what I don't know? Poor self assessment in a well-defined domain. Adv Health Sci Educ Theory Pract 2004;9:211-24.

14. Eva KW, Regehr G. Self-assessment in the health professions: a reformulation and research agenda. Acad Med 2005;80(10 Suppl):S46-54.

15. Rees C, Shepherd M. Students' and assessors' attitudes towards students' self-assessment of their personal and professional behaviours. Med Educ 2005;39:30-9.

16. Dannefer EF, Henson LC, Bierer SB, Haag M, Barclay C, Epstein RM. Peer assessment of professional competence. Med Educ 2005;39:713-22.

17. Evans R, Elwyn G, Edwards A. Review of instruments for peer assessment of physicians. BMJ Clinical research ed 2004;328:1240.

18. Shue CK, Arnold L, Stern DT. Maximizing participation in peer assessment of professionalism: the students speak. Acad Med 2005;80(10 Suppl):S1-5.

19. Arnold L, Shue CK, Kritt B, Ginsburg S, Stern DT. Medical students' views on peer assessment of professionalism. J Gen Intern Med 2005;20:819-24.

20. Lurie SJ, Nofziger AC, Meldrum S, Mooney C, Epstein RM. Effects of rater selection on peer assessment among medical students. Med Educ 2006;40:1088-97.

21. Lurie SJ, Nofziger AC, Meldrum S, Mooney C, Epstein RM. Temporal and group-related trends in peer assessment amongst medical students. Med Educ 2006;40:840-7.

22. Freedman JA, Lehmann HP, Ogborn CJ. Web-based peer evaluation by medical students. Acad Med 2000;75:539-40. 
23. van Mook WN, Van Luijk SJ, Fey-Schoenmakers MJ, Tans G, Rethans JJ, Schuwirth LW, van der Vleuten CP. Combined formative and summative professional behaviour assessment approach in the bachelor phase of medical school: a Dutch perspective. Med Teach. 2010;32:e517-31.

24. van Luijk SJ, Smeets SGE, Smits J, Wolfhagen IH, Perquin MLF. Assessing professional behaviour and the role of academic advice at the Maastricht Medical School. Medical Teacher 2000;22:168- 72.

25. van Mook WN, de Grave WS, Huijssen-Huisman E, de Witt-Luth M, Dolmans DH, Muijtjens AM, Schuwirth LW, van der Vleuten CP. Factors inhibiting assessment of students' professional behaviour in the tutorial group during problem-based learning. Med Educ 2007;41:849-56.

26. De Leng B. Wired for learning: How computers can support interaction in small group learning in higher education. Thesis Mediview, Maastricht ISBN 978-90-77201-35-0 2009.

27. National Board of Medical Examiners. Assessment of professional behaviors program. http://www.nbme.org/schools/apb/indexhtml; accessed September 24th 20102010.

28. Mazor K, Clauser BE, Holtman M, Margolis MJ. Evaluation of missing data in an assessment of professional behaviors. Acad Med 2007;82(10 Suppl):S44-7.

29. Mazor KM, Canavan C, Farrell M, Margolis MJ, Clauser BE. Collecting validity evidence for an assessment of professionalism: findings from think-aloud interviews. Acad Med 2008;83(10 Suppl):S9-12.

30. Project Team Consilium Abeundi van Luijk SJe. Professional behaviour: Teaching, assessing and coaching students. Final report and appendices. Mosae Libris 2005.

31. van Luijk S, Gorter R, Van Mook W. Promoting professional behaviour in undergraduate medical, dental and veterinary curricula in the Netherlands: evaluation of a joint effort. Medical Teacher 2010;32:733-9.

32. van Mook WN, van Luijk SJ, O'Sullivan H, Wass V, Harm Zwaveling J, Schuwirth LW, van der Vleuten CP. The concepts of professionalism and professional behaviour: Conflicts in both definition and learning outcomes. Eur J Int Med 2009;20:e85-e9.

33. Fingertips;http://www.fngtps.com/work.

34. Pendleton D, Schofield T, Tate P. A method for giving feedback. In: The consultation: an approach to learning and teaching Oxford: Oxford University Press 1984:68-71.

35. Branch WT, Jr., Paranjape A. Feedback and reflection: teaching methods for clinical settings. Acad Med 2002;77:1185-8.

36. SPSS I. SPSS 16.0.1. 2007.

37. Hojat M, Xu G. A visitor's guide to effect sizes: statistical significance versus practical (clinical) importance of research findings. Adv Health Sci Educ Theory Pract 2004;9:241-9.

38. Stark R, Korenstein D, Karani R. Impact of a 360-degree professionalism assessment on faculty comfort and skills in feedback delivery. J Gen Intern Med 2008;23:969-72.

39. Centre for Excellence in Developing Professionalism. Professionalism or Postprofessionalism? Four years of the Centre for Excellence. Liverpool, UK (chair H O'Sullivan) 2010.

40. Wheeler DW, Whittlestone KD, Smith HL, Gupta AK, Menon DK. A web-based system for teaching, assessment and examination of the undergraduate peri-operative medicine curriculum. Anaesthesia 2003;58:1079-86.

41. Tabuenca A, Welling R, Sachdeva AK, Blair PG, Horvath K, Tarpley J, Savino JA, Gray R, Gulley J, Arnold T, Wolfe K, Risucci DA. Multi-institutional validation of a web-based core competency assessment system. J Surg Educ 2007;64:390-4.

42. Ramsey PG, Wenrich MD, Carline JD, Inui TS, Larson EB, LoGerfo JP. Use of peer ratings to evaluate physician performance. JAMA 1993;269:1655-60.

43. Arnold L, Willoughby L, Calkins V, Gammon L, Eberhart G. Use of peer evaluation in the assessment of medical students. Journal of Medical Education 1981;56:35-42.

44. Arnold L, Stern D. Content and context of peer assessment. In: Measuring medical professionalism Stern, DT (ed) Oxford University Press, New York, 2006 ISBN-13: 978-0-19517226-3 2006. 


\section{Chapter 7}

Fellows' in intensive care medicine views on professionalism and how they learn it

Walther NKA van Mook, Willem S de Grave, Simone L Gorter, Arno MM Muijtjens, Jan Harm Zwaveling, Lambert W Schuwirth, Cees PM van der Vleuten 


\section{Abstract}

\section{Introduction}

The emphasis on the importance of professionalism in a recent CoBaTrICE paper was impressive. However, insight in the elements of professionalism as perceived relevant for intensivists from the fellows' view, and how these are taught and learned, is limited.

\section{Objectives and methods}

A nationwide study was performed. In 2007-2008 all ICM fellows $(n=90)$ were sent a questionnaire containing the following questions regarding training in professionalism (7-point Likert scale (1=very inadequate, $7=$ very adequate)): Which elements are perceived to be important in intensivists' daily practice (38 items, cat. I)? Which methods of learning and teaching are recognised (16 items, cat. II)? Which methods of teaching and learning are considered especially useful (16 items, cat. III)? Finally, the perceived quantity and quality of formal and informal learning methods, as well as the responsible organisational body was studied. Data were analysed using SPSS 15.0.

\section{Results}

Response was $75.5 \%$ ( $n=68)$, mean age 34 yrs. Regarding Elements, scores on virtually all items were high. The factor 'striving for excellence' explained half the variance. Two other aspects, 'Teamwork' and 'Dealing with ethical dilemmas', were identified. Regarding Methods, three dimensions, 'formal curriculum', 'private and academic experiences' and 'role modelling', proved important. The factor 'formal curriculum' explained most of the variance. Regarding Usefulness the same factors emerged with variance now mainly explained by the factor Private and academic experiences. In both categories the items 'observations in daily practice' and 'watching television programmes like ER and House' were the highest and lowest scoring items (5.99 and 5.81, and 2.69 and 2.49 respectively). Mean scores regarding the quantity of formal and informal teaching were 4.06 and 4.58 (range 1.841 and 1.519). For the quality of teaching figures were 4.22 and 4.52 (range 1.659 and 1.560 respectively). 54 suggestions for improvement of teaching were documented. The need for some form of formal teaching of professionalism aspects as well as for feedback was most frequently mentioned $(n=19$ and 16). The local training centres are considered and should remain pivotal for teaching professionalism issues $(n=17$ and 28$)$.

\section{Conclusions}

Almost all elements of professionalism were considered relevant for intensivists' daily practice. Although formal teaching methods regarding professionalism aspects are easily recognised in daily practice, learning by personal experiences and informal ways quantitatively plays a more important, and more valued role. Qualitative comments nevertheless stress the need for providing and receiving (solicited and unsolicited) feedback, thereby requesting expansion of formal teaching methods. The local training centres (should continue to) play a major role in teaching professionalism, although an additional role for the (inter)national intensive care organisations remains. 


\section{Introduction}

Medical schools increasingly pay attention to formal instruction in and assessment of professionalism and professional behaviour ${ }^{1}$. Its cause is multifactorial in nature, to which societal changes including higher demands on doctors by peers and patient(organisations), quality assurance and improvement, and guarding of patient safety all contribute ${ }^{2}$. Evidence that physicians facing disciplinary action from medical licensing boards had a higher incidence of unprofessional behaviour in medical school ${ }^{3}$ and internal medicine residency training ${ }^{4}$ strengthens the need for this attention. Likewise, developmental shifts towards competency-based residency programs are observed $^{5-9}$, in attempts to "assist future specialists in responding to the innumerable challenges as health-care providers-...- while providing the best specialty care"5-9. All major organisational bodies, including the Accreditation Council for Graduate Medical Education (ACGME) in the USA ${ }^{10}$, and the Royal College of Physicians and Surgeons in $\mathrm{Canada}^{8}$, have developed such competency frameworks. The Central College for Training of Medical Specialists (CCMS) in the Netherlands adopted the latter Canadian Medical Education Directions for Specialists (CanMEDS) competency domains ${ }^{8}$ in $2005^{9}$. Aspects of professionalism are therein mainly (but not solely) represented in one of the seven CanMEDS competency domains ('the professional'). Competencies for an international training program in intensive care medicine (ICM) were identified in $2006^{11}$. The emphasis on the importance of professionalism was impressive. It was given a prominence equal to technical ability, demonstrating the value accorded to attitudes and behaviours, particularly communication skills and self-regulation ${ }^{11}$. On this basis, reforms in postgraduate medical education have already taken place. Most reports on professionalism during residency training focus on aspects of implementation of teaching and assessment ${ }^{6,12}$, rather than investigating what residents actually mean by professionalism and how they learn $i^{13}$. Likewise, the insight in the elements of professionalism as perceived relevant for intensivists from the ICU residents' (also called fellows) view, and the way these are taught and/or learned in the intensive care unit, is currently limited ${ }^{11}$. Further elucidation of these elements and exploration of educational experiences and needs are prerequisites for (re-)designing residency training programs regarding this topic. A nationwide study among ICM fellows was therefore performed in the Netherlands. 


\section{Purpose of the present study}

The present study investigates

1. the view of ICM fellows on the relevance of elements of professionalism and professional behaviour, and

2. how ICM fellows learn about professional behaviour and develop professional behaviour during their training

\section{Methods}

The Dutch Society for Intensive Care Medicine (NVIC) as well as the local chairs of the ICM training centres approved the study. At the end of 2007 and beginning of 2008 all ICM fellows $(n=90)$ were sent a letter of introduction outlining the purpose of the study, the methods used to assure confidentiality, an invitation to participate, the questionnaire, and instructions for returning the questionnaire. Non-responders were approached by mail, e-mail or telephone. Participation was voluntary. No financial compensation was provided for the time invested to complete the questionnaire.

\section{Research tool}

The initial questionnaire was developed by Brownell et al. ${ }^{13}$. From the author, permission for its use was obtained, after which it was translated into Dutch and expanded using literature derived data $^{2}$. Subsequently it was field tested on intensive care fellows (no longer in training at the time of the study) and faculty $(n=4)$ before being finalized. The questionnaire collected demographic and contextual data that included each fellow's training level, specialty, gender, and age. The subsequent questions were answered using a 7-point Likert scale (1: very inadequate, 7: very adequate). First, it was studied which elements of professional behaviour were perceived to be important to an intensivist in his/her everyday practice (38 items, aspect I). Then, methods of learning and teaching professional behaviour as recognized during their program were explored (16 items, aspect II). Subsequently exploration of methods of teaching and learning the respondents considered especially useful in their training program was performed (16 items, aspect III). Then, the respondents were asked to indicate their opinion regarding the quantity and quality of formal as well as informal methods of learning professionalism in their training program and whether they perceived this time and quality adequate and sufficient. The respondents were finally asked to indicate their degree of comfort in explaining 
the meaning of professionalism to a more junior trainee. Ample space for comments was provided at the end of each aspect studied. The respondents were then asked to list suggestions by which teaching of professionalism issues could be improved in their program, and to name the medical body they believed was and/or should be to be most concerned with matters of professionalism in the ICM programs in the Netherlands. An existing questionnaire was used: exploratory factor analysis was nevertheless used as a measure of construct validity. For each aspect in the questionnaire an exploratory factor analysis with Varimax rotation with Kaiser normalization was performed for data reduction and to gain insight in the structure underlying the items. Internal consistency for the resulting scales was determined employing Cronbach $\alpha$. The $\alpha$-coefficient ranges from 0 to $1^{14}$. The higher the score, the more consistent the scale is. Nunnaly indicated that 0.7 is an acceptable internal consistency coefficient, but lower thresholds are sometimes used ${ }^{15}$. For our instrument, alpha thus ranges from satisfactory to excellent (see Table 7.1).

Table 7.1 Factors identified, number of items, and percentage of variance explained by each factor for the three aspects ('Relevant elements', 'Recognized methods', and 'Useful methods' (no. of cases $=67$ )

\begin{tabular}{|c|c|c|c|c|c|}
\hline $\begin{array}{l}\text { Factor } \\
\text { no. }\end{array}$ & Factor description & $\begin{array}{l}\text { Percentage } \\
\text { of variance } \\
\text { explained by } \\
\text { factor }\end{array}$ & $\begin{array}{l}\text { No. of } \\
\text { items per } \\
\text { factor }\end{array}$ & $\begin{array}{l}\text { Mean } \\
\text { item } \\
\text { score }\end{array}$ & $\begin{array}{c}\text { Cronbach } \\
\alpha\end{array}$ \\
\hline \multicolumn{6}{|c|}{ Elements of professionalism relevant for intensivists } \\
\hline 1. & Striving for excellence & 48.1 & 12 & 6.17 & 0.94 \\
\hline 2. & Communication and teamwork & 5.4 & 8 & 6.39 & 0.92 \\
\hline 3. & $\begin{array}{l}\text { Responsibility (towards patient care } \\
\text { and teaching) }\end{array}$ & 4.9 & 5 & 5.82 & 0.86 \\
\hline 4. & Ethical issues & 4.4 & 6 & 5.80 & 0.84 \\
\hline \multicolumn{6}{|c|}{ Recognition of methods of teaching and learning professionalism } \\
\hline 1. & Formal curriculum & 26.7 & 6 & 4.08 & 0.79 \\
\hline 2. & Private experience and activities & 14.2 & 6 & 4.19 & 0.78 \\
\hline 3. & $\begin{array}{l}\text { Experiential learning and role } \\
\text { modelling }\end{array}$ & 11.1 & 4 & 5.54 & 0.64 \\
\hline \multicolumn{6}{|c|}{ Perceived usefulness of methods of teaching and learning professionalism } \\
\hline 1. & Private and academic experiences & 26.0 & 6 & 3.91 & 0.75 \\
\hline 2. & Formal curriculum & 16.5 & 4 & 3.91 & 0.80 \\
\hline 3. & $\begin{array}{l}\text { Experiential learning and role } \\
\text { modelling }\end{array}$ & 12.8 & 4 & 5.62 & 0.81 \\
\hline
\end{tabular}




\section{Analysis of the data}

For the quantitative data descriptive statistics (means, standard deviations, and item variances) were computed. One of the investigators (WvM) independently carried out an initial content analysis of the qualitative comments. In an iterative process the investigators (WvM, WdG, SG) reached consensus regarding the classification and subsequently these data were rank ordered. The data were analysed using SPSS $15.0^{16}$.

\section{Results}

\section{Demographics and contextual data}

All (eight) Dutch training centres participated. The overall response was $75.5 \%$ $(n=68)$. The fellows' mean age was 34 years (range 29-44). 60\% were males. $55.4 \%$ of fellows were primarily trained in internal medicine, $32.2 \%$ in anaesthesiology, $4.4 \%$ in surgery, and the remainder evenly divided over neurology, cardiology and paediatrics. Thirty-four percent of participants were in the first semester of their program, and the other participants were approximately evenly distributed over the remaining three semesters (the maximum duration of residency training in ICM is two years depending on the primary specialty).

\section{Factor and item analysis}

The common interpretation of the items associated with a factor determined its description. The factors, the associated items and qualitative feedback received on each of the aspects, will consecutively be discussed in the sections below. The overall mean scores (over all items) and the highest and lowest scoring item per aspect are shown in Table 7.2.

\section{Elements of professionalism relevant to intensivists}

Three factors, Striving for excellence, Communication and teamwork, Responsibility and Ethical issues, were distinguished (see Table 7.1). Mean scale scores all exceeded 5.8. Communication and teamwork were considered most relevant for intensivists. Scores on virtually all items relating to this aspect were high (see Table 7.2). The highest mean score was on the item: 'Displaying responsibility for example by admitting errors'. The lowest mean score was on the item 'Altruism, placing the interests of patient and family before one's own'. 


\section{Recognition of learning and teaching methods of professionalism}

Three factors were identified, indicated as the Formal curriculum, Private and academic experiences and Role modelling (see Table 7.1). The most relevant factor was Role modelling. The other mean scale scores were relatively low. Observations in daily practice without formally scheduled discussion of the events was the highest scoring item within this factor (see Table 7.2). Among the qualitative comments, 6 related to role modelling and the informal curriculum, 4 to feedback. Furthermore, two respondents noted that norms and values are largely present at start of ICM training, either due to prior upbringing or prior medical specialist training. Additionally, extracurricular learning (e.g. personal experience), formal teaching (e.g. courses), teaching of self-reflection skills, implementation of workplace based learning and professionalism assessment were each mentioned once.

Table 7.2 Overview of overall item score per aspect and items with the highest and lowest scores per aspect

\begin{tabular}{|c|c|c|c|c|c|}
\hline $\begin{array}{l}\text { Factor } \\
\text { no. }\end{array}$ & Factor description & $\begin{array}{r}\text { Item } \\
\text { no. }\end{array}$ & Item & $\begin{array}{l}\text { Mean } \\
\text { item } \\
\text { score }\end{array}$ & $\begin{array}{l}\text { Standarc } \\
\text { deviation }\end{array}$ \\
\hline \multirow{2}{*}{\multicolumn{6}{|c|}{$\begin{array}{l}\text { Elements of professionalism relevant for intensivists } \\
\text { Al/ items }\end{array}$}} \\
\hline & & & & & \\
\hline & & & $\begin{array}{l}\text { 'Displaying responsibility for example } \\
\text { by admitting errors' }\end{array}$ & 6.62 & 0.60 \\
\hline & & 9 & $\begin{array}{l}\text { 'Altruism, placing the interests of } \\
\text { patient and family before one's own' }\end{array}$ & 4.32 & 1.61 \\
\hline \multirow[t]{3}{*}{1} & Striving for excellence & & & 6.17 & 0.71 \\
\hline & & 25 & 'Correct, non-falsified record keeping' & 6.43 & 0.65 \\
\hline & & 22 & 'Adequate way of providing feedback' & 5.79 & 1.18 \\
\hline \multirow[t]{3}{*}{2.} & Communication and & & & 6.39 & 0.62 \\
\hline & & 34 & $\begin{array}{l}\text { 'Explaining in a for the patient } \\
\text { understandable way' }\end{array}$ & 6.50 & 0.61 \\
\hline & & 36 & $\begin{array}{l}\text { 'Adequate and respectful communication } \\
\text { with nurses and other colleagues' }\end{array}$ & 6.31 & 0.68 \\
\hline \multirow[t]{3}{*}{3.} & Responsibility (towards & & & 5.82 & 0.83 \\
\hline & & 35 & $\begin{array}{l}\text { 'Listening to the patients, and providing } \\
\text { them with the opportunity to give their own } \\
\text { opinions and thoughts' }\end{array}$ & 6.31 & 0.76 \\
\hline & & 41 & $\begin{array}{l}\text { 'Having knowledge of legal aspects of ICU } \\
\text { care, and acting accordingly' }\end{array}$ & 5.56 & 1.03 \\
\hline \multirow[t]{3}{*}{4.} & Ethical issues & & & 5.80 & 0.73 \\
\hline & & 12 & $\begin{array}{l}\text { 'Correctly dealing with medical issues } \\
\text { regarding usefulness of admittance of } \\
\text { a patient' }\end{array}$ & 6.34 & 0.75 \\
\hline & & 11 & $\begin{array}{l}\text { 'Making choices or decisions related to } \\
\text { aspects of social justice' }\end{array}$ & 5.16 & 1.34 \\
\hline
\end{tabular}


Table 7.2 (continued)

\begin{tabular}{lcc}
\hline $\begin{array}{l}\text { Factor Factor description } \\
\text { no. }\end{array}$ & $\begin{array}{c}\text { Item Item } \\
\text { no. }\end{array}$ & $\begin{array}{l}\text { Mean Standard } \\
\text { item deviation } \\
\text { score }\end{array}$ \\
\hline
\end{tabular}

Recognition of methods of teaching and learning professionalism All items formally scheduled discussion of the events)'

58 'Watching television programmes, e.g. $\quad 2.69 \quad 1.65$ ER, House'

1. Formal curriculum

49 'Attending ICU symposia and congresses'

$4.08 \quad 1.24$

48 'Reading articles regarding $\quad 2.93 \quad 1.81$ professionalism in medical education journals'

2. Private and academic experiences

55 'Contacts with patients and their family' $6.00 \quad 0.85$

58 'Watching television programmes, e.g. $\quad 2.69 \quad 1.65$ ER, House'

experiential learning

53 'Observations in daily practice (without

$5.99 \quad 0.95$ formally scheduled discussion of the events)'

62 'Contact with negative role models $\quad 5.31 \quad 1.43$ regarding professionalism'

Perceived usefulness of methods of teaching and learning professionalism All items

71 'Observations in daily practice (without $\quad 5.81 \quad 1.22$ formally scheduled discussion of the events)'

$\begin{array}{llll}77 & \text { 'Watching television programmes, e.g. } & 2.49 & 1.57\end{array}$ ER, House' experiences

72 'Reflection on personal functioning and development (stimulated by supervisor)'

$\begin{array}{llll}77 & \text { 'Watching television programmes, e.g. } & 2.49 & 1.57\end{array}$

2. Formal curriculum ER, House'

67 'Attending ICU symposia and congresses'

$\begin{array}{llll}66 & \text { 'Reading articles regarding } & 3.06 & 1.79\end{array}$ professionalism in medical education journals'

3. Role modelling and experiential learning

71 'Observations in daily practice (without formally scheduled discussion of the events)'

80 'Contact with negative role models regarding professionalism' 


\section{Usefulness of learning and teaching methods of professionalism}

Factor analysis revealed the same three factors as identified for the former aspect (see Table 7.1). Role modelling was the most relevant factor, whereas mean item scores for the other factors were relatively low (see Table 7.2). 8 additional qualitative remarks were documented: 3 related to provision of feedback, 2 to the informal curriculum and role modelling, and 1 to extracurricular learning, upbringing and stimulation of self-reflection each.

\section{Explaining professionalism, and satisfaction regarding teaching}

The degree of comfort in explaining the meaning of professionalism to a (more junior) trainee was expressed in a mean score of 5.24 (range 1.12). The mean scores regarding the quantity of the formal and informal teaching and learning curriculum regarding professionalism were 4.06 and 4.58 (range 1.84 and 1.52). For the quality of teaching figures were 4.22 and 4.52 (range 1.66 and 1.56 respectively). 54 suggestions for improvement of teaching and learning of professionalism were documented. The need for some form of formal teaching of professionalism aspects as well as the need for feedback were most frequently mentioned ( $n=19$ and 16 respectively). Some fellows suggested the need for assessment regarding professionalism $(n=2)$. More attention for role modelling, addressing the informal curriculum and institutional culture changes were other suggestions ( $n=6,2$ and 4). Stimulation of self-reflection, mentoring, and (more frequent and thorough) use of error(s) were also mentioned ( $n=1,2$ and 2).

\section{Who should pay attention?}

The organisations or institutions that are perceived to currently pay most attention to professionalism issues are the local training centres $(n=17)$, and the United Committee of Intensivists (GIC, committee organising the monthly training day, $n=5$ ). Other national and international organisations (NVIC, ESICM, CoBaTrICE, KNMG) are only occasionally, if ever mentioned. When fellows are inquired about the preferable, ideal situation, the local training centres' responsibility would become even more pivotal $(n=28)$. The NVIC was also frequently mentioned $(n=10)$, followed by the KNMG $(n=6)$, and the MSRC $(n=5)$.

\section{Discussion}

So far, studies on professionalism concerned groups of family medicine and paediatric $^{17}$, surgical and paediatric ${ }^{18}$, and internal medicine, neurology and 
family practice residents ${ }^{19}$. To our knowledge, this is the first study to address the relevance of different elements of professionalism, and the ways they are perceived to be (currently and preferably) learned during ICM training. The results are discussed below.

\section{Elements of professionalism relevant for intensivists}

A// factors had high mean item scores (see Tables 7.1 and 7.2). Striving for excellence related to having a knowledge base and good technical skills on the one, and, to aspects of communication, feedback and record keeping on the other (see Table 7.2). Two other aspects, Teamwork and Dealing with ethical dilemmas, were identified in the remaining factors. Communication and Teamwork was identified as the most relevant factor (see Tables 7.1 and 7.2). Residents indeed seem to develop their perception of the meaning of professionalism in the context they work in ${ }^{13}$. Intensivists also fulfil a pivotal role in the multidisciplinary team involved in intensively caring for patients in the $\mathrm{ICU}^{6}$. Teamwork, leadership, good communication and management skills become increasingly important with increasing complexity and size of organisations ${ }^{20,21}$. Demonstrated professional excellence could thus potentially be used as one parameter contributing to selection of candidates for promotion (e.g. department leadership). Furthermore, ethical dilemmas, e.g. concerning end-of-life decisions, and limitation of treatment, also form an essential part of the intensivists' daily practice ${ }^{11}$.

A previous study of a group of internal medicine, neurology and family practice residents reported that most aspects of professionalism were valued ${ }^{19}$. Findings from this study also perhaps underscore that most of these elements are idealistic, difficult to challenge aspects of behavior ${ }^{22}$. The highest scoring item was Responsibility related to admitting errors. In a recent study, irresponsibility (e.g. unreliable attendance at clinic and not following up on activities related to patient care) and diminished capacity for self-improvement were aspects of unprofessional behaviour found to be predictive of subsequent disciplinary actions by US licensing boards ${ }^{3}$. Multidisciplinary discussion of (near) errors seems a useful method for in-depth discussions, relating both to medical and professionalism aspects of care. Sections on the use of error in renowned medical journals serve the same purpose ${ }^{23}$.

In contrast to these high item scores, altruism was given a lower mean score In a comparable study altruism was also not highlighted ${ }^{13}$. It is interesting to speculate whether this reflects changes in doctors' attitudes for example caused by the increasing importance of quality of lives outside medicine, more common part time practice, and limitation of duty hours ${ }^{2}$. In this perspective the 
finding that time pressure and associated constraints present a barrier to the incorporation of professionalism into daily practice gains importance ${ }^{19,20,24}$. On the other hand duty hour changes may promote residents' well-being, personal development, reflection, and teamwork ${ }^{19,20}$.

\section{Recognition of methods of teaching and learning professionalism}

The factor identified as most relevant was Role modelling. The highest scoring item was related to informal, experiential learning through role modelling (Item Observation in practice, see Table 7.2). This is in accordance with the fact that in residency programs the 'professionalism rules' are mostly unwritten and discovered by trial and error, often by following examples ${ }^{25}$. This so-called 'hidden' or 'informal' curriculum, plays a more important role in the clinical compared to the pre-clinical training phases ${ }^{26}$. In the contemporary intensive medicine programs ICU fellows less frequently recognise formally scheduled activities for teaching and learning professionalism.

\section{Perceived usefulness of methods of teaching and learning professionalism}

The identified factors were the same as for the former aspect. The factor Role modelling and experiential learning was perceived as the most useful method of learning professionalism. Role modelling is of paramount importance in the clinical setting, and aids developing values, attitudes and professional behaviour $^{27}$. By acknowledging that we all can still name those physicians who played a pivotal exemplary role during our own training, the significance of role models becomes self evident. However, the act of role modelling alone is insufficient, it should be combined with reflection on action followed by discussion to truly learn about professionalism ${ }^{28}$. The highest scoring item indeed relates to the role of reflection on performance, and stresses the importance of a motivated and stimulating supervisor (see Table 7.2). In contrast, the low absolute mean scores for some of the other items, resulted in an overall low mean item score for this factor.

\section{Quantity and quality of formal as well as informal ways of teaching professionalism}

The mean scores regarding the quantity as well as the quality of teaching methods of professionalism in contemporary intensivist training programs were somewhat higher for the informal than for the formal methods. This finding is supported by the finding that many fellows voiced the need for increasing formal training in professionalism issues, as well as by the relatively low overall mean item score on the factor Formal curriculum for the aspect Recognition. 
Who should pay attention to professionalism issues during intensive care medicine training?

In contemporary ICM training, the local training centres are perceived to be responsible for teaching and learning of professionalism, whereas national organisations play an additional role. The Dutch ICM fellows would however prefer an even greater role for the local training centres, whereas a minority sees a, more limited, role for (inter)national organisations as well. Adaptation of the core competency framework as developed for an international training programme in ICM to national and local needs thus is a possibility ${ }^{11}$.

\section{Limitations of the study}

Training in intensive care medicine in the Netherlands may differ from that in other European countries. Replicating the study elsewhere in Europe would be necessary to establish its generalisability. Awaiting these studies and despite this diversity, some of the current findings may nevertheless apply to other European settings as well.

\section{Conclusions}

The results from this nationwide survey among ICM fellows in the Netherlands can be used for designing and adapting those parts of the ICM training programs relating to professionalism. Almost all elements of professionalism were considered relevant for the intensivists' daily practice. Learning by informal ways in the so called 'hidden curriculum' qualitatively and quantitatively plays a more important role and are more highly valued than formal methods. Qualitative comments nevertheless stress the need for providing and receiving (solicited and unsolicited) feedback, thereby requesting expansion of formal methods of teaching and learning. The local training centres play a major role regarding teaching and learning professionalism aspects, and by the opinion of the trainees, this responsibility should be further expanded, although an additional role for the (inter)national intensive care organisations should remain. 


\section{References}

1. Stephenson AE, Adshead LE, Higgs RH. The teaching of professional attitudes within UK medical schools: reported difficulties and good practice. Med Educ 2006;40:1072-80.

2. van Mook WN, de Grave WS, Wass V, O'Sullivan H, Zwaveling JH, Schuwirth LW, van der Vleuten CP. Professionalism: Evolution of the concept. Eur J Int Med 2009;20:e81-e4.

3. Papadakis MA, Teherani A, Banach MA, Knettler TR, Rattner SL, Stern DT, Veloski JJ, Hodgson CS. Disciplinary action by medical boards and prior behavior in medical school. $\mathrm{N}$ Engl J Med 2005;353:2673-82.

4. Papadakis MA, Arnold GK, Blank LL, Holmboe ES, Lipner RS. Performance during internal medicine residency training and subsequent disciplinary action by state licensing boards. Ann Intern Med 2008;148:869-76.

5. Lee AG, Beaver HA, Boldt HC, Olson R, Oetting TA, Abramoff M, Carter K. Teaching and assessing professionalism in ophthalmology residency training programs. Surv Ophthalmol 2007;52:300-14.

6. Edelstein SB, Stevenson JM, Broad K. Teaching professionalism during anesthesiology training. J Clin Anesth 2005;17:392-8.

7. Rowley BD, Baldwin DC, Jr., Bay RC, Cannula M. Can professional values be taught? A look at residency training. Clin Orthop Relat Res 2000:110-4.

8. The Royal College of Physicians and Surgeons in Canada. http://rcpscmedicalorg/canmeds/ indexphp, accessed October 10th 2006.

9. Medische Vervolgopleidingen.nl. http://www.medischevervolgopleidingen.nl/pages/ content aspx?content=10010000000029_2_10000000001651\&contentcode=competentiesspecialist, accessed October 10th 2006.

10. Accreditation Council for Graduate Medical Education. ACGME Outcome Project enhancing residency education throught outcomes assessment: General competencies. 1999;Accessed Febr 13th 2006: http://www.acgme.org/outcome/comp/compFull.asp.

11. Bion JF, Barrett $\mathrm{H}$. Development of core competencies for an international training programme in intensive care medicine. Intensive Care Med 2006;32:1371-83.

12. Klein EJ, Jackson JC, Kratz L, Marcuse EK, McPhillips HA, Shugerman RP, Watkins S, Stapleton FB. Teaching professionalism to residents. Acad Med 2003;78:26-34.

13. Brownell AK, Cote $L$. Senior residents' views on the meaning of professionalism and how they learn about it. Acad Med 2001;76:734-7.

14. Cronbach LJ. Coefficient alpha and the internal structure of tests. Psychometrika 1951;16:297-334.

15. Nunnaly J. Psychometric theory. New York: McGraw-Hill ISBN: 0070474656 1978;2nd edition.

16. SPSS I. SPSS 12.0.1. 2003.

17. Wagner P, Hendrich J, Moseley G, Hudson V. Defining medical professionalism: a qualitative study. Med Educ 2007;41:288-94.

18. Ephgrave K, Stansfield RB, Woodhead J, Sharp WJ, George T, Lawrence J. The resident view of professionalism behavior frequency in outstanding and "not outstanding" faculty. Am J Surg 2006;191:701-5.

19. Ratanawongsa N, Bolen S, Howell EE, Kern DE, Sisson SD, Larriviere D. Residents' perceptions of professionalism in training and practice: barriers, promoters, and duty hour requirements. J Gen Intern Med 2006;21:758-63.

20. Page DW. Professionalism and team care in the clinical setting. Clin Anat 2006;19:468-72.

21. van Luijk S, van Oosterhout W, van Mook WNKA. Professionaliteit: het toetsen en leren van de professionele rol. Submitted: Netherlands Journal of Medical Education 2008.

22. van Mook WN, van Luijk SJ, O'Sullivan H, Wass V, Harm Zwaveling J, Schuwirth LW, van der Vleuten CP. The concepts of professionalism and professional behaviour: Conflicts in both definition and learning outcomes. Eur J Int Med 2009;20:e85-e9.

23. Horton R. The uses of error. Lancet 1999;353:422-3.

24. Charap M. Reducing resident work hours: unproven assumptions and unforeseen outcomes. Ann Intern Med 2004;140:814-5. 
25. Stern DT, Papadakis M. The developing physician--becoming a professional. N Engl J Med 2006;355:1794-9.

26. Hafferty FW, Franks R. The hidden curriculum, ethics teaching, and the structure of medical education. Acad Med 1994;69:861-71.

27. Wright SM, Kern DE, Kolodner K, Howard DM, Brancati FL. Attributes of excellent attendingphysician role models. N Engl J Med 1998;339:1986-93.

28. Branch WT Jr, Kern D, Haidet P, Weissmann P, Gracey CF, Mitchell G, Inui T. The patientphysician relationship. Teaching the human dimensions of care in clinical settings. JAMA 2001;286:1067-74. 


\section{Chapter 8}

Intensive care medicine trainees' perception of professionalism: a qualitative study

Walther NKA van Mook, Willem S de Grave, Simone L Gorter, Jan Harm Zwaveling, Lambert W Schuwirth, Cees PM van der Vleuten Anaesthesia Intensive Care 2011;39:107-115 


\section{Abstract}

\section{Introduction}

The Competency-Based Training program in Intensive Care in Europe (CoBaTrICE) identified 12 competency domains. Professionalism was given a prominence equal to technical ability. However, little information pertaining to fellows' views on professionalism is available.

\section{Objectives and methods}

A nationwide qualitative study was performed. The moderator asked participants to clarify the terms professionalism and professional behaviour, and to explore the questions 'How do you learn the mentioned aspects?' and 'What ways of learning do you find useful or superfluous?' Qualitative data analysis software (MAXQDA2007) facilitated analysis using an inductive coding approach.

\section{Results}

35 fellows across eight groups participated.

Professionalism themes relevant to intensivists: The themes most frequently addressed were communication, keeping distance and boundaries, medical knowledge and expertise, respect, teamwork, leadership and organization and management. Medical knowledge, expertise and technical skills seem to become more tacit when training progresses.

Teaching and learning professionalism: Topics can be categorised into the themes workplacebased learning, by gathering practical experience, by following examples and receiving feedback on action, including learning from own and others' mistakes. Formal teaching courses (e.g. communication) and scheduled sessions addressing professionalism aspects were also valued.

\section{Conclusions}

The emerging themes considered most relevant for intensivists were adequate communication skills, and keeping boundaries with patients and relatives. Professionalism is mainly learned 'on the job' from role models in the ICU. Formal teaching courses and sessions addressing professionalism aspects were nevertheless valued, and learning from own and others' mistakes was considered especially useful. Self-reflection as a starting point for learning professionalism was stressed. 


\section{Introduction}

Professional behaviour is receiving increasing attention in medical education today $^{1,2}$. This development is partly driven by evidence that physicians facing disciplinary action from medical licensing boards have a higher incidence of unprofessional behaviour in medical school $^{3}$ and during internal medicine residency training ${ }^{4}$. All major organizational bodies, including the Accreditation Council for Graduate Medical Education in the US, the Royal College of Physicians and Surgeons in Canada, and the General Medical Council in the UK, have developed competency frameworks for undergraduate and graduate training, all of which emphasize professionalism ${ }^{5-7}$. Developed under the aegis of the European Society of Intensive Care Medicine (ESICM), the CompetencyBased Training program in Intensive Care in Europe (CoBaTrICE) includes twelve competency domains for intensive care medicine $(\mathrm{ICM})^{8}$. Emphasis on professionalism was considerable, with equal prominence to technical ability ${ }^{8}$. There is general agreement that a learning-oriented environment is of vital importance for graduate training, while there are clear possibilities for improvement in this area ${ }^{9-11}$. One of the preliminary steps in designing appropriate measures to improve the quality of graduate training in ICM is to identify aspects of professionalism in the ICU as a learning environment. Currently, little is known about how ICM trainees see the role of professionalism in their training ${ }^{8,12,13}$. In order to remedy this, we conducted a nationwide qualitative focus group study to investigate ICM trainees' interpretations of professionalism and their views on their training in this respect.

\section{Methods}

\section{Study context}

ICM training in the Netherlands takes the form of fellowships based in eight, mostly academic, teaching hospitals and lasting one to two years, depending on trainees' prior specialty training. The study was approved by the Dutch Society of Intensive Care Medicine (NVIC) and the chairs of all training centres. In 2008, focus group interviews were conducted during site visits to the participating hospitals. The interviews were scheduled on days when a maximum number of fellows could participate. No further pre-selection was performed. We invited 35 fellows out of the Dutch national total of ninety at the time of the study (mean age 34 years, 55\% internal medicine, 32\% anaesthesiology and $13 \%$ surgery, neurology, cardiology, and paediatrics), all of them agreed to take part. Focus group size ranged from three to six fellows. 
Sessions lasted from ninety minutes to two hours and all participants consented to digital audio recording of the discussions. One or two moderators (WdG and/or SG), each with ample experience in conducting focus group studies but with no personal or professional experience in intensive care, guided the discussion, took notes, and asked questions to clarify points where necessary ${ }^{14,15}$. Before the actual interview commenced, one moderator explained the procedure, guaranteed full confidentiality, and created an open and non-threatening atmosphere. The moderator opened the discussion by asking the participants to clarify their interpretations of the terms professionalism and professional behaviour. Next, the participants were asked to explore the following key questions: 'How did/do you learn about the notions you just described?' and 'Which ways of learning did you find especially useful or irrelevant?' The moderators asked no other questions except when this was deemed necessary to clarify participants' rationales.

\section{Focus groups}

Focus group interviews are a particularly appropriate method to study poorly understood or ill-defined topics ${ }^{16}$, and their use in research in medical education and medicine is increasing ${ }^{17}$. Krueger describes focus group interviews as "carefully planned discussions designed to obtain perceptions on a defined area of interest as a means of qualitative data collection"17. Purposive sampling is used to compose groups that are 'focused' on the issue of interest. An experienced moderator creates a climate in which participants feel encouraged to engage and exchange feelings, views, and ideas about an issue $^{16}$.

\section{Analysis}

The interviews were analyzed using qualitative data analysis software $(M A X Q D A 2007)^{18}$. In this explanatory case study we used an approach similar to that of grounded theory as developed by Glaser and Strauss, which proposes a systematic approach to collecting and analyzing qualitative data ${ }^{19}$ using principles of open, axial, and selective coding ${ }^{20}$. The analysis commenced while data collection was still in progress to enable inclusion of new topics and aspects that emerged during the discussions. WvM analyzed all the transcripts. After assigning codes to all remarks (open coding), he used axial coding to rename and reorganize the codes into themes. This process was repeated by WdG and/or SG to crosscheck the coding system. Next, connections between the themes were explored and defined, and this resulted in a reorganization of the themes into more abstract categories (selective coding). The authors (WvM, WdG, SG) discussed the results until consensus was reached. The results are presented for each of the themes that emerged 
from the analysis. Illustrative citations are included, with letters and number in parentheses to identify the training centre and participant in question.

\section{Results}

\section{Professionalism themes relevant to intensivists}

The themes most frequently discussed by all the participating groups were: communication; keeping a professional distance and setting boundaries; medical knowledge and expertise; and respect, teamwork, leadership, organization, and management (Table 8.1). Commitment, self-reflection, empathy, and respect also received frequent and extensive attention during the discussions.

Table 8.1 Overview of 'Professionalism and professional behaviour themes', and 'Contributors to learning' as identified by intensive medicine fellows

\begin{tabular}{|c|c|c|c|c|}
\hline \multicolumn{3}{|c|}{$\begin{array}{l}\text { Professionalism and professional behaviour } \\
\text { themes }\end{array}$} & \multicolumn{2}{|c|}{$\begin{array}{l}\text { Contributors to learning about professionalism } \\
\text { and development of professional behaviour }\end{array}$} \\
\hline No. & Themes & $\begin{array}{l}\text { requency } \\
\text { of } \\
\text { ccurrence }\end{array}$ & Contributors to learning & $\begin{array}{c}\text { Frequency } \\
\text { of } \\
\text { occurrence }\end{array}$ \\
\hline 1. & Communication & 240 & Feedback & 89 \\
\hline 2. & $\begin{array}{l}\text { Keeping distance/respecting } \\
\text { boundaries }\end{array}$ & 167 & Work-based learning & 81 \\
\hline 3. & Medical knowledge and expertise & se 76 & Role modelling & 75 \\
\hline 4. & Respect & 48 & Formal teaching courses & 43 \\
\hline 5. & Teamwork & 45 & $\begin{array}{l}\text { Institutional culture, teaching } \\
\text { climate and leadership }\end{array}$ & 34 \\
\hline 6. & Organization and management & 42 & $\begin{array}{l}\text { Workplace-based assessment of } \\
\text { professionalism }\end{array}$ & 33 \\
\hline 7. & Empathy, sympathy & 31 & Discussions with colleagues & 30 \\
\hline 8. & Leadership & 28 & $\begin{array}{l}\text { Multidisciplinary meetings and } \\
\text { handovers }\end{array}$ & 27 \\
\hline 9. & Self reflection & 24 & Learning from mistakes & 27 \\
\hline 10. & Technical skills & 15 & Self-reflection & 23 \\
\hline 11. & $\begin{array}{l}\text { Commitment (including to } \\
\text { teaching) }\end{array}$ & 14 & $\begin{array}{l}\text { Context (situation as } \\
\text { encountered) }\end{array}$ & 22 \\
\hline 12. & Norms and values & 14 & Private experiences & 16 \\
\hline 13. & Attitude & 13 & Prior upbringing & 11 \\
\hline 14. & Patient centeredness & 12 & Television series & 11 \\
\hline 15. & Honesty & 11 & Inborn quality & 9 \\
\hline 16. & Appearance & 9 & Prior medical school training & 6 \\
\hline 17. & Altruism & 8 & Prior residency training & 5 \\
\hline 18. & Responsibility & 8 & $\begin{array}{l}\text { Reading (medical) journals or } \\
\text { books }\end{array}$ & 4 \\
\hline 19. & Reliability & 7 & Portfolio and mentoring & 4 \\
\hline 20. & Accountability & 5 & & \\
\hline 21. & Discipline & 2 & & \\
\hline 22. & Humour & 2 & & \\
\hline
\end{tabular}


Communication was discussed extensively, with a considerable portion of discussion time being devoted to (participants' experiences with) disrespectful communication by physicians. Less attention was paid to communication with nursing and other health care staff, but great importance was attached to communication with patients and their relatives. Related subtopics were the importance of explaining medical issues clearly, the need for regular and scheduled meetings, and keeping an open mind in approaching patients and their relatives (Citation 8.1).

Citation 8.1: "In the past years, a lot of emphasis has come to be placed on communication in medicine. Before, attention was limited. Of course everybody knows the example of the senior surgeon, the textbook example of how things should not be done". (A-R1)

Discussions on keeping an appropriate distance and setting boundaries were mainly concerned with physicians' relationships with patients and patients' relatives. An important issue was the potential negative impact on the doctorpatient relationship when a physician fails to maintain an appropriate professional distance. Balancing one's personal and professional life was a related issue. The topic of altruism arose only in this context: it could be difficult at times to maintain an appropriate level of altruism in one's work when faced with competing professional and personal obligations (Citation 8.2).

Citation 8.2: "...A young man had been cared for in the ICU of our department for a very long time. One morning his father showed up to call on his son, dressed in pyjamas and carrying his toilet bag under his arm. When this happened I thought this is really overstepping the mark, I have to tell him this is not acceptable. At such moments, boundaries have to be set". (F-R1)

Medical knowledge and medical expertise (applying medical knowledge) were frequent topics of discussion, mostly in relation to legal, cultural, and ethical issues in the ICU. The major topics related to awareness of the limitations of one's medical expertise and end-of-life decisions and withholding further treatment.

The fourth group of themes concerned teamwork, organization, management, and leadership, mainly in the context of working in a multidisciplinary ICU team and, to a lesser extent, working with colleagues from other specialties (Citation 8.3). 
Citation 8.3: "...When considering aspects of professionalism that are characteristic of the ICU, I particularly think of working in a team... .....I think coordination and working with others in a team is an important task". (H-R3).

Finally, commitment, empathy, respect, and self-reflection featured prominently in the discussions. Respect related mainly to patients - approaching them with an open attitude and respecting their dignity and privacy - but also to medical colleagues, nurses and other healthcare workers (Citation 8.4).

Citation 8.4: "...Recently, however, two patients were admitted....one of which had been sedated for at least three weeks. When she was finally taken off the ventilator, one of her first questions was: "Does the gentleman in the next bed have a new liver already?" So, this illustrates... how much privacy-sensitive and not-for-others information is discussed publicly". (G-R2)

Figure 8.1 gives an overview of the themes of professionalism with relevance to intensivists.

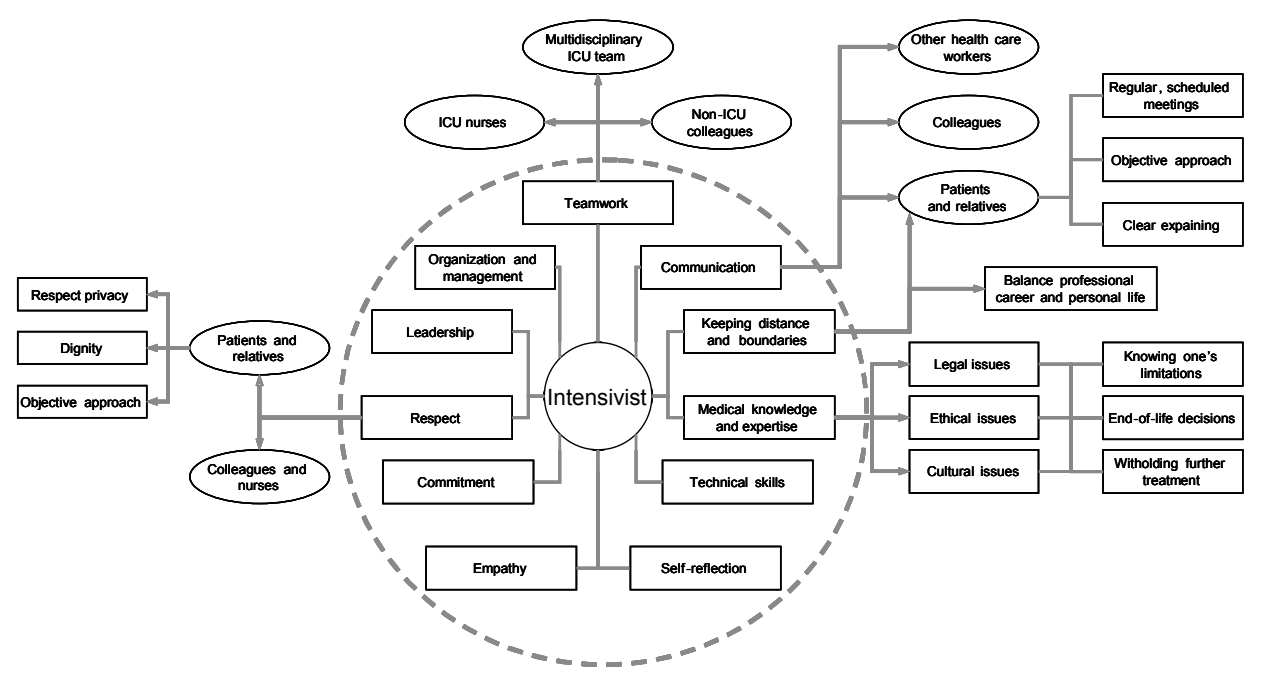

Figure 8.1 Overview of professionalism themes perceived relevant for intensivists

\section{Learning about professionalism and the development of professional behaviour}

Table 8.1 lists aspects that were discussed frequently in relation to learning about professionalism and professional behaviour. Although many fellows thought that professionalism included aspects reflecting inborn qualities or 
characteristics, which are modified by upbringing, medical education and training, and personal experiences, they looked upon learning in relation to professionalism as a process that continues throughout all stages of medical training. The topics dealing with the development of professionalism during ICM training can be categorized under the following themes: work-based learning, learning from practical experiences, learning from examples and from feedback on actions, including learning from one's own and others' mistakes.

The apprenticeship model and role modelling remain the hallmarks of clinical teaching. The participants discussed positive role models more extensively than negative ones (Citation 8.5).

Citation 8.5: “....When you learn, for example, from a colleague whom you admire and you observe him talking to patients' relatives and you think 'Hey, the way he is handling this, this is really excellent, I am going to use that too', I think this is how it works. The bottom line is that this is how you first learned to communicate from you father and mother. Why? Not because they were excellent teachers, but simply because you were around them a lot, looked up to them, and just learned by observing them". (A-R2)

Work-based assessment of professional behaviour was highly valued as a driving force for learning, and many fellows advocated it strongly. Feedback from supervisors and colleagues was highly valued as well, and fellows advocated that it should be actively solicited if it was not provided routinely (Citation 8.6).

Citation 8.6: "...A mini-CEX (short clinical evaluation exercise) can focus on medical knowledge and expertise, but also on professionalism issues. It is clearly an option to say you do the conversation with the family, while I observe your professional behaviour". (E-R2)

Habitual or stimulated self-reflection (e.g. by feedback, portfolio, mentoring), and learning from one's own and others' mistakes were considered powerful stimulators of professionalism learning (Citation 8.7).

Citation 8.7: “.. discussing things that went wrong and holding others (colleagues) accountable for their mistakes. I think doctors have a very large blind spot there". (A-R3)

Residents' experiences of situations and events are affected by the context in which they occur. The institutional culture and teaching climate are part of this context (Citation 8.8). 
Citation 8.8: "..but everybody is very approachable for consultations"...(D-R1) "Yes, I agree that the atmosphere is very good anyway, which makes work quite enjoyable and lowers the threshold for asking questions". (D-R4)

In addition to work based learning, formal courses (e.g. communication in relation to organ donation) and scheduled sessions on professionalism were also considered important. Furthermore, formal multidisciplinary meetings and debriefings (but also informal discussions with colleagues) were frequently mentioned as daily recurring situations in which professionalism issues were addressed and learning took place.

An overview of how professionalism aspects are learned and how professional behaviour is developed is provided in Figure 8.2.

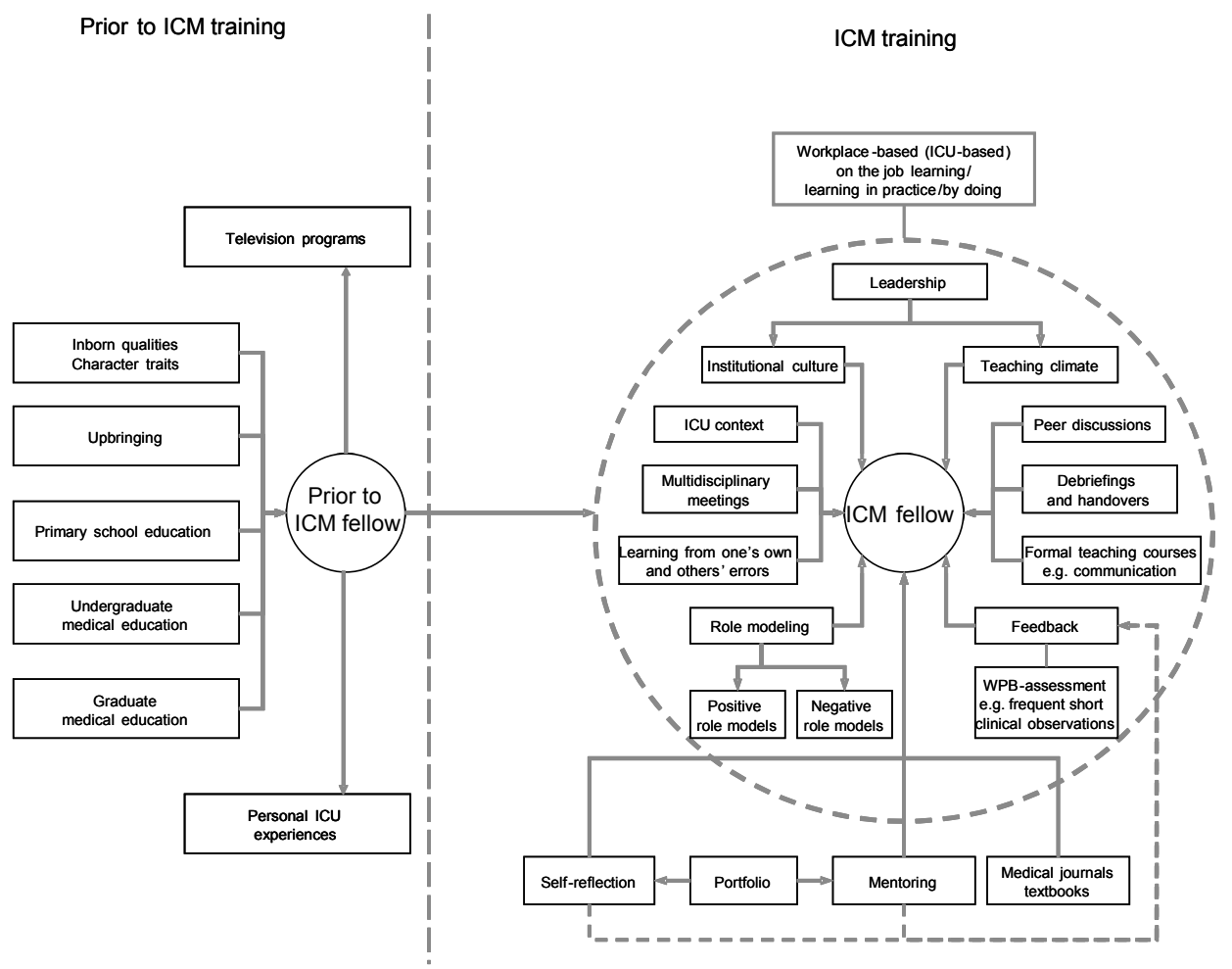

Figure 8.2 Overview of learning about professionalism and development of professional behaviour by intensive care medicine fellows 


\section{Discussion}

To our knowledge, so far only one study has addressed the development of ICM fellows' professional behaviour ${ }^{13}$, while other studies on professionalism involved more diverse groups of residents ${ }^{12,21-26}$. We conducted a nationwide qualitative focus group study to elicit fellows' perceptions regarding the relevance of different themes of professionalism and how they learned about professionalism during ICM training. We will discuss these themes in light of the relevant literature.

\section{Professionalism themes that are relevant to intensivists}

Appropriate communication skills are essential for physicians to meet their professional commitments ${ }^{27}$. Good communication skills and the ability to listen are considered crucial aspects of professionalism ${ }^{27-34}$. A major task of ICU physicians is to provide patients' relatives with appropriate information that is conveyed clearly and compassionately ${ }^{33,34}$. The results of the current study underscore this view. However, good communication alone is not sufficient: physicians should have excellent clinical, practical as well as communication skills to serve their patients well.

Contrary to our expectations, the participants in our study did not perceive medical knowledge and technical skills as the key aspects of intensivists' professional behaviour ${ }^{8}$. One might speculate whether this reflects a process whereby knowledge and technical skills become increasingly tacit and finally turn into implicit components of professionalism as residents advance in their development and gain more independence ${ }^{35,36}$. Our findings could indicate that ICM fellows have largely mastered the technical dimensions of tacit knowledge (know-how, expertise) during prior specialist training, whereas the specific environment of the ICU catalyzes the development of other aspects, including the cognitive dimensions of tacit knowledge, beliefs, perceptions, values, and emotions. The ICU is an arena 'par excellence' in which many ethical dilemmas are played out and encountered by fellows on a daily basis, such as those arising in relation to end-of-life decisions and limitation and withdrawal of treatment ${ }^{8}$. While medical ethics may sensitize, raise awareness, and promote reflection ${ }^{37}$, factors like overtime, fatigue, hunger and everyday ICU stress may interfere with demands of morality, a phenomenon termed 'akrasia', ${ }^{38}$.

The topic of setting boundaries featured prominently in the focus group interviews, mainly in relation to patients and their relatives. On the one hand evaluations of relatives' needs were considered a source of important information which could be used to improve relatives' comprehension, 
satisfaction and attitudes ${ }^{33,39}$, but, on the other hand, dilemmas like 'staying within the lines' and 'watching your step ${ }^{40,41}$ were seen as potential problems for physicians and nurses alike, which could arise during the long-term care of patients in the ICU setting. 'Setting boundaries' was also, but to a lesser extent, related to colleagues and to balancing personal and professional life. Altruism was almost exclusively discussed in connection with boundaries, which might reflect recent changes in physicians' attitudes, such as the growing emphasis on one's quality of life outside medicine, an increase in part time work, and the limitation of duty hours ${ }^{42}$. The literature identified time pressure as a barrier to incorporating professionalism in daily practice ${ }^{23,43,44}$, but at the same time suggested that reduced working hours could promote fellows' well-being, personal development, reflection, and teamwork ${ }^{23,43}$, which are also important aspects of professionalism. An earlier study among family physicians showed that most respondents struggled to prevent their professional work from intruding too much on their personal life. The authors of that study concluded that it is important for physicians to acknowledge and address this infringement of work life on one's private sphere in order to prevent physician burnout and premature retirement from clinical practice ${ }^{45}$. More education on boundaries and relationships was also deemed necessary in a study among psychiatry residents ${ }^{46}$.

Teamwork and leadership were also stressed. Prior research, including studies in intensive care, have shown that teamwork can reduce mortality, improve clinical care and patient satisfaction, and contain costs at the same time ${ }^{47-49}$. Organizations like the Royal College of Physicians have formulated recommendations on leadership and teamwork ${ }^{50,51}$.

\section{Learning about professionalism issues by intensive care fellows}

A substantial part of the focus group discussions was devoted to learning 'at work', learning from interactions within the complex clinical practice ${ }^{52}$. The participants in our study regarded feedback as a powerful stimulus for learning and recommended asking for feedback if supervisors did not provide it of their own accord. Feedback and subsequent reflection were considered of paramount importance in learning about professionalism in the workplace. Reflection can be fostered by discussing critical incidents with relevance to professional behaviour, events that are experienced as difficult, and unexpected results of personal actions (see below) ${ }^{53}$. The impact of supervisors as role models thus remains significant ${ }^{54-57}$. Apart from 'learning by doing', formal training courses (e.g. in communication, feedback, and management) were also appreciated. 
Institutional leadership and institutional culture were perceived as important factors in promoting professionalism. Indeed, unprofessional behaviour is frequently encountered in practice ${ }^{58}$. One might get the impression 'good students, bad schools ${ }^{, 59}$ : our actions in practice need to be congruent with our rhetoric $^{60}$. Approaches to transform institutional culture vary ${ }^{61-66}$, but strong institutional leadership is essential ${ }^{63}$. Excellence in professionalism might be used as an adjunct parameter in selecting candidates for leadership positions.

The fellows suggested multidisciplinary discussion of (near-)errors as a useful method to promote discussion of both medical and professionalism aspects of care. The University of Washington, and The Lancet for example have set mechanisms in place to facilitate learning from errors ${ }^{66,67}$.

\section{Limitations of the study}

Our data may not be representative of the entire group of Dutch ICM fellows, even though the number of participants was relatively large. Furthermore, differences between European ICM training programs likely restrict the findings' generalisability. Although some of the current findings could apply to other European settings as well, replication of this study in different settings will have to shed further light on this issue. Strengths of the study are the use of experienced moderators, whose lack of ICM experience safeguarded against bias, and the fact that the analysis was performed iteratively and independently.

\section{Conclusions}

The professionalism themes that ICM fellows consider particularly relevant to intensivists are: adequate communication skills and setting boundaries in relationships with patients and their relatives. While these themes are not unique to ICM, the specific ICM context and their experiences as members of a multidisciplinary ICU team substantially influenced the ICM fellows' perceptions of professionalism. Furthermore, the development of professionalism appeared to be a continuous process during ICM training, unlike the acquisition of medical knowledge, expertise and procedural skills, which seem to become increasingly tacit as students advance in competence. Professionalism is mainly absorbed and learned 'on the job' from role models. Formal courses and sessions on professionalism were also valued, while the fellows thought it was particularly useful to learn from their own and others' errors. Self-reflection was emphasized as a starting point for learning around professionalism. It can be stimulated through assessment, structured feedback and use of portfolios. Guidelines for the latter are currently being developed within the CoBaTrICE project $^{68}$. 


\section{References}

1. Stephenson AE, Adshead LE, Higgs RH. The teaching of professional attitudes within UK medical schools: reported difficulties and good practice. Med Educ 2006;40:1072-80.

2. Lee AG, Beaver HA, Boldt HC, Olson R, Oetting TA, Abramoff M, Carter K. Teaching and assessing professionalism in ophthalmology residency training programs. Surv Ophthalmol 2007;52:300-14.

3. Papadakis MA, Teherani A, Banach MA, Knettler TR, Rattner SL, Stern DT, Veloski JJ, Hodgson CS. Disciplinary action by medical boards and prior behavior in medical school. N Engl J Med 2005;353:2673-82.

4. Papadakis MA, Arnold GK, Blank LL, Holmboe ES, Lipner RS. Performance during internal medicine residency training and subsequent disciplinary action by state licensing boards. Ann Intern Med 2008;148:869-76.

5. Accreditation Council for Graduate Medical Education. ACGME Outcome Project enhancing residency education throught outcomes assessment: General competencies. 1999;Accessed Febr 13th 2006: http://www.acgme.org/outcome/comp/compFull.asp.

6. The Royal College of Physicians and Surgeons in Canada. http://rcpscmedicalorg/ canmeds/indexphp, accessed October 10th 2006.

7. General Medical Council. Tomorrow's Doctors: Education Outcomes and standards for undergraduate medical education. ISBN: 978-0-901458-36-0 2009.

8. Bion JF, Barrett $\mathrm{H}$. Development of core competencies for an international training programme in intensive care medicine. Intensive Care Med 2006;32:1371-83.

9. Hoff TJ, Pohl H, Bartfield J. Creating a learning environment to produce competent residents: the roles of culture and context. Acad Med 2004;79:532-9.

10. Brown J, Chapman T, Graham D. Becoming a new doctor: a learning or survival exercise? Med Educ 2007;41:653-60.

11. Teunissen PW. Unravelling learning by doing. Thesis Amsterdam ISBN 978-90-9023787-9 2009.

12. Brownell AK, Cote L. Senior residents' views on the meaning of professionalism and how they learn about it. Acad Med 2001;76:734-7.

13. van Mook WN, de Grave WS, Gorter SL, Muijtjens AM, Zwaveling JH, Schuwirth LW, van der Vleuten CP. Fellows' in intensive care medicine views on professionalism and how they learn it. Int Care Med 2010; 36:296-303.

14. Gorter S, Scherpbier A, Brauer J, Rethans JJ, van der Heijde D, Houben H, van der Vleuten $\mathrm{C}$, van der Linden S. Doctor-patient interaction: standardized patients' reflections from inside the rheumatological office. The Journal of Rheumatology 2002;29:1496-500.

15. Visschers-Pleijers AJ, Dolmans DH, de Grave WS, Wolfhagen $I H$, Jacobs JA, van der Vleuten CP. Student perceptions about the characteristics of an effective discussion during the reporting phase in problem-based learning. Med Educ 2006;40:924-31.

16. Kitzinger J. Qualitative research. Introducing focus groups. BMJ Clinical research ed 1995;311:299-302.

17. Krueger RA. Focus groups. A practical guide for applied research. ISBN-10 0803955677 1994.

18. MAXQDA. Verbi Gmbh, Marburg, Germany 2007.

19. Strauss A, Glaser B. The discovery of grounded theory. Strategies for qualitative research. Chicago Aldine de Gruyter ISBN 02023026011967.

20. Boeije H. Analysis in qualitative research 2009;London: Sage (ISBN 978184787007 0).

21. Wagner $P$, Hendrich J, Moseley G, Hudson V. Defining medical professionalism: a qualitative study. Med Educ 2007;41:288-94.

22. Ephgrave K, Stansfield RB, Woodhead J, Sharp WJ, George T, Lawrence J. The resident view of professionalism behavior frequency in outstanding and "not outstanding" faculty. Am J Surg 2006;191:701-5. 
23. Ratanawongsa N, Bolen S, Howell EE, Kern DE, Sisson SD, Larriviere D. Residents' perceptions of professionalism in training and practice: barriers, promoters, and duty hour requirements. J Gen Intern Med 2006;21:758-63.

24. Rowley BD, Baldwin DC, Jr., Bay RC, Cannula M. Can professional values be taught? A look at residency training. Clin Orthop Relat Res 2000:110-4.

25. Reed DA, West CP, Mueller PS, Ficalora RD, Engstler GJ, Beckman TJ. Behaviors of highly professional resident physicians. JAMA 2008;300:1326-33.

26. Haurani MJ, Rubinfeld I, Rao S, Beaubien J, Musial JL, Parker A, Reickert C, Raafat A, Shepard A. Are the communication and professionalism competencies the new critical values in a resident's global evaluation process? J Surg Educ 2007;64:351-6.

27. Whitcomb ME. Communication and professionalism. Patient Educ Couns 2000;41:137-44.

28. Hodges B, Turnbull J, Cohen R, Bienenstock A, Norman G. Evaluating communication skills in the OSCE format: reliability and generalizability. Med Educ 1996;30:38-43.

29. Rees C, Sheard C, McPherson A. Medical students' views and experiences of methods of teaching and learning communication skills. Patient Educ Couns 2004;54:119-21.

30. Schnabl GK, Hassard TH, Kopelow ML. The assessment of interpersonal skills using standardized patients. Acad Med 1991;66(9 Suppl):S34-6.

31. Lewin LO, Cole-Kelly K, Greenfield M. A year-long course for third-year students on ethics, professionalism, and communication. Acad Med 2001;76:511.

32. Buchanan D, Rohr L, Kehoe L, Glick SB, Jain S. Changing attitudes toward homeless people. J Gen Intern Med 2004;19:566-8.

33. Azoulay E, Pochard F, Chevret S, Lemaire F, Mokhtari M, Le Gall JR, Dhainaut JF, Schlemmer B; French FAMIREA Group. Meeting the needs of intensive care unit patient families: a multicenter study. American journal of respiratory and critical care medicine 2001;163:135-9.

34. Angus DC. Charting (and publishing) the boundaries of critical illness. American Journal of Respiratory and Critical Care Medicine 2005;171:938-9.

35. Sturmberg JP, Martin CM. Knowing--in medicine. J Eval Clin Pract 2008;14:767-70.

36. Wyatt JC. Management of explicit and tacit knowledge. J R Soc Med 2001;94:6-9.

37. Pellegrino ED. Professionalism, profession and the virtues of the good physician. Mt Sinai $J$ Med 2002;69:378-84.

38. Huddle TS. Viewpoint: teaching professionalism: is medical morality a competency? Acad Med 2005;80:885-91.

39. Molter NC. Needs of relatives of critically ill patients: a descriptive study. Heart Lung 1979;8:332-9.

40. Holder KV, Schenthal SJ. Watch your step: nursing and professional boundaries. Nurs Manage 2007;38:24-9.

41. Sheets VR. Staying in the lines. Nurs Manage 2000;31:28-33.

42. van Mook WN, de Grave WS, Wass V, O'Sullivan $\mathrm{H}$, Zwaveling JH, Schuwirth LW, van der Vleuten CP. Professionalism: Evolution of the concept. Eur J Int Med 2009;20:e81-e4.

43. Page DW. Professionalism and team care in the clinical setting. Clin Anat 2006;19:468-72.

44. Charap M. Reducing resident work hours: unproven assumptions and unforeseen outcomes. Ann Intern Med 2004;140:814-5.

45. Miedema B, Easley J, Fortin P, Hamilton R, Tatemichi S. Crossing boundaries: family physicians' struggles to protect their private lives. Canadian family physician Medecin de Famille Canadien 2009;55:286-7 e5.

46. Lapid M, Moutier C, Dunn L, Hammond KG, Roberts LW. Professionalism and ethics education on relationships and boundaries: psychiatric residents' training preferences. Acad Psychiatry 2009;33:461-9.

47. Veloski JJ, Hojat M. Measuring specific elements of professionalism: empathy, teamwork and lifelong learning. In: Measuring medical professionalism Stern, DT (ed) Oxford University Press, New York, 2006 ISBN-13: 978-0-19-517226-3 2006.

48. Knaus WA, Draper EA, Wagner DP, Zimmerman JE. An evaluation of outcome from intensive care in major medical centers. Ann Intern Med 1986;104:410-8. 
49. Gibson SJ, Martin SM, Johnson MB, Blue R, Miller DS. CNS-directed case management. Cost and quality in harmony. J Nurs Adm 1994;24:45-51.

50. Council GM. Tomorrow's doctors. Recommendations on undergraduate medical education. 2003.

51. Tallis RC. Doctors in society: medical professionalism in a changing world. Clin Med 2006;6:7-12.

52. Teunissen PW, Scheele F, Scherpbier AJ, van der Vleuten CP, Boor K, van Luijk SJ, van Diemen-Steenvoorde JA. How residents learn: qualitative evidence for the pivotal role of clinical activities. Med Educ 2007;41:763-70.

53. Boenink AD. Teaching and learning reflection on medical professionalism (thesis). Gildeprint Drukkerijen BV, Enschede 2006;ISBN 90-8659-031-4.

54. Wright S, Wong A, Newill C. The impact of role models on medical students. J Gen Intern Med 1997;12:53-6.

55. Wright SM, Carrese JA. Excellence in role modelling: insight and perspectives from the pros. CMAJ 2002;167:638-43.

56. Wright SM, Kern DE, Kolodner K, Howard DM, Brancati FL. Attributes of excellent attendingphysician role models. N Engl J Med 1998;339:1986-93.

57. Jones WS, Hanson JL, Longacre JL. An intentional modeling process to teach professional behavior: students' clinical observations of preceptors. Teaching and learning in medicine 2004;16:264-9.

58. Hicks LK, Lin Y, Robertson DW, Robinson DL, Woodrow SI. Understanding the clinical dilemmas that shape medical students' ethical development: questionnaire survey and focus group study. BMJ Clinical research ed 2001;322:709-10.

59. Hafferty F. Measuring medical professonalism: a commentary. In: Measuring medical professionalism Stern, DT (ed) Oxford University Press, New York, 2006 ISBN-13: 978-0-19517226-3 2006.

60. Shrank WH, Reed VA, Jernstedt GC. Fostering professionalism in medical education: a call for improved assessment and meaningful incentives. J Gen Intern Med 2004;19:887-92.

61. Wasserstein AG, Brennan PJ, Rubenstein AH. Institutional leadership and faculty response: fostering professionalism at the University of Pennsylvania School of Medicine. Acad Med 2007;82:1049-56.

62. Humphrey HJ, Smith K, Reddy S, Scott D, Madara JL, Arora VM. Promoting an environment of professionalism: the University of Chicago "Roadmap". Acad Med 2007;82:1098-107.

63. Smith KL, Saavedra R, Raeke JL, O'Donell AA. The journey to creating a campus-wide culture of professionalism. Acad Med 2007;82:1015-21.

64. Suchman AL, Williamson PR, Litzelman DK, Frankel RM, Mossbarger DL, Inui TS. Toward an informal curriculum that teaches professionalism. Transforming the social environment of a medical school. J Gen Intern Med 2004;19:501-4.

65. Christianson CE, McBride RB, Vari RC, Olson L, Wilson HD. From traditional to patientcentered learning: curriculum change as an intervention for changing institutional culture and promoting professionalism in undergraduate medical education. Acad Med 2007;82:1079-88.

66. Fryer-Edwards K, Van Eaton E, Goldstein EA, Kimball HR, Veith RC, Pellegrini CA, Ramsey PG. Overcoming institutional challenges through continuous professionalism improvement: the University of Washington experience. Acad Med 2007;82:1073-8.

67. Horton R. The uses of error. Lancet 1999;353:422-3.

68. Competence Based Training in Intensive Care in Europe project. www.cobatrice.org, accessed September 10th 2009. 



\section{Chapter 9}

The minority reports: Elements of professionalism in unsolicited health care complaints

Walther NKA van Mook, Simone L Gorter, Wendy Kieboom, Miem GTH Castermans, Jeantine de Feijter, Willem S de Grave, Jan Harm Zwaveling, Lambert W Schuwirth, Cees PM van der Vleuten Under peer review 


\section{Abstract}

\section{Objectives}

a. Content analysis of unsolicited patient complaints and associated Complaint Committee judgments pertaining to professionalism elements

b. Comparison of the resulting categories of professionalism elements to those perceived relevant by physicians

\section{Design}

Qualitative study

Data

Complaints and judgment letters filed 2004-2009

\section{Setting}

Complaints committee, tertiary-referral, academic medical centre

\section{Results}

137 complaints $(98 \%)$ were available for analysis. 46 different professionalism elements were identified. Perceived medical complications and error were most frequently reported in the complaint letters $(n=77)$. The aspects 'Having to wait for care' and 'Insufficient or unclear clarification' were mentioned 52 and 48 times in the complaint letters. The combined non-cognitive aspects of professionalism (especially communication aspects) are far more prominent than the cognitive aspects (perceived knowledge and skills issues resulting in medical error). Most categories of professionalism elements were considered important physicians, but still revealed from analysis of patient complaints. Physicians' practice is perhaps not yet optimally congruent with their rhetoric. Categories of professionalism elements mentioned by physicians were more abstract, less specific and concrete than identified by complaint letters' content analysis. Some issues (e.g. 'altruism', 'appearance', 'keeping distance' and 'respecting boundaries with patients') were not perceived a problem by patients and relatives. Conversely, eight categories revealed during complaint letter analysis (e.g. 'having to wait for care', 'lack of continuity of care' and 'lack of shared decision making'), but were not considered essential by physicians.

\section{Conclusions}

Unsolicited patient complaints about perceived medical errors and complications are common, but the vast majority of elements identified related to non-cognitive professionalism aspects of care. Complaints pertaining to unsatisfactory communication were especially noticeable. Incongruence is noted between the physicians' view and the patients' perception of actual care. Systematic analysis of patients' complaints can potentially provide insight into professionalism aspects of care on an individual, interpersonal and institutional level, and feed focused intervention strategies. 


\section{Introduction}

It is estimated that approximately $15 \%$ of physicians will be 'impaired' in the sense of being unable to fulfil their professional responsibilities e.g. due to substance abuse or psychiatric illness at some points in their careers ${ }^{1}$. Apart from diagnostic and treatment errors, impairment may result in inappropriate professional behaviour, such as ineffective communication, failure to attend to patients' psychological needs, an uncaring or disrespectful manner, not relating appropriately to patients and boundary violations ${ }^{2,3}$. These violations of standards of professionalism are not only associated with poor adherence to guidelines, impeded collaboration, information transfer, workplace relationships, low staff morale and turnover, but also to medical errors, adverse outcomes and malpractice suits ${ }^{4-14}$. Analysis of unsolicited patient complaints has yielded similar findings ${ }^{15,16}$, which are especially relevant since they "connect dimensions of medical care that are unsatisfying to patients to dimensions that may be injurious to them" ${ }^{\prime 17}$. Although both quality of care and professionalism are considered as part of the core business of contemporary health care, data on patient satisfaction and complaints has only recently been recognised as a valuable source of information ${ }^{18-27}$. Patient satisfaction surveys are commonly invitational and distributed by hospitals to patients after discharge, whereas voluntary complaint processes are initiated by patients ${ }^{27}$. Patient satisfaction is associated with patient complaints and risk management episodes (defined as incidents that can lead to legal action or for which a compensation request is filed $)^{28}$. Wofford et al. reported that at least one third of US patients experienced some degree of dissatisfaction with their hospital care $^{26}$, but only a minority of patients actually talked about their experiences with physicians, while even fewer lodged a formal complaint ${ }^{26,29}$. Earlier studies reported that $20 \%$ of patient complaints were due to communication problems between patients and healthcare providers and $10 \%$ were based on perceived disrespect ${ }^{30}$. A recent content analysis study reported that at least $35 \%$ of unsolicited complaints were related to professionalism issues ${ }^{27}$. It thus appears that episodes of disruptive, unprofessional behaviour are neither common nor rare ${ }^{4}$. Wofford et al. used the business adage 'A complaint is a gift' to underscore that "complaints may offer valuable feedback to business organisations from which they can learn to better serve their customers" ${ }^{26}$. Health care organisations may likewise benefit from systematic monitoring of patient (dis)satisfaction and analysis of patient complaint data to enhance quality assurance and improvement ${ }^{26}$. An analysis of complaints specifically relating to professionalism could thus provide valuable information about professional lapses in health care. 


\section{Purpose of the present study}

Based on the above considerations we conducted a study of unsolicited patient complaints pertaining to professionalism in which we:

1. used content analysis to analyse and compare unsolicited health care complaints and related judgements from the hospital Complaints Committee and

2. compared the resulting categories of elements of professionalism with categories of professionalism elements perceived as relevant by physicians (intensivists-in-training) ${ }^{31}$.

\section{Methods}

\section{Study context}

Maastricht University Medical Centre (MUMC) is an academic tertiary care referral medical centre in Maastricht, the Netherlands. Its annual activities comprise approximately 30,000 inpatient admissions, 400,000 outpatient visits, 26,000 emergency department visits and 18,000 day-case visits. The Patient Information Centre provides easily accessible support for patients that are dissatisfied with their care. When initial efforts to resolve reported issues are not effective, the Complaints Officers provide further support and impartial mediation. If he or she deems it necessary, the patient can request the Complaints Committee to pronounce a formal judgement in accordance with a law enacted in 1995 defining patients' rights to lodge complaints with health care providers ${ }^{32}$. Patients can also request a hearing by the Complaints Committee, in which case they must submit their complaint in writing. After the hearing, the Committee pronounces a formal judgement. The Complaints Committee can advise the board of directors to make improvements in the organisation of care. The hospital complaints database contains detailed records of complaints and the judgements of the Complaints Committee. The MUMC's board of directors, the medical director and the Complaints Committee approved the research protocol of this study, which involved analysis of the complaints lodged with the Complaints Committee between 2004 and 2009 as well as of the related judgements.

\section{Analysis}

We conducted content analysis of complaint letters and judgements using qualitative data analysis software (Atlas.ti.5.2.0) ${ }^{33}$. This involved systematic collection and analysis of qualitative data ${ }^{34}$ using standardised coding 
principles $^{35}$. Elements of professionalism which we had established in prior research were the starting point for coding ${ }^{31}$. When we came across elements of professionalism that did not fit the previous coding scheme we assigned new $\operatorname{codes}^{31}$. Multiple units of comments contained in one linguistic clause but covering different topics were coded as different units of comments. WvM analysed all the transcripts and SG cross-checked the coding scheme. Disagreements between the researchers were resolved through discussion. After a consensus was established the final elements of professionalism were restructured into more abstract categories. Descriptive statistics were obtained from quantitative analysis of the codes and categories using SPSS 16.0.1 $1^{36}$.

\section{Results}

During the five-year study period the Patient Information Centre, the Complaints Officers Office and the Complaints Committee received 368, 2199 and 140 complaints ( $5 \%$ of the total), respectively. The study examined only the complaints lodged with the Complaints Committee. Two complaints were withdrawn before judgement was pronounced and one complaint file was in use in the adversarial process and therefore not available for analysis. Thus, 137 complaints and the related Complaints Committee judgements were analysed. We consecutively report the general characteristics of the complaints and the judgements and the professionalism elements identified therein, and compare the categories of professionalism elements derived from the complaint letters with those identified in a previous study among physicians (intensivists-in-training) ${ }^{31}$.

\section{Characteristics of the general complaints and judgements}

The majority of complaints were from patients $(61 \%)$ or their partners $(15 \%)$, children $(10 \%)$ and parents $(7 \%)$. Of the complaints $59 \%, 5 \%$ and $2 \%$ were about physicians, nurses and other health care professionals, respectively. Twenty-one per cent of the complaints involved multiple categories of health care providers, such as physicians and nurses, while $12 \%$ of complaints were directed at a more general, organisational or departmental level. Thirty-seven per cent of the complaints $(51 / 137)$ resulted in 67 recommendations to the board of directors relating to organisational issues (30\%), provision and transfer of information to patients and other care providers $(30 \%)$, need for adequate protocols $(12 \%)$, responsibility for coordination and continuity of care $(12 \%)$ and collaboration with regional hospitals and family physicians $(7 \%)$. Other suggested areas of improvement were transfers/handovers $(1 \%)$, record keeping and documentation (4\%) and patient centeredness (4\%). 


\section{Professionalism elements identified in formal complaints and judgements}

Forty-six different elements of professionalism were identified in the complaint letters and judgements of the Complaints Committee, 29 of which occurred more than five times in the total of 137 complaints (Table 9.1). Elements of professionalism in the remaining group of 17 items were language issues (being addressed in the local dialect), noisy clinical environment and care providers not introducing themselves properly to patients.

Comparison of the occurrence of the 46 elements of professionalism in the complaint letters and the related judgements yielded between one and four additional elements of professionalism in 50\% (69/137) of the complaints. The elements 'medical error', 'insufficient clarification', 'organisational issues', 'lack of leadership' and 'lack of respect for patients' and relatives' opinions' were mentioned 8 to 26 times more often in the judgements than in the patients' letters.

\section{Comparison of the categories of elements of professionalism derived from the complaint letters with those identified by physicians (intensivists-in-training)}

The categories of professionalism elements established in this study were compared with the categories of professionalism elements which a prior study had shown to be considered relevant by physicians (intensivists-in-training) $\left(\right.$ Table 9.2) ${ }^{31}$. Many categories were identified in both studies, i.e. were mentioned both by physicians and by patients or their family members, but some categories mentioned by the physicians were more abstract, less specific and less concrete than those identified in the present study. Categories like 'norms and values', 'attitude' and 'altruism' did not occur in the letters. Three categories that were considered important by the physicians were not mentioned by the patients and relatives: 'keeping distance and respecting boundaries with patients', 'technical skills' and 'appearance'. Eight categories that emerged in the present study were not considered essential from the physicians' point of view: 'waiting for care', 'continuity of care', 'documentation and record keeping', 'shared decision making', 'accessibility and approachability', 'problems around discharge', 'financial issues and billing problems', and 'privacy of the patient-doctor relationship'. 
Table 9.1 Professionalism elements emerging from unsolicited health care complaints and the subsequent judgments by the Complaints Committee

\begin{tabular}{|c|c|c|c|c|}
\hline No. & Element & Example(s) & $\begin{array}{l}\text { Frequency in } \\
\text { unsolicited } \\
\text { health care } \\
\text { complaints } \\
\text { (no.) }\end{array}$ & $\begin{array}{c}\text { Frequency in } \\
\text { judgements by } \\
\text { Complaints } \\
\text { Committee } \\
\text { (no.) }\end{array}$ \\
\hline 1. & $\begin{array}{l}\text { Medical } \\
\text { complications } \\
\text { and error }\end{array}$ & $\begin{array}{l}\text { Medical error, unexpected } \\
\text { complications, iatrogenic damage, } \\
\text { medication administration error }\end{array}$ & 77 & 103 \\
\hline 2. & Waiting for care & $\begin{array}{l}\text { All theatres occupied, having to wait } \\
\text { for surgery, no bed available for } \\
\text { admission. }\end{array}$ & 52 & 45 \\
\hline 3. & $\begin{array}{l}\text { Insufficient } \\
\text { clarification/ unclear } \\
\text { information }\end{array}$ & $\begin{array}{l}\text { Insufficient information is provided } \\
\text { regarding reasons for delay, expected } \\
\text { time of surgery, too much medical } \\
\text { jargon }\end{array}$ & 48 & 74 \\
\hline 4. & $\begin{array}{l}\text { Disrespectful } \\
\text { communication }\end{array}$ & $\begin{array}{l}\text { Cynicism, sarcasm, arrogance, eating } \\
\text { while consulting, inappropriate smiling } \\
\text { etc }\end{array}$ & 42 & 44 \\
\hline 5. & Lack of teamwork & $\begin{array}{l}\text { Poor communication between health } \\
\text { care members, within and between } \\
\text { specialties }\end{array}$ & 34 & 27 \\
\hline 6. & $\begin{array}{l}\text { Lack of sympathy } \\
\text { and empathy }\end{array}$ & $\begin{array}{l}\text { Insensitivity to patients' concerns, not } \\
\text { seriously dealing with patient worries, } \\
\text { ignoring the human being behind the } \\
\text { patient }\end{array}$ & 33 & 34 \\
\hline 7. & Lack of reliability & $\begin{array}{l}\text { Not keeping promises regarding } \\
\text { nature of scheduled operation, not } \\
\text { visiting patient despite promises }\end{array}$ & 30 & 18 \\
\hline 8. & $\begin{array}{l}\text { Receiving confusing } \\
\text { information }\end{array}$ & $\begin{array}{l}\text { Hearing conflicting, contradictory, and } \\
\text { frequently changing information by } \\
\text { different doctors }\end{array}$ & 28 & 20 \\
\hline 9. & $\begin{array}{l}\text { Lack of respect for } \\
\text { patients' and } \\
\text { relatives' opinion }\end{array}$ & $\begin{array}{l}\text { Not listening to patients and/or } \\
\text { relatives, ignore patients' or relatives' } \\
\text { clinical observations }\end{array}$ & 28 & 36 \\
\hline 10. & $\begin{array}{l}\text { Lack of continuity } \\
\text { of care }\end{array}$ & $\begin{array}{l}\text { Ever changing and varying doctors } \\
\text { and nurses }\end{array}$ & 26 & 17 \\
\hline 11. & $\begin{array}{l}\text { Lack of ad-hoc } \\
\text { communication }\end{array}$ & $\begin{array}{l}\text { Relatives not informed on change of } \\
\text { ward, no change of time of surgery, } \\
\text { no phone call received after surgery }\end{array}$ & 25 & 25 \\
\hline 12. & $\begin{array}{l}\text { Documentation } \\
\text { problems }\end{array}$ & $\begin{array}{l}\text { Incomplete records, missing charts, } \\
\text { limited documentation }\end{array}$ & 23 & 27 \\
\hline 13. & Insufficient care & $\begin{array}{l}\text { Insufficient ante-/post-mortem care } \\
\text { (patient alone too long, not dressed in } \\
\text { appropriate clothing), sometimes } \\
\text { related to MRSA isolation }\end{array}$ & 22 & 25 \\
\hline 14. & $\begin{array}{l}\text { Lack of knowledge/ } \\
\text { experience }\end{array}$ & $\begin{array}{l}\text { Insufficient medical/paramedical skills } \\
\text { regarding catheterisation, wound } \\
\text { care, plasters }\end{array}$ & 19 & 20 \\
\hline
\end{tabular}


Table 9.1 (continued)

\begin{tabular}{|c|c|c|c|c|}
\hline No. & Element & Example(s) & $\begin{array}{l}\text { Frequency in } \\
\text { unsolicited } \\
\text { health care } \\
\text { complaints } \\
\text { (no.) }\end{array}$ & $\begin{array}{c}\text { Frequency in } \\
\text { judgements by } \\
\text { Complaints } \\
\text { Committee } \\
\text { (no.) }\end{array}$ \\
\hline 15. & $\begin{array}{l}\text { Lack of responsibility } \\
\text { and commitment }\end{array}$ & $\begin{array}{l}\text { Health care member not committed to } \\
\text { providing excellent care: hasty while } \\
\text { doing venapunctures, treating } \\
\text { physician not seen during admission }\end{array}$ & 19 & 16 \\
\hline 16. & $\begin{array}{l}\text { Insufficient } \\
\text { infrastructure, } \\
\text { facilities }\end{array}$ & $\begin{array}{l}\text { Poor maintenance/cleaning, } \\
\text { insufficient software for opening } \\
\text { radiology images from other hospitals, } \\
\text { poor wheelchair maintenance }\end{array}$ & 17 & 14 \\
\hline 17. & $\begin{array}{l}\text { Problems with pain } \\
\text { relief }\end{array}$ & Inadequate changes in medication & 15 & 12 \\
\hline 18. & $\begin{array}{l}\text { Organisational } \\
\text { issues }\end{array}$ & $\begin{array}{l}\text { Too much bureaucracy on arrival ED, } \\
\text { non-adequate test results reporting } \\
\text { system, to few operation theatres } \\
\text { available }\end{array}$ & 13 & 28 \\
\hline 19. & $\begin{array}{l}\text { Difficulties regarding } \\
\text { accessibility and } \\
\text { approachability }\end{array}$ & $\begin{array}{l}\text { Difficulties making appointments for } \\
\text { consultations and information } \\
\text { sessions }\end{array}$ & 12 & 6 \\
\hline 20. & Discharge issues & Perceived too early discharge & 12 & 12 \\
\hline 21. & Financial issues & $\begin{array}{l}\text { Unclarity regarding billing of delivered } \\
\text { care }\end{array}$ & 11 & 10 \\
\hline 22. & $\begin{array}{l}\text { Provision of incorrect } \\
\text { information to other } \\
\text { health care members }\end{array}$ & $\begin{array}{l}\text { Provide incorrect information } \\
\text { regarding presumed personal } \\
\text { relationships, and cohabitation to } \\
\text { other healthcare members }\end{array}$ & 10 & 16 \\
\hline 23. & Intimidation & $\begin{array}{l}\text { Exerting excessive pressure, } \\
\text { threatening }\end{array}$ & 9 & 8 \\
\hline 24. & $\begin{array}{l}\text { Lack of scheduled } \\
\text { information sessions }\end{array}$ & $\begin{array}{l}\text { No pre-planned, structured and } \\
\text { planned meetings on progress } \\
\text { regarding diagnosis and treatment }\end{array}$ & 8 & 7 \\
\hline 25. & Lack of leadership & $\begin{array}{l}\text { Unclarity regarding central } \\
\text { coordination of care, who is in the } \\
\text { lead? }\end{array}$ & 7 & 19 \\
\hline 26. & $\begin{array}{l}\text { Lack of shared } \\
\text { decision making }\end{array}$ & $\begin{array}{l}\text { Plan of care not discussed with } \\
\text { patient or relatives }\end{array}$ & 7 & 7 \\
\hline 27. & $\begin{array}{l}\text { Violation of } \\
\text { professional code of } \\
\text { conduct regarding the } \\
\text { privacy of the patient- } \\
\text { doctor relationship }\end{array}$ & $\begin{array}{l}\text { Provide medical information without } \\
\text { patient authorisation }\end{array}$ & 7 & 8 \\
\hline 28. & $\begin{array}{l}\text { Lack of honesty and } \\
\text { self-reflection }\end{array}$ & $\begin{array}{l}\text { Not admitting mistakes, not filing } \\
\text { reports for near-misses }\end{array}$ & 6 & 10 \\
\hline 29. & $\begin{array}{l}\text { Lack of } \\
\text { patient/relatives' } \\
\text { consent }\end{array}$ & $\begin{array}{l}\text { Lack of consent regarding } \\
\text { diagnostics, and therapeutic } \\
\text { interventions }\end{array}$ & 6 & 8 \\
\hline
\end{tabular}

Remark: - professionalism aspects scored in a frequency of five or less in the primary complaint letters were not included in this table.

- examples of these 17 remaining aspects are provided in the text. 
Table 9.2 Comparison of categories of professionalism elements as identified by physicians during focus group interviews ${ }^{31}$ to those identified by patients (and/or their relatives) in unsolicited complaint letters

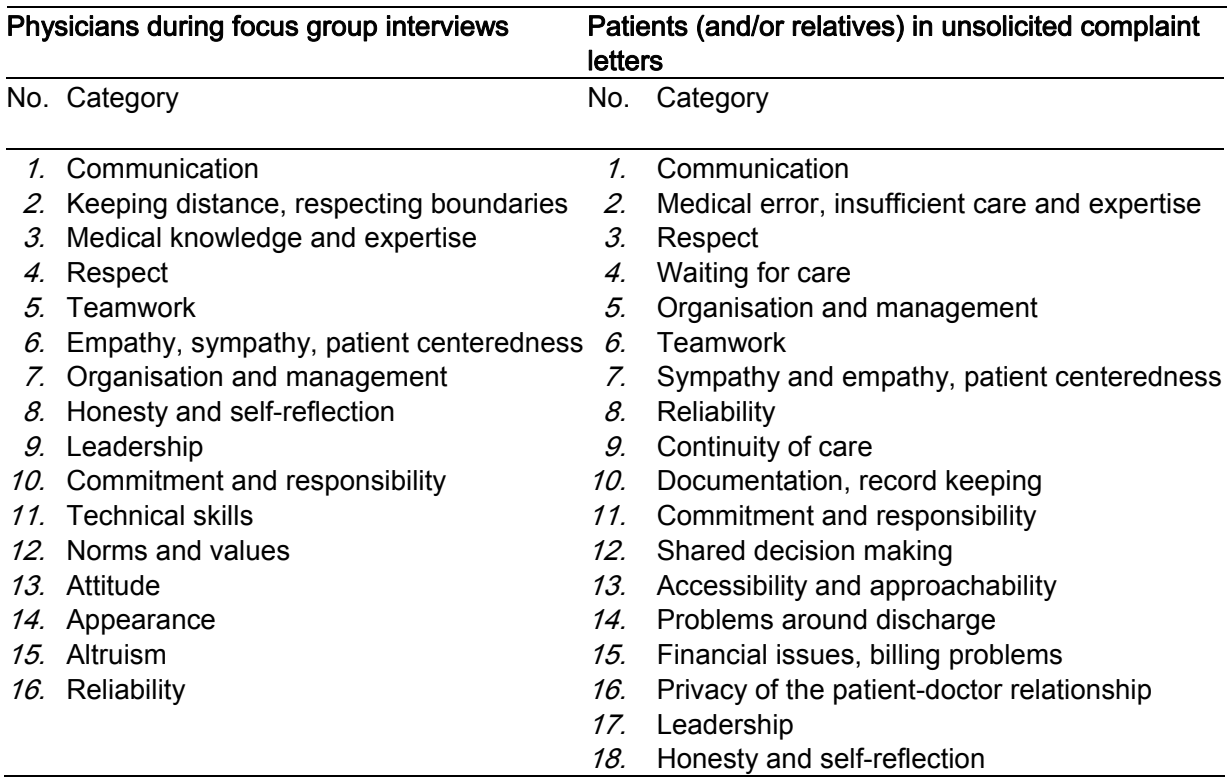

\section{Discussion}

This study specifically focuses on elements of professionalism in unsolicited patient complaints. In our view it offers a potentially valuable 'window' on lapses of professionalism in health care professionals and the results may suggest avenues for quality improvement. The first part of the discussion is organised by the same topics as the results section. Subsequently some general lessons to be drawn from the results as well as the study's limitations are discussed.

\section{Characteristics of the general complaints and judgements}

The results confirm that patients are quite tolerant of received unsatisfactory health care $^{26,29}$, with only a minority making a formal complaint to the Complaints Committee. The majority of complaints were about physicians and one fifth concerned other health care staff. The general literature on complaint analysis includes reports of similar findings, such as those of a nationwide Finnish study ${ }^{37}$, but an Australian study of complaints lodged with the Office of 
Patient and Family Relations found that $78 \%$ of complaints were not about physicians $^{27}$. This notable difference with our results may be, at least partly, due to the fact that complaints filed at the Patient Information Centre and the Complaints Officers' Office were not included in our analysis.

\section{Professionalism elements identified in complaints and judgements}

Perceived medical errors and complications are at the top of the list of elements of professionalism generated by our content analysis (Table 9.1). That unintended medical harm due to adverse events is indeed a major issue is reflected by their reported occurrence in $5.7 \%$ of 1.3 million hospital admissions in the Netherlands in 2004. Of these cases $2.3 \%$ involved preventable harm ${ }^{38}$. Although professionalism was initially defined as 'a body of knowledge and skills (expertise) put into the service for the welfare of society, the lion's share of the currently prevailing concept of professionalism is grounded in the noncognitive domain ${ }^{19}$. Our results show that although medical issues play an important part in unsolicited health care complaints, the (more generic) professionalism elements by far outnumber the specifically medical elements (Tables 9.1 and 9.2).

Complaints about unsatisfactory communication were particularly conspicuous in our results. The element with the highest number of occurrences in this category was 'insufficient clarification/unclear information', which comprised unclear information about diagnosis and treatment due to the use of too much medical jargon as well as failure to provide written information (brochures) to the patient. No or insufficient information about reasons for delay in medical care, such as expected time of surgery, was another source of anxiety and frustration. Other authors have pointed to the benefits to patients and staff that can be achieved by improving information and communication: "improving the flow of patient calls through your organization can dramatically boost efficiency, lower labour costs, and increase both patient and staff satisfaction: you don't have to look any further than the plastic box sitting on your desk with all the buttons -- the telephone" 39 .

\section{Comparison of the categories of elements of professionalism} derived from the complaint letters with those identified by physicians (intensivists-in-training)

A clear difference between elements of professionalism emerging from patient complaints and physicians' views is that the latter gave rise to more abstract formulations, such as 'attitude' and 'altruism', while the complaint letters provided more specific and concrete elements ${ }^{31}$. It seems that more abstract definitions of elements of professionalism, even though fully compatible with 
commonly accepted professionalism definitions ${ }^{25,40-43}$, are of limited practical operational significance, at least from a patient's perspective. Attitude was seldom, and (lack of) altruism never identified in the complaints analysis. Similarly, physicians' concerns regarding 'keeping distance and respecting boundaries with patients' and 'appearance' were apparently not shared by patients and their family members, who never cited these elements as a cause for complaint.

Despite these differences, many categories of professionalism elements from the complaint letters were perceived to be important by the physicians too (Table 9.2). It seems that although physicians and patients share a common denominator of elements of professionalism that are important, the practical implementation of these elements by physicians requires further attention. It seems that physicians' practice is not yet optimally congruent with their rhetoric. An example is lack of teamwork, with complaints focusing on poor communication between individual staff members as well as within and between specialties. This suggests that additional courses on leadership, team development, teamwork training and team communication might be useful in improving patient satisfaction.

More disturbingly, eight categories from the complaint letters were not considered essential from the physicians' point of view. This may be explained by the fact that physicians, unlike their patients, do not experience the negative effects of professionalism elements like 'having to wait for care', the category that showed a very high frequency rate in the complaint letters and includes for example repeatedly hearing that all theatres are occupied and (again) having to wait for surgery or no bed being available for a patient's (scheduled) admission. Waiting for care had almost equal prominence in the complaints as did 'medical error and complications'! A second patient grievance that was not shared by physicians was 'lack of continuity of care', which was perceived as suboptimal due to ever changing doctors and nurses. Increased work load and part time work as well as the recent restriction of duty hours may partly explain this problem $^{19}$. In the literature time pressure is also identified as a barrier to incorporating professionalism in daily practice ${ }^{44-46}$, although it has also been suggested that reduced working hours can promote fellows' well-being, personal development, reflection and teamwork ${ }^{44,45}$. This apparent contradiction between demands of contemporary medical practice and the striving for excellence in professionalism is increasingly noted ${ }^{31}$, and may even contribute to burnout and premature retirement from clinical practice ${ }^{47}$. Other elements whose absence can cause patient dissatisfaction are 'shared decision making' and the desire to be approached as full partners in health care, which are in stark contrast to doctors that largely ignore the patient's view 
or leave treatment decisions completely to the patient. Patients also want their physicians to be 'accessible and approachable' and to respect their privacy during admission.

\section{General lessons}

The concept of professionalism does encompass the entire continuum from the individual (attributes, capacities and behaviours), via the interpersonal (interactions of patients and health care professionals) to the macro-social level (e.g. institutional and social responsibility and economic imperatives). In the same way our results appear to identify potential areas of improvement on all three levels, with beneficiaries extending from the individual health care professional to the institution and society as a whole. It has indeed been suggested that in order to make any sustainable quality improvement, hospitals should be more proactive and not be content to (only) respond to patient complaints in a reactive way on an individual, case-by-case basis ${ }^{48}$. Complaint data should preferably be systematically documented in a complaint management system that can not only support analysis of individual (case-tocase) complaint data, but also provide information about structural systemic problems $^{48}$. We found that 140 isolated complaints resulted in 67 recommendations to the board of directors for system improvements. In line with the above-mentioned findings, a sizeable proportion of these recommendations pertained to organisational aspects of the provision and transfer of information to patients.

The general lessons pertaining to the individual and interpersonal domains that can be drawn from the results of this study are summarised in Table 9.3. Although they are derived from patients' perceptions of what transpired during their hospital stay, some of the findings are confirmed by prior studies comparing video-taped communication behaviours of physicians who had and those who had not been involved in malpractice suits ${ }^{49,50}$.

\section{Limitations of the study}

This single-centre study included only local unsolicited complaints. It is known, however, that complaint-related safety systems integrated in provider organisations such as hospitals are well positioned to receive and respond to patient complaints ${ }^{17,51}$. Some of the identified issues may nevertheless have resulted from unique local or (Eu)regional factors (e.g. language issues, and issues related to methicillin-resistant staphylococcus aureus (MRSA). This may limit the generalisability of the results. Moreover, if our analysis was not limited to unsolicited complaints but also included actively solicited pre-discharge 
patient interviews, more elements may have been found ${ }^{52}$. Nevertheless, an effect on patient satisfaction remains to be established for both approaches ${ }^{52}$.

Table 9.3 Lessons regarding adequate patient-physician communication: do's and don'ts in communication (adapted from studies on the relationship between malpractice suits and patient-physician communication ${ }^{49}$ (with permission), and the study herein presented)

No. Lessons learned

1. Prepare for the meeting, make sure a well equipped room is available, with sufficient chairs for all participants, and preferably have a nurse present.

2. Before seeing patients, take time to prepare by reviewing their charts. Knowing about patients' situations before you meet is one of the indications of your respect.

3. Introduce yourself properly to your patients and, if circumstances permit, shake hands with them. This gesture shows concretely that you acknowledge patients as people in their own right and thus helps establish good rapport. Communicate in the national language, and not in a local or regional dialect.

4. Acknowledge patients as individuals with their own stories to tell; let them describe what symptoms or problems mean to them personally. Acknowledge the individual human behind the patient; lack of sympathy and/or empathy is noticed by patients. Offer reassurance where possible.

5. Pay close attention to and regard for remarks and observations/views made by the patient and relatives, and if related requests seem reasonable and achievable, agree with them.

6. Show patients they have your full attention, and avoid interruptions during interviews. Interruptions influence how patients perceive the duration and quality of consultations, particularly when the visit is short.

7. If you do not have much time or feel rushed for any reason, it is better to tell patients how much time you have rather than risk their interpreting your behaviour as a sign of indifference. Adjust the amount of time allotted if you are delivering bad news. Remember that bad news has to be considered from patients' perspectives, not your own.

8. The more meaningful the content of the interview or conversation to patients, the greater the chance your interventions will succeed, and the more satisfied patients will be. Make sure to provide clear information, avoid medical jargon. Appropriate humour is appreciated, cynicism and arrogance is misplaced.

9. Discuss the diagnostic or treatment plan with the patient and/or his relatives in a process of shared decision making, rather than simply conveying your own opinion, or leaving the decision completely to the patient. Exerting pressure, intimidating or threatening patients or relatives is extremely unprofessional.

10. Take time to make sure your patients understand you. Never take it for granted that they do! Despite your best efforts to explain situations, patients' understanding is often fragmentary. And, if they do not understand, they will think you explained matters badly.

11. Take time to ask patients if they have any questions. Provide patients with sufficient time to think about the information they received.

12. Never make promises you cannot keep: "I'll come and see you at the end of day", or "I will perform the necessary surgery myself", for example. To patients, a broken promise is a sign of negligence, lack of regard, perceived lack of commitment and responsibility.

13. Never expect patients to voice dissatisfaction or give their opinions spontaneously; the traditional asymmetry in roles dictates that physicians 'run' interviews.

14. Admit mistakes and errors to the patient, report them to the responsible authorities, and make sure these reports are dealt with in a professional manner.

15. Patients should be informed about the process and outcome of their complaints and reports. 
Table 9.3 (continued)

No. Lessons learned

16. Schedule structurally planned meeting with patients and relatives to discuss progress regarding diagnosis and treatment, preferably with the same central contact.

17. Make sure there is clarity for the patient who is the physician in charge of care and cure: who is coordinating the process of care, who is responsible, who is the central person to address and schedule appointments with. The latter will prevent the patient being confronted with incorrect views and information, as well as information varying from one physician or nurse to the other.

18. Try and avoid too much variation in treating physicians and nurses. Try to approach the patient and his medical problems with objectivity, and to resist the influences of (a sometimes pressing) environment: maintain you own professional values despite e.g. less optimal approaches due to time/work pressure or other contextual circumstances.

19. Adequately and timely communicate with all colleagues within the same and other specialties about the diagnostic and treatment plan. Make sure all information is correct, not too limited nor superfluous or irrelevant in nature. However, do not discuss a patient's medical problems without the patient's consent.

20. Make sure accessibility for ad-hoc communication and making appointments is optimal; calls should be answered rapidly, and returned if an immediate solution is not within reach.

21. If information provided to the patient may prove incorrect against the odds, inform the patient or his relatives timely about (the reasons) for the unexpected change e.g. in clinical condition, scheduled surgery.

22. Attempt to prevent delays in care as much as possible; they form a serious grievance for patients. Pay sufficient attention to the patient's pain medication.

23. Adequately document all relevant issues, such as reasons for important medical decisions, and outcome of communication with the patient, relatives and/or co-treating physicians.

24. Unavoidable patient transport to other healthcare facilities should be carefully planned, adequately guided if necessary, and all necessary documentation accompanying the patient.

\section{Conclusions}

Unsolicited patient complaints about perceived medical errors and complications are common, but the vast majority of complaints relate to professionalism aspects of care. The category 'having to wait for care' was frequently identified in the complaint letters with a prominence equal to 'medical error and complications'. Unclear or insufficient information was another important patient grievance. A comparison of the different categories shows that complaints about unsatisfactory communication predominate. Incongruence is noted between professionalism elements revealed by the analysis of patients' (and relatives') complaints and those perceived important by physicians. There seems to be a discrepancy between physicians' practice and their rhetoric. This study shows that systematic analysis of unsolicited health care complaints has the potential to provide insight into patient care-related professionalism aspects on an individual, interpersonal and institutional level. Signalling of issues leading to patient complaints can, when and wherever deemed necessary, be succeeded by focused intervention strategies. Further intervention studies followed by studies of potential improvement of physician behaviour and reduced occurrence of disciplinary actions and law suits are recommended. 


\section{References}

1. Boisaubin EV, Levine RE. Identifying and assisting the impaired physician. Am J Med Sci 2001;322:31-6.

2. Irvine D. Patients, professionalism, and revalidation. BMJ 2005;330:1265-8.

3. Galletly CA. Psychiatrist-patient sexual relationships: the ethical dilemmas. Aust $\mathrm{N} \mathrm{Z} \mathrm{J}$ Psychiatry 1993;27:133-9.

4. Hickson GB, Pichert JW, Webb LE, Gabbe SG. A complementary approach to promoting professionalism: identifying, measuring, and addressing unprofessional behaviors. Acad Med 2007;82:1040-8.

5. Leape LL, Fromson JA. Problem doctors: is there a system-level solution? Ann Intern Med 2006;144:107-15.

6. McLemore MR. Workplace aggression: beginning a dialogue. Clin J Oncol Nurs 2006;10: 455-6.

7. Rosenstein AH. Original research: nurse-physician relationships: impact on nurse satisfaction and retention. Am J Nurs 2002;102:26-34.

8. Rosenstein $\mathrm{AH}, \mathrm{O}$ 'Daniel $\mathrm{M}$. Study links disruptive behavior to negative patient outcomes. OR Manager 2005;21:1, 20, 22.

9. Rosenstein $\mathrm{AH}, \mathrm{O}$ 'Daniel M. Disruptive behavior and clinical outcomes: perceptions of nurses and physicians. Am J Nurs 2005;105:54-64.

10. Rosenstein AH, O'Daniel M. Impact and implications of disruptive behavior in the perioperative arena. J Am Coll Surg 2006;203:96-105.

11. Rosenstein $\mathrm{AH}$, O'Daniel M. A survey of the impact of disruptive behaviors and communication defects on patient safety. Jt Comm J Qual Patient Saf 2008;34:464-71.

12. Rosenstein $\mathrm{AH}, \mathrm{O}^{\prime}$ Daniel $\mathrm{M}$. Invited article: Managing disruptive physician behavior: impact on staff relationships and patient care. Neurology 2008;70:1564-70.

13. Rosenstein $\mathrm{AH}$, Russell $\mathrm{H}$, Lauve R. Disruptive physician behavior contributes to nursing shortage. Study links bad behavior by doctors to nurses leaving the profession. Physician Exec 2002;28:8-11.

14. Felps WA, Mitchell TR, Byington EK. How, when and why bad apples spoil the barrel: negative group members and dysfunctional groups. Research in Organizational Behavior 2006;27:181-230.

15. Volpintesta E. Patient complaints and risk of being sued. JAMA 2002;288:1585; author reply 1585-6.

16. Hickson GB, Federspiel CF, Pichert JW, Miller CS, Gauld-Jaeger J, Bost P. Patient complaints and malpractice risk. JAMA 2002;287:2951-7.

17. Sage WM. Putting the patient in patient safety: linking patient complaints and malpractice risk. JAMA 2002;287:3003-5.

18. Stephenson AE, Adshead LE, Higgs RH. The teaching of professional attitudes within UK medical schools: reported difficulties and good practice. Med Educ 2006;40:1072-80.

19. van Mook WN, de Grave WS, Wass V, O'Sullivan H, Zwaveling JH, Schuwirth LW, van der Vleuten CP. Professionalism: Evolution of the concept. Eur J Int Med 2009;20:e81-e4.

20. Lee AG, Beaver HA, Boldt HC, Olson R, Oetting TA, Abramoff M, Carter K. Teaching and assessing professionalism in ophthalmology residency training programs. Surv Ophthalmol 2007;52:300-14.

21. Edelstein SB, Stevenson JM, Broad K. Teaching professionalism during anesthesiology training. J Clin Anesth 2005;17:392-8.

22. Rowley BD, Baldwin DC, Jr., Bay RC, Cannula M. Can professional values be taught? A look at residency training. Clin Orthop Relat Res 2000(378):110-4.

23. Medischevervolgopleidingen.nl M. http://www.medischevervolgopleidingen.nl/pages/ content. aspx? content=10010000000029_2_10000000001651\&contentcode=competentiesspecialist, accessed October 10th 2006. 
24. Accredition Council for Graduate Medical Education. ACGME Outcome Project enhancing residency education throught outcomes assessment: General competencies. 1999;Accessed Febr 13th 2006: http://www.acgme.org/outcome/comp/compFull.asp.

25. Royal College of Physicians and Surgeons in Canada. The CanMeds Framework. http://rcpsc.medical.org/canmeds/index.php. Accessed November 27th 2008

26. Wofford MM, Wofford JL, Bothra J, Kendrick SB, Smith A, Lichstein PR. Patient complaints about physician behaviors: a qualitative study. Acad Med 2004;79:134-8.

27. Montini T, Noble AA, Stelfox HT. Content analysis of patient complaints. Int J Qual Health Care 2008;20:412-20.

28. Stelfox HT, Gandhi TK, Orav EJ, Gustafson ML. The relation of patient satisfaction with complaints against physicians and malpractice lawsuits. Am J Med 2005;118:1126-33.

29. Tax S, Brown S. Recovering and learning from service failures. Sloan Management Review. 40 (1), 75-88 1998;40:75-88.

30. Pichert JW, Miller CS, Hollo AH, Gauld-Jaeger J, Federspiel CF, Hickson GB. What health professionals can do to identify and resolve patient dissatisfaction. Jt Comm J Qual Improv 1998;24:303-12.

31. van Mook WNKA, De Grave WS, Gorter SL, Zwaveling JH, Schuwirth LW, Van der Vleuten CPM. Intensive care medicine trainees' perception of professionalism: a qualitative study. Submitted Anaesth Int Care 2010.

32. Wet Klachtrecht Clienten Zorgsector (WKCZ). http://wetten.overheid.nl/BWBR0007414/ geldigheidsdatum_31-07-2010; accessed July 31th 2010.

33. Atlas.ti version 5.2.0. Scientific Software Development Gmbh, Berlin 2009.

34. Strauss A, Glaser B. The discovery of grounded theory. Strategies for qualitative research. . Chicago. Aldine de Gruyter. ISBN 02023026011967.

35. Boeije H. Analysis in qualitative research 2009;London: Sage(ISBN 978184787007 0).

36. SPSS I. SPSS 16.0.1. 2007.

37. Kuosmanen L, Kaltiala-Heino R, Suominen $S$, Kärkkäinen J, Hätönen $H$, Ranta $S$, Välimäki M. Patient complaints in Finland 2000-2004: a retrospective register study. J Med Ethics 2008;34:788-92.

38. De Bruijne MC, Zegers M, Hoonhout LHF, Wagner C. Onbedoelde schade in Nederlandse ziekenhuizen. ISBN: 978-90-69050845-0: EMGO instituut/VUmc en Nivel 2007.

39. Reduced telephone tag results in $60 \%$ fewer patient complaints, more efficiency. Perform Improv Advis 2004;8:8-11, 1.

40. American Board of Internal Medicine CoEoCC. Project Professionalism. ABIM, Philadelphia. 1995.

41. Royal College of Physicians. Doctors in Society: medical professionalism in a changing word. Report of a Working Party of the Royal College of Physicians of London. . ISBN 1-86016-255X. Lavenham Press Ltd. Suffolk, Great Brittain; http://www.rcplondon.ac.uk/pubs/books/ docinsoc 2005.

42. The royal college of physicians and surgeon's of Canada's Canadian Medical Education directions for Specialists 2000 project. Skills for the new millenium: report of the societal needs working group. CanMeds 2000 Project 1996;Ottawa, Ontario, Canada.

43. Frank JRe. The CanMEDS 2005 Physician Competency Framework. Better standards. Better physicians. Better care. 2005;Ottawa: The Royal College of Physicians and Surgeons of Canada.

44. Page DW. Professionalism and team care in the clinical setting. Clin Anat 2006;19:468-72.

45. Ratanawongsa N, Bolen S, Howell EE, Kern DE, Sisson SD, Larriviere D. Residents' perceptions of professionalism in training and practice: barriers, promoters, and duty hour requirements. J Gen Intern Med. 2006;21:758-63.

46. Charap M. Reducing resident work hours: unproven assumptions and unforeseen outcomes. Ann Intern Med 2004;140:814-5.

47. Miedema B, Easley J, Fortin P, Hamilton R, Tatemichi S. Crossing boundaries: family physicians' struggles to protect their private lives. Can Fam Physician 2009;55:286-287 e5.

48. Hsieh SY. Factors hampering the use of patient complaints to improve quality: an exploratory study. Int J Nurs Pract 2009;15:534-42. 
49. Lussier MT, Richard C. Doctor-patient communication: complaints and legal actions. Can Fam Physician 2005;51:37-9.

50. Levinson W, Roter DL, Mullooly JP, Dull VT, Frankel RM. Physician-patient communication. The relationship with malpractice claims among primary care physicians and surgeons. JAMA 1997;277:553-9.

51. Bovbjerg RR, Miller RH, Shapiro DW. Paths to reducing medical injury: professional liability and discipline vs. patient safety--and the need for a third way. J Law Med Ethics 2001;29:369-80.

52. Garbutt J, Bose D, McCawley BA, Burroughs T, Medoff G. Soliciting patient complaints to improve performance. Jt Comm J Qual Saf 2003;29:103-12. 



\section{Chapter 10}

Discussion, conclusions and recommendations 
| Chapter 10 


\section{What are the answers to the research questions?}

In this Chapter each of the research questions outlined in Chapter 1 is discussed separately in light of the results of the relevant studies reported in this dissertation. Conclusions are then formulated based on these discussions. The results of the research in this dissertation open avenues for further inquiry into education and assessment of professionalism and professional behaviour, leading to suggestions for further research. Further recommendations for additional studies are derived from the increasing number of publications on professionalism and the work of the Professionalism Theme Working Group (IOC-PWG) of the 2010 International Ottawa Conference ${ }^{1}$. Finally, the limitations of the studies are considered and implications for medical education practice summarized.

\section{Research question 1}

Can an assessment approach that addresses unprofessional behaviour fit within the current professionalism teaching and assessment framework (Chapters 2, 3 and 4)?

Jordan Cohen, president emeritus of the Association of the American Medical Colleges summarized the challenge of assessment of professionalism in two statements: "If it can't be measured, it can't be improved", and "They don't respect what you expect, whereas they respect what you inspect"2. These observations imply that assessment can be both a powerful stimulus for learning (formative assessment, or assessment for learning) and a method for assessment of learning (summative assessment), which inevitably will reveal the occasional episode of unprofessional behaviour. Addressing unprofessional behaviour could be an alternative, complementary approach to professionalism assessment, which is essential to enable medical schools to meet their social contract by ensuring the competence of graduating students on entering practice ${ }^{3}$. The literature study in Chapter 2 shows the merits of addressing unprofessional behaviour. A distinction can be made between two approaches: as part of an admission procedure, i.e. to select students, and during the educational programme. Selection before entry into medical school can be based on personal attributes predisposing students to becoming excellent doctors and on attributes that are predictive of unprofessional behaviour. Addressing unprofessional behaviour after admission to medical education is based on triangulated methods during undergraduate and postgraduate education and training. It is generally accepted that it should start early, that the threshold for reporting lapses of professionalism should be kept low, that staff 
and student awareness of and training in professionalism should be optimized, that formative and summative assessment methods should be used and that a formal structure for dealing with lapses and/or unprofessional behaviour must be developed ${ }^{4}$. Today, few institutions have such formal programmes for postgraduate training and beyond ${ }^{5,6}$. Problems, once identified, are frequently dealt with in a haphazard, ad hoc, informal and reactive manner ${ }^{5}$. National guidelines for dealing with residents' unprofessional behaviour are currently being developed by the Professionalism Special Interest Group of the Dutch Association for Medical Education (NVMO). Although the prevalence of systematic, severely unprofessional behaviour is low (in contrast to that of lapses in professionalism), addressing unprofessional behaviour can contribute to restoring society's trust in the medical profession, and be cost effective as well $^{7}$. It remains to be unravelled whether any single selection method affords sufficient positive or negative predictive value with regard to unprofessional behaviour. The literature on this topic is rather limited ${ }^{8-13}$, resulting in a paucity of data on the validity, reliability and positive and negative predictive values of admission tests. One test method, the multiple-mini interview (MMI) consisting of short OSCE-style stations, seems especially promising as a selection tool. It can cover the domains of critical thinking, ethical decision-making, communication skills, and knowledge of the health care system. For example, candidates discuss a health-related issue (e.g. the use of placebo) with an interviewer, interact with a standardised patient (while an examiner observes the interpersonal skills displayed) and answer traditional interview questions ${ }^{14}$. $\mathrm{MMI}$ outcomes have been shown to consistently afford better differentiation between candidates compared to outcomes obtained with other interview formats ${ }^{14,15}$. This translates into higher predictive value and stronger correlations with future performance ${ }^{16-18}$. The MMI has been shown to be the best predictor of subsequent clinical performance ${ }^{16,17}$, professionalism ${ }^{18}$, communication with patients and success on national licensing examinations ${ }^{17,19}$. At Maastricht it is used to select applicants to the graduate entry programme. There is also ample experience in dealing with students' lapses in professionalism in Maastricht ${ }^{20}$ (Chapter 4). Although formative and summative assessment of professional behaviour may seem incompatible and mutually exclusive at first glance, the professionalism assessment framework that is used in Maastricht medical school combines the two approaches as two sides of the same coin. Four years of experience with the framework in the first three years of the six-year undergraduate curriculum has resulted in several findings.

First, some quantitative phenomena emerged. The number of 'no judgement possible' increased among first-year students, reflecting an attendance problem, while the number of negative judgments relating to professional 
behaviour during regular educational sessions remained stable. The number of critical incident reports (reports of unprofessional behaviour outside regular educational sessions) also increased among first-year students, mainly due to unannounced and unauthorized absences from simulated patient encounters or resits, failure to meet portfolio obligations and failure to respond to calls to attend hepatitis B immunisation. In recent articles, such irresponsible behaviour in medical school was reported to be predictive of unprofessional behaviour as a practising physician ${ }^{21-23}$. One might speculate whether repeated failure of first-year students to attend regular educational sessions, often without proper communication with the tutor (resulting in 'no judgment possible') can be interpreted as reflecting a lack of responsible behaviour (e.g. towards the tutorial group). The number of students invited to a meeting with the Professional Behaviour Committee increased as a result of repeated negative judgments or 'judgment not possible', students' (unsatisfactory) explanations and/or advice of student councillors. The number of negative end-of-year judgments in the first year also showed a steep increase, even after correction for changes in the total number of judgments. This increase requires explanation. It may be a transient phenomenon, which would be a good thing, considering the limited availability and feasibility of remediation programmes for unprofessional behaviour.

Second, from a qualitative perspective, negative 'regular' judgments almost always related to 'Dealing with work' and 'Dealing with others', and seldom to 'Dealing with oneself'. This could be interpreted as an effect of the context of the tutorial group being less suitable to reliably judge students' reflective capabilities. Nevertheless, most of the negative judgements and critical incident reports occurred after repeated feedback had failed to result in behavioural change. This indirectly suggests that students have deficiencies in selfreflective abilities and/or abilities to change, and thus supports the need for training sessions in reflection (skills). In almost all years, male students received more negative judgments and 'no judgment possible' compared to their female colleagues. This finding and its consequences remain to be fully examined. Several US studies of physicians disciplined by state medical boards showed a similar association with male $\operatorname{sex}^{24-26}$. A more recent UK case-control study also suggested that male sex (as well as lower socioeconomic background and early academic difficulties) could be risk factors for subsequent professional misconduct ${ }^{27}$. However, a study by Papadakis et al. showed no significant association between gender and disciplinary action by medical boards (odds ratio 2.24, $p=0.09$ ) ${ }^{22}$, although these authors reported problematic behaviour, for example in obstetrics/gynaecology by a greater proportion of male than female students ${ }^{28}$. Whether gender differences, for example in relation to interpersonal 
communication skills, render male students more prone to unprofessional behaviour merits further investigation.

Finally, early identification of unprofessional behaviour using triangulated methods with different observers in different contexts and complemented by remediation and longitudinal follow-up is currently standard practice in Maastricht medical school. This strategy functions alongside the formative assessment of professionalism from the perspective of the Committee on Professional Behaviour ${ }^{20}$. Chapter 3 provides further evidence that most Dutch veterinary medical schools, dental schools and medical schools have implemented, or even evaluated their policies regarding assessment of professionalism, and, like Maastricht, use combined formative and summative approaches. Whereas it has become common practice in undergraduate medical education to use a combined formative and summative approach to deal with professional lapses and unprofessional behaviour, similar guidelines or frameworks are hard to find in postgraduate and CME programmes.

\section{Conclusions regarding Research question 1}

Summative assessment of unprofessional behaviour is not a contrasting but a complementary approach alongside formative assessment. Selection processes for medical school addressing general and professional behaviour aspects appear to have merit. In undergraduate medical education, the approaches used to address unprofessional behaviour fit well with professionalism assessment frameworks, as is evidenced by the international literature and descriptions of national and local evaluation strategies.

\section{Directions for future research}

1. The perceived acceptability and usefulness of the framework for dealing with unprofessional behaviour have not been evaluated from the students' perspective. Exploring students' ideas, listening to their voices from 'the trenches' as it were, is required to optimize the framework. A mixed method approach with focus group interviews and surveys seems suitable for this purpose.

2. Relationships found between gender and professionalism require further study, such as the finding that male students show more frequent involvement in later unprofessional behaviour than female students. The underlying professionalism aspects that contribute to a gender effect remain to be unravelled, although it has been speculated that personality differences and communication styles may play a role ${ }^{27}$. The global trend of feminization of the medical profession will likely impact on professionalism 
and how it is perceived. The influence of this trend should be elucidated in light of potential practical consequences (women prefer part-time work, are less interested in hospital-based specialties, prefer convenient working hours and few shifts, and favour patient contacts).

3. Despite calls in the literature for intervention studies to examine ways to remedy students' and/or physicians' unprofessional behaviour and thereby prevent disciplinary action and law suits, it is unlikely that such studies will be conducted in the Netherlands, because the data required for them are not yet available in the public domain and subject to privacy law. Most likely such studies will have to come from North America.

4. The increasing number of negative end-of-year judgments of professional behaviour suggests that an increasing number of medical students will be advised to leave medical school (a so-called Consilium Abeund ), an advice that the majority of students is known to ignore. However, the new Dutch Higher Education Act which became effective as of September 2010 introduces the ludiucium Abeund ${ }^{29-31}$. In the perspective of a new legislative era, the frequency of use of this act, the nature of the problems necessitating its use and the route resulting in this ultimum refugeum should all be subjects of further study.

5. The multiple-mini interview (MMI) is currently used at Maastricht as part of the admission procedure to the graduate entry programme. However, little is known about the predictive power of $\mathrm{MMI}$ outcomes in relation to performance during the first two years of this programme. Results of studies examining the relative contributions of the different constituents of the $\mathrm{MMI}$, especially the professionalism elements, could be used to optimize the selection process.

6. The assessment of professional behaviour is generally labour intensive, while limited information is available about its maximum efficiency. A decrease in the number of assessment moments or an increase of the threshold for meetings with the Committee on Professional Behaviour (to two or more negative judgments) may be inevitable to reduce costs and increase long-term feasibility. The effects of such measures on the reliability of end-of-year judgments are unclear and should be investigated. 


\section{Research question 2}

To what extent have published guidelines on teaching and assessing professional behaviour been implemented nationally and locally, and which enabling and limiting conditions for education and assessment of professional behaviour can be identified in undergraduate medical education (Chapters 3, 4 and 5)?

The answer to this question is provided by the evaluations described in Chapters 3, 4 and 5. Before 2002, all medical, dental and veterinary schools in the Netherlands used their own, if any, methods and regulations to deal with (un)professional behaviour. The Consilium Abeundi report, produced by a Special Interest Group on Professional Behaviour of the Association of Universities in the Netherlands (VSNU) and published in $2002^{32}$ was aimed at promoting a uniform approach to teaching and assessing professional behaviour and dealing with unprofessional behaviour in the undergraduate medical, dental and veterinary curricula ${ }^{32}$. Although compliance with the published standards was not compulsory, it de facto produced national standards for the Netherlands ${ }^{3}$. Adherence to these guidelines by the medical, dental and veterinary medical schools in the Netherlands was explored in a qualitative survey among representatives of the various schools to examine currently used frameworks (and instruments) for teaching and assessing professionalism, the consequences of unprofessional behaviour and the availability of faculty development programmes. Chapter 3 describes that all schools endorse the content of the Consilium Abeundi report, and that attention for professionalism has increased considerably since its publication. All schools have adopted at least part of the recommendations and use commonly accepted methods of teaching and assessing professional behaviour ${ }^{33}$. The main differences between schools are found in the organisational structure and in assessment instruments. A general tendency was noted to make professional behaviour more explicit and visible in the curriculum rather than to introduce new content on professionalism. All schools used longitudinal assessment of professional behaviour. Assessment of professional behaviour has led to a major culture change in some schools. Society's call to focus on patient safety and thus on assessment of (un)professional behaviour was considered to be a strong stimulus for education and assessment of professionalism $^{34}$ (see Chapter 9). Apart from the successful implementation of aspects of professional behaviour, Chapter 3 also emphasizes the difficulties relating to assessment of professionalism ${ }^{3}$. Hurdles to be taken are the lack of consideration of students' views, the need to improve teachers' self confidence in their ability to assess professional behaviour, identification of quantitatively sufficient and qualitatively efficient remediation programmes and logistic and administrative support ${ }^{34}$. Reflection skills of teachers and students should be 
enhanced to facilitate discussions of professional behaviour. Teachers in particular should be trained to deal with students' unprofessional behaviour. The development of remedial teaching programmes is in its infancy, and schools are advised to co-operate and exchange case studies on remediation strategies, since it seems increasingly important to tailor these strategies to individual students' needs ${ }^{3,34}$. Most schools have no data on students with unprofessional behaviour, which obscures the magnitude and nature of the problem. The magnitude of the problem was studied for Maastricht medical school, which has fully implemented the guidelines of the Consilium Abeundi report $^{20}$, as was described in Chapter 4. Evaluation of the framework revealed that long-term endurance of the framework is likely to be negatively affected by the increasing number, severity and persistence of reported unprofessional behaviour. The associated administrative and logistic burden (and thus the costs) will presumably necessitate 'skimming' of the current programme by reducing the number of assessment moments and/or the frequency of meetings with the Professional Behaviour Committee. The lack of adequate, individualised remedial programmes is noticed both nationally and locally. Finding a trade-off between the scientifically optimal strategy and the practically achievable optimal strategy poses a further challenge. The acceptability and feasibility of remediation programmes is increasingly threatened by cost-related constraints.

Furthermore, the longitudinal aspect of assessment of professional behaviour currently receives insufficient attention. Teachers should be able to follow up on end-of-course judgments and learning goals from prior courses. Transfer of results and goals between isolated teaching activities, educational phases (bachelor-master, undergraduate-graduate) and teaching facilities (e.g. teaching hospitals offering clerkship rotations) is currently being explored. Regular Committee on Professional Behaviour meetings with the Examination Committee are needed to optimize formal communication in order to facilitate longitudinal tracking of student performance. Expansion of the Professional Behaviour Committee's responsibilities to include all six years of medical school is considered crucial in this regard. Continued assessment of professional behaviour during the clinical years coordinated by the Committee would be essential to investigate whether and in how far behaviour during the first three years predicts later behaviour (in medical school). However, this is again hampered by financial constraints, and its implementation will therefore most likely be gradual. Chapter 5 delved deeper into the educational activity during which professional behaviour is most commonly assessed in the undergraduate curriculum: the tutorial group. The study explored the views of students in years 2-4 with regard to factors contributing to suboptimal assessment of professionalism and whether these could be attributed to 
students or teachers or both. Whereas it was known that the role of the tutor was important for effective functioning of the tutorial group in general ${ }^{35,36}$, little was known about factors adversely affecting assessment of professional behaviour. Insight into those factors could be used in designing and enhancing faculty development programmes ${ }^{37}$. Five negative factors were identified, four of which were indicative of a need to improve tutors' role performance, while three indicated a need to provide students with better information about assessment of professional behaviour. The strongest inhibitory factor was failure on the part of the tutor both to confront students with unprofessional behaviour and to provide adequate feedback. The tutor's role proved pivotal once again. Staff development should motivate teachers by equipping them with the knowledge and skills to conduct sound assessment of professional behaviour. Confronting students with their behaviour and appropriate and constructive feedback should be stimulated ${ }^{38}$. The results of this study have been used to design video fragments to facilitate tutor (and student) training in assessing professional behaviour. Although the pivotal role of the tutor was confirmed by this study and addressed, it should be noted that the contribution of the students should not be ignored.

\section{Conclusions regarding Research question 2}

The 2002 Consilium Abeundi guidelines have been widely implemented both nationally and locally, specifically at Maastricht. The need to boost teachers' confidence in their skills to assess professional behaviour, develop quantitatively sufficient and qualitatively efficient individually tailored remediation programmes and the need for (increasing) logistic and administrative support ${ }^{34}$ were identified as national and local hurdles still to be taken. In Maastricht specifically, the increase in reports of unprofessional behaviour hampers the implementation of a formal continuum of professional behaviour development (which requires expansion of the framework across different training phases). On a micro-level, the role of the tutor proved pivotal in assessing professional behaviour in the tutorial group, suggesting a need for individually tailored teach-the-teacher programmes.

\section{Directions for future research}

1. A similar comparison of the magnitude and nature of the occurrence of unprofessional behaviour as performed for Maastricht medical school remains to be conducted for the other veterinary medical, dental and medical schools. Such studies could provide insight into differences between male/female ratios of students and underlying patterns of unprofessional behaviour between the different dental, veterinary and medical schools. 
2. A comparison of the magnitude and nature of unprofessional behaviour in medicine and other health care professions is recommended. Such studies should address the question whether reports of unprofessional behaviour are mainly related to medicine related factors or to more generic ones.

\section{Research question 3}

Which enabling and limiting conditions with regard to teaching and assessing professional behaviour can be identified during postgraduate medical education (Chapters 7 and 8)?

So far, studies of professionalism in postgraduate training have been conducted among residents in family medicine and paediatrics ${ }^{39}$, surgery and paediatrics $^{40}$, internal medicine and neurology and family practice ${ }^{41}$. Information regarding intensive care medicine fellows' views on professionalism and how it is learned was derived from the studies described in Chapters 7 and 8.

Aspects considered most important for professionalism in Chapter 7 were reflection on performance and a motivated and stimulating supervisor (comparable to the conclusion for undergraduate training in Chapter 5). 'Observations in daily practice' and 'Experiential learning and role modelling' received high ratings. Learning from personal experiences and informal 'onthe-job' learning featured more prominently than scheduled formal educational activities in intensive care medicine training. Role modelling alone was insufficient and should be combined with reflection on action followed by discussion to truly promote learning about professionalism ${ }^{42}$. The need for formal teaching regarding professionalism was mentioned by $28 \%$ of participants, and improvement seems possible in this regard. Small group sessions in which participants can reflect on (near) errors and discuss formal patient complaints may offer ways to stimulate awareness and self-reflection. The need for feedback to stimulate reflection was also frequently mentioned (24\% of participants), but other suggestions for improving reflection were few. Regular feedback seems too infrequent and teach-the-teacher programmes should provide clinical teachers with background knowledge and skills to improve this. Since portfolio use is now incorporated in all Dutch specialty training programmes, mentoring and portfolio use may also play a role here ${ }^{43}$. Mentors must be well prepared for their tasks. The intensive care medicine fellows expected an increasing role of local training centres in teaching professionalism, although an additional, albeit considerably smaller, role was envisaged for (inter)national intensive care organizations. 
Chapter 8 describes an exploration of enabling and limiting conditions regarding teaching and learning professionalism in intensive care medicine training. The context of the Intensive Care Unit (ICU) seems eminently suitable for learning about professionalism. Intensivists fulfil a central role in the multidisciplinary team involved in caring for patients in the $\mathrm{ICU}^{44}$, a context that is increasing in complexity and size and where teamwork, leadership, good communication and management skills become increasingly important ${ }^{45,46}$. Furthermore, ethical dilemmas, for example relating to end-of-life decisions and limitation of treatment, are an essential part of intensivists' daily practice ${ }^{47}$. As described in Chapter 7, a substantial part of the focus group discussions related to learning while working, i.e. on the job learning. Most topics relating to teaching and learning professionalism during ICM training were concerned with 'work-based learning', 'role modelling' and 'feedback' on actions. Feedback and subsequent reflection were considered of paramount importance in learning about professionalism in the workplace, with feedback being the most frequently discussed contributor to learning ${ }^{48}$. The focus group participants recommended asking for feedback if supervisors did not provide it of their own accord. Reflection could be fostered by discussing critical incidents with relevance to professional behaviour, such as events that were experienced as difficult and unexpected results of personal actions. Learning from mistakes was also stressed ${ }^{48}$. Furthermore, institutional leadership and institutional culture were perceived as important factors in promoting professionalism.

\section{Conclusions regarding Research question 3}

Apprenticeship and experiential learning are crucial to the way fellows in intensive care medicine learn about professionalism. Fellows underscore the importance of supervisors as role models ${ }^{49-52}$ and local faculty development programmes (teach-the-teacher sessions, addressing institutional culture and leadership). Apart from attention to the informal curriculum, formal teaching sessions on professionalism are important and adequate feedback should be provided when- and wherever possible. Another important aspect is the notion that multidisciplinary discussions of (near) errors offer a useful method for attending to medical and professionalism aspects of care. This finding parallels the recent idea that professionalism can be considered from the perspective of quality of patient care and patient safety ${ }^{44,53-61}$ (Chapters 4 and 9). Both feedback and formal discussions of near errors can stimulate self-reflection on professionalism issues. 


\section{Directions for future research}

1. To our knowledge, the educational climate of (Dutch) intensive care training centres has not been subject of extensive study. The D-direct is a tool specifically designed and eminently suited for measuring the learning environment as experienced by residents ${ }^{62-66}$. In light of the finding that local training centres are considered by trainees to be highly important in teaching professionalism issues, a nationwide study of institutional and departmental learning climates could be a useful initial step towards improvement in this area.

2. It could also be useful to examine ways in which outcomes of such a study could be used to change the culture of education and practice, particularly with regard to the hidden curriculum.

3. The P-MEX, a mini clinical evaluation exercise, specifically designed for measuring professional behaviour is available for professionalism assessment in clinical training ${ }^{66,67}$. The tool was proved to be reliable for Canadian and Japanese settings with 8 and 10 judgments, respectively, and it had adequate validity (after addition of an item specific for the Japanese context). Given its promise in international settings, it seems worthwhile to validate the P-MEX in the Dutch setting ${ }^{67,68}$.

4. Teamwork is becoming increasingly important in contemporary healthcare, and this is especially true for intensive care medicine. Further studies could examine the role of teamwork in the development of professional behaviour $^{69}$ in primary versus secondary health care and in different disciplines in secondary care.

\section{Research question 4}

To what extent are innovations also improvements in the assessment of professionalism in undergraduate medical education (Chapter 6)?

Digital technology can play a potentially useful role in teaching, learning and assessing professionalism ${ }^{70}$, for example to facilitate anonymous gathering and analysis of information. It should not be a goal in itself, however, but only a means for improvement. The study described in Chapter 6 analyzed the quantity and quality of comments about professionalism made by students, their peers and the tutor as well as the feasibility, acceptability and perceived usefulness of a web-based versus paper-based method (as described in Chapter 4). The results revealed significantly more comments from the webbased group compared to the paper-based group. Apparently peers felt more strongly obliged to provide feedback when they were asked to do so in an individual, semi-anonymised context compared to the face-to-face setting of the tutorial group. The quality of the feedback measured in relation to five 
commonly accepted feedback criteria ${ }^{71,72}$ was similar for both conditions. An increase in the amount of feedback, with unchanged quality, can be considered an improvement suggesting a preference for web-based feedback. However, the respondents strongly favoured the traditional paper-based method, considering the interpersonal nature of professional behaviour assessment in the group to be eminently suitable for 'en-groupe', face-to-face discussion. The study seems to warrant the conclusion that assessment of professional behaviour does not necessarily require advanced assessment technologies, even though web-based assessment offered a quantitative advantage without loss of quality. Nevertheless, the labour intensive nature of traditional assessment methods of professional behaviour may make the use of other technologies inevitable in the future.

\section{Conclusions regarding Research question 4}

From the perspective of students and tutors, advanced assessment technologies offer only a limited advantage for the assessment of professional behaviour in the tutorial group, although an increase in amount of feedback, with unchanged quality was noted. The interpersonal nature of professional behaviour assessment was considered eminently suited to 'en-groupe', faceto-face discussion.

\section{Directions for future research}

1. The place of advanced assessment technologies, such as electronic and/or web-based methods, in the current assessment armamentarium warrants further investigation. More recent multisource feedback technologies, specifically designed to assess professional behaviour, may be able to redress the aspects that were now perceived as negative, while sustaining the superior quantitative response. An example is the National Board of Examiners (NMBE)' Assessment of Professional Behaviours (APB) programme, which currently uses web-based technology ${ }^{73-75}$.

\section{Research question 5}

How can the concept of professional behaviour be further refined and defined from the perspective of the medical educationalist (Chapter 2), the physician (Chapters 7 and 8), and the patient (Chapter 9)?

As described in Chapter 2, the medical education literature considers the complementary approach which also takes account of unprofessional behaviour instead of only stimulating and teaching good professional behaviour a useful addition to the assessment toolbox for professional behaviour. The 
approach starts with admission to medical school. Assessment of professional behaviour before entry into medical school can be based on personal attributes predisposing students to becoming excellent doctors or on identification of students that are most likely to develop unprofessional behaviour. After admission to the undergraduate programme or subsequent specialty training, the focus moves to early identification of unprofessional behaviour using triangulated approaches, with many different observers in as many contexts as possible. However, a clear gold standard is lacking.

In Chapters 7 and 8 the concept of professionalism was refined from physicians' (fellows' in intensive care medicine) points of view. Virtually all professionalism items were considered relevant for intensivists' daily practice, confirming the findings of a previous study among residents in internal medicine, neurology and family practice ${ }^{41}$. This supports the notion that professionalism elements that are relevant to education programmes are easy to agree on and difficult to challenge, but also difficult to translate into operational definitions. 'Striving for excellence', 'Teamwork' and 'Dealing with ethical dilemmas' were identified as important categories in the survey, whereas the focus group interviews emphasized the importance of 'Communication', 'Keeping a professional distance and setting boundaries', 'Medical knowledge and expertise' and, to a lesser extent, 'Respect', 'Teamwork', 'Leadership' and 'Organization and management'.

\section{Several new findings were noted}

First, contrary to our expectations, medical knowledge and technical skills were not perceived as the key aspects of intensivists' professional behavior ${ }^{47}$. This may indicate that ICM fellows have largely mastered the technical dimensions of knowledge (know-how, expertise) during prior specialist training, whereas the specific environment of the ICU catalyzes the development of other aspects, such as non-cognitive dimensions of knowledge, beliefs, perceptions, values and emotions. Aspects that were mastered before intensive care medicine training may have become 'tacit' and as a result are not brought up during focus group discussions.

Furthermore, 'Teamwork' and 'Dealing with ethical dilemmas' were considered important, although 'Teamwork' and 'Leadership' are absent from many descriptions of professionalism in the literature ${ }^{76}$. It is clearly recognized, however, that there is a pivotal role for intensivists in the ICU, a context of increasing complexity and size in which multidisciplinary teamwork, leadership, good communication and management skills are increasingly important ${ }^{45,46}$. Prior research has shown that good teamwork can reduce mortality, improve 
clinical care and patient satisfaction, and contain costs at the same time ${ }^{77-79}$. The relevance to physicians of appropriate communication skills and the ability to listen in order to meet their professional commitments was underscored in Chapters 7 and $8^{80-87}$. ICU physicians frequently have to provide patients and/or their families with clearly and compassionately conveyed, adequate information ${ }^{86,87}$. Ethical dilemmas, concerning for example end-of-life decisions and limitation of treatment, are another essential part of intensivists' day-to-day practice $^{47}$. It is known that medical ethics can sensitize, raise awareness and promote reflection ${ }^{88}$. The influence of the ICU context on perceptions of professionalism is clearly reflected in the results of these two studies. The ICU may serve as an arena 'par excellence' for learning about ICU specific professionalism issues.

Next, several of the elements of professionalism were defined in rather abstract, idealistic, not very specific terms, such as altruism and attitude. This contrasts with the findings from the patient complaints study (Chapter 9), where patients' letters framed complaints in very specific and concrete elements ${ }^{48}$.

Finally, setting boundaries was an important topic in the focus group interviews, mainly in relation to patients and their relatives. Dilemmas like 'staying within the lines' and 'watching your step ${ }^{, 89,90}$ were seen as potential problems for physicians, which could arise during the long-term care of patients in the ICU setting. 'Setting boundaries' was also, but to a lesser extent, related to colleagues and to balancing private and professional life. This prominence may reflect recent changes in physicians' attitudes, such as growing emphasis on the quality of life outside medicine, an increase in part-time work and an externally imposed limitation of duty hours ${ }^{54}$. The era in which individuals function thus influences their perceptions of professionalism. In times of change, when societal organization is changing, perceptions of professionalism may have a struggle to keep up.

Chapters 7 and 8 also contribute to the understanding of how professionalism is learned in the intensive care workplace from a physician's point of view. It became apparent that the apprenticeship model, learning from role models, remains the hallmark for learning professional behaviour in the ICU. In both studies informal learning was considered more important and more valuable than formal teaching. The impact of supervisors as role models was evident $^{49-52}$, as was the impact of associated faculty development programmes. Contextual differences notwithstanding, these latter findings seem to be consistent with the findings regarding the importance of the tutor in the assessment of professional behaviour in the tutorial group. Multidisciplinary discussion of (near) errors was considered a useful method to promote 
discussion of both medical and professionalism aspects of care. This interesting finding parallels the recently developed attention for professionalism from the perspective of quality of patient care and patient safety ${ }^{44,53-61}$.

Chapter 9 explored the concept of professionalism from a care receivers' point of view. The Chapter focused on professionalism from the recently identified perspective of quality of care and patient safety ${ }^{44,53-61}$. Qualitative analysis of recent five-year data from unsolicited complaints to the Complaints Committee of Maastricht University Medical Centre resulted in a good impression of which professionalism issues were perceived as relevant from the patients' (and their relatives') points of view. Although complaints about perceived medical errors and complications were common, the vast majority of complaints were concerned with non-cognitive, professionalism aspects of care. A comparison of the different categories shows that complaints about unsatisfactory communication predominate. 'Having to wait for care' was frequently mentioned in the complaint letters and had equal prominence to 'Medical error and complications'. 'Unclear or insufficient information', 'Disrespectful communication' and 'Lack of teamwork' were other important grievances.

To our knowledge, no studies have compared categories of professionalism elements identified by care receivers with similar categories considered important from a physician's point of view ${ }^{48}$ with the aim to identify any differences or incongruence between the views of these two groups of stakeholders in health care. The study in Chapter 9 explored new research territory. Most categories of professionalism elements described in Chapters 8 and 9 were mentioned by both physicians and patients (or their family members). The physicians described elements of professionalism that were to be achieved, whereas the patients were actually exposed to the practical outcomes of this effort, i.e. physicians' performance in daily practice (the highest level of Millers' pyramid) ${ }^{91}$. It seems that, at least occasionally, physicians' practice is not optimally congruent with their rhetoric, especially in view of the fact that only a small minority of patients file a formal complaint. It seems that despite the shared view of physicians and patients regarding the importance of many elements of professionalism, the practical implementation of these views by physicians merits further scrutiny. Some elements were uniquely identified from the analysis of the patient complaints in Chapter 9 , and were thus not mentioned by physicians. Disturbingly, this was the case for eight categories from the complaint letters, including 'Having to wait for care' and 'Lack of continuity of care'. Continuity of care was apparently perceived as suboptimal due to ever changing schedules of doctors and nurses. Increased work load and part time work as well as recent restrictions of duty hours may offer a partial explanation for this problem $^{54}$. In the literature, time pressure is 
acknowledged as a barrier to incorporating professionalism in daily practice $^{41,45,92}$ although it has been suggested that reduced working hours can also promote physicians' well-being, personal development, reflection and teamwork $^{41,45}$. This apparent contradiction between the demands of contemporary medical practice and striving for excellence in professionalism is becoming increasingly noticeable ${ }^{48}$, and may even contribute to burnout and premature retirement from clinical practice ${ }^{93}$. The incongruence between patients' and physicians' perceptions in relation to the categories of professionalism may be explained by the fact that physicians, unlike their patients, do not experience the negative effects of these previously unnoticed elements of professionalism. Taking account of patients' views in defining and teaching of professionalism can thus improve our understanding of professionalism from yet another perspective. So far, patient complaints are under utilized as a (valuable) source of information about professional behaviour issues of health care personnel, although the association between unprofessional behaviour and quality of care and patient safety has clearly been demonstrated. Although a formative approach may suffice for the majority of health care workers, summative approaches may nevertheless be necessary for a small minority. Addressing professionalism issues while actively practising medicine, i.e. during continuing professional development, is also still in its infancy. Signalling professionalism issues that can lead to patient complaints can, when and wherever this is deemed desirable be followed by focused intervention strategies. Whether these efforts should primarily be directed at an individual level (physicians that numerically make an extraordinary contribution to the number of complaints filed), the interpersonal level (attention to group processes, communication and management skills) and/or the departmental/institutional level (e.g. organizational issues, learning climate, leadership) can be revealed by such an analysis (although this was not possible in our study because the data were anonymised).

\section{Conclusions regarding Research question 5}

The context in which physicians work influences their perception of professionalism and the importance attributed to its individual elements. The vast majority of complaints were related to non-cognitive, professionalism aspects of care, in which complaints about unsatisfactory communication predominated. Since, in general, the same elements of professionalism were considered important by both physicians and patients; it seems that physicians' practice and rhetoric are somewhat incongruent. However, there were also issues that were not identified as important by physicians, but were repeatedly emphasized by patients. Systematic analysis of unsolicited health care 
complaints can thus provide valuable insight into patient care-related professionalism aspects on an individual, interpersonal and institutional level.

\section{Directions for future research}

1. The experienced infringement of work life on private life is a relatively new phenomenon. How it impacts on the perceived importance of different professionalism items from different perspectives remains to be determined.

2. Further comparison of common definitions and conceptions of professionalism in medicine to those in other professions has not been performed. It is unknown whether medicine-specific professionalism elements can be identified, or whether professionalism elements are mostly generic.

3. The concept of professionalism and its assessment across different linguistic, cultural and sometimes religious contexts should be studied. Some languages do not seem to have a word that adequately conveys the meaning of the word professionalism. Furthermore, behaviours considered appropriate in one culture may be considered rude in others, and vice versa. Within one homogeneous culture these differences may be relatively unimportant in daily practice, but in multicultural societies these differences appear to be playing an increasingly important role. For example, how important is shaking hands or making eye contact for establishing a good patient doctor relationship? What are the consequences of refusal to shake hands, or of wearing or not wearing a headscarf, niqab, burqa or comparable garment?

4. So far it has not been determined whether different categories of elements can be distinguished with regard to definitions of professionalism. Are there elements of professional behaviour that, more than others are amenable to learning (and therefore remediation) and are there other elements that are more immutable and therefore suitable for inclusion in selection processes? Such knowledge could be used to refine selection processes, remediation pathways and the framework for dealing with unprofessional behaviour.

5. Further investigations of links between assessment of professionalism and quality of patient care offer promise. The differences between aspects of professionalism considered of primary importance by patients in patient satisfaction surveys and in formal complaints by patients to the patient 
information centre and complaints officers, as examples of institutional structures with different hierarchical status, also warrant further investigation.

\section{Limitations of the studies in this dissertation}

\section{Context}

A limitation of several studies in this dissertation is the context in which they were performed. Findings from studies performed within one institution, within one specialty, or within one country, allow only limited and cautious extrapolation to other contexts. Nevertheless, some of these findings may apply to other settings as well. Replication of studies in different settings may shed further light on the generalisability of some of the research findings.

\section{Selection}

The value of professionalism issues in relation to the quality of care can be studied at different levels, ranging from solicited pre discharge data about patient satisfaction to formal unsolicited complaints. The latter can be filed at different hierarchical levels within one institution but also differ between institutions. If our analysis had included actively solicited pre-discharge patient interviews, both the quantitative and qualitative results would undoubtedly have been affected.

\section{Perspective}

Another limitation is the exclusive focus on students' perceptions in Chapter 5. This precluded comparisons between tutors' and students' views. However, tutors' views are equally important considering their pivotal role in the tutorial group process in general, and in professionalism issues in particular.

\section{Changes over time}

Data presented were derived from cross-sectional studies, so that no firm conclusions can be drawn regarding real changes over time, as this would require a proper longitudinal design. Furthermore, data were aggregated and analyzed, e.g. per year group, providing only limited information about (changes) on the level of the tutorial group or individuals. 


\section{Consequences for medical educational and clinical practice}

The results of the studies in this dissertation may have operationalisational consequences for teaching and assessment of professional behaviour in undergraduate and (post)graduate training. Some of the most obvious consequences are listed below.

1. Selection for medical school in general, and pertaining to professionalism in particular, has proven to have merit and may be used to select increasing numbers of applicants to medical school, thereby reducing the number of students admitted on the basis of the current lottery process.

2. Addressing unprofessional behaviour in undergraduate medical education requires ample administrative and logistic support, and is thus labour intensive and costly. The extent to which a framework for education and assessment of professionalism that is based on the best available evidence and scientific insights will be implemented ultimately depends on a trade-off between the ideal to be sustained and the feasibility and acceptability of the practical measures required.

3. The teachers' role in the assessment of professionalism is paramount. Faculty development programmes to teach teachers about professionalism education need to be developed and further evaluated.

4. In intensive care medicine, the impact of supervisors as role models for learning professional behaviour is also significant ${ }^{49-52}$, and local faculty development programmes (teach-the-teacher sessions about professionalism and feedback) are likewise considered indispensable.

5. Formal teaching sessions on professionalism issues should also be instituted in intensive care medicine training programmes. Multidisciplinary discussion of (near) errors is considered an especially useful method to promote discussion of professionalism aspects of care, and can serve to stimulate self-reflection on action.

6. Since the use of advanced assessment technologies has only limited, quantitative advantages in the assessment of professional behaviour, this limited advantage should preferably be combined with face-to-face, engroupe discussion of professional behaviour, which was considered eminently suitable in assessing professional behaviour. However, the 
labour intensive nature of traditional assessment methods of professional behaviour may make the use of other technologies inevitable in the future.

7. Since the vast majority of health care receivers' complaints relate to noncognitive, professionalism aspects of care, with a dominant place for unsatisfactory communication, knowledge and skills relating to these aspects should be given sufficient attention during medical school and residency training.

8. Taking account of patients' views in defining and teaching professionalism issues can improve our understanding of professionalism from yet another perspective.

9. Systematic analysis of unsolicited health care complaints can offer valuable insights into patient care-related professionalism aspects on an individual, interpersonal and departmental/institutional level. Complaints can be used as a formal teaching tool to stimulate reflection and in that way contribute to improving the quality of care. 


\section{References}

1. Hodges B, Ginsburg S, Cruess R, et al. Assessment of professionalism: Recommendations from the Ottawa 2010 conference. Accepted Medical Teacher.

2. Cohen JJ. Professionalism in medical education, an American perspective: from evidence to accountability. Med Educ 2006;40:607-17.

3. Cruess RL, Cruess SR. Professionalism is a generic term: practicing what we preach. Med Teach 2010;32:713-4.

4. van Mook W, Gorter S, de Grave W, et al. Bad apples spoil the barrel: addressing unprofessional behaviour. Medical Teacher 2010;32:891-8.

5. Leape LL, Fromson JA. Problem doctors: is there a system-level solution? Ann Intern Med 2006;144:107-15.

6. Hickson GB, Pichert JW, Webb LE, Gabbe SG. A complementary approach to promoting professionalism: identifying, measuring, and addressing unprofessional behaviors. Acad Med 2007;82:1040-8.

7. Knights JA, Kennedy BJ. Medical school selection: impact of dysfunctional tendencies on academic performance. Med Educ 2007;41:362-8.

8. Albanese MA, Snow MH, Skochelak SE, Huggett KN, Farrell PM. Assessing personal qualities in medical school admissions. Acad Med 2003;78:313-21.

9. Morrison J. Professional behaviour in medical students and fitness to practise. Med Educ 2008;42:118-20.

10. Morrison J. How to choose tomorrow's doctors. Med Educ 2005;39:240-2.

11. Lumsden MA, Bore M, Millar K, Jack R, Powis D. Assessment of personal qualities in relation to admission to medical school. Med Educ 2005;39:258-65.

12. Lowe M, Kerridge I, Bore M, Munro D, Powis D. Is it possible to assess the "ethics" of medical school applicants? J Med Ethics 2001;27:404-8.

13. Bore M, Munro D, Kerridge I, Powis D. Selection of medical students according to their moral orientation. Med Educ 2005;39:266-75.

14. Eva KW, Rosenfeld J, Reiter HI, Norman GR. An admissions OSCE: the multiple miniinterview. Med Educ 2004;38:314-26.

15. Dodson M, Crotty B, Prideaux D, Carne R, Ward A, de Leeuw E. The multiple mini-interview: how long is long enough? Medical education 2009;43:168-74.

16. Eva KW, Reiter HI, Rosenfeld J, Norman GR. The ability of the multiple mini-interview to predict preclerkship performance in medical school. Acad Med 2004;79:S40-2.

17. Eva KW, Reiter HI, Trinh K, Wasi P, Rosenfeld J, Norman GR. Predictive validity of the multiple mini-interview for selecting medical trainees. Medical education 2009;43:767-75.

18. Reiter HI, Eva KW, Rosenfeld J, Norman GR. Multiple mini-interviews predict clerkship and licensing examination performance. Medical education 2007;41:378-84.

19. Hofmeister M, Lockyer J, Crutcher R. The multiple mini-interview for selection of international medical graduates into family medicine residency education. Medical Education 2009;43: 573-9.

20. van Mook WN, van Luijk SJ, Feij MJG, et al. Combined formative and summative professional behaviour assessment approach in the bachelor phase of medical school: a Dutch perspective. Accepted Medical Teacher 2010.

21. Papadakis MA, Hodgson CS, Teherani A, Kohatsu ND. Unprofessional behavior in medical school is associated with subsequent disciplinary action by a state medical board. Acad Med 2004;79:244-9.

22. Papadakis MA, Teherani A, Banach MA, et al. Disciplinary action by medical boards and prior behavior in medical school. N Engl J Med 2005;353:2673-82.

23. Stern DT, Frohna AZ, Gruppen LD. The prediction of professional behaviour. Med Educ 2005;39:75-82.

24. Morrison J, Morrison T. Psychiatrists disciplined by a state medical board. Am J Psychiatry 2001;158:474-8. 
25. Morrison J, Wickersham P. Physicians disciplined by a state medical board. Jama 1998;279:1889-93.

26. Taragin MI, Wilczek AP, Karns ME, Trout R, Carson JL. Physician demographics and the risk of medical malpractice. Am J Med 1992;93:537-42.

27. Yates J, James D. Risk factors at medical school for subsequent professional misconduct: multicentre retrospective case-control study. Bmj;340:c2040.

28. Papadakis MA, Loeser $\mathrm{H}$. Using critical incident reports and longitudinal observations to assess professionalism. In: Measuring medical professionalism Stern, DT (ed) Oxford University Press, New York, 2006 ISBN-13: 978-0-19-517226-3 2006:159-74.

29. van der Hoeven MJA, Rutte M. Memorie van toelichting op WHOO. In te zien op: http://www.minocw.nl/documenten/Mvtwetophethogeronderwijsenonderzoek.pdf 2006.

30. Bonke B, van Luijk S. Protocol ludicium Abeundi. Accessed November 25th 2010 at: http://www.nfu.nl/indexphp?id=64\&no_cache=1\&tx_ttnews\%5Btt_news\%5D=1304\&tx_ttnews $\% 5$ BbackPid\%5D=3 2010.

31. de Leeuw P. Iudicium abeundi. Ned Tijdschr Geneeskd 2010;154:B612.

32. Project Team Consilium Abeundi van Luijk SJe. Professional behaviour: Teaching, assessing and coaching students. Final report and appendices. Mosae Libris 2005.

33. van Mook WN, Gorter SL, O'Sullivan H, Wass V, Schuwirth LW, van der Vleuten CP. Approaches to professional behaviour assessment: tools in the professionalism toolbox. Eur $\mathrm{J}$ Intern Med 2009;20:e153-7.

34. van Luijk S, Gorter R, Van Mook W. Promoting professional behaviour in undergraduate medical, dental and veterinary curricula in the Netherlands: evaluation of a joint effort. Medical Teacher 2010;32:733-9.

35. Gijselaers W, Schmidt HG. Development and evaluation of a causal model of problem-based learning. In: Innovation in Medical Education: An evaluation of its present status Eds: AM Nooman, HG Schmidt, ES Ezzat 1990;Springer, New York, ISBN 0-8261-5850-1:95-113.

36. Steinert $Y$. Student perceptions of effective small group teaching. Med Educ 2004;38:286-93.

37. Steinert Y, Cruess S, Cruess R, Snell L. Faculty development for teaching and evaluating professionalism: from programme design to curriculum change. Med Educ 2005;39:127-36.

38. van Mook WN, de Grave WS, Huijssen-Huisman E, et al. Factors inhibiting assessment of students' professional behaviour in the tutorial group during problem-based learning. Med Educ 2007;41:849-56.

39. Wagner P, Hendrich J, Moseley G, Hudson V. Defining medical professionalism: a qualitative study. Med Educ 2007;41:288-94.

40. Ephgrave K, Stansfield RB, Woodhead J, Sharp WJ, George T, Lawrence J. The resident view of professionalism behavior frequency in outstanding and "not outstanding" faculty. Am J Surg 2006;191:701-5.

41. Ratanawongsa N, Bolen S, Howell EE, Kern DE, Sisson SD, Larriviere D. Residents' perceptions of professionalism in training and practice: barriers, promoters, and duty hour requirements. J Gen Intern Med 2006;21:758-63.

42. Branch WT, Jr., Kern D, Haidet $P$, et al. The patient-physician relationship. Teaching the human dimensions of care in clinical settings. Jama 2001;286:1067-74.

43. Van Mook W, Bion J, Wilde J, Schuwirth L, on behalf of the CoBaTrICE collaboration. Workplace based assessment: how to use it in the ICU. Submitted Int Care Med 2010.

44. Edelstein SB, Stevenson JM, Broad K. Teaching professionalism during anesthesiology training. J Clin Anesth 2005;17:392-8.

45. Page DW. Professionalism and team care in the clinical setting. Clin Anat 2006;19:468-72.

46. van Luijk S, van Oosterhout W, van Mook WNKA. Professionaliteit: het toetsen en leren van de professionele rol. Submitted: Netherlands Journal of Medical Education 2008.

47. Bion JF, Barrett H. Development of core competencies for an international training programme in intensive care medicine. Intensive Care Med 2006;32:1371-83.

48. van Mook WNKA, De Grave WS, Gorter SL, Zwaveling JH, Schuwirth LW, Van der Vleuten CPM. Intensive care medicine trainees' perception of professionalism: a qualitative study. Accepted Anaesth Int Care 2010. 
49. Wright S, Wong A, Newill C. The impact of role models on medical students. J Gen Intern Med 1997;12:53-6.

50. Wright SM, Carrese JA. Excellence in role modelling: insight and perspectives from the pros. Cmaj 2002;167:638-43.

51. Wright SM, Kern DE, Kolodner K, Howard DM, Brancati FL. Attributes of excellent attendingphysician role models. N Engl J Med 1998;339:1986-93.

52. Jones WS, Hanson JL, Longacre JL. An intentional modeling process to teach professional behavior: students' clinical observations of preceptors. Teach Learn Med 2004;16:264-9.

53. Stephenson AE, Adshead LE, Higgs RH. The teaching of professional attitudes within UK medical schools: reported difficulties and good practice. Med Educ 2006;40:1072-80.

54. van Mook W, de Grave W, Wass V, et al. Professionalism: Evolution of the concept. Eur J Int Med 2009;20:e81-e4.

55. Lee AG, Beaver HA, Boldt $\mathrm{HC}$, et al. Teaching and assessing professionalism in ophthalmology residency training programs. Surv Ophthalmol 2007;52:300-14.

56. Rowley BD, Baldwin DC, Jr., Bay RC, Cannula M. Can professional values be taught? A look at residency training. Clin Orthop Relat Res 2000:110-4.

57. Medische vervolgopleidingen.nl http://www.medischevervolgopleidingennl/pages/ contentaspx?content $=10010000000029 \_2 \_10000000001651 \&$ contentcode $=$ competentiesspe cialist, accessed October 10th 2006.

58. Accredition Council for Graduate Medical Education. ACGME Outcome Project enhancing residency education throught outcomes assessment: General competencies. 1999;Accessed Febr 13th 2006: http://www.acgme.org/outcome/comp/compFull.asp.

59. Royal College of Physicians and Surgeons in Canada. The CanMeds Framework. http://rcpsc.medical.org/canmeds/indexphp Accessed November 27th 20082005.

60. Wofford MM, Wofford JL, Bothra J, Kendrick SB, Smith A, Lichstein PR. Patient complaints about physician behaviors: a qualitative study. Acad Med 2004;79:134-8.

61. Montini T, Noble AA, Stelfox HT. Content analysis of patient complaints. Int J Qual Health Care 2008;20:412-20.

62. Boor K, van der Vleuten C, Teunissen P, Scherpbier A, Scheele F. Development and analysis of D-RECT, an instrument measuring residents' learning climate. Medical Teacher, 2010 (accepted for publication).

63. Boor K, Scheele F, van der Vleuten CP, Scherpbier AJ, Teunissen PW, Sijtsma K. Psychometric properties of an instrument to measure the clinical learning environment. Med Educ 2007;41:92-9.

64. Riquelme A, Herrera C, Aranis C, Oporto J, Padilla O. Psychometric analyses and internal consistency of the PHEEM questionnaire to measure the clinical learning environment in the clerkship of a Medical School in Chile. Med Teach 2009;31:e221-5.

65. Schonrock-Adema J, Heijne-Penninga M, Van Hell EA, Cohen-Schotanus J. Necessary steps in factor analysis: enhancing validation studies of educational instruments. The PHEEM applied to clerks as an example. Med Teach 2009;31:e226-32.

66. Norcini JJ, Blank LL, Duffy FD, Fortna GS. The mini-CEX: a method for assessing clinical skills. Ann Intern Med 2003;138:476-81.

67. Cruess R, Mcllroy JH, Cruess S, Ginsburg S, Steinert $\mathrm{Y}$. The professionalism mini-evaluation exercise: a preliminary investigation. Acad Med 2006;81:S74-8.

68. Tsugawa $\mathrm{Y}$, Tokuda $\mathrm{Y}$, Ohbu S, et al. Professionalism Mini-Evaluation Exercise for medical residents in Japan: a pilot study. Medical Education 2009;43:968-78.

69. Boaden N, Leaviss J. Putting teamwork in context. Med Educ 2000;34:921-7.

70. De Leng B. Wired for learning: How computers can support interaction in small group learning in higher education. Thesis Mediview, Maastricht ISBN 978-90-77201-35-0 2009.

71. Pendleton D, Schofield T, Tate P. A method for giving feedback. . In: The consultation: an approach to learning and teaching Oxford: Oxford University Press 1984:68-71.

72. Branch WT, Jr., Paranjape A. Feedback and reflection: teaching methods for clinical settings. Acad Med 2002;77:1185-8.

73. National Board of Medical Examiners. Assessment of professional behaviors program. http://www.nbme.org/schools/apb/indexhtml; accessed September 24th 2010. 
74. Mazor K, Clauser BE, Holtman M, Margolis MJ. Evaluation of missing data in an assessment of professional behaviors. Acad Med 2007;82:S44-7.

75. Mazor KM, Canavan C, Farrell M, Margolis MJ, Clauser BE. Collecting validity evidence for an assessment of professionalism: findings from think-aloud interviews. Acad Med 2008;83:S9-12.

76. van Mook W, van Luijk S, O'Sullivan $\mathrm{H}$, et al. The concepts of professionalism and professional behaviour: Conflicts in both definition and learning outcomes. Eur J Int Med 2009;20:e85-e9.

77. Veloski JJ, Hojat M. Measuring specific elements of professionalism: empathy, teamwork and lifelong learning. In: Measuring medical professionalism Stern, DT (ed) Oxford University Press, New York, 2006 ISBN-13: 978-0-19-517226-3 2006.

78. Knaus WA, Draper EA, Wagner DP, Zimmerman JE. An evaluation of outcome from intensive care in major medical centers. Ann Intern Med 1986;104:410-8.

79. Gibson SJ, Martin SM, Johnson MB, Blue R, Miller DS. CNS-directed case management. Cost and quality in harmony. J Nurs Adm 1994;24:45-51.

80. Whitcomb ME. Communication and professionalism. Patient Educ Couns 2000;41:137-44.

81. Hodges B, Turnbull J, Cohen R, Bienenstock A, Norman G. Evaluating communication skills in the OSCE format: reliability and generalizability. Med Educ 1996;30:38-43.

82. Rees C, Sheard C, McPherson A. Medical students' views and experiences of methods of teaching and learning communication skills. Patient Educ Couns 2004;54:119-21.

83. Schnabl GK, Hassard TH, Kopelow ML. The assessment of interpersonal skills using standardized patients. Acad Med 1991;66:S34-6.

84. Lewin LO, Cole-Kelly K, Greenfield M. A year-long course for third-year students on ethics, professionalism, and communication. Acad Med 2001;76:511.

85. Buchanan D, Rohr L, Kehoe L, Glick SB, Jain S. Changing attitudes toward homeless people. J Gen Intern Med 2004;19:566-8.

86. Azoulay E, Pochard F, Chevret $\mathrm{S}$, et al. Meeting the needs of intensive care unit patient families: a multicenter study. Am J Respir Crit Care Med 2001;163:135-9.

87. Angus DC. Charting (and publishing) the boundaries of critical illness. Am J Respir Crit Care Med 2005;171:938-9.

88. Pellegrino ED. Professionalism, profession and the virtues of the good physician. Mt Sinai $J$ Med 2002;69:378-84.

89. Holder KV, Schenthal SJ. Watch your step: nursing and professional boundaries. Nurs Manage 2007;38:24-9; quiz 9-30.

90. Sheets VR. Staying in the lines. Nurs Manage 2000;31:28-33; quiz -4.

91. Miller G. The assessment of clinical skills/competence/performance. Acad Med65(suppl) 1990;65 (suppl):S63-7.

92. Charap M. Reducing resident work hours: unproven assumptions and unforeseen outcomes. Ann Intern Med 2004;140:814-5.

93. Miedema B, Easley J, Fortin P, Hamilton R, Tatemichi S. Crossing boundaries: family physicians' struggles to protect their private lives. Can Fam Physician 2009;55:286-7 e5. 
Summary 
200 


\section{Teaching and assessment of professional behaviour: rhetoric and reality}

Dissertation on aspects of teaching and assessing professional behaviour before, during and after undergraduate and postgraduate medical education and training

\section{Introduction}

The perfect physician not only possesses extensive medical knowledge and excellent technical and procedural skills but he or she is also honest, responsible, respectful and empathetic to patients. Preferably, he or she is also a pleasant colleague. Unfortunately, not everyone is born with all these qualities. In recent years it has increasingly dawned upon the medical education community that aspects other than knowledge and medical technical skills can and should be learned and taught at all stages of the medical curriculum. This has given rise to definitions of the terms professionalism and professional behaviour, referring to very similar concepts but from slightly different perspectives. In the following the terms will be used interchangeably. In the wake of the upsurge of interest in professional behaviour, much effort has gone into revising undergraduate, postgraduate and continuing medical education programmes in order to incorporate aspects of professionalism. The increasing interest is also reflected in a considerable body of literature. While the stream of publications on topics like new empirical definitions of professionalism and professional behaviour continues unabatedly, frameworks for teaching and assessing professional behaviour have been in place in undergraduate medical education programmes for a sufficiently long period to warrant some (re-)evaluation studies. As for postgraduate training, there is a current shift towards competency-based programmes, all of which incorporate professionalism as one of the competencies. In some of these programmes the full details of curricular content around professional behaviour remain to be worked out fully, while teachers and curriculum developers are occasionally seen to struggle with the implementation of professionalism education and assessment. In summary, the implementation of aspects of professionalism in medical education programmes is in a state of flux, underscoring the timeliness of studies re-evaluating current best educational practices in undergraduate programmes on medical professionalism aimed at identifying enabling and impeding factors. These can subsequently inform efforts to optimize the implementation of professionalism in undergraduate medical education. In postgraduate programmes, on the other hand, exploratory research seems 
more opportune, delving into the notions and connotations associated with the terms professional behaviour and professionalism, the ways medical specialists learn about professionalism during their training, before becoming involved in the development and implementation of clinical teaching and assessment strategies aimed at enhancing the professionalism and professional behaviour of future generations of specialists. The Chapters in this dissertation present outcomes and insights gained in both exploratory and evaluative research undertaken between 2006-2010 in order to shed light on perceptions and practices around learning, teaching and assessing professional behaviour in all stages of medical education starting with admission to undergraduate medical training and continuing through postgraduate training to continuing professional development and beyond.

\section{Chapter 1}

This introductory Chapter provides some historical background to explain the semantic evolution of the terms professionalism and professional behaviour and how this has led to current operationalisations of teaching and assessment of professional behaviour. The Chapter addresses different conceptualizations underlying the terms professional behaviour and professionalism, general educational aspects, and similarities and differences in this regard between undergraduate, postgraduate and continuing medical education. The place of professional behaviour in medical education is also discussed from the perspective of patient safety and quality of care.

\section{Chapter 2}

The literature review in Chapter 2 examines different approaches to dealing with unprofessional behaviour and their potential value to medical education.

When applied in relation to admission to undergraduate medical education, the approach is called selection. Two different approaches are relevant herein. First, selection can involve screening for the presence of personal characteristics identified as predisposing students to becoming excellent doctors. Alternatively, selection can screen for qualities that predispose students to future unprofessional behaviour. Selection of medical school applicants is of relatively recent date in the Netherlands and it is a popular topic in the current public debate. The available literature suggests that selection may contribute to restoring society's trust in the medical profession, while also being cost-effective. The literature offers not enough evidence to decide whether one single selection method has sufficient positive and negative predictive power with respect to professional behaviour. One of the most promising selection tools seems to be the multiple mini interview (MMI), which presents applicants with a series of OSCE-like contacts, using interactive or 
standard interviews and simulated patients to assess critical thinking, ethical issues, communication skills and knowledge of the health care system. The $\mathrm{MMI}$ appears to consistently differentiate better between candidates than do other selection methods. Compared to traditional interview methods, the results of the $\mathrm{MMI}$ are better correlated with future clinical performance, professional behaviour, doctor-patient communication and successful completion of undergraduate medical training. In Maastricht, the MMI is used in the admission procedure of the graduate entry medical programme.

It is widely acknowledged and accepted that, after the initial selection process, unprofessional behaviour requires consistent attention and assessment. A single tool does not seem sufficient, and usually combinations of instruments, known as triangulation, are used, preferably sampling over a variety of contexts and reviewers. Identification of unprofessional behaviour should start as early as possible, and the threshold for reporting be kept low. This requires that students and staff be familiarised with professional behaviour, its backgrounds and the available assessment methods, as well as the institutional regulatory framework to deal with reported unprofessional behaviour. Students and faculty should be adequately trained in the skills of teaching and assessing professional behaviour. Today, attention to these issues is assured in undergraduate medical training in the Netherlands. In postgraduate training, however, little guidance is available for staff and residents on how to deal with unprofessional behaviour, and approaches tend to be ad hoc, informal and reactive, while formal procedures are rarely present.

The next four Chapters are devoted to issues relating to the operationalisation of professional behaviour in order to facilitate its incorporation in undergraduate medical education and assessment.

\section{Chapter 3}

Chapter 3 describes the adherence to the guidelines on teaching and assessing professional behaviour, defined in a report published in 2002 by a task group of the Association of Universities in the Netherlands (VSNU) and intended for implementation by the dental, veterinary and medical faculties in the Netherlands. The report de facto introduced national standards, although adherence to the recommendations is not mandatory. A questionnaire survey among representatives of the various faculties with responsibility for professional behaviour reveals that all faculties strongly endorse the content of the report, and that attention to professional behaviour has increased dramatically in all schools since the publication of the guidelines. Today, all schools have, at least partially, incorporated the recommendations in their 
programme with any differences being mostly related to curricular organization and educational tools and formats. Most schools have decided to give more prominence to aspects of professional behaviour that were already present in the existing curriculum, rather than develop new materials and new educational activities. All schools now have in place a longitudinal assessment process for professional behaviour. The increasing emphasis on aspects of quality of care and patient safety in relation to professional behaviour, and the associated focus on the signalling of unprofessional behaviour are perceived to be strong enabling factors for the construction of a sound educational framework for professional behaviour. Remaining hurdles include the need to seek and incorporate students' views on the implemented frameworks, optimizing faculty members' confidence in their assessment skills through teach-the-teacher sessions, quantitative and qualitative shortcomings of remedial teaching programmes regarding professional behaviour and lack of administrative and logistical support, such as secretarial staff. So far, most schools do not record data on the number of students reported to show unprofessional behaviour, which makes it difficult to determine the extent and nature of the problem of unprofessional behaviour on an institutional, let alone national level. Such data has now been gathered at Maastricht University.

\section{Chapter 4}

This Chapter describes the results of a four-year study of formative and summative approaches to assessing professional behaviour and the quantity and nature of reports of unprofessional behaviour during the first two years of undergraduate medical education at Maastricht University. It proved feasible to combine in one framework a formative and summative approach to assessing professional behaviour. Various quantitative and qualitative phenomena were observed. From a quantitative perspective the following developments were noted. The number of students given 'no judgment possible' due to frequent absence from educational activities increased markedly. The number of negative end-of-year judgments has been relatively stable for a long time, although recently there was a marked increase in the number of negative endof-year judgments for first year students. A similar increase was seen in the number of critical incident reports regarding professional behaviour outside regular educational assessment moments. These reports mainly concerned unannounced, unauthorized absences from simulated patient contacts, not meeting appointments and agreements regarding the portfolio, and failure to respond to repeated calls to attend hepatitis $B$ vaccination. The number of students invited to a meeting with the Committee on Professional Behaviour also increased. This was related to inadequate and unsatisfactory explanatory responses from students to requests from the Committee and to suggestions 
from study advisors based on prior (negative) experiences with students. Given the limited availability and labour-intensive nature of individually tailored remediation programmes, it is hoped that these quantitative developments are a transient phenomenon. Finally, male students generally received more negative professional behaviour judgments and 'no judgment possible' reports than female students, a finding that is not yet fully understood.

From a qualitative perspective, almost all negative judgments of professional behaviour during regular educational activities related to 'Dealing with work' and 'Dealing with others' and rarely to 'Dealing with oneself'. This suggests that the tutorial group is less suitable for assessing self-reflection, although all negative judgments are preceded by repeated feedback to students when their behaviour shows no significant improvement. This indirectly points towards a lack of self-reflective capabilities and/or an inability to change.

\section{Chapter 5}

Chapter 5 describes the results of a survey exploring the perceptions of first, second and third year students regarding factors inhibiting assessment of professional behaviour in tutorial groups, and whether these factors are attributable to students, teachers or both. Four out of five factors that were identified were associated with the tutor, and three of the five factors suggested that students should be better informed about the background and methods of assessment of professional behaviour. Not confronting students with observed unprofessional behaviour and inadequate feedback were the strongest inhibitory factors. The results underscore the pivotal role of the tutor. Faculty development programmes should therefore focus on the necessary background knowledge and skills with respect to professional behaviour assessment, with emphasis on confronting students and providing feedback. As a direct spin-off from this study, video vignettes were produced for exactly this purpose.

\section{Chapter 6}

This Chapter describes whether an assessment tool using web-based technology can increase the quantity and quality of feedback in comparison with the traditional paper based method. During the first block of the second year of the Maastricht curriculum, the tutorial groups were assigned to the traditional, paper-based assessment or the new tool. Comments were counted and the quality of feedback was assessed. A questionnaire explored the feasibility, acceptability and perceived usefulness of the two methods. The web-based tool yielded significantly more comments than the paper form. This suggests that the web-based tool, which allows for more individualized and 
semi-anonymous assessment causes peers to feel less inhibited and more ready to give their opinion than the tool that requires comments to be given in group. The quality of comments did not differ between the two tools. Nevertheless, an increase without loss of quality can be considered an improvement. The questionnaire, however, showed that tutors and students clearly preferred the traditional paper based method, because its interpersonal nature was considered to be eminently suitable for 'en-groupe' discussion. This preliminary study suggests that innovative, modern technology is not a priorian improvement in the case of assessment of professional behaviour, despite the marked quantitative increase in comments. Despite preferences for the paperbased assessment, it is conceivable that in the future even newer modern technology will have to be implemented in order to reduce the high costs associated with the traditional method.

The next two Chapters focus on elements of professional behaviour that intensivists in training (intensive care medicine fellows) considered relevant for their future profession and how they learned these. Two nationwide studies were performed, one using a previously published questionnaire and the other using focus group interviews.

\section{Chapters 7 and 8}

Elements of professional behaviour relevant to intensivists

Almost all elements of professional behaviour are considered relevant to daily practice by intensive care fellows. The questionnaire item receiving the highest rating in Chapter 7 concerns reflection on action and enthusiastic and supportive supervisors. 'Teamwork' and 'Dealing with ethical dilemmas' were also important. The focus group interviews described in Chapter 8 emphasize 'Communication', 'Keeping distance and setting boundaries', 'Medical knowledge and expertise' and, to a lesser extent, 'Respect', 'Teamwork', 'Leadership' and 'Organization and management'.

These two Chapters reveal several new insights. First, medical knowledge and skills were not considered to be key elements of professional behaviour. Perhaps the fellows had learned and mastered these elements during prior specialty training, and consequently spent less time on them now. Second, teamwork was considered important, although it is not included in many existing definitions of professionalism. This finding underscores the key role of intensivists in the ICU in modern multidisciplinary patient care. Third, ethical dilemmas, for instance relating to decisions not to initiate or to withdraw treatment were an important topic during the focus group interviews, again 
reflecting the nature of intensivists' daily work. Furthermore, good communication and listening skills were considered critically important in the long-term guidance of critically ill patients and their families. Finally, 'Keeping distance and setting boundaries' was also emphasized, particularly in relation to patients and their families and, to a lesser extent, colleagues. The struggle to find a balance between personal and professional life was also stressed, which could reflect a change in professional attitudes towards working hours, increasing priority of private versus professional activities and increased parttime work. In conclusion, the fellows' perceptions of professional behaviour appeared to be influenced by their specific work context as well as by the era in which they live and work.

Learning aspects of professional behaviour in intensive care medicine

Chapters 7 and 8 also provide insight into how fellows learned about professional behaviour in the intensive care environment. In Chapter 7, 'Observations in daily practice' and 'Experiential learning and role modelling' received the highest ratings. The role of supervisors as role models of professional behaviour is evident and faculty development (teach-the-teacher sessions) seems indispensable. A quarter of the participants emphasized the importance of feedback on their actions as a stimulus to reflect on their behaviour. A similar proportion suggested an increase in the number of formal teaching sessions about professional behaviour. Multidisciplinary discussions of their own and others' (near) errors were considered a useful formal teaching method for both medical and professional aspects of care. In the fellows' opinions, the local training institutions should be given a key coordinating and executive role in the teaching of professional behaviour. The focus group interviews in Chapter 8 emphasize workplace learning, role modelling and feedback. The participants suggested that feedback should be actively sought if not provided voluntarily. Difficult situations in real practice relating to professional behaviour or unexpected results of actions could be discussed to stimulate reflection on action. Learning from mistakes was mentioned as a valuable learning tool, which was used too infrequently. Leadership and a healthy educational climate were seen as major enabling factors for learning about professional behaviour. The main conclusion from both Chapters is that for intensivists-in-training the most important contribution to their learning about professional behaviour is made by role models which they encounter while working and training in the intensive care unit.

\section{Chapter 9}

The last Chapter of this dissertation focuses on professional behaviour from the perspective of quality of care and patient safety. It reports on an analysis of 
complaint letters sent by patients (or relatives) to the Complaints Committee of Maastricht University Medical Centre. The elements of professional behaviour occurring in these letters were compared to those identified by physicians (Chapter 8). First, doctors used more abstract, idealistic formulations (e.g. altruism and attitude), compared to more concrete and specific elements mentioned by patients and their relatives. Second, the majority of complaints related to aspects of professional behaviour, although complaints about perceived medical errors and complications were also common. Inadequate communication featured most prominently as a cause for complaint. Major grievances included 'Having to wait for care', 'Receiving unclear and/or insufficient information', 'Disrespectful communication' and 'Lack of teamwork'. Thirdly, comparison with the categories of elements that emerged from Chapter 8 reveals that most categories were mentioned by patients (or relatives) as well as doctors. It thus appears that the level of professional behaviour which doctors strive for in their work is not always achieved or perceived as having been achieved by patients, especially when we realize that only a significant minority of patients actually files a complaint. Eight categories of elements were mentioned by patients, but not by physicians, including 'Having to wait for care' and 'Lack of continuity of care'. Doctors may not experience adverse effects of these elements in their day-to-day work, but for patients they may be extremely burdensome and thus a cause of major grievances. In conclusion, systematic analysis of complaint letters sent by patients (or relatives) can teach important lessons about care aspects of professional behaviour at the individual level, interpersonal level (e.g. group processes, communication), and departmental/institutional level (e.g. organizational aspects, learning environment and teaching climate). Complaints more frequently pertain to aspects of communication and other generic aspects of professional behaviour than to medical knowledge and expertise. 


\section{Overview}

In summary, the studies described in this dissertation provide directions regarding the operationalisation of teaching and assessment of professional behaviour before and during all subsequent phases of the medical education continuum. The main findings can be summarized as follows:

1. Selection methods that include aspects of professional behaviour seem to have merit for procedures of admission to undergraduate medical education.

2. The administrative process for dealing with unprofessional behaviour during undergraduate medical training is very labour intensive and costly. A balance should be aimed for between the scientific ideal and a practical, feasible and acceptable framework.

3. A web-based method for assessing professional behaviour yielded more feedback of similar quality compared to the traditional paper-based method. Participants preferred the traditional paper and group based method. Innovative tools may nevertheless prove inescapable in the future from a cost reduction perspective.

4. The role of faculty in learning, teaching and assessing professional behaviour is crucial and thus faculty development (teach-the-teacher training) is essential. This holds for tutors (in relation to students) and supervisors in the intensive care unit (in relation to intensive care medicine fellows). Feedback is indispensable in this regard.

5. The intensive care context appears to be an ideal environment for learning about professional behaviour in situations that are encountered on a daily basis in the care of critically ill patients.

6. In addition to learning from role models in the workplace, formal educational sessions on professional behaviour should be implemented in intensive care training programmes. Multidisciplinary discussion of (near) errors, for example, seems to be eminently suitable for this purpose.

7. The majority of formal complaints lodged by patients or their families have to do with aspects of professional behaviour rather than medical errors or complications. Complaints about inadequate communication predominate. Taking account of patients' views in defining and learning about aspects of professional behaviour may help to further optimize the quality of care provided to patients by individuals, teams, departments and organizations. 



\section{Samenvatting}

Delen van dit hoofdstuk zijn in aangepaste vorm gepubliceerd in:

Nederlands Tijdschrift voor Geneeskunde 2009;153:1-6

Tijdschrift voor Medisch Onderwijs 2007;26:174-183

Tijdschrift voor Medisch Onderwijs 2007;26:237-246 
${ }_{212} \mid$ 


\section{Onderwijs en toetsing van professioneel gedrag: retoriek en realiteit}

Dissertatie welke aspecten van het onderwijs in en de toetsing van professioneel gedrag voor, tijdens en na de artsopleiding en de medische vervolgopleiding beschrijft.

\section{Inleiding}

De ideale arts bezit ruime medische kennis, goede technische vaardigheden, is daarnaast integer, verantwoordelijk, respectvol en empathisch naar patiënten. Als het even kan is hij of zij ook nog een prettige collega om mee samen te werken. Helaas is niet iedereen geboren met deze kwaliteiten. Tijdens de opleiding tot arts en de medische vervolgopleidingen bestaat toenemende belangstelling voor het leren en beoordelen van professioneel gedrag en professionaliteitaspecten. Terwijl het aantal publicaties met daarin onder andere beschrijvingen van telkens nieuwe empirische definities van professionaliteit en professioneel gedrag nog steeds toeneemt, zijn de al bestaande richtlijnen wat betreft onderwijs en toetsing van professioneel gedrag in de artsopleiding al aan evaluatie toe. De medische vervolgopleidingen zijn momenteel in ontwikkeling tot competentie gerichte programma's, die allemaal professionaliteit als competentie bevatten. In sommige van deze vervolgopleidingen zijn details over de inhoud van het curriculum met betrekking tot professioneel gedrag nog niet helemaal duidelijk. Opleiders en curriculumontwikkelaars worstelen daarnaast soms met implementatievraagstukken met betrekking tot onderwijs en toetsing van professioneel gedrag. Bovenstaande feiten onderstrepen de noodzaak om studies te verrichten die de huidige praktijk van onderwijs en toetsing van professioneel gedrag in de opleiding geneeskunde (her)evalueren, en faciliterende en beperkende factoren wat betreft implementatie en uitvoering ervan identificeren, met als doel deze te kunnen optimaliseren. In de medische vervolgopleidingen dient middels explorerend onderzoek de perceptie en wijze van leren van professioneel gedrag door medisch specialisten in opleiding geïnventariseerd te worden voordat ontwikkeling en implementatie van onderwijs en toetsing hiervan in de klinische praktijk kan plaatsvinden. De Hoofdstukken in dit proefschrift beschrijven aldus de resultaten van zowel evaluerend en explorerend onderzoek verricht in de periode 2006 - 2009 naar het de perceptie, het leren en beoordelen van professioneel gedrag voor, en tijdens de artsopleiding, in de medische vervolgopleiding, en na het afronden daarvan. 


\section{Hoofdstuk 1}

Dit Hoofdstuk bevat de introductie, welke de lezer een overzicht geeft van de historische achtergrond en de evolutie van de betekenis van professioneel gedrag tot heden. De concepten professioneel gedrag en professionaliteit, algemene aspecten van leren en toetsen van professioneel gedrag, en overeenkomsten en verschillen tussen de verschillende onderwijsfasen worden beschreven. Daarnaast wordt de waarde van professioneel gedrag vanuit het perspectief van patiëntveiligheid en kwaliteit van zorg toegelicht.

\section{Hoofdstuk 2}

De literatuurstudie die beschreven wordt in Hoofdstuk 2 geeft inzicht in de mogelijke wijze waarop het kijken naar aspecten van onprofessioneel gedrag van aanvullende waarde kan zijn ten opzichte van het aanleren en stimuleren van professioneel gedrag. Gebeurt dit in de fase voorafgaand aan het starten met de opleiding geneeskunde dan spreekt men van selectie. Met betrekking tot selectie zijn twee benaderingen mogelijk. Enerzijds kan selectie plaatsvinden op basis van persoonlijke, karaktereigenschappen die studenten predisponeren om uitstekende dokters te worden. Anderzijds kan geselecteerd worden op eigenschappen die studenten predisponeren tot onprofessioneel gedrag. Selectie staat momenteel in Nederland erg in de belangstelling. De literatuur suggereert dat selectie kan bijdragen aan het herstel van het vertrouwen van de maatschappij in de medische beroepsgroep, en tegelijkertijd kosteneffectief kan zijn. Of toepassing van slechts één selectiemethode kan resulteren in voldoende hoge positief en negatief voorspellende waarde met betrekking tot professioneel gedrag moet nog duidelijk worden, daar de literatuur over dit onderwerp nog relatief beperkt is. Een van de meest veelbelovende selectie instrumenten is het multipele mini interview (MMI), bestaande uit een aantal stationstoets (OSCE)-achtige contacten waarin studenten worden beoordeeld op gebied van kritisch denken, ethische problematiek, communicatie vaardigheden en kennis van de gezondheidszorg, gebruikmakend van interactieve of standaard interviews en simulatiepatiënten. Het MMI lijkt beter reproduceerbaar te kunnen differentiëren tussen kandidaten dan andere selectiemethoden. De uitslag van het MMI correleert bijvoorbeeld sterker met toekomstige klinische performance, professionaliteit, communicatie-vaardigheden met patiënten, en succesvol afronden van de artsopleiding dan de klassieke interview methoden. Het MMl wordt in Maastricht gebruikt voor het selecteren van kandidaten voor de opleiding ArtsKlinisch Onderzoeker (AKO), zij die al een vooropleiding succesvol hebben afgerond. Nadat studenten begonnen zijn met hun opleiding geneeskunde is aandacht schenken aan onprofessioneel gedrag een algemeen geaccepteerd gegeven. Ook hier lijkt één beoordelingsinstrument niet voldoende, en maakt 
men meestal gebruik van combinaties van instrumenten, zogenaamde triangulatie. Bij voorkeur wordt beoordeeld in verschillende contexten door meerdere beoordelaars. Identificatie van onprofessioneel gedrag zou zo vroeg mogelijk moeten plaatsvinden, en de drempel om dit te melden moet laag zijn. Daarnaast moeten studenten en staf bekend zijn met de achtergronden en instrumenten waarmee professioneel gedrag wordt beoordeeld en de wijze waarop er met beoordelingen onprofessioneel gedrag wordt omgegaan. Daarnaast moeten studenten en staf getraind worden in de vaardigheden die nodig zijn om professioneel gedrag op een goede wijze aan te leren en te beoordelen. Aan deze voorwaarden wordt tijdens de artsopleiding in Nederland al veel aandacht geschonken. Voor de medische vervolgopleidingen en daarna bestaan tot op dit moment nauwelijks richtlijnen hoe om te omgaan met assistenten of medisch specialisten die zich onprofessioneel gedragen. Het omgaan met de disfunctionerende assistent (en waarschijnlijk ook het omgaan met de disfunctionerende specialist) is dan ook vaak te omschrijven als ad hoc, informeel, en reactief, waarbij een procedurele afhandeling vaak ontbreekt.

De volgende vier Hoofdstukken beschrijven operationaliseringsaspecten van het onderwijs en toetsen van professioneel gedrag in de artsopleiding.

\section{Hoofdstuk 3}

Hierin wordt onderzocht in welke mate de richtlijnen ten aanzien van onderwijs en toetsen van professioneel gedrag, zoals die in 2002 door een speciale werkgroep van de Vereniging voor Universiteiten (VSNU) voor de faculteiten tandheelkunde, diergeneeskunde, en geneeskunde in Nederland zijn opgesteld, feitelijk zijn gevolgd door deze faculteiten. Dit zogenaamde Consilium Abeundi rapport doet daarnaast ook aanbevelingen t.a.v. begeleiding en omgaan met onprofessioneel gedrag. De facto betreft het dus nationale richtlijnen, hoewel deze aanbevelingen geen verplichtend karakter kennen. De resultaten van het in Hoofdstuk 3 beschreven vragenlijstonderzoek onder de voor professioneel gedrag verantwoordelijke stafleden van de genoemde opleidingen laten zien dat alle opleidingen nog steeds achter de inhoud van het rapport staan, en dat de aandacht voor professioneel gedrag in alle scholen enorm is toegenomen. Alle scholen hebben de aanbevelingen tenminste ten dele overgenomen, en verschillen bestaan heden ten dage vooral in de organisatiestructuur van het onderwijs en de toetsing van professioneel gedrag, evenals de doorvoor gebruikte instrumenten. Het meer zichtbaar maken van professionele gedragsaspecten in het bestaande curriculum, in plaats van het ontwikkelen van daarvoor geschikt nieuw materiaal en nieuwe onderwijssituaties was een algemene tendens, en alle scholen kennen momenteel een longitudinaal beoordelingstraject voor 
professioneel gedrag. Als invloedrijke, stimulerende factor werd de toenemende aandacht voor professioneel gedrag vanuit het perspectief van patiëntveiligheid en kwaliteit van zorg genoemd, en de daarmee gepaarde aandacht voor vroegtijdige onprofessioneel gedrag signalering. Te nemen hindernissen bleken het ontbreken van de visie van studenten ten aanzien van het leer- en beoordelingsproces, optimaliseren van het vertrouwen van de staf wat betreft hun beoordelingscapaciteiten met betrekking tot professioneel gedrag, het ontbreken van kwantitatief en kwalitatief goede en efficiënte remediëringsprogramma's voor disfunctionerende studenten, evenals voldoende administratieve en logistieke ondersteuning, in concreto een goed uitgerust secretariaat. De meeste opleidingen hebben tot op heden geen overzicht van het aantal studenten met onprofessioneel gedrag binnen hun opleiding, waardoor het moeilijk blijft de nationale omvang en aard van het onprofessionele gedrag vast te stellen, en vergelijking van faculteiten onmogelijk is. Voor de faculteit geneeskunde te Maastricht zijn deze gegevens inmiddels wel beschikbaar.

\section{Hoofdstuk 4}

Dit Hoofdstuk beschrijft de gecombineerde formatieve en summatieve beoordelingsstructuur, evenals de omvang en aard van de meldingen onprofessioneel gedrag tijdens de eerste twee jaren van de bachelorfase aan de Faculteit Geneeskunde te Maastricht over een periode van vier jaar. De formatieve en summatieve benadering van professioneel gedrag blijken binnen één beoordelingssysteem gecombineerd te kunnen worden. Diverse kwantitatieve en kwalitatieve fenomenen werden opgemerkt. Vanuit een kwantitatief perspectief vallen de volgende zaken op: Het aantal studenten bij wie geen beoordeling mogelijk bleek ten gevolge van te frequente afwezigheid bij de onderwijsactiviteiten nam toe. Het aantal onvoldoende eindoordelen bleef lange tijd relatief stabiel, hoewel het aantal onvoldoende eindbeoordelingen in jaar 1 recent fors toenam. Recent nam het aantal incidentele meldingen professioneel gedrag, meldingen buiten de reguliere beoordelingsmomenten om, eveneens toe. Deze meldingen bleken vooral te maken te hebben met de niet aangekondigde, noch toegestane afwezigheid bij simulatiepatiënten contacten, niet nakomen van afspraken met de mentor ten aanzien van het portfolio, en niet reageren op herhaaldelijke oproepen voor hepatitis B vaccinatie. Daar daarnaast de reacties door studenten op de ontbrekende beoordeling professioneel gedrag in de optiek van de Commissie niet afdoende of inadequaat was, en de studieadviseurs een aantal studenten onder de aandacht van de Commissie bracht, nam het aantal gesprekken van studenten met de Commissie Professioneel Gedrag eveneens toe. Gezien de beperkte beschikbaarheid, en het arbeidsintensieve karakter van op het individu 
toegespitste remediëringsprogramma's is dit hopelijk een voorbijgaand fenomeen. Tot slot krijgen mannen in nagenoeg alle jaren veel vaker 'onvoldoende' en 'geen oordeel' meldingen dan vrouwen, een fenomeen welk niet volledig verklaarbaar is. Vanuit een kwalitatief perspectief bezien, hebben de onvoldoende beoordelingen tijdens reguliere onderwijsactiviteiten nagenoeg altijd te maken met 'Omgaan met werk' en 'Omgaan met anderen', en zelden met 'Omgaan met zichzelf'. De context van de onderwijsgroepen is dus misschien minder geschikt voor het geven van een adequaat oordeel over de zelfreflectieve capaciteiten van studenten. Echter, een onvoldoende beoordeling wordt alleen gegeven nadat herhaaldelijke feedback geen verbetering in gedrag heeft opgeleverd, hiermee op indirecte wijze gebrek aan zelfreflectie en/of onmogelijkheid tot verandering weerspiegelend.

\section{Hoofdstuk 5}

Bij probleemgestuurd leren vormt de onderwijs- of werkgroep een van de hoekstenen van het onderwijs. Hoofdstuk 5 beschrijft een vragenlijstonderzoek onder eerste, tweede en derdejaars studenten naar factoren die vanuit het student perspectief de beoordeling van professioneel gedrag in de onderwijsgroep belemmeren, en of deze factoren toe te schrijven zijn aan studenten of docenten, of beiden. Vijf factoren werden geïdentificeerd. Vier daarvan bleken samen te hangen met de uitvoering van de rol van de tutor, die daarmee voor verbetering vatbaar bleek, en drie van de vijf factoren suggereerden dat studenten beter op de hoogte gebracht moesten worden van de achtergronden en wijze van professioneel gedrag beoordeling. Het niet confronteren van studenten met waargenomen onprofessioneel gedrag en niet adequaat geven van feedback kwamen als meest belemmerende factoren naar voren. Uit deze studie blijkt dat de niet alleen voor het algemeen functioneren van de onderwijsgroep belangrijk is, maar ook ten aanzien van professioneel gedrag beoordeling een spilfunctie heeft. Docentprofessionalisering dient zich dus te richten op het verkrijgen van de noodzakelijk achtergrond kennis en vaardigheden t.a.v. professioneel gedrag beoordeling, met speciale aandacht voor het confronteren en van feedback voorzien van studenten. Hiertoe zijn video fragmenten ontwikkeld.

\section{Hoofdstuk 6}

In dit Hoofdstuk wordt beschreven of het gebruik van een modern beoordelingsinstrument, welk gebruik maakt van 'world-wide-web gebaseerde technologie, leidt tot een toename in het aantal commentaren en de kwaliteit van deze feedback in vergelijking met de traditioneel gebruikte papieren methode. De onderwijsgroepen in blok 2.1 van het Maastrichtse curriculum werden om die reden verdeeld in een helft die het papieren formulier gebruikte, 
en een helft die de elektronische variant gebruikte. De commentaren werden geteld, en de kwaliteit ervan door middel van een geaggregeerde score uit vijf algemeen geaccepteerde feedback criteria beoordeeld. Daarnaast is gebruikmakend van een vragenlijst gekeken naar de haalbaarheid, acceptatie, en de gepercipieerde zinvolheid van de 'webgebaseerde', elektronische benadering versus de traditioneel gebruikte papieren methode. Het aantal commentaren was in de groep die gebruik maakte van de elektronische variant significant hoger dan in vergelijking met de papieren methode. Medestudenten voelen zich wellicht meer verplicht en minder geremd hun mening te geven op een individueel, semi-anoniem niveau, dan plenair in de onderwijsgroep. De kwaliteit van deze commentaren, zoals bekeken met de genoemde geaggregeerde feedback score was echter niet verschillend tussen de twee groepen. Een toename van het aantal commentaren, met behoud van de kwaliteit zou echter al een verbetering genoemd kunnen worden. Echter, de respondenten op de vragenlijsten, die de haalbaarheid, acceptatie en gepercipieerde nut van de twee methoden evalueerden, hadden een uitgesproken voorkeur voor de traditionele, papieren methode. Het interpersoonlijke karakter van professioneel gedrag beoordeling zou beter tot zijn recht komen tijdens 'en-groupe' bespreking ervan. Gebaseerd op dit voorlopige onderzoek met één specifiek instrument, is innovatie gebruik makend van moderne technologie in geval van professioneel gedrag beoordeling dus niet a priori beter, hoewel het aantal commentaren met ongewijzigde kwaliteit wel duidelijk toeneemt. Toch is het voorstelbaar dat het gebruik van wellicht nog modernere technologie wel kan bijdragen aan het verminderen van het arbeidsintensieve karakter (en daarmee kosten) van de traditionele manier van professioneel gedrag beoordeling.

De volgende twee Hoofdstukken richten zich op het identificeren van elementen van professioneel gedrag zoals die relevant geacht worden voor hun latere beroepsuitoefening door intensivisten in opleiding in de medische vervolgopleiding, en de wijze waarop deze geleerd worde. Hiertoe werden twee nationale studies uitgevoerd, één gebruikmakend van een eerder voor dit doel ontwikkelde vragenlijst, en één uitgaande van focusgroepen.

\section{Hoofdstukken 7 en 8}

\section{Elementen van professioneel gedrag relevant voor intensivisten}

Nagenoeg alle elementen van professioneel gedrag bleken belangrijk geacht te worden voor de dagelijkse praktijk van de intensivist vanuit het perspectief van de fellows intensive care geneeskunde. Het hoogst scorende item in Hoofdstuk 7 heeft te maken met de rol van reflectie op het eigen handelen, en 
onderstreept het belang van een gemotiveerde en stimulerende supervisor. 'Teamwork' en 'Omgaan met ethische dilemma's' werden in het vragenlijst onderzoek eveneens als belangrijk geduid. Tijdens de focusgroep interviews beschreven in Hoofdstuk 8 werden 'Communicatie', 'Houden van afstand en het stellen van grenzen', 'Medische kennis en expertise', en, in mindere mate 'Respect', 'Teamwork', 'Leiderschap', 'Organisatie en management' benadrukt.

Uit de geaggregeerde studieresultaten komen diverse nieuwe bevindingen naar voren. Ten eerste, medische kennis en vaardigheden kwamen niet als kernelementen naar voren. Wellicht hebben de fellows deze elementen van professioneel gedrag voldoende geleerd in hun voorafgaande opleiding, en komt het om die reden minder aan bod. Ten tweede, teamwork kwam prominent naar voren, hoewel het element in veel definities van professionaliteit niet voorkomt. Deze constatering benadrukt de sleutelrol van de intensivist op de IC in de multidisciplinaire zorg van de patiënt. Ten derde waren ethische dilemma's, bijvoorbeeld in beslissingen om de behandeling van een patiënt te staken of niet te initiëren, prominent onderdeel van gesprek tijdens de interviews, wat ook het geval is tijdens het dagelijkse werk van de intensivist. Ten vierde werd het hebben van goede communicatie- en luistervaardigheden in de langdurige begeleiding van intensive care patiënten en hun familie benadrukt. Tot slot kwam het bewaken en stellen van grenzen naar voren, in het bijzonder in relatie met patiënten en familie, maar in mindere mate ook in relatie tot collega's en het zoeken van balans tussen het privé en zakelijke leven. Dit laatste zou een afspiegeling kunnen zijn van veranderende professionele houding ten aanzien van werktijden, toename van het belang welk gehecht wordt aan het privé leven en toename van parttime werken. Concluderend blijkt naast de prominente invloed van de specifieke intensive care unit context, ook het tijdperk waarin individuen leven en hun artsenberoep (gaan) uitoefenen van invloed te zijn op de perceptie van professioneel gedrag.

\section{Leren van professioneel gedragaspecten in de intensive care geneeskunde}

Hoofdstuk 7 en 8 geven daarnaast inzicht in hoe professioneel gedrag aspecten in de intensive care omgeving worden geleerd. In Hoofdstuk 7 werd 'Observaties in de dagelijkse praktijk' als hoogste scorende item en 'Ervaringsleren en rolmodellen' als de factor met de hoogste gemiddelde item score geïdentificeerd. De rol van supervisoren als rolmodellen die intensivisten in opleiding met betrekking tot professioneel gedragsaspecten ervaren is dus evident, en docentprofessionalisering lijkt ook hier onmisbaar. Als stimulus om te reflecteren op het eigen gedrag benadrukte een kwart van de deelnemers het geven van feedback. Een vergelijkbaar deel vroeg tevens om uitbreiding van het formele onderwijs in professioneel gedrag aspecten. De multidisciplinaire bespreking van eigen en (bijna)fouten van anderen werd als 
een nuttig formeel onderwijsmoment gezien om zowel medische als professionaliteitaspecten voor het voetlicht te brengen. De locale opleidingsinstituten moeten in de organisatie en uitvoering hierin in de ogen van de fellows een sleutelrol vervullen. In Hoofdstuk 8 bleek dat een substantieel deel van de discussie in de focusgroepen over het leren op de werkvloer ging, en de besproken onderwerpen waren terug te voeren op werkplekleren, rolmodellen en feedback. Naar deze feedback zouden fellows ook moeten vragen als deze niet spontaan wordt gegeven. Het bespreken van lastige situaties met betrekking tot professioneel gedrag, of onverwachte resultaten van eigen handelen zouden aanleiding kunnen geven tot zelfreflectie. Het leren van fouten werd ook hier als ondergewaardeerd leerinstrument genoemd. Een leidinggevende die het belang van professioneel gedrag onderschrijft, en een daarbij horend goed opleidingsklimaat werden als belangrijke stimulerende factoren gezien voor het leren van professioneel gedrag. Concluderend komt uit beide Hoofdstukken naar voren dat het leren van rolmodellen, terwijl men bezig is met patiëntenzorg op de intensive care afdeling de belangrijkste bijdrage levert aan het leren van professioneel gedragsaspecten door intensivisten in opleiding.

\section{Hoofdstuk 9}

De laatste studie in dit proefschrift richtte zich op professioneel gedrag vanuit het perspectief van kwaliteit van zorg en patiëntveiligheid, gebruikmakend van klachtenbrieven ingediend bij de Klachtencommissie van het Maastricht Universitair Medisch Centrum. De hierin naar voren komende categorieën van professioneel gedragselementen zijn daarnaast vergeleken met de visie op professioneel gedrag door artsen (Hoofdstuk 8). Hieruit kwamen de volgende zaken naar voren. Ten eerste gebruiken de artsen meer abstracte, idealistische formuleringen (bijv. altruïsme en attitude), die dus minder concreet, en specifiek zijn dan de uitingen van patiënten en hun familie. Ten tweede had het merendeel van de klachten te maken met niet medisch inhoudelijke zaken, maar met professionaliteitaspecten van zorg, hoewel klachten over mogelijke medische fouten en complicaties frequent naar voren kwamen. Communicatieaspecten voeren de boventoon in de klachtenbrieven. Belangrijke grieven waren onder andere 'Moeten wachten op zorg', 'Ontvangen van onduidelijke en/of onvoldoende informatie', 'Niet respectvolle communicatie', en 'Gebrek aan teamwork'. Ten derde laat vergelijking met de categorieën zoals die naar voren kwamen in Hoofdstuk 8, zien dat de meeste categorieën door zowel patiënten (of familie), als door de artsen worden genoemd. Datgene waar artsen op gebied van professioneel gedag naar streven in hun dagelijkse werk, is dus lang niet altijd hetzelfde als wat door de patiënten wordt ervaren, zeker niet als we ons realiseren dat slechts een 
belangrijke minderheid van de patiënten daadwerkelijk een klacht indient. Ten vierde werd een achttal categorieën wel door patiënten, maar niet door artsen genoemd. Naast 'Moeten wachten op zorg', werd bijvoorbeeld 'Gebrek aan continuïteit van zorg' genoemd. Dokters hebben in de praktijk persoonlijk weinig hinder van deze door patiënten genoemde grieven. Concluderend kan er lering getrokken worden uit het systematisch analyseren van klachten van patiënten en hun familie met betrekking tot professioneel gedrag aspecten van zorg op individueel niveau, interpersoonlijk niveau (bijv. groepsprocessen, communicatievaardigheden), en afdelings/institutioneel niveau (bijvoorbeeld organisatorische aspecten en leerklimaat). Klachten blijken vaker betrekking te hebben op aspecten van communicatie en andere generieke aspecten van professioneel gedrag, dan dat ze betrekking hebben op medisch inhoudelijke zaken.

\section{Overzicht}

Samenvattend geven de resultaten van de studies zoals beschreven in dit proefschrift richting aan de operationalisering van het leren en toetsen van professioneel gedrag voor en tijdens de opleiding geneeskunde, in de medische vervolgopleiding tot intensivist en daarna. De belangrijkste bevindingen in dit kader zijn:

1. Selectie voor de opleiding geneeskunde waarbij tevens gekeken wordt naar professioneel gedragaspecten lijkt veelbelovend.

2. De administratieve afhandeling van onprofessioneel gedrag meldingen tijdens de opleiding geneeskunde is bijzonder arbeid- en kostenintensief. Het is onvermijdelijk dat een balans gezocht moet worden tussen het wetenschappelijke ideaal enerzijds, en het praktisch haalbare anderzijds.

3. Hoewel het gebruik van 'web-based' beoordelingstechnologie ten opzichte van de klassieke, papieren methode meer feedback opleverde zonder aan kwaliteit in te boeten, gaven de respondenten aan een sterke voorkeur te hebben voor de klassieke wijze van 'en-groupe' professioneel gedrag bespreking. Toch kan het gebruik van vergelijkbare of modernere technologie wellicht wel bijdragen aan een reductie in arbeidsintensiteit en daarmee kosten.

4. De rol van de docent/begeleider bij de het leren, bespreken en toetsing van professioneel gedrag is cruciaal, en docentprofessionalisering daarom onmisbaar. Dit is zowel het geval voor tutoren in de onderwijsgroepen (met studenten), als voor supervisoren op de intensive care (met assistenten in opleiding tot intensivist). 
5. Naast het leren van rolmodellen op de werkplek moet ook formeel onderwijs in professioneel gedragaspecten in de intensive care opleiding geïmplementeerd worden. De multidisciplinaire bespreking van (bijna) fouten lijkt hiervoor bijvoorbeeld bij uitstek geschikt te zijn.

6. De intensive care context blijkt een ideale leeromgeving te zijn waarin dagelijks veel verschillende professioneel gedrag aspecten naar voren komen.

7. De meerderheid van klachten ingediend door patiënten of hun familie heeft te maken met professioneel gedrag aspecten. Klachten over niet adequate communicatie komen het meest naar voren. Het betrekken van deze op deze manier kenbaar gemaakte visie van patiënten bij het definiëren en leren van professioneel gedrag aspecten kan bijdragen aan verdere verbetering van de kwaliteit van zorg door individuen, teams, afdelingen, en organisaties. 
List of abbreviations 
224 


\section{List of abbreviations}

\begin{tabular}{|c|c|}
\hline AAMC & Association of the American Medical Colleges \\
\hline ABIM & American Board of Internal Medicine \\
\hline ACGME & Accreditation Council on Graduate Medical Education \\
\hline ACP-ASIM & $\begin{array}{l}\text { American College of Physicians - American Society of Internal } \\
\text { Medicine Foundation }\end{array}$ \\
\hline APB & Assessment of Professional Behaviours \\
\hline CCMS & Central College of Medical Specialists \\
\hline CEDP & Centre for Excellence in Developing Professionalism \\
\hline CFI & Comparative Fit Index \\
\hline CME & Continuous Medical Education \\
\hline CoBaTrICE & $\begin{array}{l}\text { Competency-Based Training program in Intensive Care } \\
\text { medicine in Europe }\end{array}$ \\
\hline CORE & Consultation and Reflection skills training \\
\hline CPB & Committee on Professional Behaviour \\
\hline EC & Examination Committee \\
\hline ECTS & European Credit Transfer System \\
\hline EFIM & European Federation of Internal Medicine \\
\hline ESICM & European Society of Intensive Care Medicine \\
\hline FHML & Faculty of Health, Medicine and Life Sciences \\
\hline GPA & Grade Point Average \\
\hline $\mathrm{ICM}$ & Intensive Care Medicine \\
\hline ICU & Intensive Care Unit \\
\hline IOC-PWG & $\begin{array}{l}\text { Professionalism Theme Working Group of the } 2010 \text { Miami } \\
\text { Ottawa Conference }\end{array}$ \\
\hline KNMG & Royal Dutch Medical Association \\
\hline MCAT & Medical Colleges Admissions Test \\
\hline MEMIC & Centre for Data and Information Management \\
\hline MMI & Multiple Mini Interview \\
\hline MRSA & Methicillin-Resistant Staphylococcus aureus \\
\hline MSRC & Medical Specialists Registration Committee \\
\hline MUMC & Maastricht University Medical Centre+ \\
\hline NBME & National Board of Medical Examiners \\
\hline NVIC & Netherlands Association for Intensive Care Medicine \\
\hline NVMO & Dutch Association for Medical Education \\
\hline OER & Exam Regulations \\
\hline OSCE & Objective Structured Clinical Examination \\
\hline PB & Professional Behaviour \\
\hline PBC & Professional Behaviour Committee \\
\hline PBL & Problem Based Learning \\
\hline P-MEX & Professionalism Mini-Evaluation Exercise \\
\hline
\end{tabular}




$\begin{array}{ll}\text { RMSEA } & \text { Root Mean Square Error of Approximation } \\ \text { SD } & \text { Standard Deviation } \\ \text { SP } & \text { Standardised Patient } \\ \text { TLI } & \text { Tucker-Lewis index } \\ \text { UK } & \text { United Kingdom } \\ \text { UM } & \text { University of Maastricht } \\ \text { US } & \text { United States (of America) } \\ \text { VSNU } & \text { Association of Universities in The Netherlands } \\ \text { WHOO } & \text { Higher Education and Research Act (new) } \\ \text { WHW } & \text { Higher Education and Research Act (old) } \\ \text { WKCZ } & \text { Law on Complaints of Clients of the Healthcare Sector (Wet } \\ & \text { Klachtrecht Cliënten Zorgsector) } \\ \text { WPBA } & \text { Work Place Based Assessment }\end{array}$


List of publications 
228 


\section{Articles}

van Mook WNKA, Simonis FSM, Schneeberger PM, van Opstal JL. A rare case of dissiminated actinomycosis caused by Actinomyces meyeri. Netherlands Journal of Medicine 1997;51:39-45

van Mook WNKA, Simonis FSM, Schneeberger PM, van Opstal JL. Een patient met een gegeneraliseerde actinomycose. Nederlands Tijdschrift Geneeskunde 1998;142:373-374 (letter)

van Mook WNKA, Rijken J, Theunissen PHMH, Lustermans FATh, Nix M. A large gastro-intestinal stromal tumor (GIST). European Journal of Internal Medicine 1998;9:53-56

van Mook WNKA, van Haren EH. Respiratoir syncytial virus als oorzaak van pneumonie bij volwassenen. Tijdschrift voor Geneeskunde 1999;55:667-670

van Mook WNKA, Fickers MMF, van der Kley JAM, Theunissen PHMH. A case of herpes like Sweet's syndrome in acute myelogenous leukemia during treatment with G-CSF. Netherlands Journal of Medicine 1999;55:235-241

van Mook WNKA, Fickers MMF, van der Kley AMJ, Theunissen PHMH, Duijvestijn JA, Flikweert DC. Paraneoplastic pemphigus as the initial presentation of chronic lymphocytic leukemia. Annals of Oncology 2001;12:115-118

van Mook WNKA, Fickers MMF, van der Kley JAM, Theunissen PHMH. A case of herpes like Sweet's syndrome in acute myelogenous leukemia during treatment with G-CSF.Review Series Oncology 2001;3:10-11

van Mook WNKA, Fickers MMF, Verschueren TAM. Immunological evaluation of primary splenic irradiation in chronic lymphocytic leukemia: a study of 24 cases. Annals of Haematology 2001;80: 216-223

van Mook WNKA, Bourass-Bremers IHDN, Engels LGJB, Bos LP, Verhoeven HMJM. The yield of upper gastrointestinal evaluation of anemic iron deficient outpatients with a negative colonoscopy. European Journal of Internal Medicine 2001;12:122-126

van Mook WNKA, Ramsay G. Manual of Intensive Care Medicine. Book review. Intensive Care Medicine 2001;27:442

van Mook WNKA, Bourass-Bremers IHDN, Engels LGJB, Bos LP, Verhoeven HMJM. The yield of upper gastrointestinal evaluation of anemic iron deficient outpatients with a negative colonoscopy. European Journal of Internal Medicine 2002;13:144

van Mook WNKA, van der Geest S, Goessens MLMJ, Schoon EJ, Ramsay G. Gas within the wall of the stomach: due to infection or not ? European Journal of Gastroenterology and Hepatology 2002; $14: 1155-1160$

van Mook WNKA, Hulsewé-Evers HPMG, Ramsay G. Acute abdominal compartment syndrome after gastroscopy for upper gastrointestinal bleeding: a preventable complication. Lancet 2002;360: 1502

van Mook WNKA., Hulsewé-Evers HPMG. Critical illness polyneuropathy. Current Opinion in Critical Care 2002;8:302-310 
de Beus E, van Mook WNKA, Ramsay G, Stappers JLM, van der Putten HWHM. Peripartum cardiomyopathy - A condition intensivists should be aware of. Intensive Care Medicine 2003;29: $167-174$

Gielen-Wijfels SEMJ, van Mook WNKA, Ramsay G. Behandeling en preventie van bloedingen met recombinant-geactiveerde-factor VII, niet alleen bij hemofilie. Nederlands Tijdschrift voor Geneeskunde 2003, 147, 9: 419 (letter)

van Mook WNKA, Bos LP, Koek GH, Ceelen ThJ. Intestinal spirochetosis: Any clinical significance? European Journal of Gastroenterology and Hepatology 2004;16:83-87

Gielen-Wijfels SEMJ, van Mook WNKA, van der Geest S, Ramsay G. Succcesful treatment of severe bleeding with recombinant factor VIla after kidney transplantation. Intensive Care Medicine 2004;30:1232-1234

Linssen KC, Jacobs JA, Poletti VE, van Mook WNKA, Cornelissen El, Drent M. Reactive type II pneumocytes in bronchoalveolar lavage fluid. Acta Cytologica 2004;48:497-504

van Mook WNKA, de Krom MCTFM. De (sub)acute polyneuropathie bij patiënten op de intensivecare unit. Tijdschrift voor Neurologie en Neurochirurgie 2004;105:214 (letter)

van Mook WNKA, Jongen J, de Bijl NPYM, Duijnstee-Bijvoet HEM, Bos MA. Casus Meneer B, oftwel de donatievraag aan het eind van het leven. Tijdschrift voor Geneeskunde en Ethiek $2004 ; 14: 48-53$

van Mook WNKA, Bos LP, Koek GH, Ceelen ThJ. Intestinal spirochetosis: Any clinical significance? European Journal of Gastroenterology and Hepatology 2004;16:83-87

de Feiter PW, van Mook WNKA, Jacobs MJHM. Trachea compression due to an innominate artery aneurysm after thoracic aortic aneurysm repair in a patient with Marfan's disease. Journal of Thoracic and Cardiovascular Surgery 2005;129:943-944

van Mook WNKA, Faber CG, de Krom MCTFM. Spierzwakte ontstaan op de Intensieve Zorg: vaak critical illness polyneuropathie. Tijdschrift voor Geneeskunde 2005;61:1186-1191

van Mook WNKA, Peeters L. Severe cardiac disease in pregnancy. Part I: Haemodynamic changes in, and approach to complaints during pregnancy, and general management of cardiac disease in pregnancy. Current Opinion in Critical Care 2005, 11: 430-434

van Mook WNKA, Peeters L. Severe cardiac disease in pregnancy. Part II: Impact of congenital and acquired cardiac diseases during pregnancy. Current Opinion in Critical Care 2005;11:435-448

van Mook WNKA, Rennenberg RJMW, Schurink GW, Oostenbrugge van RJ, Mess WH, Hofman, PAM, Leeuw de PW. The cerebral hyperperfusion syndrome. Lancet Neurology 2005;4:877-888

Stockbrugger R, Brummer RJ, van Mook WNKA, Toebosch S. MAS: a simple clinical test for chronic diarrhoea and constipation. Hospital Heath Care 2005, L19-21 ISBN 1-904471-43-9

Plas van de A, Stolk L, Verhoeven MAM, Kooman JP, van Mook WNKA. Successful treatment of acute phenobarbital intoxication by hemodiafiltration. Clinical Toxicology 2006;44:93-94

Hamaekers AEW, van Mook WNKA, Peeters L, Marcus MAE. Succesfull use of recombinant factor VIla for treatment of severe post-partum haemorrhage. American Journal of Critical Care 2006;15 399-401 
van Mook WNKA, Rennenberg RJWM, Schurink GWH, van Oostenbrugge RJ, Mess, WH. Hofman PAM, Kroon AA. Het cerebrale hyperperfusiesyndroom Tijdschrift voor Neurologie en Neurochirurgie 2006;107:106-116

Pham PC, de Feiter PW, van der Kuy HPM, van Mook WNKA. Long QTc interval and torsades de pointes caused by fluconazole. Annals of Pharmacotherapy 2006;40:1456-1461

Van Onzenoort HA, Bussink M, van Mook WNKA, van der Kuy PHM. Sublingual captopril versus intravenous enalapril on angiotensin II plasma levels. Pharmacy World and Science 2006;28: $131-134$

Snoeijs MGJ, van Heurn WLW, van Mook WNKA, Christiaans MH, van Hooff JP. Controlled donation after cardiac death - A European perspective Transplantation Reviews 2007; 21:219-229

van Mook WNKA, de Grave WS, Huijssen-Huisman EJ, de Witt-Luth ME, Dolmans DHJM, Muijtjens AMM, Schuwirth LW, van der Vleuten CPM. Factors impeding assessment of students' professional behaviour in the tutorial group in problem based learning. Medical Education 2007;41: 849-856

van Mook WNKA, van Luijk SJ, Oudhuis GJAPM, Gulikers MTH, Schuwirth LW, van der Vleuten CPM. Professioneel gedrag in de opleiding geneeskunde. Tijdschrift voor Medisch Onderwijs 2007; 26:174-183

van Mook WNKA, van Luijk SJ, Fey-Schoenmakers MJG, Oudhuis GJAPM, Gulikers MTH, Schuwirth LW, van der Vleuten CPM. Bespreking en beoordeling van professioneel gedrag aan de Faculteit Geneeskunde te Maastricht. Tijdschrift voor Medisch Onderwijs 2007;26:237-246

Koeijers JJ, Verhoeven CL, Boersma HH, van Mook WNKA. Successful treatment of theophylline intoxication using continuous venovenous hemofiltration. Netherlands Journal of Critical Care 2008; $12: 32-34$

Linssen CFM, Jacobs JA, Schouten JSAG, van Mook WNKA, Ramsay G, Marjolein Drent. Influence of antibiotic therapy on the cytological diagnosis of ventilator-associated pneumonia. Intensive Care Medicine 2008;34:865-872

Onzenoort van HA, Bussink M, Menheere PP, van Mook WNKA, van der Kuy PHM. The effect of sublingual lisinopril on angiotensin II plasma levels. Nederlands Tijdschrift voor Anesthesiologie 2008;20:26-28

van Mook WNKA, de Grave WS, Wass V, O'Sullivan H, Zwaveling JH, Schuwirth LW, van der Vleuten CP. Professionalism: Evolution of the concept. European Journal of Internal Medicine 2009;20:e81-e84

van Mook WN, van Luijk SJ, O'Sullivan $\mathrm{H}$, Wass V, Harm Zwaveling J, Schuwirth LW, van der Vleuten CP. The concepts of professionalism and professional behaviour: Conflicts in both definition and learning outcomes. European Journal of Internal Medicine 2009;20:e85-e89.

van Mook WN, van Luijk SJ, O'Sullivan H, Wass V, Schuwirth LW, van der Vleuten CP. General considerations regarding assessment of professional behaviour. European Journal of Internal Medicine 2009;20:e90-e95.

van Mook WN, de Grave WS, van Luijk SJ, O'Sullivan H, Wass V, Schuwirth LW, van der Vleuten $\mathrm{CP}$. Training and learning professionalism in the medical school curriculum: Current considerations. European Journal of Internal Medicine 2009;20:e96-e100. 
van Mook WN, van Luijk SJ, de Grave W, O'Sullivan H, Wass V, Schuwirth LW, van der Vleuten $\mathrm{CP}$. Teaching and learning professional behaviour in practice. European Journal of Internal Medicine 2009;20:e105-111

van Mook WN, Gorter SL, O'Sullivan H, Wass V, Schuwirth LW, van der Vleuten CP. Approaches to professional behaviour assessment: tools in the professionalism toolbox. European Journal of Internal Medicine 2009;20:e153-157

van Mook WN, Gorter SL, de Grave WS, van Luijk SJ, O'Sullivan H, Wass V, Zwaveling JH, Schuwirth LW, van der Vleuten CP. The educational continuum: professionalism in and beyond medical school. European Journal of Internal Medicine 2009;20:e148-152

van Luijk SJ, van Mook WNKA, van Oosterhoudt WPJ. Het leren en toetsen van de professionele rol. Tijdschrift voor Medisch Onderwijs 2009;28:107-118

van Mook WNKA, van Luijk SJ, van der Vleuten CPM. Professioneel gedrag in de geneeskunde Nederlands Tijdschrift voor Geneeskunde 2009;153:1588-1592

Keeris LM, Bergmans DCJJ, van der Sande FM, Wind T, Van Suylen RJ, van Mook WNKA. Succesvolle niertransplantatie van een donor met ernstige diffuse intravasale stolling en verminderde nierfunctie. Nederlands Tijdschrift voor Geneeskunde 2009:153:418-420

Wittekamp BHJ, van Mook WNKA, Tjan DHT, Zwaveling JH, Bergmans DCJJ. Clinical review: post-extubation laryngeal edema and extubation failure in critically ill adult patients. Critical Care 2009;13:233-42

van Mook WNKA, de Grave WS, Gorter SL, Muijtjens AMM, Zwaveling JH, Lambert W. Schuwirth, Cees P.M. van der Vleuten.Fellows' in intensive care medicine views on professionalism and how they learn it. Intensive Care Medicine 2010;26:296-303

Gorter R, van Luijk SJ, van Mook WNKA. Promoting professional behaviour in undergraduate medical, dental and veterinary medical curricula in the Netherlands: evaluation of a joined effort. Medical Teacher 2010;32:733-739

van Mook WNKA, Gorter SL, de Grave WS, van Luijk SJ, Wass V, Zwaveling JH, Schuwirth LW, van der Vleuten CPM. Bad apples spoil the barrel: Addressing unprofessional behaviour. Medical Teacher 2010;32:891-898

van Mook WNKA, van Luijk SJ, Fey-Schoenmakers MJG, Tans G, Rethans JJE, Schuwirth LW, van der Vleuten CPM. Combined formative and summative professional behaviour assessment approach in the bachelor phase of medical school: a Dutch perspective. Med Teacher 2010;32:e517-e531

Vanspauwen MJ, Linssen CFM, Bruggeman CA, Jacobs JA, Drent M, Bergmans DCJJ, van Mook WNKA. Clara cell protein in bronchoalveolar lavage fluid: a predictor of ventilator-associated pneumonia? Critical Care 2011, 15:R14 (Epub ahead of print)

van Mook WNKA, de Grave WS, Gorter SL, Zwaveling JH, Schuwirth LW, van der Vleuten CPM. Intensive care medicine trainees' perception of professionalism: a qualitative study. Anesthaesia and Intensive Care 2011;39:107-115

Hamers LA, Linssen CF, Lancé MD, Maessen JG, Weerwind P, Winkens B, Bergmans DC, van Mook WN. Positive cultures from cardiopulmonary bypass: prevalence and relevance regarding postoperative infection. Eur J Cardiothorac Surg. 2011 Jan 17. [Epub ahead of print] 
Geerse DA, Span LFR, Pinto-Sietsma SJ, van Mook WNKA. Prognosis of patients with haematological malignancies admitted to the intensive care unit: SOFA trend is a powerful predictor of mortality. European Journal of Internal Medicine 2011;22:57-61

Donker DW, Peeters L, van Mook WNKA. Peripartum cardiomyopathy: an intensivist's perspective. Current Women's Health Reviews, accepted

Schols SEM, Bos G, van Mook WNKA, Hamulyák K. A case of severe disseminated intravascular coagulation during pneumococcal septic shock. Journal of Coagulation Disorders, accepted

Hodges B, Ginsburg S, Cruess R, Cruess S, Delport R, Hafferty F, Ho MJ, Holmboe E, Holtman MC, Ohbu S, Rees CE, ten Cate O, Tsugawa Y, van Mook WNKA, Wass V, Wilkinson T, Wade WB. Assessment of professionalism: Recommendations from the Ottawa 2010 conference. Medical Teacher, accepted

O'Sullivan H, Fewtrell R, van Mook WNKA, Wass V. AMEE GUIDE: Commentary Integrating Professionalism into the curriculum. Medical Teacher, accepted

van Mook WNKA, Bion J, van der Vleuten CPM, Schuwirth LW. Integrating education, training and assessment; competence-based intensive care medicine training. Netherlands Journal of Critical Care, accepted

van Mook WNKA, Schuwirth LW, Bion J, on behalf of the CoBaTrICE collaboration. Workplace based assessment: how to use it in the ICU. Submitted

Frankfort M, Koeijers JJ, Zwaveling JA, van Mook WNKA. Severe retropharyngeal haematoma after apparent minor injury. Submitted

van Dijk NM, Linssen CFM, Bussink M, Span LFR, van Mook WNKA. Critical illness due to human metapneumovirus after acquisition by horizontal nosocomial transmission on the hematology ward. Submitted

van Mook WNKA, Arno M.M. Muijtjens, Simone L. Gorter, Jan Harm Zwaveling, Lambert W. Schuwirth, Cees P.M. van der Vleuten. Web-assisted assessment of professional behaviour: novel yet no improvement! Submitted

Wind J, Snoeijs M, van Mook WNKA, Brugman CA, Vervelde J, Zwaveling JH, van Heurn LW. Prediction of death in potential controlled donors after cardiac death. Submitted

Wagenvoort GJH, van Mook WNKA, Bodelier AGL. An intern with acute chest pain. Submitted

\section{Chapters}

van Mook WNKA. Temperatuurregulatie en hyperthermie. Chapter 4. In: TempO2, 9e symposium van de LVIZ. Mady Relief, Kerkrade 2003 ISBN 90-802550-0-9.

van Mook WNKA, Gorter SL, Scherpbier AJJA. Kwaliteitsverbetering in de geneeskunde, met speciale aandacht voor de waarde van protocllen en leercurven in de acute geneeskunde. Chapter 6. In: Opleiden in de urgentiegeneeskunde. J.J.L.M. Bierens, Sabbe M. (red.). Elsevier Gezondheidszorg 2005: 63-78. ISBN 9035227581. 
van Mook WNKA, Peeters L. Severe cardiac disease in pregnancy, Chapter 25, page 269-290. In: Acute heart failure. Springer Verlag 2008, London Limited. ISBN 978-1-84628-781-7, e-ISBN 9781-84628-782-4

L. Keeris L, van Mook WNKA. Ethische aspecten met betrekking tot orgaandonatie. Pgn 287-312. In: Intensive Care Capita Selecta 2008 Stichting Venticare, Utrecht 2008, Lannoo. ISBN 978-9072651-24-2

van Mook WNKA. Neuromuscular dysfunction in critical illness: Critical illness polyneuropathy (CIP) and critical illness myopathy (CIM). In: The critically ill patient (II malato critico: principe e pratica della terapia intenisiva (Ezio Romano, ed., UTET Scienze Mediche, Torino, Italy, 2009)

O'Sullivan H, van Mook WNKA, Fewtrell R, Wass V. AMEE Guides in Medical Education, AMEE Guide no 56. Integrating Professionalism into the Curriculum. In press 
Dankwoord 


\section{Dankwoord}

Promoveren. Goh. Als ik de boekjes als eindresultaat van jaren noeste arbeid van de diverse promovendi in ogenschouw nam gedurende het afgelopen decennium, bekroop me een altijd een gevoel van respect. Dat was zeker het geval als de inhoud een voor mij ingewikkeld, haast ongrijpbaar onderwerp betrof, met dito analyses. Een promotieverplichting ontbrak in mijn contract als intensivist, maar het niet gepromoveerd zijn werd al snel door mijzelf als een gemis ervaren, zeker nadat Simone Gorter in 2003 promoveerde. De persoonlijke en enthousiaste begeleiding vanuit het onderwijsinstituut bij haar promotie waren me wel bijgebleven. Hoewel ik het onderwerp en de medische onderwijskundige achtergronden van Simone's promotie destijds niet helemaal kon doorgronden, genoot medisch onderwijs wel al snel mijn belangstelling. Toen Cees van der Vleuten me vroeg om bij vertrek van Scheltus van Luijk naar het VU Medisch Centrum het voorzitterschap van de Commissie Professioneel Gedrag over te nemen, wilde ik dat dan ook wel graag doen, maar wel ad interim, gedurende maximaal een jaar..... het is iets langer geworden....

Het proefschrift is er, met mijn naam als enige op de voorzijde. Het moge duidelijk zijn dat een clinicus die promoveert op een hem initieel vreemd onderwerp, gebruik makend van voor clinici deels onbekende onderzoekstechnieken, van literatuur onder andere komende uit de hoek van de psychologie, sociologie en het medisch onderwijs, hiervoor dank verschuldigd is aan velen. Het risico accepterend dat ik mensen ga vergeten (mijn oprechte verontschuldiging daarvoor!), ga ik toch een poging doen enkele mensen persoonlijk te bedanken.

Professor dr. L. Schuwirth, beste Lambert, beste Lammie, daar onze karakters nogal compatibel zijn (to say the least), klikte het naast onze persoonlijke vriendschap ook op begeleidingsvlak erg goed. 'Ha, die Walther', of 'Ha jong', waren toch steevast de woorden waarmee je meestal goedgemutst de telefoon op nam op het moment dat ik weer eens ergens niet uit kwam. Daarnaast bezit je het zeldzame talent om bijzonder ingewikkelde materie op een bijzonder eenvoudige wijze uit te leggen, en ook nog met aan de medische praktijk gelieerde voorbeelden en metaforen toe te lichten. Het boek 'Medical Education Research Made Ridiculously Simple' zou zo aan je pen kunnen ontspruiten. Na jouw (en Iris') vertrek naar Australië gaan wij het nuttigen van de Feuerzangenbowle op Oudejaarsavond zeker missen..... Het ga je bijzonder goed 'Down Under'. 
Professor dr. C. van der Vleuten, beste Cees, op gebied van onderzoek van medisch onderwijs behoor je tot de absolute wereldtop. Het gaf me dan ook vertrouwen dat je, samen met Lambert en Jan Harm aan dit promotietraject wilde beginnen. Van je uitgebreide ervaring heb ik veel mogen leren, evenals van de inspirerende discussies tijdens bijzonder efficiënte vergadersessies. Daarnaast ben je een geweldig rolmodel. Altijd geef je feedback op gepaste wijze, je communicatiestijl is altijd constructief, en waar mogelijk worden complimenten gegeven. Je snelheid van correctie van manuscripten is ongeëvenaard, en werd gemeten in uren tot hooguit dagen, maar nooit in weken. Je vermogen om mensen samen te brengen, te netwerken, samenwerkingsverbanden te zoeken, en contacten te leggen is daarnaast fenomenaal. De positieve connotatie van de omschrijving 'pater familias' is in mijn perceptie een adequate beschrijving van jouw manier van begeleiden. Ik hoop na het afronden van het proefschrift nog veel met je samen te werken.

Professor dr. Jan Harm Zwaveling, beste Jan Harm, ik vond het best spannend toen er na het vertrek van Prof. Dr. Graham Ramsey een nieuw afdelingshoofd Intensive Care werd benoemd. Van enige 'incompatibilité des humeurs' bleek gelukkig geen sprake, integendeel. Jij gaf mij, net als Graham, veel ruimte om zelfstandig zaken te regelen, op te zetten en af te handelen, en mezelf te ontplooien, waarvoor ik je dankbaar ben. Daarnaast hoop ik wat overgenomen te hebben van je vaak heldere, werkzame kijk op organiseren en management. Vanaf het begin was het duidelijk dat jij enorm voorstander was van het verrichten van een promotieonderzoek op gebied van medisch onderwijs, en je hebt dit promotieonderzoek dan ook mede geïnitieerd. Het lezen van de psychologisch, sociologisch en soms haast filosofische getinte stukken was voor ons allebei in het begin erg wennen. $\mathrm{lk}$ wil je bedanken voor het in mij gestelde vertrouwen, en vind het leuk om als eerste (en gezien je vertrek naar het Maxima Medisch Centrum tevens laatste) Intensive Care staflid uit Maastricht mijn promotieonderzoek onder je begeleiding af te mogen ronden.

Dr. S.J. van Luijk, beste Scheltus, gelukkig blijven we samen ook na je vertrek uit Maastricht met enige regelmaat symposia, workshops en lezingen over PG geven, een samenwerking die wij beiden volgens mij waarderen. Omdat je aan de wieg hebt gestaan van mijn professioneel gedrag interesse, ik veel van je geleerd hebt daar er eigenlijk niemand is die zoveel ervaring en kennis van dit onderwerp heeft als $\mathrm{jij}$, en je bovendien als persoon bijzonder waardeer, ben ik trots dat jij mijn paranimf wilt zijn.

Dr. F. Jungbauer, beste Frank, we hebben samen een geweldige opleidingstijd gehad, zowel in het ziekenhuis als daarbuiten. Je bent naast intelligent ook heel levenswijs, hebt een nuchtere, heldere, objectieve kijk op complexe 
zaken, en bent altijd bijzonder gastvrij en geïnteresseerd in anderen. Hoewel we graag naar Groningen rijden om jou en Corrie weer te zien, waardeer ik het zeer dat jij nu als paranimf naar het Maastrichtse wilt afreizen, iets wat jij vast als thuiskomen ervaart.

Dr. Willem de Grave, beste Willem, je bent betrokken geweest bij een groot aantal projecten uit dit boekje. Je uitgebreide ervaring, onder andere met focus groep interviews was bijzonder waardevol, en gelukkig konden Simone en jij het samen prima vinden. Het kostte me in het begin moeite om de voor jou ogenschijnlijk zo eenvoudige materie te doorgronden, maar gelukkig ging het met de door jou ter hand gestelde literatuur al snel beter. Dank voor de vele uren die je daarnaast al luisterend en interviewend door hebt gebracht op de Intensive Care afdelingen door heel het land.

Dr. Arno Muijtjens, beste Arno, gelukkig zijn er statistici zoals jij die medici zoals ik richting geven bij hun analyses. Het tevoren overleggen over de wijze van opbouw van een dataset, en de geëigende analyses bleken veel tijdsbesparing op te leveren, en gaven het noodzakelijke aanvullende inzicht in de achtergronden daarvan, hoewel niet alles hiervan direct beklijfde. Op het moment dat alle auteurs al tevreden waren wilde jij toch nog graag een paar (vaak, maar niet altijd) statistische puntjes op de i zetten, een streven naar het hoogste niveau welk ik bijzonder kan waarderen.

Professor Dr. Val Wass, dear Val, we first met at your dissertation after-party in Maastricht. After initiating the research for my dissertation it became apparent that we shared the same interest regarding professionalism issues. I was fortunate to be in the position to receive feedback on my research and publications from your critical, but yet constructive perspective, and appreciate the warmth and kindness with which you approach others. Luckily the cooperation does not end after completion of this dissertation.

Dr. H. O'Sullivan, dear Helen, as the director of the Centre for Excellence in Developing Professionalism (CEDP) in Liverpool professionalism development is your daily core business. I enjoyed your innovative ways of thinking regarding professionalism, and the personal communication regarding several manuscripts.

De Commissie Professioneel Gedrag en haar leden: Marij J.G. FeySchoenmakers, Sophie Deckers, Marleen Gulikers, Guy Oudhuis, en Niek Zonnebeld, Karlijn Cornel, en Marre Andre Wiltens (studentleden). Alle leden zijn op hun eigen wijze waardevol voor het functioneren van de Commissie. Onmisbaar is er echter maar één. Marij, je nauwgezetheid en gedrevenheid 
zijn te roemen, en je bijdrage aan de Commissie Professioneel Gedrag is goud waard. Ik vind het dan ook leuk dat je hebt meegeschreven aan een aantal artikelen over professioneel gedrag in en buiten het kader van dit boekje. Fijn dat Sophie het secretariaat inmiddels is komen versterken. Drs. G. Oudhuis, beste Guy, we kennen elkaar al heel lang als leden van de door Scheltus in het leven geroepen Commissie Professioneel Gedrag. We hebben al vaker besproken dat we qua handelen en denken toch wel erg veel op elkaar lijken. Naast noeste arbeid is er altijd tijd voor gepaste humor en jolijt. Ik hoop nog lang binnen en buiten de Commissie Professioneel Gedrag te kunnen genieten van je levenslust en hoge streefniveau van handelen. Mevr. M. Gulikers, beste Marleen, de twee door dezelfde bril kijkende clinici kunnen niet zonder jouw heldere kijk op PG zaken! Dank hiervoor.

De studieadviseurs geven eveneens een gezonde alternatieve, nuancerende kijk op de meldingen onprofessioneel gedrag van de individuele studenten, en die wisselwerking met de Commissie Professioneel Gedrag blijkt waardevol in de praktijk. Drs. M. Boumans, beste Marjo, jij hebt mij als student geprobeerd op te voeden wat betreft sociale vaardigheden; wanneer gaan we weer eens naar een casino? Dr. G. Tans, beste Guido, dank voor je bijdrage aan het artikel over de toetsing van PG in het Maastrichtse curriculum.

Dr. J.J. Rethans, beste Jan Joost, als CORE coördinator spreken wij elkaar met enige regelmaat over PG aspecten, maar gelukkig zien we elkaar privé ook met enige regelmaat. Je wijze van voorzitten van bijeenkomsten is onevenaarbaar, en je altijd beschouwende visie wordt gewaardeerd.

Dr. R. Stalmeijer, beste Renée, dank voor je adviezen t.a.v. de vragenlijsten. Ik verheug met op toekomstig samenwerking op gebied van kwalitatief en kwantitatief onderzoek in en buiten de kliniek. Mevr. N. Verleng, beste Nicky, dank voor de tijd die je hebt geïnvesteerd in het digitaliseren van de brongegevens voor mijn onderzoek. Mevr. L. Swaen, beste Lilian, dank voor het in goede banen leiden van veel zaken rondom mijn promotie. Mevr. M. Gorsira, beste Mereke, je wist de artikelen vaak nog naar een duidelijk hoger plan te tillen wat betreft het gebruik van de Engelse taal! Dank voor deze finishing touch.

De studenten Elise J. Huijssen-Huisman, Marianne E. de Witt-Luth, en Kirsten Thijsen wil ik bedanken voor hun ondersteuning bij de voorbereiding van onderzoek en invoer van studieresultaten van een tweetal studies. Anita Legtenberg, data manager van het MEMIC, wil ik bedanken voor het managen van de dataset van de web-based assessment studie. De mensen achter de schermen op de Intensive Care afdelingen in den lande wil ik bedanken voor 
hun inspanningen voor de focusgroep interviews en het coördineren van het retourneren van de vragenlijsten door de fellows intensive care: mevr. Jennie Wegh-Holtland (UMCN, Nijmegen), mevr. Thea Elzinga en mevr. Jannie Wolterman-Hovenga (UMCG, Groningen), mevr. Irine Lammerse (Leiden), mevr. Astrid Koffrie en Rosalie Jenster (UMCU, Utrecht), mevr. Samantha Cramer (OLVG, Amsterdam), mevr. Grace Koningstein (VUMC, Amsterdam), mevr. Mary Anne Simons-Hartman (AMC, Amsterdam), en mevr. Esmeralda Mulleneers (MUMC, Maastricht).

Mr. W. Kieboom, Mr. M.G.T.H. Castermans, beste Wendy en Miem, het was leuk om jullie onvoorwaardelijke steun te krijgen bij de uitvoering van het klachtenonderzoek. Met de privacy van alle betrokkenen in het achterhoofd hebben jullie veel tijd gestoken in het geanonimiseerd aanleveren van de ruwe data voor dit onderzoek. Op naar het uitbreiden van het onderzoek naar de klachten ingediend bij de klachtenfunctionarissen!

Dit proefschrift is grotendeels tot stand gekomen na drukke en minder drukke diensten op de Intensive Care afdeling. Voor mij is de haalbaarheid om dit soort additionele werkzaamheden naast je reguliere werkzaamheden op de Intensive Care te verrichten afhankelijk van de werksfeer op de afdeling. Het relatief jonge, enthousiaste en duidelijk communicerende medische team op onze Intensive Care afdeling is nog steeds erg leuk om in en mee te werken. Daar het noemen van alle individuele stafleden hier helaas niet haalbaar is, beperk ik met tot een viertal. Dr. D. Bergmans, beste Dennis, als mijn sparringpartner op de IC is het mijn ervaring dat we blindelings op elkaar kunnen vertrouwen. Of om in voetbaltermen te spreken: 'je moet elkaar blindelings kunnen vinden om te kunnen scoren...' lk verheug me op voortzetting en uitbreiding van deze goede samenwerking op gebied van onderwijs, opleiding en onderzoek. Dr. P. Breedveld, beste Paul, dank voor het binnen het mogelijke honoreren van al die onmogelijke roostervoorkeuren. Dr. Dr. D. Donker, beste Dirk, mein Freund, eindelijk kunnen we nu op (nagenoeg) gelijkwaardig niveau met elkaar spreken.... Dr. P. Roekaerts, beste Paul, dank voor de ondersteuning die je als afdelingshoofd in de laatste fase van het promotietraject hebt gegeven. De verpleging op de Intensive Care afdelingen draag ik (zoals bekend) op handen: van jullie heb ik tijdens mijn opleiding wellicht nog het meeste geleerd!

Dr. K. Linssen, beste Kitty, het is een feest met je samen te mogen werken! Volgens mij vinden we het allebei leuk dat we na het afronden van jouw proefschrift telkens weer nieuwe Intensive Care gerelateerde projecten bedenken die we (inmiddels samen met Dennis) onderzoeken. Die (onderzoeks)lijn moeten we echt voortzetten. 
Mevr. T. Wouters, beste Tiny, wat kan ik zeggen: iedereen kent je reputatie denk ik al: de prachtige lay-out van de inhoud van dit boekje is jouw verdienste. Daarnaast was het overleg ook altijd heel gezellig! Heel hartelijk bedankt voor beiden!

Dhr. C. Tonnaer, beste Con, dank voor de mogelijkheid die je me zonder aarzelen geboden hebt om een keuze te mogen maken uit het vele werk in je portfolio. Ik hoop dat je het voorliggende boekje net zo kunt waarderen als ikzelf.

Dhr. Nico van Mook, mijn vader, lieve pappa. Helaas mag het niet zo zijn dat je het gereed komen van het boekje nog mee mag maken. Ik ben er zeker van dat je bijzonder trots geweest zou zijn als dat wel het geval was geweest. Ik herken gelukkig dagelijks veel van jouw karaktereigenschappen in mijn eigen handelen. Je wijze en nuchtere adviezen in lastige situaties blijf ik echter missen. Ik draag dit proefschrift met trots aan je op!

Mevr. Tiny van Mook-van de Laar, mijn moeder, lieve mamma, ik wil je bedanken voor de ruimte en de gelegenheid die ik gekregen heb om te gaan studeren, en me te ontwikkelen tot degene die ik nu ben. Je nauwgezetheid is me blijvend tot voorbeeld!

Dhr. en mevr. L. en J. Gorter-Gremmen, mijn schoonouders, lieve Leonie en Johan, jullie flexibiliteit en gastvrijheid zijn lovenswaardig, en ik hoop nog lang van jullie levensplezier te kunnen genieten. Dank voor alle interesse en gezelligheid in de afgelopen jaren!

Mevr. C. Froijen-Leclaire, lieve Ceciel, al heel veel jaren zorg je, nu soms ook samen met Cor op voortreffelijke wijze voor een deel van de opvang van onze kinderen. Altijd ben je bereid om ons daarnaast op de meest onmogelijke momenten uit de brand te helpen. Jullie aanwezigheid was en is voor ons dan ook onmisbaar en waardevol! Wij koesteren jullie vriendschap als waren jullie naaste familie.

Jasper, Niels en Sanne, alledrie lopen jullie over van energie, gelukkig niet allemaal op dezelfde gebieden, maar soms helaas wel tegelijkertijd. ledere dag is het echter ook weer genieten van de overeenkomsten maar zeker ook van de verschillen in jullie persoonlijkheden. Gelukkig maken we al jaren veelvuldig ruim tijd voor leuke dingen met jullie, en nog leuker is dat jullie je blijdschap en tevredenheid hierover gewoon naar ons toe uitspreken! Van dat soort leuke gezinsmomenten moeten er wat mij betreft nu nog veel meer gaan komen! 
Dr. Simone Gorter, lieve Simone, het was erg leuk om in het kader van dit proefschrift samen te kunnen werken aan onderwijskundig onderzoek. Dank voor je hulp bij de analyses en je kritische en nuchtere kijk op de manuscripten. Je besloot het dankwoord in je eigen proefschrift destijds met de woorden "Eindelijk zijn de weekenden er nu voor jou en Jasper". En inderdaad: in het weekend werd er principieel niet gewerkt aan mijn boekje, en toch is het nu klaar. Met jou als maatje in het leven, en de kinderen om dat te onderstrepen zie ik de toekomst met vertrouwen tegemoet!

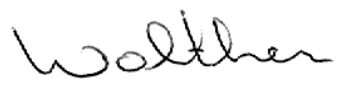



Curriculum Vitae 


\section{Curriculum Vitae}

Walther van Mook was born in Helmond, the Netherlands on November 16th 1967. In 1986 he enrolled into the study of Medicine at the Faculty of Medicine of Maastricht University, where the master's and medical doctor's degree were obtained 'with honour', the latter in 1993. He started his specialist training in Internal Medicine at the De Wever Ziekenhuis in Heerlen in 1994 (chair Dr. F. Lustermans), a training which was subsequently completed at the Maasland Ziekenhuis, Sittard (chair Dr. B. Looij), and the Maastricht University Hospital, azM (chair Prof. dr. H. Hillen). In October 2000 registration in Internal Medicine was ratified. Walther van Mook initiated training in Intensive Care Medicine at the Maastricht University Hospital in November 2000 (chair Prof. dr. G. Ramsay), and subsequently became a senior staff member in April 2002. His interest for medical education was evoked by the medical education dissertation by Dr. S.L. Gorter (promotores Prof. dr. D. van der Heijde, and Prof. dr. A. Scherpbier). After joining the Professional Behaviour Committee of the Faculty of Health, Medicine and Life Sciences (FHML) as a member in 2002, and as chair in 2004, this interest focused on professional behaviour development and assessment. Under the guidance of his promotores (Prof. dr. L. Schuwirth, Prof. dr. C. van der Vleuten and Prof. dr. J. Zwaveling) he also participated in other activities, e.g. the membership of the Steering Committee of the Competence Based Training program for Intensive Care Medicine in Europe (CoBaTrICE) of the European Society of Intensive Care Medicine (ESICM), medical education consultancy activities for the School of Medicine and Health Sciences, University for Development Studies, Tamale, Ghana, and the Faculty of Medicine, University Eduardo Mondlane, Maputo, Mozambique, and chairing of the regional intensive care meetings for the provinces Limburg and South East Brabant (ICUZON) (co-chair Dr. N. Foudraine, Venlo). Future focus in medical education research and development will be professional behaviour development and assessment, as well as on aspects of postgraduate training in general and in intensive care medicine specifically. Walther van Mook lives together with Simone Gorter, and they have three children, Jasper, Niels and Sanne (born in 2002, 2004 and 2007). 
248 


\section{SHE dissertations series}

In the SHE Dissertation Series dissertations are published of $\mathrm{PhD}$ candidates from the School of Health Professions Education (SHE) who defended their PhD thesis at Maastricht University. The most recent ones are listed below. For more information go to: www.maastrichtuniversity.nl/she.

De Leng, B. (8-12-2009).

Wired for learning. How computers can support interaction in small group learning in higher education.

Maiorova, T. (29-05-2009).

The role of gender in medical specialty choice and general practice preferences.

Bokken, L. (04-03-2009).

Innovative use of simulated patients for educational purposes.

Wagenaar, A. (18-09-2008).

Learning in internships. What and how students learn from experience.

Driessen, E. (25-06-2008).

Educating the self-critical doctor. Using portfolio to stimulate and assess medical students' reflection.

Derkx, H. (18-06-2008).

For your ears only. Quality of telephone triage at out-of-hours centres in the Netherlands.

Niessen, Th. (30-11-2007).

Emerging epistemologies: making sense of teaching practice.

Budé, L. (05-10-2007).

On the improvement of students' conceptual understanding in statistics education.

Niemantsverdriet, S. (26-07-2007).

Learning from international internships: A reconstruction in the medical domain.

Marambe, K. (20-06-2007).

Patterns of student learning in medical education - A Sri Lankan study in traditional curriculum.

Pleijers, A. (19-01-2007).

Tutorial group discussion in problem-based learning.

Sargeant, J. (21-09-2006).

Multi-source feedback for physician learning and change. 
Dornan, T. (12-06-2006).

Experience-based learning

Wass, V. (12-05-2006).

The assessment of clinical competence in high stakes examinations.

Prince, K. (21-04-2006).

Problem-based learning as a preparation for professional practice. 